\title{
Burial Archaeology Current Research, Methods and Developments
}

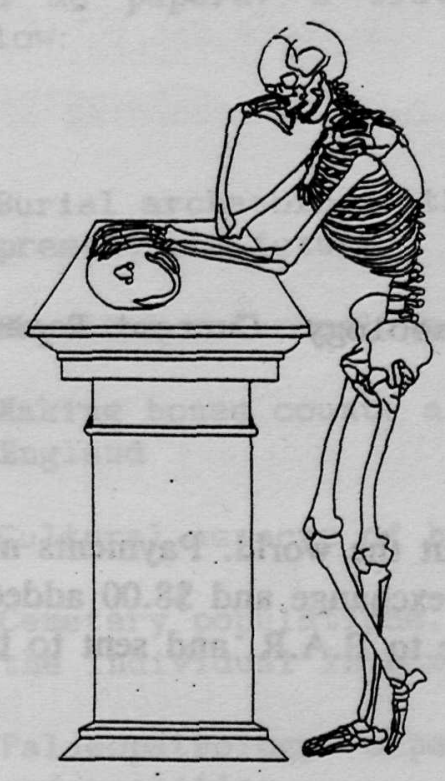

\section{edited by}

Charlotte A. Roberts,

Frances Lee and John Bintliff

BAR British Series 211

1989 


\section{B.A.R.}

\section{5, Centremead, Osney Mead, Oxford OX2 0DQ, England.}

\section{GENERAL EDITORS}

A.R. Hands, B.Sc., M.A., D.Phil.

D.R. Walker, M.A.

BAR 211, 1989: 'Burial Archaeology: Current Research, Methods and Developments'

Price $£ 18.00$ post free throughout the world. Payments made in dollars must be calculated at the current rate of exchange and $\$ 8.00$ added to cover exchange charges. Cheques should be made payable to B.A.R. and sent to the above address.

C. The Individual Authors, 1989

ISBII 0860546713

For details of all new B.A.R. publications in print please write to the above address. Information on new titles is sent regularly on request, with no obligation to purchase.

Volumes are distributed from the publisher. All B.A.R. prices are inclusive of postage by surface mail anywhere in the world.

Printed in Great Britain 


\section{STRUCTURE OF COMFEREMCE}

The conference was originally divided into several sections:

1. Anthropology, Demography and Cultural Aspects of Burial Archaeology

2. Palaeopathology

3. Environmental Aspects of Burial Archaeology

4. Conservation, Taphonomy, On-Site Recording, Processing of Human Bone and Computing

5. Case Studies 1.e. human bone specialist and archaeologist

In addition, there were many posters presented at the conference, some of which are published as papers. A list of speakers and poster presenters are given below:

\section{PAPERS \\ Keith Manchester \\ - Burial archaeology: the state of the art past, present and future \\ Ann Stirland \\ - Physical anthropology: the bastc bones \\ Andy Boddington \\ - Making bones count: a case study of Anglo-Saxon England \\ Rick Jones \\ - Cultural aspects of burial archaeology \\ John Bintliff \\ - Cemetery populations, carrying capacities and the individual in history \\ Donald Ortner \\ - Palaeopathology: expectations, methodologies and realities \\ Simon Hillson \\ - Teeth: some current developments in research \\ Tony Waldron \\ - Some epidemiological problems in palaeopathology}


Andrew Jones

Harry Kenward

Simon Mays

Philip Bethell

Jacqueline McKinley

Janet Henderson

Jim Spriggs

Neil Garland and

Rob Janaway

Julian Richards

Dominic Powlesland

Case Studies

Alan Savilie and

Jullet Rogers

Jan Wills and

Charlotte Roberts

Catherine Hills and

Jacqueline McKinley

John Kagilton and

Frances Lee

Yax Adams and

Jez Reeve

Margaret Cox

Wilbert Bouts
- Evidence of intestinal parasites associated with human remains

- Inhumation insects: myths and maggots

- Trace element analysis: dietary investigation using bone strontium

- Chemical analyses of shadow burials

- Cremations - possibilities and limitations

- Sexing by grave goods and morphology

- On and off site conservation of bone

- The taphonomy of inhumation burials

- Computers and burial archaeology

- On site recording of burials

- Hazleton Long Barrow, Gloucestershire

- The cemetery at Beckford

- Spang Hil1

- The leper hospital of St. James and St. Mary Magdalene, Chichester

- Nasty modern rubish: implications of the examination of an $18 \mathrm{th}$ and 19 th century burial vault

- The crypt population at Christchurch, Spitalfields

- Bricks or bones 
POSTERS

W1 Ibert Bouts and Tjeerd Pot

- Computerised recording and analysis of excavated human dental remains

El1zabeth Cruwys

- Tooth wear methodology: its role in archaeological research

Ke1th Dobney

- Studies on archaeological dental calculus

Chris Gaffney

- Geophysical prospection and burlal archaeology

Rhonda Gillett

- Pubic symphyseal ageing: a comparison of techniques

Valerie Higgins

- A model to assess the levels of stress within a peasant population

Denise Hodges

- Methodological issues in determining the individual's age-at-stress from enamel hypoplasia defects

El1zabeth O' Sull1van, Sonia Williams and M. E. J. Curzon

- Dental caries and nutritional stress in English archaeological child populations

Sally Parker

- The experimental investigation of the potential of cremated bone as indicators of past cremation practices and techniques

Jullet Rogers

- Palaeorheumatology

Sarah Wenham and Jenny Wakely

- Microscopical features of blade infuries to bone surfaces in six Anglo-Saxon cemeteries

Sonia Williams, Elizabeth O'Sullivan and M. E. J. Curzon

- Dental caries pattern in the primary dentition among English children living between the preRoman and late Medleval perlods

Joe Zias

- Death and disease in the Byzantine monasterles of the Judean desert 
Al1 speakers and poster presenters were given the opportunity to publish papers in this volume providing the material was original and had not been, or would not be, published elsewhere. Naturally, several authors felt that, under the circumstances, their material should not be presented for publication. For those people who did not present their material, their abstracts are recorded in this volume.

The editors would like to thank everybody who helped with the organisation of the conference, particularly Kelth Dobney, Rhonda Gillett and Denise Hodges, and the University of Bradford Conference Office and Continuing Education Unit for their assistance.

The conference organisers were Frances Lee, Keith Manchester and Charlotte Roberts of the University of Bradford. 


\section{LIST OF COITRIBUTORS}

Adams, $\mathbf{M}$

Bethell, P.

Bintliff, J .

Bouts, W.

$\operatorname{Cox}, \mathbf{M}$

Cruwys, E.

Curzon, M.E. J.

Dobney, K.

Gaffney, C.

Garland, A.N.

Gillett, R.

Henderson, J.

Higgins, V.

Hills, C.

Hillson, S.

Hodges, D.

Janaway, $R$.
- 1 The Nook, Hoylands Swain, Sheffield S30 6JV.

- 22 Montpellier Terrace, Mount Pleasant, Swansea, SA1 6JW

- Department of Archaeological Sclences, University of Bradford, Bradford, BD7 1DP

- Academic Computing Service, The Open University, Walton Hall, Milton Keynes, MK7 6AA

- Hinthamerstraat 153, 5211 MK's Hertogenbosch, The Netherlands

- Department of Human Environment, Institute of Archaeology, 31-34 Gordon Square, London, WC1H OPY

- Scott Polar Institute, Lensfield Road, Cambridge, CB2 1ER

- Department of Child Dental Health, School of Dentistry, University of Leeds, Leeds, LS2 9LU

- The Old Customs House, Hoy, Orkney Islands

- Department of Archaeological Sclences, University of Bradford, Bradford, BD7 1DP

- Department of Pathology, The Medical School, University of Manchester, Stopford Bullding, Oxford Road, Manchester, M13 9PT

- Department of Anthropology, Rawles Hall 108, Indiana University, Bloomington, Indiana 47405, U.S.A.

- 7d Compton Road, London, I1 2PA

- Department of Archaeology and Prehistory, University of Sheffield, Sheffield, S10 2TN

- Department of Archaeology, University of Cambridge, Downing Street, Cambridge, CB2 3DZ

- Department of Human Environment, Institute of Archaeology, 31-34 Gordon Square, London, WC1H OPY

- Office of the State Archaeologist, Eastlawn Building, University of Iowa, Iowa City, IA 52242 , U.S.A.

- Department of Archaeological Sciences, University of Bradford, Bradford, BD7 1DP

(v) 


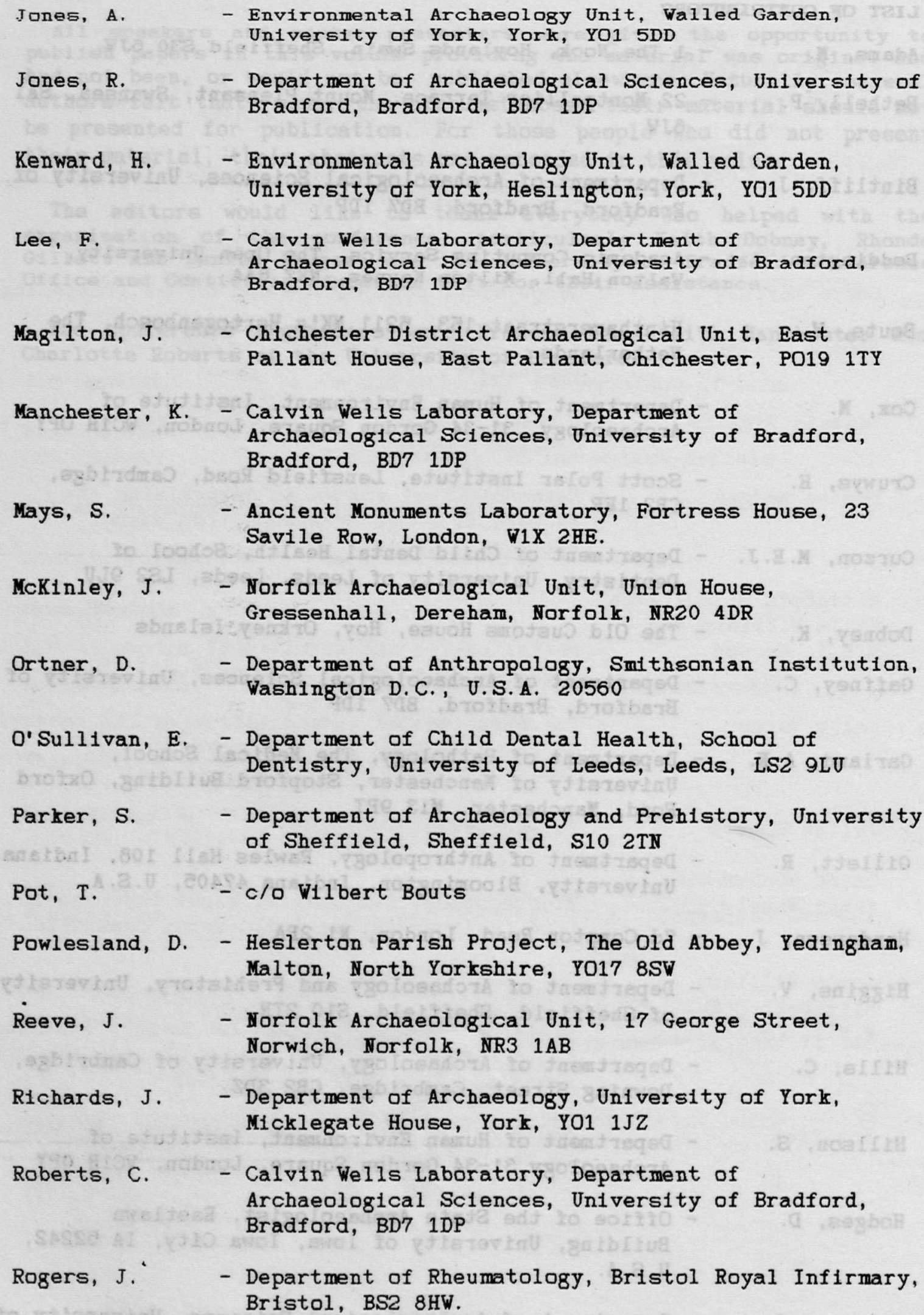

Parker, S.

- Department of Archaeology and Prehistory, University of Sheffield, Sheffield, S10 2TN

Pot, T. $\quad-$ c/o W1lbert Bouts

Powlesland, D. - Heslerton Parish Project, The Old Abbey, Yedingham, Malton, North Yorkshire, Y017 8SW

Reeve, J. - Morfolk Archaeological Unit, 17 George Street, Norwich, Norfolk, NR3 $1 \mathrm{AB}$

Richards, J. - Department of Archaeology, University of York, Micklegate House, York, YO1 $1 \mathrm{JZ}$

Roberts, C. - Calvin Wells Laboratory, Department of Archaeological Sclences, University of Bradford, Bradford, $\mathrm{BD} 71 \mathrm{DP}$

Rogers, J. - Department of Rheumatology, Bristol Royal Infirmary, Bristol, BS2 8HW. 


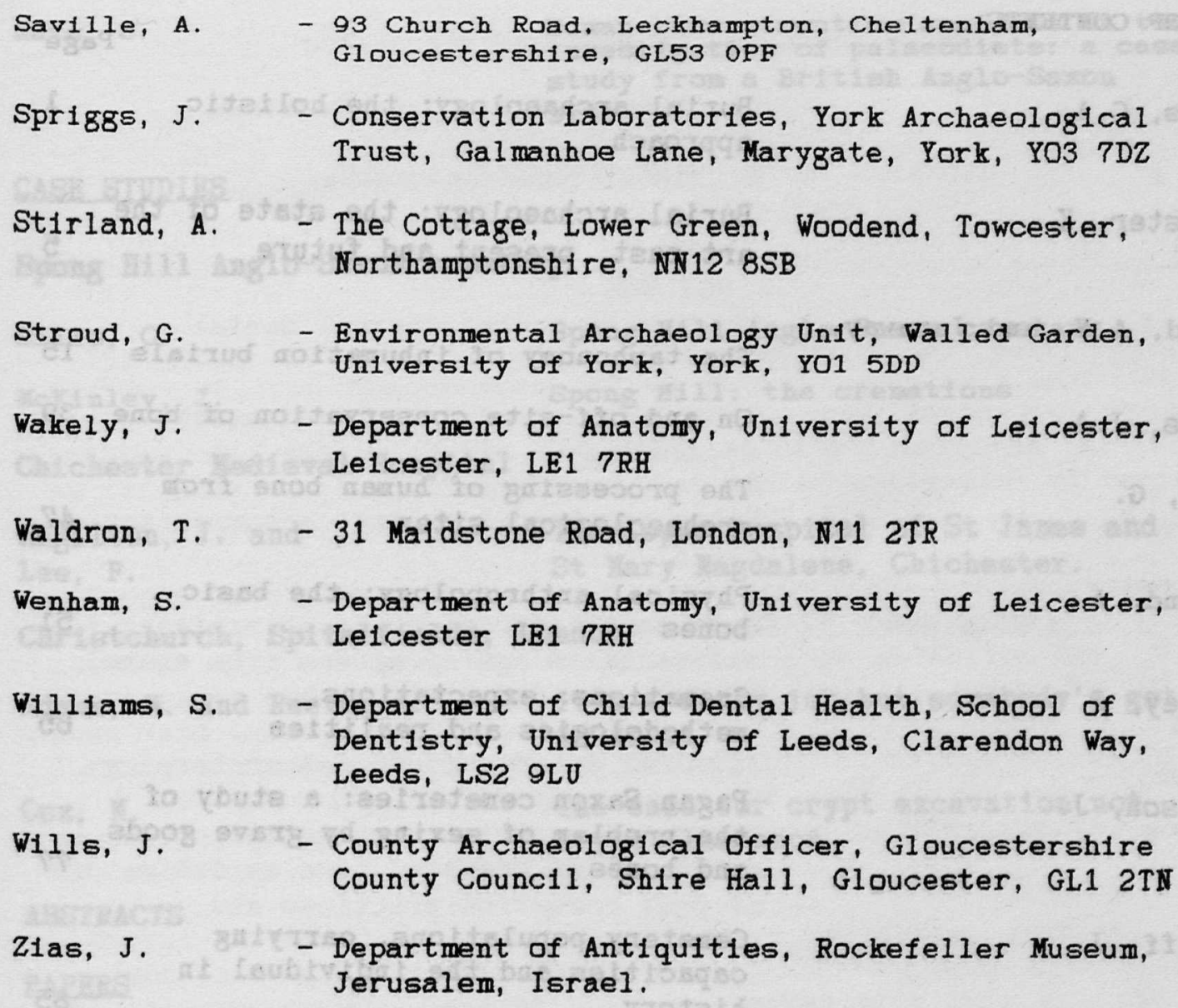

St1rland, A. - The Cottage, Lower Green, Woodend, Towcester, Northamptonshire, NN12 8SB

Stroud, G. - Environmental Archaeology Unit, Walled Garden, University of York, York, YO1 5DD

Wakely, J. - Department of Anatomy, University of Leicester, Leicester, LE1 7RH

Waldron, T. - 31 Maidstone Road, London, N11 2TR

Wenham, S. - Department of Anatomy, University of Lelcester, Lelcester LE1 7RH

Williams, S. - Department of Child Dental Health, School of Dentistry, University of Leeds, Clarendon Way, Leeds, LS2 9LU

Wills, J. - County Archaeological Officer, Gloucestershire County Counc1l, Shire Hall, Gloucester, GL1 2TN

Zlas, J. - Department of Antiquities, Rockefeller Museum, Jerusalem, Israel. 
Roberts, C.A.

Manchester, $K$.

Garland, A. N. and Janaway, R. C.

Sprig8s, J.A.

Stroud, G.

Stirland, A.

KcKinley, J.

Henderson, J.

Bintliff, J.

Richards, J .

Bouts, w. and Pot, Tf.

Hillson, S.

Cruwys, E.

Sullivan, E. O., Williams, S. and Curzon, M.E.J.

Higgins, V.

Bethell, P.
Burial archaeology: the holistic approach

Burial archaeology: the state of the art past, present and future

The taphonomy of inhumation burials 15

On and off-site conservation of bone 39

The processing of human bone from archaeological sites

Physical anthropology: the basic bones

Cremations: expectations, methodologies and realities

Pagan Saxon cemeteries: a study of the problem of sexing by grave goods and bones

Cemetery populations, carrying capacities and the individual in history

Computers and burial archaeology

Computerised recording and analysis of excavated human dental remains

Teeth: some current developments in research

Tooth wear and the archaeologist:

the role of human tooth wear in archaeological research

Dental carles and nutritional stress in English archaeological child populations

A model for assessing health patterns from skeletal remains

Chemical analysis of shadow burials

205 
Mays, 5.

Human bone strontium analysis in the investigation of palaeodiets: a case study from a British Anglo-Saxon

\section{CASE STUDIES}

\section{Spong Hill Anglo-Saxon cemetery}

Hills, C.

MoKinley, J.
Spong H111 Anglo-Saxon cemetery

Spong Hill: the cremations

247

Chichester Medieval Hospital

Magilton, J. and

Lee, F.

The leper hospital of St James and St Mary Magdalene, Chichester.

Christchurch, Spitalfields, London

Adams, M. and Reeve, J.

It's a dirty job but somebody's got to do $1 t$

Cox, M.

The case for crypt excavation not crypt clearance

ABSTRACTS

\section{PAPERS}

Boddington, A.

Making bones count: a case study from Anglo-Saxon England

Jones, A.K.G.

Evidence of intestinal parasites associated with human remains

Jones, $R$.

Cultural aspects of cemetery studies

Kenward, H.

Inhumation insects: myths and maggots

Ortner, D.J.

Palaeopathology: expectations, methodologies and realities

\section{CASE STUDIES}

Hazleton Feolithic Long Barrow

Saville, A.

Hazleton, Gloucestershire

Rogers, J .

The human bone analysis from Hazleton 
The Iron Age/Early Roman Cemetery at Beckford

Roberts, $C$.

The human remains from Beckford

Bouts, $W$.

Bricks or bones

\section{POSTERS}

Dobney, $\mathrm{K}$.

Studies on archaeological dental calculus

Gaffney, C.

Geophysical prospection and burial archaeology

Gillett, $R$.

Pubic symphyseal ageing: a comparison of techniques

Hodges, D. and Wilkinson, R. Methodological issues in determining the individual's age-at-stress from enamel hypoplastic defects

Jones, R.

Cultural aspects of burial archaeology

Parker, S.

The experimental investigation of the potential of cremated bone as indicators of past cremation practices and techniques

Rogers, J.

Palaeorheumatology

Wenham, S. and Wakely, J.

Microscopical features of blade injuries to bone surfaces in six Anglo-Saxon skeletons from Eccles, Kent

Villiams, S., O'Sullivan, E. and Curzon, M.E.J.

Dental caries in the primary dentition among English children living between the pre-Roman and late Medieval periods

Zias, J.

Death and disease in the Byzantine monasteries of the Judean desert 
BURIAL ARCHAEOLOGY: THE HOLISTIC APPROACH

\author{
Charlotte Roberts \\ Calvin Welis Laboratory \\ Department of Archaeological Sciences \\ University of Bradford \\ Bradford \\ BD7 1DP
}

The study of cemeteries containing samples of past populations, whether of Iron Age or more recent periods such as the Christchurch, Spitalfields Crypt in London (see Cox, and Adams and Reeve this volume), has attracted the attention of many interested parties going as far back as the Victorian era when the investigation of barrows was a popular preoccupation.

People have always had a fascination for their ancestors and $1 t$ has not always been the human remains which have provided the most interest (for example, the early excavations at Sutton Hoo, Suffolk). Grave goods and furniture have seemed to draw the attention of people, past (and even present) in terms of their value as rellcs of the past. In many instances the study of the human remains has become relegated to a low priority. Sometimes plans for post-excavation analysis of cemetery populations are not even organised by the time the skeletons are excavated.

Burial archaeology was chosen as a valuable area to base a conference around in May 1988 because of the many disciplines and specialists who can be potentially involved with this subject. Burlal archaeology specialists, conversant with grave structures, grave goods, associated environmental evidence, computing and, not least, the human remains, are all encompassed by this very broad area of archaeological information; one without the others is meaningless and, in the ideal situation where time and money are plentiful, everybody involved (perhaps without exception, in this case) would advocate close co-operation and planning from pre-excavation discussions with all specialists to post-excavation analysis and interpretation. Unfortunately, this is not the case for the majority of cemetery excavations and it was therefore deemed essential to hold a conference where everybody could have their say, exchange and pass on information about their discipline to others and meet other people involved in the excavation of cemeteries. The nature of the meeting reflected the broad nature of burlal archaeology; this may have been criticised by some but it was considered that opportunity should be given to all those who belleved they could make some contribution on the subject. This fact was reflected in the large attendance figures at the conference (around 180).

The original title for the conference was 'Burial Archaeology: expectations, methodologies and realities'. All speakers and poster presenters were briefed to produce contributions which adhered to this theme; it was hoped that useful information could be transferred which could aid workers involved with future cemetery excavation projects. 'Expectations' covered the information which, in an ideal situation, one would hope to get from the material under examination; 
'methodolagies' included the ways in which this potential information could be extracted; 'realities' dealt with what actually came out of the study in the real world.

The study of cemeteries and their populations has become a particular focus of attention in some areas of the world, and in America and Australia there has been demand for reburial of American Indian and Aborlginal skeletons (e. 8 see Preston, 1989 and Webb, 1987). In Britain there have been few instances where cemetery excavations have come across opposition to the removal of skeletons from the ground. This is, in fact, a real threat to the continuity of research in burial archaeology, not only for human remains study but all the potentially associated evidence. Recently, the subject has been ralsed in the archaeological press by Rahtz, and real concern expressed about the need for a recognised ethical policy in the excavation of cemeteries (Rahtz, 1988). As Rahtz reiterated, "... we disturb the dead in the name of science..." and that, particularly, human remains, "...are the nearest we can get to our ancestors..." . If, as Sparey-Green has sald (1988), human remains are not excavated and studied, "...archaeology becomes not much more than an architectural study of empty ruins surrounded by the traces of a landscape created or transformed by invisible human agents". One can hardly dispute this statement.

One must emphasise that, In general, the public are interested in archaeology and, when given the opportunity and data presented in the correct way, will show enthusiasm for the information which can be extracted from cemetery populations; it is a subject to which they can directly relate. One of the main aims of any archaeologist or specialist should be to present data on thelr analyses in a way which can easily be understood and interpreted by the layman. In this way, the general public would feel more involved and not 'blinded by science'. Of course, the work would be published with a different emphasis in professional publications too. In this way both parties would have the benefit of the excavation. In addition, on the subject of reburial, if a case can be convincingly stated for the study of material from cemetery sites, particularly the human remains, with the alm of showing show that the work that is being done is useful and that future methodological advances will help us to gain even more detailed information, it may be legitimately possible to prevent the reburial issue becoming a serious problem in Britain.

Unfortunately, everybody is not always on our side. The media are often at fault for making cemetery excavations appear to be a grisly occupation; only interesting for the macabre element of the archaeological world. It is our job to ensure that this does not happen. Disinterment and the study of human remains and their associated evidence should be defended at all costs but with reference to ethical considerations. Hopefully, the World Archaeological Congress on 'Archaeological ethics and the treatment of the dead' in South Dakota, United States held in August 1989, will be able to develop guidelines for cemetery excavation. But, whatever happens, everybody involved with burial archaeology should be working together to produce a picture of an important aspect of past societies which everybody can understand (e.g. see Mumcuoglu and Zias, 1988). Every 
specialist has their part to play but none can be seen as more important than the rest; furthermore, everybody's contribution should be acknowledged and not undeservedly criticised (see Bush, 1988). There can be no expert in every aspect of burlal archaeology but people can be experts in their own narrow field. Of course, a whole reconstruction should be looked at, the 'holistic approach' perhaps? As the human remains session at the Theoretical Archaeology Group Conference in Sheffield in 1988 showed, there are many people involved with the study of past populations at all levels.

Archaeology has become a complex subject. Furthermore, scientific methods of analysis of archaeological materlal have developed to such an extent that it has become possible for more detailed examination of archaeological material, particularly in the case of human remains (e.8. see Dobney and Brothwell, 1988); the potential is huge for future work. This conference on Burlal Archaeology hoped to bring many specialists together to discuss the theme with the end result that future directions may be outlined. As Arnold has written (1986:38), "Specialists must continue with their research; none need, nor has any right, to believe that their specialisation is superior to any other; each must feed their data, observed patterns and generalisations to those who seek to take a more generalised overview of past human behaviour, an overview which must incorporate all types of evidence". This theme has already been developed in some instances (e. 8 Garland, Janaway and Roberts, 1988, SHARP, 1988).

The depth of study of all types of evidence related to burlal archaeology is reflected in the papers presented in this volume.

\section{BIBLIOGRAPHY}

Arnold, C.J., 1986 - "Archaeology and history: the shades of confrontation", pp. 32-51 in J. Bintliff and C. Gaffney (Eds), Archaeology at the interface: studies in archaeology's relationship with history, geography, biology and physical science. British Archaeological Reports International Series, Vol. 300.

Bush, H., 1988 (unpublished) - Abstract from introductory paper in the human remains session". (A matter of 11 fe and death) at the Theoretical Archaeology Group Conference, University of Sheffield, December 1988, p. 8 .

Dobney, K. and Brothwell, D., 1988 - "A scanning electron microscope study of archaeological dental calculus". pp 372-385. in S. Olsen (ed) Scanning Electron Microscopy in Archaeology, British Archaeological Reports International Series, Vol. 452.

Garland, A.N., Janaway, R. C and Roberts, C.A., 1988 - "A study of the decay processes of human skeletal remains from the parish church of the Holy Trinity, Rothwell, Northants". Oxford J. Archaeology, Vol. $7(2)$, pp. 235-252 
Mumsugglu, Y.K, and Zias, J., 1988 - "Head lice, pediculus humanus capitis (Anoplura:pediculidae) from hair combs excavated in Israel dated from the 1 st century B.C. to the 8 th century A. D". I. Medical Entomology, Vol. $25(6)$, pp. 545-547.

Preston, D.J., 1989 - "Skeletons in our museums' closets. Native Americans want their ancestors' bones back". Harpers Ferry Magazine. February, pp. 66-75.

Rahtz, P., 1988 - "Archaeology and the dead". British Archaeological News, Vol.3(4), p. 33 .

SHARP, 1988 - "Sharp Practice 2. 2nd report on researches into the Nedieval hospital Soutra, Lothlan Region. Scotland". Soutra Hospital Archaeoethnopharmacological Research Project, Edinburgh.

Sparey-Green, C., 1988 - "Archaeology and the dead. Reply to Rahtz". British Archaeological News, Vol. $3(8)$, p. 80 .

Webb, S., 1987 - "Reburying Australian skeletons". Antiquity, Vol.61, pp. $292-296$ 
THE STATE OF THE ART, PAST AMD PRESERT

\author{
Dr Keith Manchester \\ Calvin Wells Laboratory \\ Department of Archaeological Sciences \\ University of Bradford \\ Bradford. \\ BD7 1DP.
}

In this introduction to the conference on Burial Archaeology it is appropriate for the author to review some aspects of the history of the discipline, to consider the present state, and to suggest possible future developments.

Although, "the conference was designed to bring together archaeologists, human bone specialists, and environmentalists". The author is mindful that, in this capacity, he is a paleopathologist. It would be arrogant and presumptuous to preach to archaeologists and environmentalists of matters within these disciplines. The major part of this paper is therefore referable to human osteoarchaeology, in particular palaeopathology. However, the papers in this volume demonstrate the close interrelationship and interdependence which there is in excavation and post-excavation specialisms.

In earlier days there were two separate specialisms in matters related to burlal excavation, and these separate speclalists acted in total independence of each other in most circumstances. Indeed, the very raison d'etre of the excavation depended upon which represented speciallsm undertook the task. On the one hand there was the archaeologist whose sole interest was the recovery of artefacts and their post-excavation examination and typology. One suspects that many treasure hunters may have operated in this quasi academic way. Even the great Lord Caernarvon shelved some of his finds, as we now know. Fortunately, his enlightened descendent is giving them light of day. Closer to home, the prodigious excavations of J.R. Mortimer in East Yorkshire revealed much evidence of Bronze Age burial (Mortimer, 1905). However, even he neglected the proper examination of the human skeletal remains recovered during his barrow digging. This quite substantial collection, languishing for years in Hull Yuseum, has been studied intermittently for specific purposes since Mortimer's day.

These comments, which are somewhat critical, are not intended to be damning remarks on earlier scholars. It is only too easy to criticise, with later expertise and knowledge, the work of our predecessors, and we should all, perhaps, be more humble and note our own shortcomings.

On the other hand, Professor Moller-Christensen, in his monumental excavations of the lazar cemetery at Naestved in Denmark (MollerChristensen, 1953), paid little attention to the archaeological interpretation of his excavations. His excavation was purely palaeopathological in motivation, and this is his own admission and comment. Notwithstanding this deficiency, his palaeopathological research was, without doubt, of the highest quality and value. 
It seems therefore, that the slant of the archaeologist in burial excavation in earlier days was towards the artefactual evidence, and the slant of the pathologist was towards the osteology,

Quite paradoxically, the early excavation of the Anglo-Saxon cremation cemetery at Sancton was carried out by George Rolleston, Linacre Professor in Anatomy at Oxford, and his interest during the latter years of the 19 th century was in the cremation urns themselves. He completely neglected the cremated human remains contained therein. But, disinterest in cremated remains was not just a phenomenon of these early years. The human cremated remalns from the excavations at Sancton in the $1950^{\prime} \mathrm{s}$ were similarly ignored. Thankfully, due to recent work on the Spong Hill cremations by Jackie Mckinley (see this volume), the potential of the study of these fragmentary remains is being realised.

In the early days, there was little attempt made to correlate archaeological data from excavation, data of artefact analysis, and the results of the human corporeal examination. There was little attempt made to understand burlal ritual, and the potential of the total information in palaeodemography was not fulfilled.

Turning to the past examination of human skeletal remains from archaeological contexts, once again the emphasis of results reflected the interest and expertise of the scholar. The significance and planning of the examination, and the presentation of the results tended to divide into two areas of study: physical anthropology, and palaeopathology. Physical anthropology consisted largely of recording a large number of discontinuous morphological skeletal variants, and of multiple osteometric measurements. The object seems to have been to determine genetic relationships, and racial origins. But even after many years these observations and measurements are largely of unknown significance, and certainly of unproven value. Very little attention was paid to the determination of age at death, a factor which is so important in palaeodemography and in the understanding of palaeopathology. More attention was given to the determination of sex from skeletal remains, but this surely was a facet of morbid anatomy and was not specifically directed at osteoarchaeological problems.

Fortunately, much work has been undertaken concerning both sex and age determination during the past 20 years or so, and this $1 s$ reflected in the wealth of research papers published. Perhaps a stimulus to this research has been the relevance of the determinants to forensic pathology. To be able to determine closely an age at death and to be able to identify without doubt the sex of buried human remains is germane to the ldentification of the remains, be they complete or incomplete. Although in archaeological circumstances much of the work on refinements of method and improvements of validity has been towards gross morphological and metrical differentiation, research has gone on into radiological aspects of skeletal ageing, and more recently, into the histomorphology of bone ageing. Maybe these tools, which are of research value at present, will become the commonplace in human osteoarchaeology of the future. And it is not just in the determinants of age that such research has taken place. Preliminary work, which may or may not have a future, has been done 
and published on the quantification of bone citrate as a measure of sex differentiation. But work of this kind will, I suspect, always remain a research tool. However, exploration of new techniques and the development of new methods of improved validity is to be encouraged in age and sex studies, because this is the very basis of palaeodemography. Statements regarding numbers of individuals in graveyards, and thereby in communities, of antiquity are a matter largely for the archaeologist, backed by purely anatomical assessment of the excavated skeletal collection. Statements on the sex distribution, age distribution, and mortality patterns, are the responsibility of the human skeletal blologist. These factors are surely so 1 mportant to our understanding of social and economic change in communities, changes in mortality patterns and changes in socioeconomic conditions being to some extent reciprocal. These basic data of sex distribution and mortality characteristics are also so obviously significantly important in our understanding of disease patterns and of disease in relation to the environment, that discipline which we term palaeoepidemiology, itself a growth out of palaeopathology.

In earlier days, palaeopathology was treated in isolation, just as was physical anthropology. Research was largely an antiquarian pursuit of clinicians and anatomists. The publications of such scholars as Virchow (1895), Elliot-Smith and Wood-Jones (1910), and Ruffer (1913) consisted of descriptions of individual pathological lesions, or groups of individuals or single skeletons. Scant regard was paid to the associated physical anthropological data or to the relevance of artefactual evidence. Even the publication of Moodle (1923), contains numerous illustrations of lesions, which were very good for the time, but with little information on age and sex, and no additional anthropometric or anthropomorphic data. But these were the early days in the discipline; days when scholars were feeling their way, and showing their professional colleagues that there was value in the study of archaic human remains. Indeed, it was only in 1913 that Sir Marc Armand Ruffer (1913) created the definition of palaeopathology as the science of the diseases which can be demonstrated in human and animal remains in ancient times. In these early days, clinical interpretations of pathological lesions were not attempted, although diagnoses were made, and palaeoepidemiology as we know it was unknown.

In this country, it was the work of Brothwell (1981), Brothwell and Sandison (1967), and Wells (1964) which marks a turning point in palaeopathology and heralds the integration of burial archaeology. Brothwell, during the late $1950^{\prime} \mathrm{s}$ and $1960 \mathrm{~s}$, integrated physical anthropology and palaeopathology. He showed by his single volume 'Digging up Bones' (1981), surely a bench top reference book for many, that physical anthropology and palaeopathology should be one and the same in human osteoarchaeology. Sandison, whose untimely death in 1982 at a Palaeopathology Association Meeting was a sad blow to us al1, paved the way for a clinicopathological approach to diagnosis. Moreover, the book 'Diseases in Antiquity' (Brothwell and Sandison 1967), was and still is a major source for palaeopathological and medical historical information. The name of Calvin Wells is, to most medical and lay people, synonymous with palaeopathology. As a 
clinician, his approach was interpretative. His aim was to inculcate to the archaeological world that what we are digging up are not merely skeletons, but are the remains of once living people, and that they had sensations, emotions, and lifestyles of which we, as palaeopathologists, may enlighten. He probably did more than anyone else to bring palaeopathology and the history of disease to the attention of the academe and public alike.

Equally however, the names of Hackett (1976) and Moller-Christensen (1953) are also prominent in palaeopathology proper. Hackett formalised the osseous diagnostic criteria of syphilis and related diseases in a most painstaking way. Moller-Christensen not only did this for leprosy, but actually identified, de novo, the osseous lesions. It is with great regret that the publications of these two masters are not more readily available.

In more recent times, the scientific basis of palaeopathology has achieved credibility through the application of microscopy (Ascenzi, 1969; Stout and Simmonds, 1979), of radiology (Ortner and Putschar 1981; Roberts 1988), and of physicochemical analysis (Lambert, Szpunar and Buikstra, 1979; Bumsted, 1985; Waldron, 1973). These separate techniques illustrate what Professor Ortner has long preached; that an understanding of palaeopathological processes depends upon an understanding and interpretation of biological actions, both cellular and biochemical.

Whilst in this vein a cautionary note should be sounded. Although it is satisfying, and, indeed, proper to make a diagnosis of a specific disease in palaeopathology in those specimens of pathognomonic lesions, it is improper to give an unequivocal diagnosis where lesions are of doubtful cause. Lesions must be described in terms which are universally accepted, understood and without ambiguity, and the description for publication in the definitive archaeological work must be in a language acceptable outside the esoteric world of pathology. We cannot integrate and inter-relate, any more than can other specialisms, if we put up a wall of technical jargon. As a practicing clinician, it is painful to say this, for medicine has thrived on language which enhances the mystique of the art.

Notwithstanding this note of caution, the words of Sir Mortimer Wheeler should be remembered, "archaeology is a science that must be lived, must be seasoned with humanity. Dead archaeology is the driest dust that blows" (Mortimer, 1905). This plea to humanise archaeology applies equally to osteoarchaeology. Unless we all practice discretionary interpretation and suggest in-life 11lness for our skeletal remains, then our study becomes pure science and of little value in oyerall archaeology. But also, archaeology must put iffe into antiquity. The public holds the purse strings and the public therefore has a right to know the results of archaeological work. If this means presenting findings with a tinge of artistic license, so be $1 t$, providing always that the scientific results are absolutely honest and presented in academic ilterature. 
Thus human skeletal biologists, are striving to improve their standards in descriptive, diagnostic, and interpretative terms. In so doing it must be remembered that the source material is the skeletal remains recovered by archaeological excavation. Therefore, striving must be matched by high standards of archaeological practice, in pre, intra, and post excavation circumstances. Many people are familiar with poor osteoarchaeological analysis and presentation. Osteoarchaeologists are famillar with outrageous diagnosis and with osteometric and osteomorphic interpretation which stretches credibility to the point of disbelief. The palaeopathological mind often runs riot with clinical and social interpretation. Osteoarchaeologists are also familiar with poor archaeological excavation and post-excavation treatment and curation of skeletal remains. The author has personally witnessed, at a very prestiglous and long running excavation in rural Yorkshire, one excavator recovering a skeleton. Unfortunately the bone box beside him was too small for the complete femur excavated. He solved the problem by snapping the femur in two. It was not appropriate at the time to enquire at what department of archaeology this man was an undergraduate, but clearly $1 t$ was not one teaching human osteoarchaeology. The vital importance of good archaeological practice is equally relevant to archaeometallurgists, pottery experts, and enviromentalists, all of whom are involved with burial archaeology. There is little that can be done after post-depositional degradation, but at least one should make the most of what one has. In the realms of human health and disease in antiquity, it is not just the recovery of skeletal parts in burial excavation which is important. The Burial Archaeology Conference has dealt with the recovery and usefulness of insect remains in understanding the palaeoenvironment, and the value of parasitic examination in relation to human health w1ll be described. During excavation of individual graves, the possibility of recovering visceral calcull such as gall stones, kidney stones, and bladder stones should be considered. That such problems existed in the past is well known to us. The anguish of Samuel Pepys and his contemporaries with the pain and strangury of bladder stones and the consequent and necessary surgical operation without anaesthesia and antiseptic or aseptic technique seems unbelievable today. But the problem was by no means uncommon in the $17 t h$ century, and, presumably, in earlier times. In literature we know little of gall stones, but a case has been demonstrated in a dynastic period mummy. If anyone should be in any doubt as to the durability of gall stones, may I remind you of the case of John George Haigh, a man with more than a passive interest in wealthy ald ladies. In the late 1940's he lured and murdered a well-to-do widow of Kensington. To destroy his evidence he 1 mmersed her body in a bath of strong commercial sulphurlc acld. Unfortunately for Halgh, the only human tissues to survive were $3 \mathrm{gall}$ stones, together with her acrylic resin dentures. The evidence was sufficient to send him to Wandsworth gallows. Urinary calculi have perhaps been identified more commonly in the archaic context. Moller-Christensen dentified, by his own excavation, a calcium oxalate renal stone of Medieval context. Therefore, in excavation workers should be aware of the existence of these various stones, and excavators should really learn something of their in vivo anatomical sites. 
Certainly the refinements of parasitic and insect study from the excavation of inhumations was completely unknown in the early days of burial study. Also unknown was the potential, even the possibility, of physicochemical analysis of skeletal tissue in the reconstruction of palaeodiet, for example. This latter scientific technique demands its own specific standard of burial excavation, and requires strict pre-excavation planning.

Thus, it can be seen that there has been seen a gradual integration of specialisms in the study of human burials in antiquity. At the same time however, there have been new specialisms which have developed, and those specialisms, both old and new, have developed scientifically and in intellectual merit.

But where does all this lead us, and what is the future for this discipline?

Firstly, the simplistic objectives of the very early days have been abandoned. No longer are archaeologists interested solely in the structure of a round barrow, in the recovery of the grave goods, or in the human osteology. The objective now is an understanding of the cultural practices of burial, at individual and group level, an understanding of mortality patterns and, as a corollary, palaeodemography and an understanding of disease in relation to all aspects of the early ancient environment.

In achieving these objectives, the topography of the total cemetery and individual grave distribution, correlated with archaeological information on burial posture, must be integrated with the study of grave goods, and with what can be learnt of the site environment from enviromental evidence. All this, too, must be related to the physical anthropological and palaeopathological analysis of the skeletal remains at individual and group level.

Therefore, what is vital for the future, and what is to some extent already being practiced, is close co-operation and dialogue between all members involved in burial archaeology at all stages of research, from long before the spade hits the ground to the time when the report goes to press.

At the pre-excavation planning stage of burial research, specialists should meet and decide on desirable, potential and possible individual research designs and how they may fit into a coherent excavation plan. For example, pre-planning is vital if trace element studies of bone or palaeoserology for blood group analysis is to be undertaken, because quite specific and stringent requirements during excavation are necessary. Soll sampling for parasitic studies, or for the possible detection of stomach contents requires careful pre-excavation planning. Is it sufficient nowadays to excavate a skeleton, pack it into a box into which it may or may not fit, send it to a specialist with or without information on context, and expect back an erudite report outlining everything from genetic associations to blood groupings? The author assumes that similar stringent methods are required for grave goods and environmental studies. 
During the excavation itself, it is highly desirable, but rarely attainable, that individual specialists are present and, perhaps, practically involved in the recovery. The position of Individual bones, indeed, their very presence or absence, may be highly relevant to palaeopathological interpretation. It may be more meaningful to the post-excavation specialist actually to see three-dimensionally, and to feel, the objects and remains in situ. Particularly in the case of very fragmentary and eroded specimens, examination during the excavation may be the only possible means of study. This surely has been demonstrated in a most elegant manner by Martin Carver at Sutton Hoo (Bethell and Carver, 1987). His exposure and interpretation of shadow burlals, those results of post-inhumation tissue degradation, are quite thrilling, and his synthetic method of recording and preservation is stunning. Maybe the information on physical anthropology and palaeopathology from such remains is negligible at present, but the information on burlal culture certainly justifies all efforts at excavation. In the same way, the in situ examination of eroded artefacts may be of great interpretative value. By way of 1llustration, consider the excavation of the Anglo-Saxon cemetery at Eccles, Kent (Manchester and Elmhirst, 1980) in which a so-called knife was noted in the floor of a grave. It was known in the postexcavation analysis that the highly significant association of artefact and bone was noted, and 1 t was realised, in fact, that the artefact represented a weapon. Although pehaps not fatal, the infury inflicted by this (in fact) arrowhead certainly slowed the victim for the 'coup de grace'. How much more meaningful would it have been for the skeletal biologist to have been present at excavation, and to have noted the relationship of this skeleton to the other victims of belligerent infury in the cemetery. Ideally of course this is amply covered by meticulous on site recording.

As to the future exploitation of the potential in burial archaeology, it is arguably, the post-excavation stage which offers most promise. Of course, research designed excavation of high standard is vital. Equaliy, meticulous recording of burials, including corporeal remains and grave artefacts, is essential. But, it is the application of sclentific analytical method to excavated remains, both organic and inorganic, which heralds the advance.

The identification of trading contacts in cremation urns for example, determined by texture analysis and by examination of decoration, surely says something of funerary ritual and its importance to early communities. A correlation of this information with the age and sex and, indeed, the number of individuals contained in the urns also throws light on funerary customs.

But once more displaying the authors obvious bias, it is perhaps in the realms of human osteology that most advances will be made. It is well known that with methods currently avallable 1 is not possible to determine the sex of all adult skeletons recovered from excavated cemetery sites. It 15 also quite impossible to determine the sex, with accuracy, of infants and juveniles. This deficiency in subadult sexing is a major constraint in the analysis of infant mortality patterns, particularly in relation to sex differences in infantile disease and in cultural attitudes to male and female children in past 
societies. It is hoped that through further research, the reliability of sex determination of all age groups will be 1 mproved. Conversely, with certain assumptions, the age at death of infants and juveniles can be assessed with accuracy, but the age at death of adults 15 contentious. In fact, much as we all, particularly palaeodemographers, would like to establish narrow age brackets for death, there are osteologists who will give no more precision than young adult, mature adult, and old adult. Clearly, if mortality patterns in antiquity are to have any meaning and be of any value, more specific and more valid assessments of age at death must be made. But such assessments must be based on firm criteria.

Hopefully, in due course such criteria will be established, and the radiological and histomorphological avenues being explored currently may lead to this situation. Hopefully too, the 'hotch potch' of metrical and morphological data may be ordered to indicate genetic associations.

In palaeopathology, there will be advances made through radiography and microscopy in diagnostic criteria. By these means diagnostic labels may one day be put on osseous lesions which are, at present, 111-understood. But establishment of criteria must be backed by comparable modern clinicopathological specimens and study. It is really only possible to work from the known modern to the unknown archaic. Terminology will, we hope, become universally accepted and understood, and thereby standardisation will be achieved. Further work on physicochemical analysis of inorganic constituents of bone such as calcium and strontium and carbon isotope studies may allow inferences to be made generally on palaeodiet, already a well studied field. The analysis of collagen remnants in long dead bone, may lead to acceptable blood group data. It may also be an aid in the differential diagnosis of such difficult problems as joint disease in palaeopathology. Furthermore, methods such as 1 mmunochemistry may allow diseases, hitherto unrecognised in palaeopathology, to be identified.

There is one further development in burlal archaeology which, although somewhat peripheral, may have considerable potential. This is an input into the field of forensic science. Recent work on the Pennine Moors, in Lancashire, has given the police an enormous problem in grave location. It seems not all that infrequently that rows of police officers comb tracts of land in the search for burled remains and for clues as to their location. Hitherto, the geophysical expertise of archaeology has not been applied to this task, although in the latest Moors Murder search, advice was offered by the Bradford Department of Archaeological Sciences. Whilst not denying their skill in other areas, perhaps the police are not the most adept at locating graves, and neither are they at excavating skeletal remains. This is the province of the archaeologist, or as I have suggested earlier, the human osteologist. This skill too has now been acknowledged by the police, and members of the Bradford Department, were recently involved in the excavation of the remains of a body in West Yorishire. Furthermore, forensic pathologists, by common custom, deal with soft tissue human remains, but rarely do they examine solely skeletal remains. This again is the domain of the human osteoarchaeologist. 
Beveral of us in Britain and elsewhere are now called upon to assist in the possible criminal investigation of excavated human skeletal remains. It is early days however, there is still a rapport to be developed with police, coroners' departments, and forensic pathologists.

But surely, the greatest advance in the discipline of burlal archaeology will be through co-operation of specialists and the integration of data so that we may all understand better the life and terminal sufferings of earlier peoples, and the cultural attitudes of kinsmen towards disposal of the dead.

\section{BIBLIOGRAPHY}

Ascenz1, A., 1969 - "M1croscopy and prehistorlc bone", pp. 526-538 in Brothwell, D. and Higgs, E. (Eds), Science in Archaeology Thames and Hudson, London.

Bethell, P.H., and Carver, M. O.H., 1987 - "Detection and enhancement of decayed inhumation at Sutton Hoo" pp. 110-122 in A. Boddington, A.N. Garland and R.C. Janaway (Eds), Death, Decay and Reconstruction. Approaches to archaeology and forensic sclence. Manchester University Press, Manchester.

Brothwel1, D.R., 1981 - "Digging up Bones". Oxford University Press, Oxford and British Museum (Natural History), London.

Brothwell, D. R. and Sandison, A.T., (Eds) 1967 - "Diseases in Antiquity". Charles Thomas, Springfield, Illinols.

Bumsted, M.P., 1985 - "Past human behaviour from bone chemical analysis - respects and prospects". L. Human Evolution, Vol. 14, pp. 539-551.

Elliot-Smith, G. and Wood-Jones, F., 1910 - "Report on the human remains". Archaeological Survey of Nubia 1907-1908 Egyptian Survey Department, Calro.

Hackett, C.J., 1976 - "Dlagnost1C Criteria of Syphil1s, Yaws and Treponarid (Ireponamatoses) and of some other diseases in Dry Bones" Springer - Verlag, Berlin.

Lambert, J.B., Szpunar, C. B., and Buikstra, J., 1979 - "Chemical analysis of excavated human bone from Middle and late Woodland Sites". Archaeometry, Vol. $21(2)$, pp. 115-129.

Manchester, K, and Elmhirst, O.E.C., 1980 - "Forensic aspects of an Anglo-Saxon infury". Ossa, Vol. 7, pp 179-188.

Moodie, R.L. 1923 - "Palaeopathology". University of Illinols Press, Urbana. 
Moller-Christensen, V. 1953 - "Ten Lepers from Nastved in Denmark", Danish Science Press Ltd., Copenhagen.

Mortimer, J.R., 1905 - "Forty years Researches in British and Saxon Burlal Mounds of East Yorkshire", A. Brown and Sons Ltd, , London.

Ortner, D.J and Putschar W.G.J., 1981 - "Identification of Pathological Conditions in Human Skeletal Remains". Smithsonian Institution Press, Washington.

Roberts, C.A., 1988 - "Irauma and its Ireatment in British Antiquity". Unpublished $\mathrm{PhD}$ thesis, Department of Archaeological Sciences, University of Bradford.

Ruffer, M.A., 1913 - "Studies in palaeopathology in Egypt". I, Rathological Bacteria, Vol. 18, pp. 149-162.

Stout, S. and Simmonds, D.J., 1979 - "Use of histology in ancient bone research". Yearbook of Phys. Anthrop., Vol. 22, pp. 228-249.

Virchow, R., 1895 - "Exostosen und Hyperostosen von extremitätenknochen des Menschen in Hinblick auf den Pithecanthropus". Ztschr. F. Ethmol. Berlin, Vol. 27, pp. 787-793.

Waldron, H.A., 1973 - "Lead poisoning in the ancient world". Medical History, Vol. 17, pp. 391-399.

Wells, C., 1964 - "Bones, Bodies and Disease". Thames and Hudson, London. 
THE TAPHOMOIY OF INHUKATIO BURIALS

\author{
A. Neil Garland \\ Department of Pathology \\ Stopford Building \\ Oxford Road \\ Manchester \\ M13 9PT \\ and \\ Robert C. Janaway \\ Department of Archaeological Sciences \\ University of Bradford \\ Bradford \\ BD7 1DP \\ Roberts Graves, Goodbye To All That
}
"The colour of the dead faces changed from white to yellow-grey, to red, to purple, to green, to black, to slimy"

\title{
Introduction
}

Taphonomy is a term which was introduced into the literature by the Russian palaeontologist Efremov in 1940, and it is derived from the Greek words for tomb or burial (taphos) and for law or system of laws (nomos). It is an interpretative model for a scientific understanding of the processes which operate on organic remalns after death. In a human context taphonomy is concerned, on the one hand, with thanatology (the phenomenon accompanying death: autolysis, putrefaction, skeletalisation, adipocere formation, accidental desiccation and deliberate mummification, and with necrology (the decay of skeletal remains), and on the other hand with the processes responsible for the preservation of the organic remains (Efremov, 1940; Behrensmeyer, 1984). In other words the taphonomic history of a body may be regarded as an interplay between the opposing agencies of preservation and destruction. This paper will consider both the agencies of preservation and destruction.

Taphonomy involves two distinct but necessarily related ifnes of investigation. The first is the full and proper scientific study and analysis of the archaeological and skeletal evidence, the second is the laboratory induced simulation of the factors which affect skeletal decay (Gifford, 1981; Von Endt and Ortner, 1984; Grupe and Piepenbrink, 1988).

For the purpose of this paper we shall adhere to the following definitions from the Shorter Oxford English Dictionary:

Inhumation - the action or practice of burying in the ground; the fact or condition of being buried, interment. The burying of a thing in the ground. 
Excarnate - to remove flesh

Bury - the act of interment

The scope of this paper is to examine the processes that affect whole bodies which are placed or buried in the ground. In this we are concerned principally with the natural processes of decay following death and burial, although, as will become apparent, both environmental and behavioural influences will affect decay both before and after burial. For reasons of trying to confine ourselves to an already broad topic we will deliberately exclude human remains which have had the flesh removed by the process of cremation or excarnation in separate mortuary structures. Whilst the disturbance and curation of human remains will be mentioned we will not deal in detail with the taphonomic processes of charnel deposits, as one such deposit has recently been discussed in some detail (Garland, Janaway and Roberts, 1988).

The spectacular preservation of largely whole bodies from antiquity is dependent upon general or local environmental conditions which inhibit microbiological activity. A number of examples of preserved bodies recovered from anaerobic soils, permafrost and conditions conducive to desiccation have recently been listed (Brothwell, 1987). To these can also be added "Copper Man" (Bird, 1975).

\section{The nature of burials}

The taphonomic behaviour of a cadaver is influenced by a very large number of interacting factors. Initially we can divide these according to the following: the cause of death or the state of the body at death; the time interval between death and burial and the treatment of the body prior to burial; the factors of the burial environment which affect short-term taphonomic processes/preservation; factors within the burial environment which affect the human biological (or organic) material which has survived short-term destructive processes (Mant, $1950 ; 1953 ; 1987$ ).

The agents included in these categories will affect the nature and rate of decay. It is not our intention to refer to timescales as even those used in medical jurisprudence are imprecisely understood (Bass, 1984; Polson, Gee and Knight, 1985). For example, Kant (1987) described a remarkable case to illustrate this: two bodies were killed at the same moment, buried in the same graveyard, in adjacent graves but had different rates of skeletalisation.

We would now like to discuss briefly the factors which influence decomposition and skeletalisation.

Bodies which are thin and emaciated may skeletalise very quickly. Bodies which have been subject to either antemortem or postmortem wounding are more susceptible to invasion by extracorporeal microorganisms than bodies which are burled with the skin intact, and hence skeletalise more rapidly. Where a body has been subject to septicaemia, a form of blood poisoning, before death, decomposition may be very rapid. 


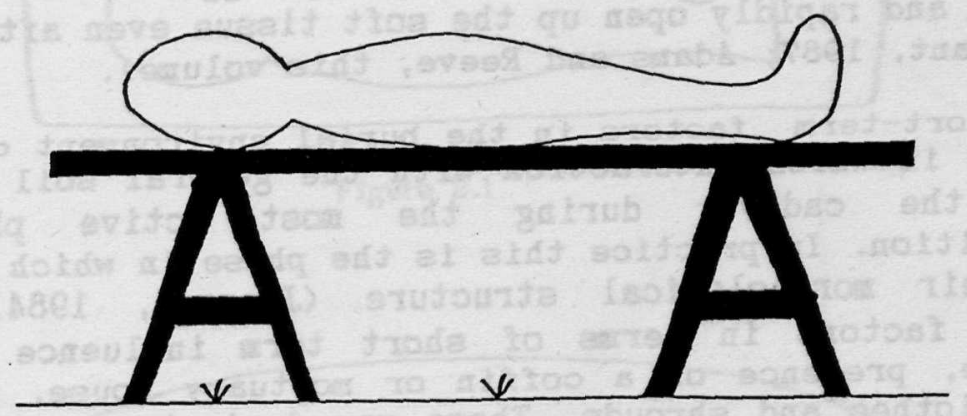

Above ground: higher terperature, diurnal fluctuations, bigher oxygen and lower carban dioxide. Fasy access by decompaser organisms, rats. dogs and flying insects

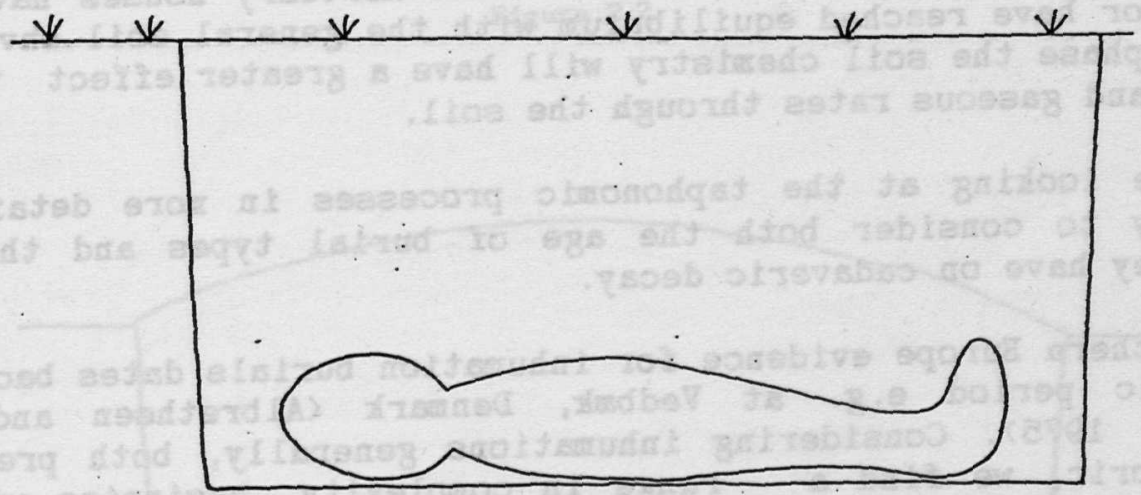

Below Ground: lawer temperature, less diurnal fluctuations, lower axygen, bigher carbon dioxide due to limited gas excharge, burrowing soil invertebrates

Figure 1 
In general a body will decompose more rapidly above ground (Figure 1), and the longer a body is kept above ground prior to burial the more rapid its rate of decomposition. This is because soil burial and the presence of coffins will limit the access of micro and macroorganisms as well as slowing down gaseous diffusion rates. However, exposure above ground even for a short period will allow insects and carnivorous larvae to lay eggs on the body which will colonise and rapidly open up the soft tissue even after burial (Evans, 1963a; Mant, 1987; Adams and Reeve, this volume).

The short-term factors in the burial environment can be identified as those in which interaction with the general soil environment will affect the cadaver during the most active phases of early decomposition. In practice this is the phase in which the soft tissues lose their morphological structure (Janssen, 1984). Probably the greatest factors in terms of short term influence are the grave structure, presence of a coffin or mortuary house, associated grave goods, clothes and shrouds. These may dominate or largely negate the effects of the general soil environment. A soll may be very well drained and, hence, lead to desiccation of a body, but if the body is in a well-sealed coffin, the body's burial environment will be wet until the coffin breaks down, by which time a particular set of decomposition processes will have taken place.

The long-term factors are those which relate to the more active phases of decomposition when coffins and mortuary houses have either decayed or have reached equilibrium with the general soil environment. In this phase the soil chemistry will have a greater effect than soil biology and gaseous rates through the soil.

Before looking at the taphonomic processes in more detall it is necessary to consider both the age of burial types and the effect which they have on cadaveric decay.

In northern Europe evidence for inhumation burials dates back to the Mesolithic period e.8. at Vedbak, Denmark (Albrethsen and Brinch Petersen, 1975). Considering inhumations generally, both prehistoric and historic, we find a range in complexity, beginning with the body placed directly into a simple 'hole' in the ground, with or without archaeologically recognisable grave goods. More complex burials have wooden or stone coffins or more elaborate mortuary structures (e.g. Plank et.al., 1985).

The grave can either be flat or covered with an earthern mound. Figure 2 illustrates some of the variations. Figure 2.1 represents a shallow grave near the surface without a coffin; Figure 2.2, a shallow grave with a coffin; Figures 2.3 and 2.4 represent deeper graves, whilst Figures $2.5,2.6$ and 2.7 illustrate graves with raised mounds. The example shown in Figure 2.7 has a wooden mortuary chamber which itself contains a relatively large volume of air as compared with the coffined burials. These variations will have a profound influence upon access to the body by microarganisms and larger soil fauna as well as regulating the gaseous and liquid diffusion from and to the decomposing body. These factors are, of course, also heavily influenced by the soil properties of the surrounding sail. 


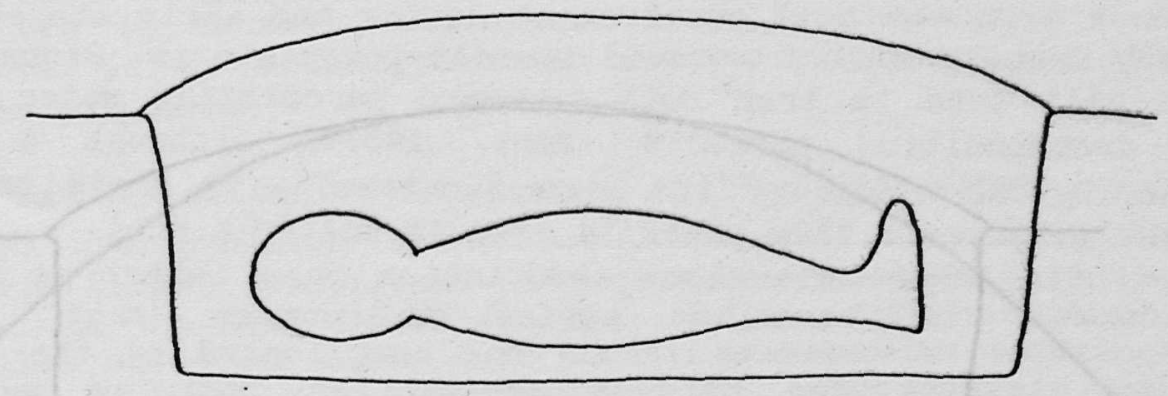

Figure 2.1

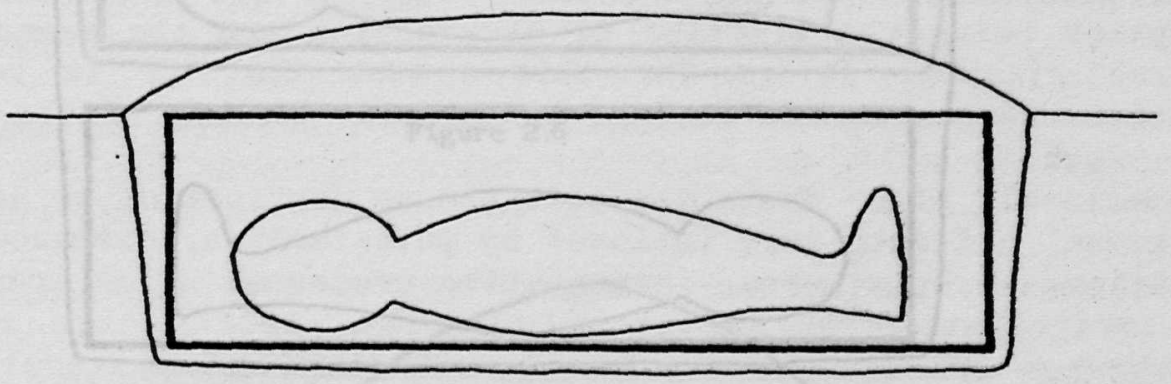

Figure 2.2

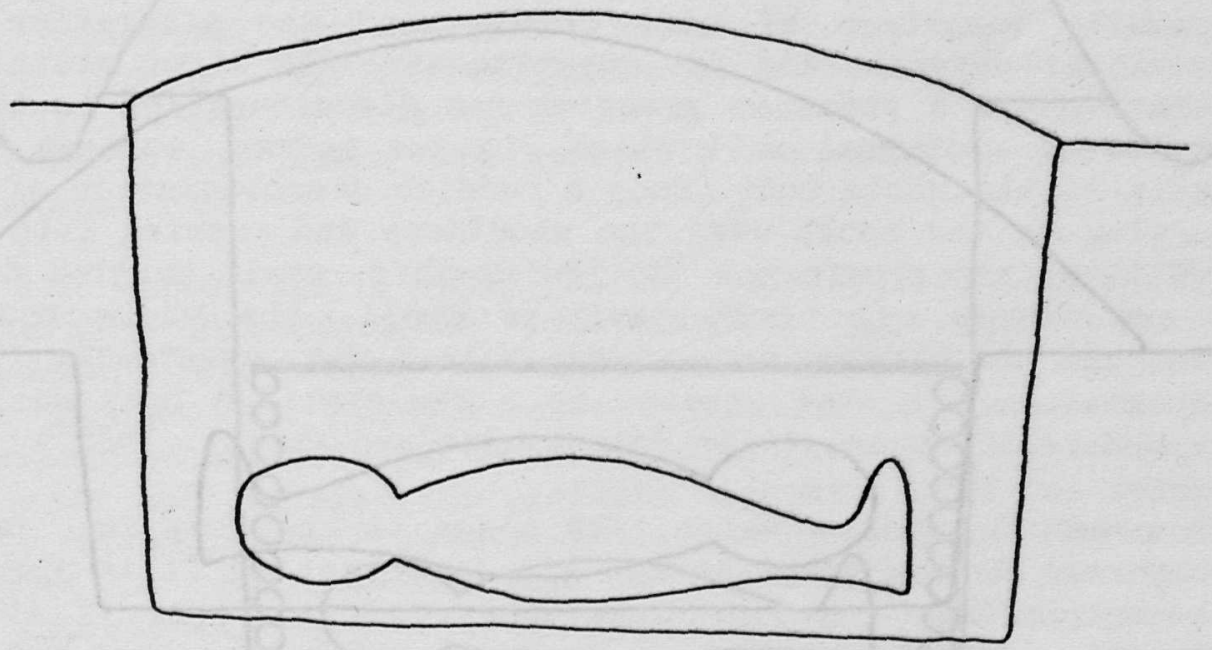

Figure 2.3 


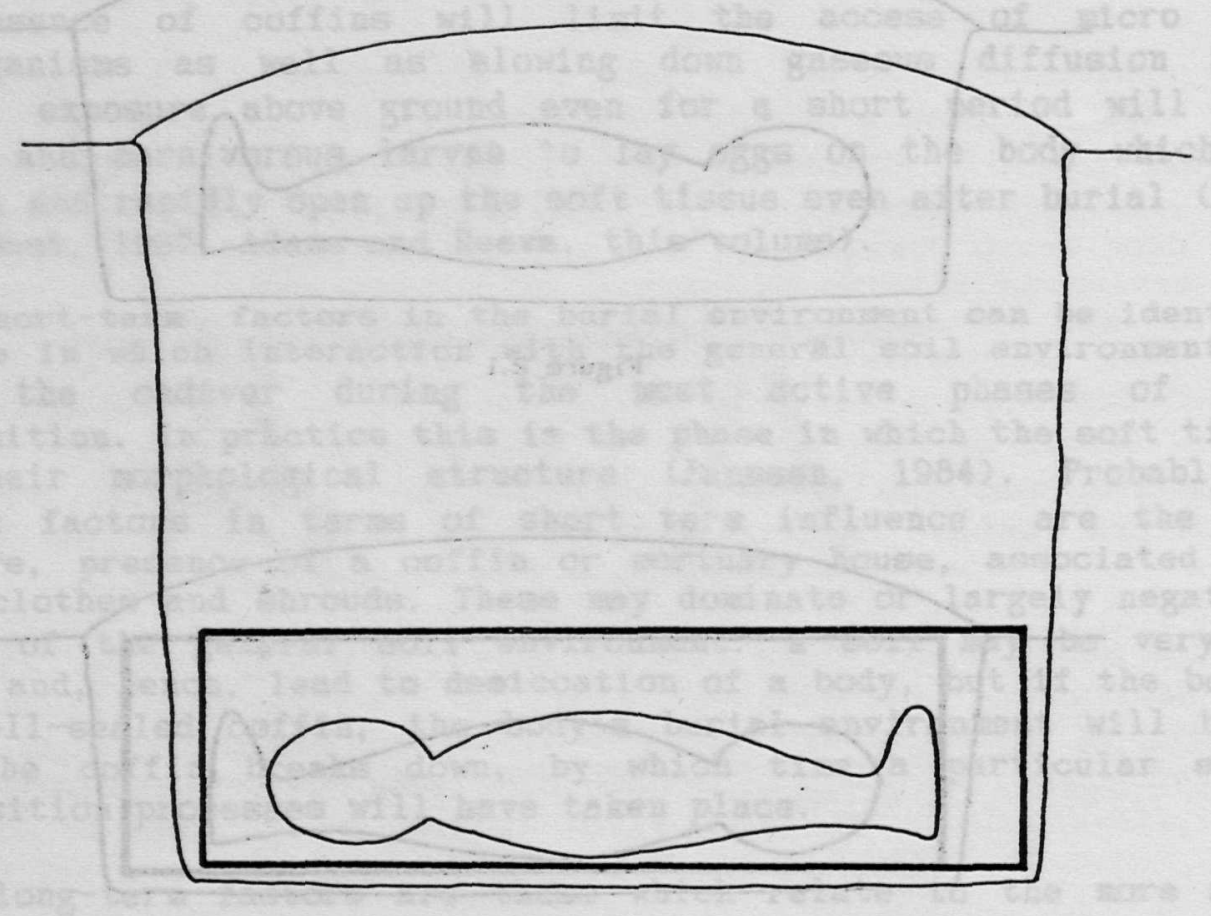

Figure 2.4

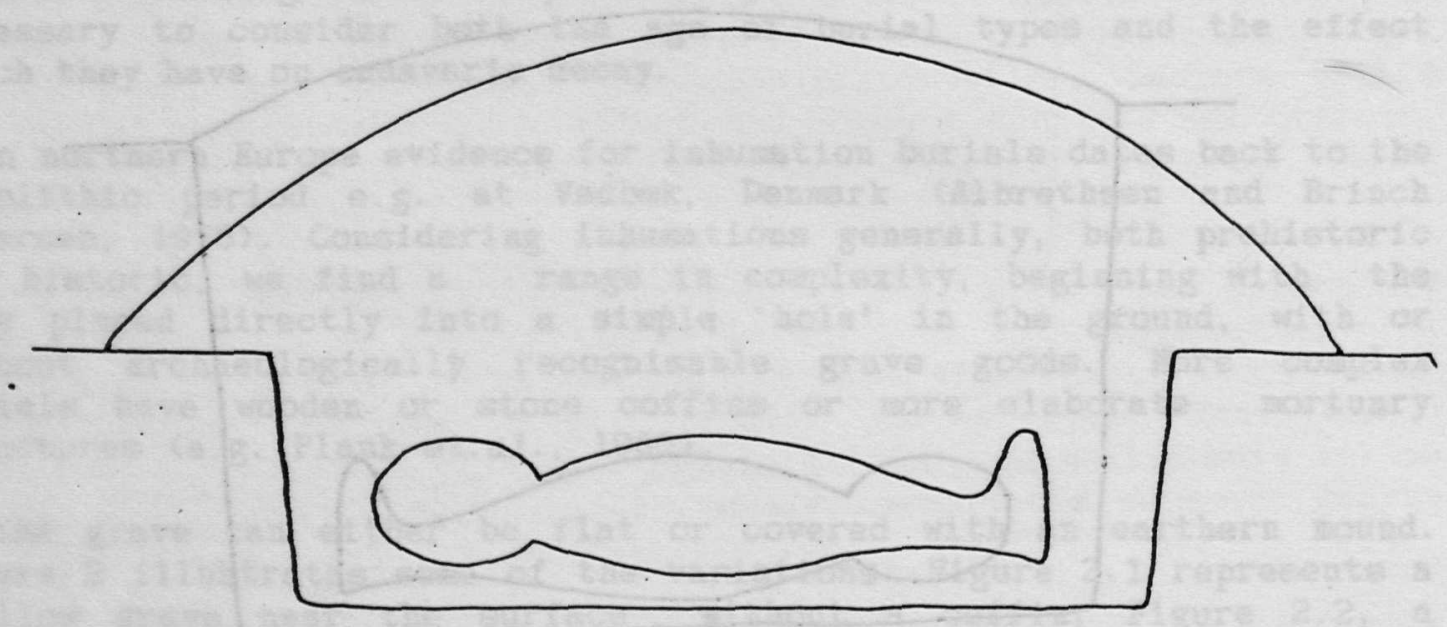

Figure 2.5 


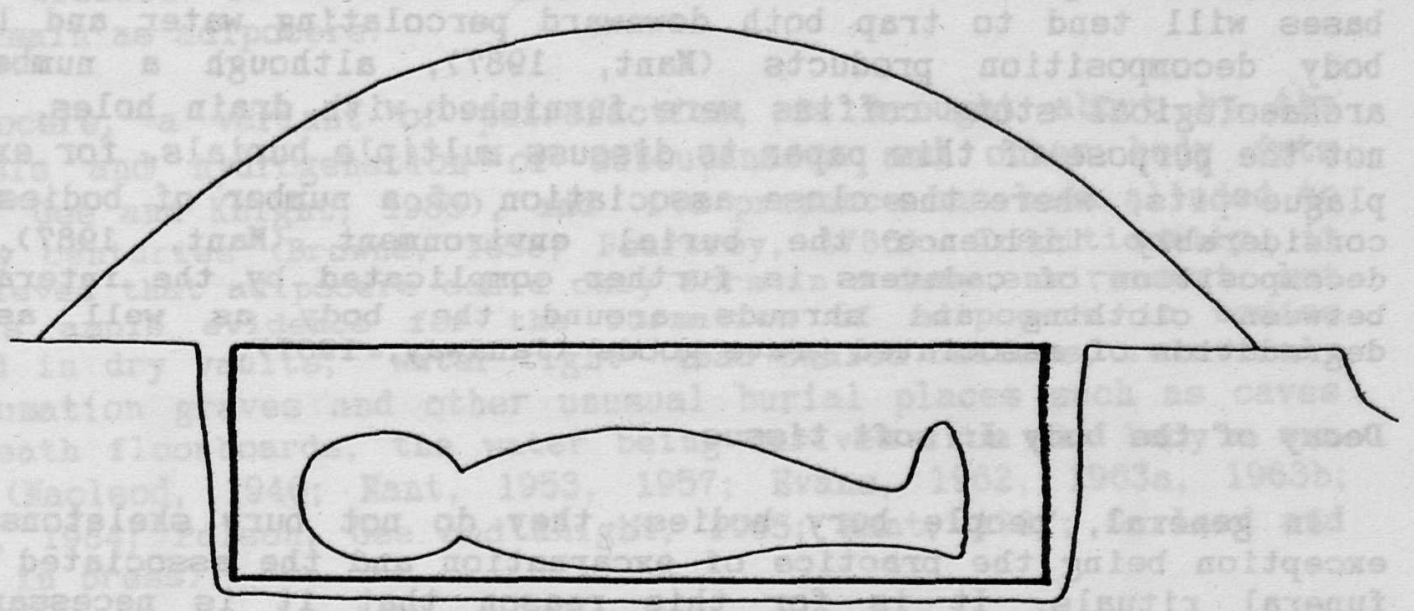

Figure 2.6

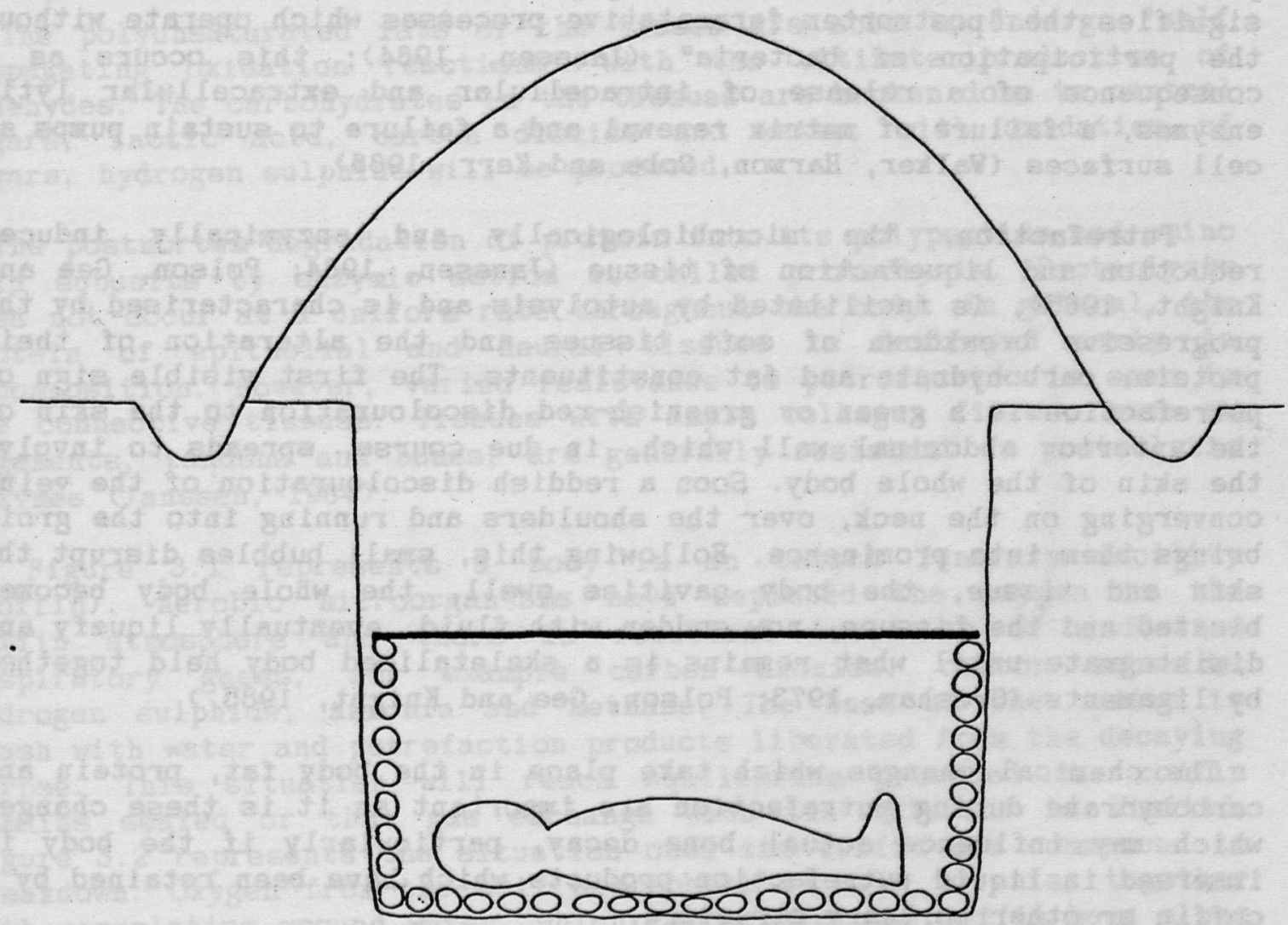

Figure $2 . ?$ 
The coffins and mortuary structures will have the effect of isolating the body from the soil environment during the early stages, although in many cases ground water will usually percolate in. Stone and wooden bases will tend to trap both downward percolating water and liquid body decomposition products (Mant, 1987), although a number of archaeological stone coffins were furnished with drain holes. It is not the purpose of this paper to discuss multiple burials, for example plague pits, where the close association of a number of bodies will considerably influence the burial environment (Mant, 1987). The decomposition of cadavers is further complicated by the interaction between clothing and shrouds around the body as well as the degradation of associated grave goods (Janaway, 1987).

\section{Decay of the body I: soft tissue}

In general, people bury bodies; they do not bury skeletons, the exception being the practice of excarnation and the associated postfuneral rituals. It is for this reason that it is necessary to consider the postmortem changes of the soft tissues of the body.

Immediately after death the soft tissue destruction or decomposition processes, and autolysis followed by putrefaction, commence. Autolysis signifies the "postmortem fermentative processes which operate without the participation of bacteria" (Janssen, 1984); this occurs as a consequence of a release of intracellular and extracellular lytic enzymes, a failure of matrix renewal and a failure to sustain pumps at cell surfaces (Walker, Harmon, Gobe and Kerr, 1988).

Putrefaction, the microbiologically and enzymically induced reduction and liquefaction of tissue (Janssen, 1984; Polson, Gee and Knight, 1985), is facilitated by autolysis and is characterised by the progressive breakdown of soft tissues and the alteration of their protein, carbohydrate and fat constituents. The first visible sign of putrefaction is a green or greenish-red discolouration to the skin of the anterior abdominal wall which, in due course, spreads to involve the skin of the whole body. Soon a reddish discolouration of the veins converging on the neck, over the shoulders and running into the groin brings them into prominence. Following this, small bubbles disrupt the skin and tissue, the body cavities swell, the whole body becomes bloated and the tissues, now sodden with fluid, eventually liquefy and disintegrate until what remains is a skeletalised body held together by ligaments (Gresham, 1973; Polson, Gee and Knight, 1985.)

The chemical changes which take place in the body fat, protein and carbohydrate during putrefaction are important as it is these changes which may influence actual bone decay, particularly if the body is immersed in liquid putrefaction products which have been retained by a coffin or other mortuary structure.

Fat can undergo two types of degradation reactions, hydrolysis and oxidation. The body neutral fat (that is, glycerol, lipids and glycalipids) is hydrolysed to some extent by the body's own intrinsic lipases into fatty acids (oleic, palmitic and stearic). However, hydralysis occurs to a greater extent through the lipolytic enzymes (e.8. lechithinase) produced by bacteria, particularly those of the 
species Clostridia. Although water is essential for these reactions to take place there is usually sufficient water in the corpse's own internal tissues. If no further chemical changes take place the fatty acids remain as adipocere.

Adipocere, a variant of putrefaction, is brought about by the hydrolysis and hydrogenation of subcutaneous and other body fats (Polson, Gee and Knight, 1985), and its presence has been alluded to for many centuries (Browne, 1658; Fourcroy, 1786). Traditionally, it was believed that adipocere could only form in a damp environment, but there is ample evidence for the formation of adipocere in bodies interred in dry vaults, "water-tight" lead-sealed coffins, relatively dry inhumation graves and other unusual burial places such as caves and beneath floorboards, the water being derived from the body's own tissue (Kacleod, 1946; Mant, 1953, 1957; Evans, 1962, 1963a, 1963b; Janssen, 1984; Polson, Gee and Knight, 1985; Mant, 1987; Garland and Lawler, in press).

The appearance of relatively recent adipocere is that of a white or reddish-brown stained material; older adipocere is white or grey. It may also be soft and greasy or dry and brittle.

The polyunsaturated fats of the tissue are able to undergo "self propagating oxidation reactions" with the ultimate production of aldehydes. The carbohydrates in the tissues are broken down to neutral sugars, lactic acid, carbon dioxide and water; with oxidation of sugars, hydrogen sulphide will be produced.

The postmortem degradation of protein into its polypeptide and amino acid subunits by enzymic action is called proteolysis. Proteolysis does not occur at a uniform rate throughout the body. In general, the protein of epithelial and neural tissues is destroyed early in decomposition. However, varied resistance to putrefaction is seen in the connective tissues. Tissues with ample collagen fibres, such as ligaments, tendons and bones, are generally resistant to proteolytic enzymes (Janssen, 1984).

Figure 3.1 represents a body in an intact funerary facility (coffin). Aerobic microorganisms have depleted the oxygen in the coffin atmosphere and there is resultant build up of reductive respiratory gases, for example carbon dioxide, carbon monoxide, hydrogen sulphide, ammonia and methane. The base of the coffin is awash with water and putrefaction products liberated from the decaying corpse. This situation will reach equilibrium provided the coffin remains sealed or that gas exchange with the exterior is limited. Figure 3.2 represents the situation once the coffin has commenced to breakdown. Oxygen from the soil atmosphere is able to enter together with percolating ground water, which collects in the coffin base along with the liquid putrefaction products. The reductive gases are able to escape. The onset of coffin breakdown would be expected to hasten the rate of soft tissue degradation, not only for the reasons already stated, and it will also allow the ingress of bacteria and fungi from the soil. 


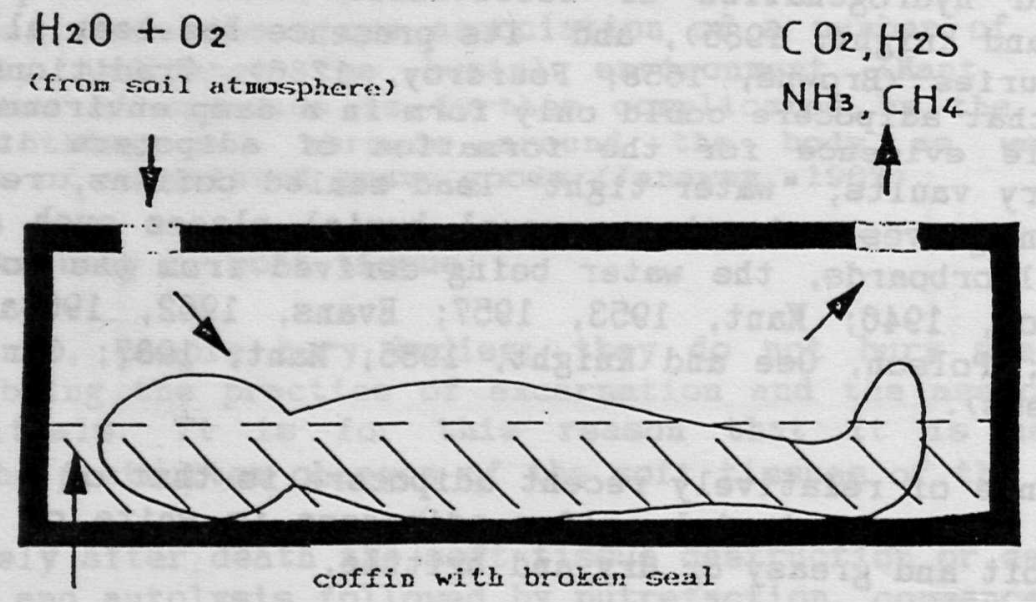

liquid decomposition product:s and water from soil

Figure 3.1

reductive gases from decomposition

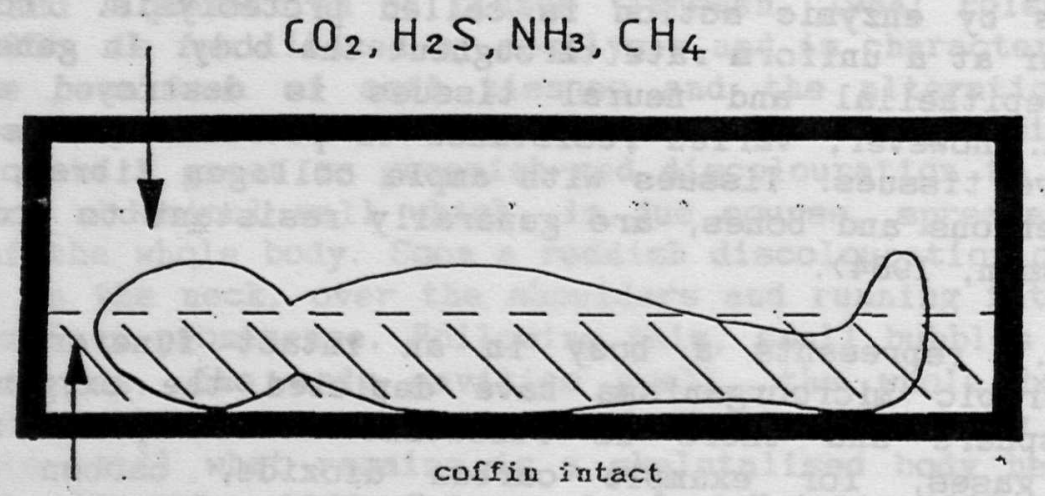

liquid decomosition products

Figure 3.2 
Little has been witten on the pH changes which occur during putrefaction. As discussed previously, with the progression of cadaveric decay, there will be some tendency for an increase in acidity to occur and hence a lowering of the pH. However, concomitant with this increase in acidity will be an increase in buffering capacity, and the production of more ionic charge groups of all kinds. In theory, therefore, there will be no real change in pH.

However, in practice the situation is not quite as simple. The inhumation grave cannot simply be considered as a body placed in the soil. The presence of a coffin, wooden or metal, metal grave goods and other associated organic artefacts will contribute to changes in $\mathrm{pH}$ (Janaway, 1985, 1987). For example, the breakdown of a wooden coffin by oxidation of its cellulose component will result in a fall of the $\mathrm{pH}$. Similarly, the pH will tend to acidity with oxidation of phenols derived from the wood.

Although coffin liquor has been described by many workers during the examination of exhumed corpses, little is known of its composition. Preliminary study, by the present authors, of 6 samples of coffin liquor recovered from excavations of the $18 \mathrm{th}$ and $19 \mathrm{th}$ century burlal vaults at the church crypt of Spitalfields, London, showed the pH of the specimens to range between 7.2 and 7.4 . Histological examination revealed the presence of "amorphous" tissue, strands of birefringent material, bacteria and fungi.

For the sake of completeness, two other postmortem changes have to be mentioned. These are munification and desiccation. Although the terms are often used synonymously and interchangeably, mumification should only be referred to bodies artificially preserved by the deliberate application of the embalming chemicals of ancient Egypt. Desiccation, on the other hand, results from the placing of a corpse in a perpetually dry or very cold environment (Cockburn and Cockburn, 1980).

\section{Decay of the body II: Bone}

Following degradation of the soft tissues of the body, bone becomes susceptible to interaction with the various chemical and physical factors and biological agents within the burial environment. Every bone has a "preservation potential" which is primarily a function of the physical characteristics of the bone, and so what is recovered at excavation is the result of the interplay between the opposing forces of preservation and of destruction. The state of preservation of exhumed skeletal remains is often recorded inadequately and judged qualitatively.

Bone is a composite tissue comprised mainly of a protein (collagen) and mineral (which is primarily hydroxyapatite). The strength of bone is the result of an intimate, albeit rather enigmatic, relationship between these components. The relationship is simply known as the protein-mineral bond (Von Endt and Ortner, 1984).

The bones, as seen at excavation, are the result of a complicated series of reactions brought about by both intrinsic and extrinsic 
factors, the extrinsic factors being the immediate environment of the bone after death (Baud, 1982; Henderson, 1987). The various variables within the burial environment such as soil pH, temperature, axygen and water content, bacteria and fungi have effects on the rate of the decay of bone. Central to our understanding of the concept of bone decay is the disruption of the protein-mineral bond. Anything which alters this bond will exacerbate changes in both protein and mineral components and will have a deleterious effect on the chemical and, hence, the morphological integrity of bone.

One observation that is commonly made when skeletons are excavated from archaeological sites concerns the extent of the differences in preservation between burials, even amongst those from the same site. One grave may contain the remains of a completely interred skeleton whereas the remains in the adjacent grave may comprise only a few. slithers of cortical bone. The archaeological and palaeopathological literature has a plethora of unimaginative and non-scientific terms which describe this so-called "bone preservation"; for example, the bones were well preserved, the bones were badly preserved, the bones were weathered. These terms are readily accepted as an indication of the macroscopic state of the bones but they give little insight into the interactions which have taken place between the bones and the various chemical and physical factors and biological agents within the burial environment (Garland 1988, and 1989).

Numerous techniques have been used to assess bone decay, or 'diagenesis'. These are $11 \mathrm{ght}$ and electron microscopy (Hassan and Ortner, 1977; Garland, 1987; Garland, Janaway and Roberts, 1988; Garland, 1988 and 1989; Race et al, 1968; Hanson and Buikstra 1987), also X-ray diffraction (Herrmann and Hewesley, 1982; Newesley 1989), atomic absorption spectrometry (Grupe and Plepenbrink, 1988), neutron activation analysis (Badone and Farquar, 1982) and inductively induced coupled plasma emission (Bethell and Smith, 1989). These studies have demonstrated the need for analysing postmortem changes in bone prior to assessing diet, bone elemental analysis and non-invasive measurement of bone mineral content.

\section{Differential preservation of bone}

Although the differential preservation of animal material has been extensively studied (e.g Behrensmeyer and H111, 1980; Behrensmeyer, 1978; Binford, 1981) the only quantitative study published on human remains was by Waldron (1987). using data from 88 adult skeletons from the Romano-British site of West Tainter Street, London. Waldron calculated an "expected" number from each bone. At the same time he coded the condition of both the proximal and distal ends of each bone. The observed number of bones in the assemblage were computed and expressed as a proportion of the expected number. From bis study Waldron found that the bones which were least well represented (numbering less than $20 \%$ of the expected score), were the phalanges of the hands and feet, the carpals and the coccyx. The bones occupying an anterior position in the body, the sternum, coracoid, acromion, pubis and patella, were also interestingly under-represented. 
The results from this study suggested that in some respects bone survival at this site was not haphazard but may be determined by size, ratio of cortical to cancellous bone, and also anatomical position.

\section{Conclusions}

A simple model contrasting cadaveric decay in a flat grave, with and without a coffin is shown in Figure 4 . Figure 4.1 represents a body wrapped in a shroud and placed directly in a flat earth grave. While the grave fill remains loose and uncompacted there will be a relatively free exchange of oxygen and water from the atmosphere and reductive gases from the body. At this early stage of decomposition burrowing invertebrates and small mammals will be attracted to the cadaver. Their access will, however, be impeded by textiles around the body. At a later stage (Figure 4.2 ) as the grave fill becomes more compact, gas exchange is reduced. The body has been reduced to a skeleton held together by ligaments and is surrounded by a rotting pultaceous, or liquifying, mass which may be held in place by the remains of the shroud or of the clothing. Body liquid degradation products may be washed down by percolating ground water and fixed onto mineral complexes. These biochemical complexes can be detected as chemical residues, even after thousands of years. In soft tissue loss is almost complete, although the skeleton is still articulated by the ligaments. Microbiological activity is reduced by the lack of readily available substrate. Figure 4.3 represents the grave as excavated by the archaeologist. The fill has compacted, the skeleton has collapsed and the soft tissue is represented only by chemical residues in the soll. With a body buried in a coffin (Figure 5.1) the early stages of decomposition may proceed largely in isolation from the surrounding soll environment. This will depend on the quality of the coffin construction. The environment within the coffin will quickly become anaerobic and the liquid and gaseous decomposition products will be trapped inside. Animal activity will be limited, the exception being insect larvae which have hatched from eggs laid before burial. Likewise, the ingress of microorganisms from the soil will be curtailed. When the coffin starts to break down (Ftgure 5.2) limited gaseous exchange will be facilftated and soll water can enter. The appearance of the skeleton at excavation may be determined by whether the skeleton has fully collapsed before the coffin lid "caves in" (Figure 5.3) or whether the collapsing coffin lid presses down on the still decomposing corpse (Figure 5.4). There my be an interaction between the decomposition of coffin wood and the body, although in the early stages the coffin will, in fact, shield the body from the external environment.

It is not easy to relate a discussion of skeletal "decay" with soft tissue breakdown of the body as a whole. However, the two are undoubtedly linked. In particular, it is difficult to state at which stage bone demineralisation commences. Crucial to this debate is the role of the liquid decomposition products to skeletal decay. Since present knowledge would seem to indicate a "neutral" to slightly "alkaline" buffering action, large amounts of body decomposition products would preclude simple chemical hydrolysis. However, demineralisation could occur through the formation of chemical complexes with the decomposition products, and it is also clear that 
microbiological action is an additional factor to consider. What is not clearly understood is whether the destructive micrabiological activity within the bone takes place, only after the bulk of the soft tissue has been lost. 


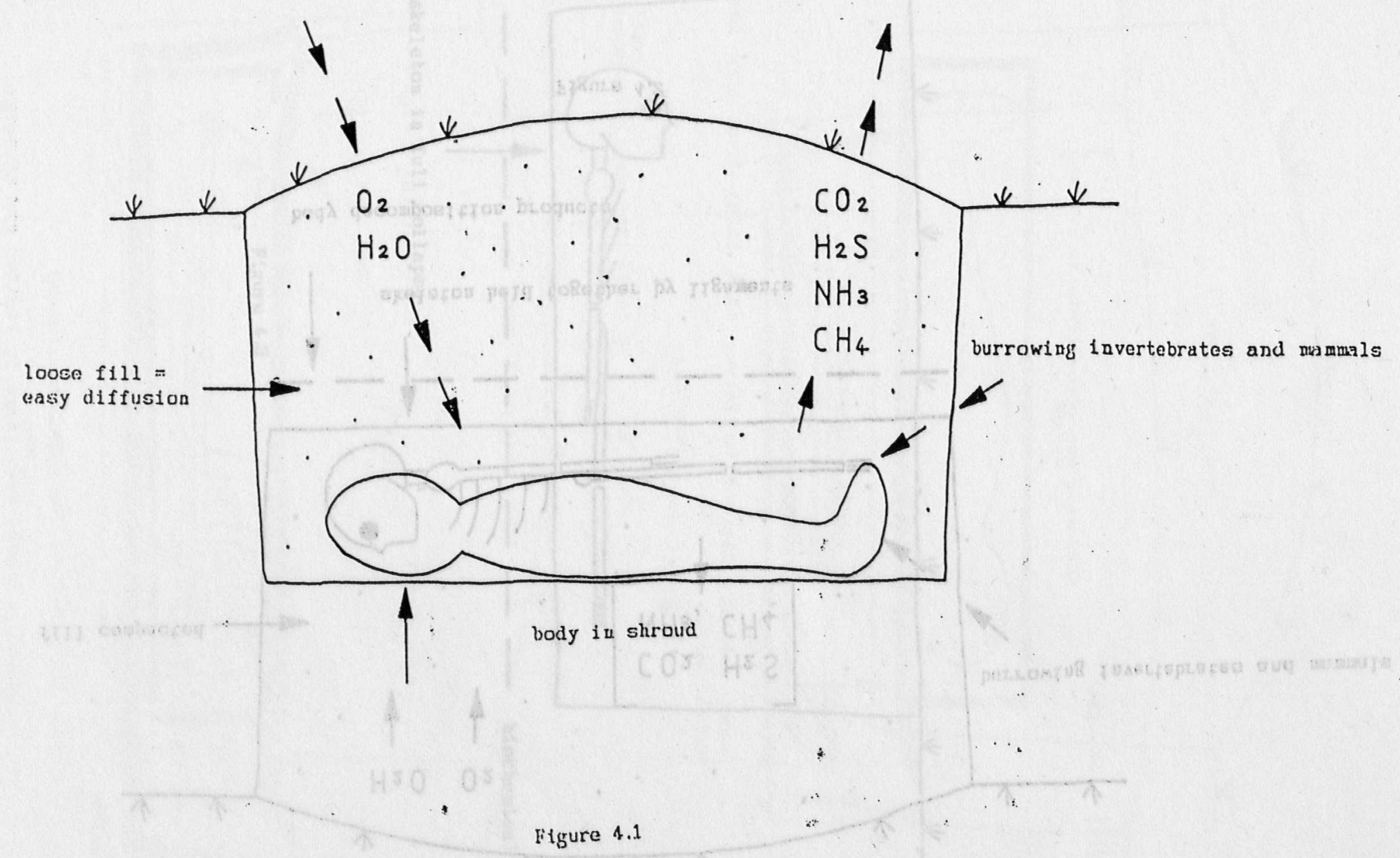




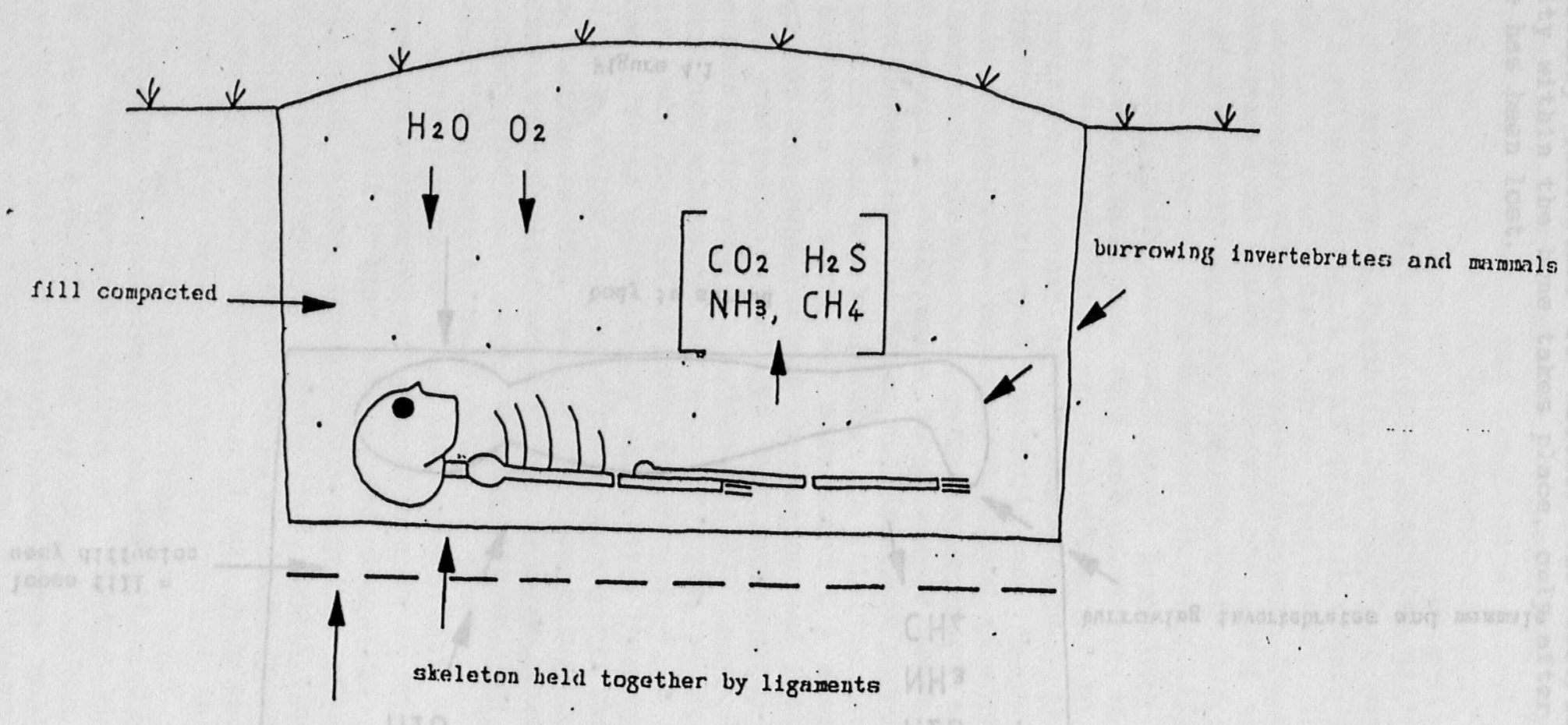

bady decomposition products

Figure 1.2 


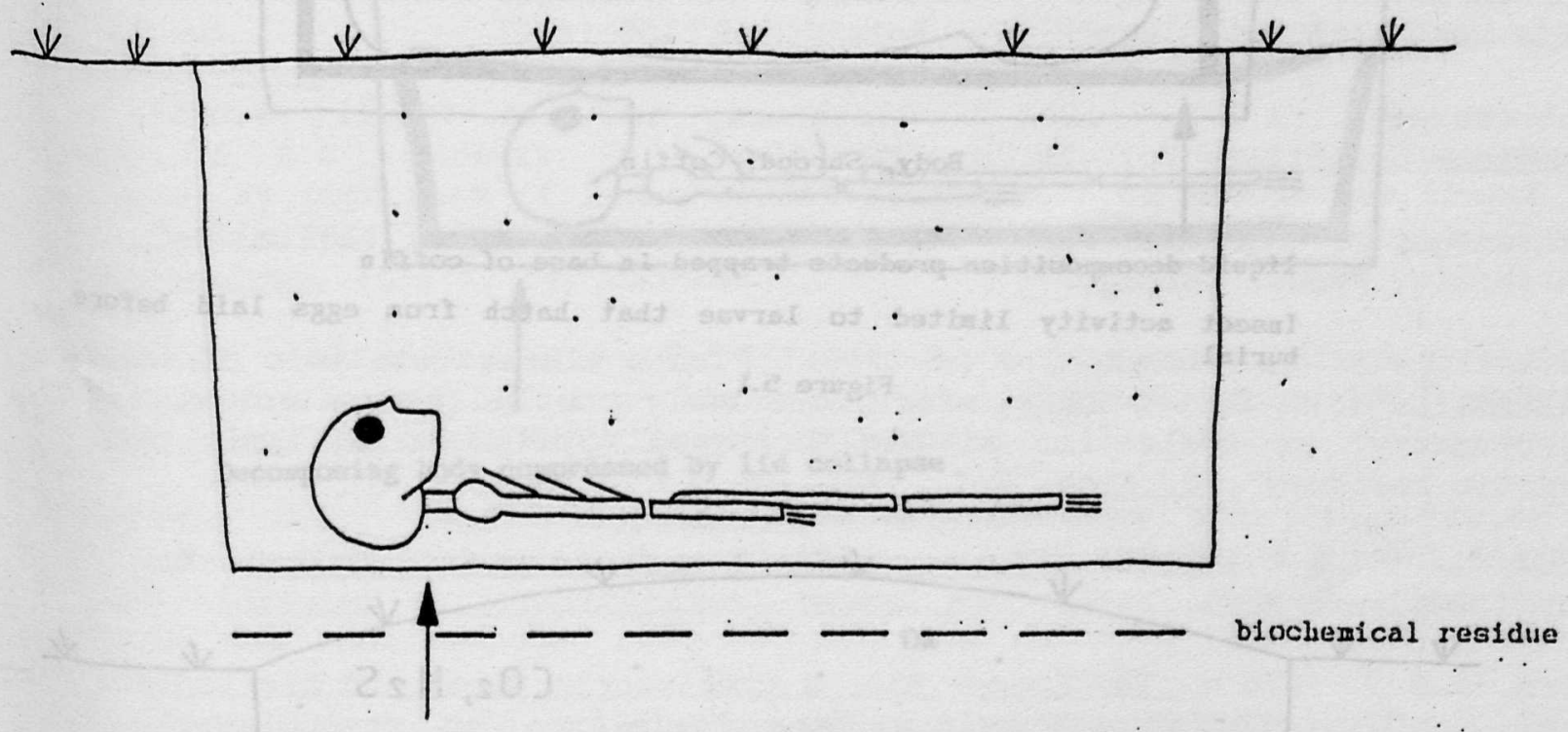

skeleton in full collapse

Figure 4.3 


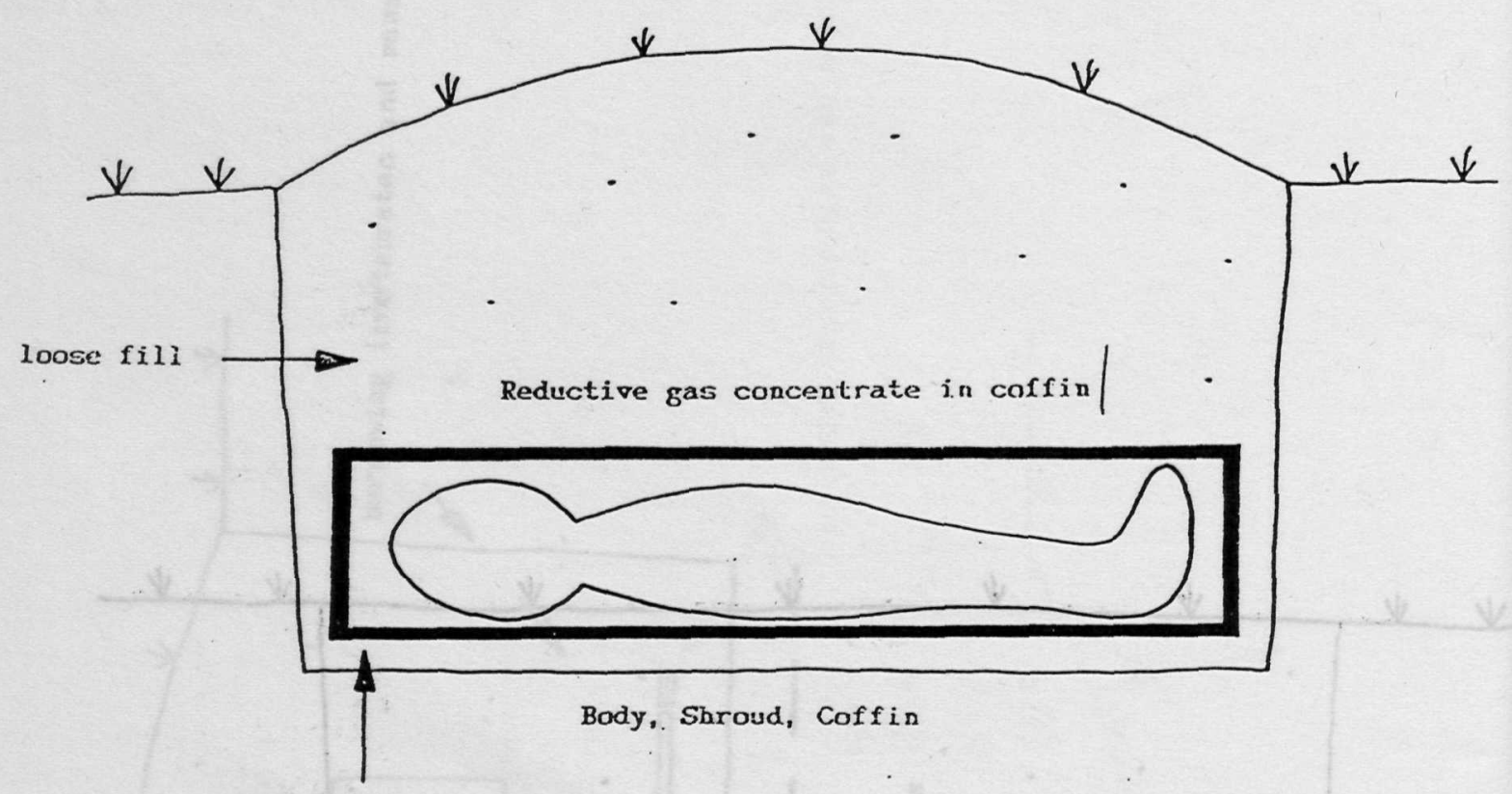

liquid decomposition products trapped in base of coffin

Insect activity limited to larvae that hatch from eggs laid before burial

Figure 5.1

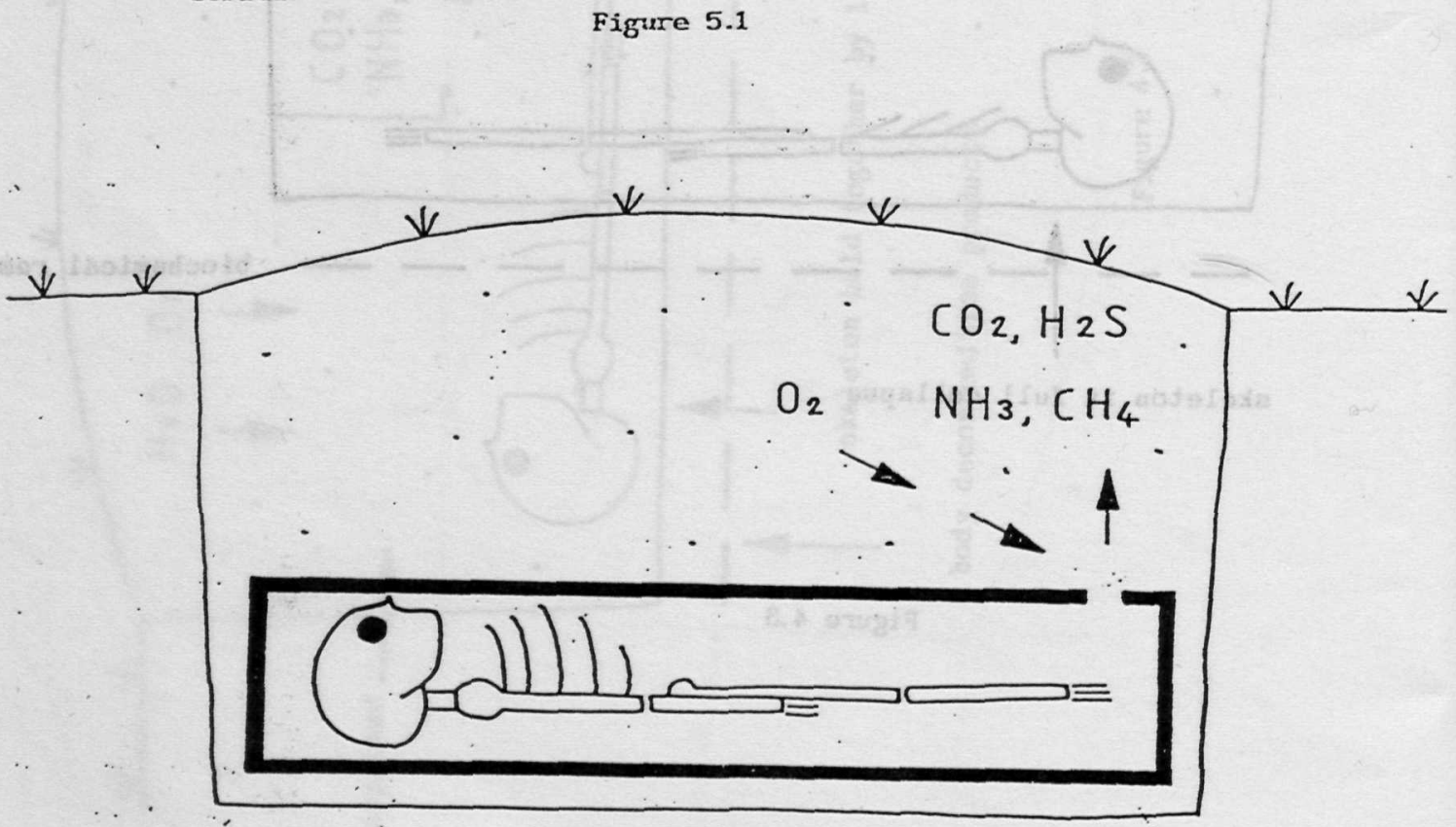

Figure 5.2

Hs coffin breaks down there is limited gas exchange

Liquid decomosition products trapped in coffin 


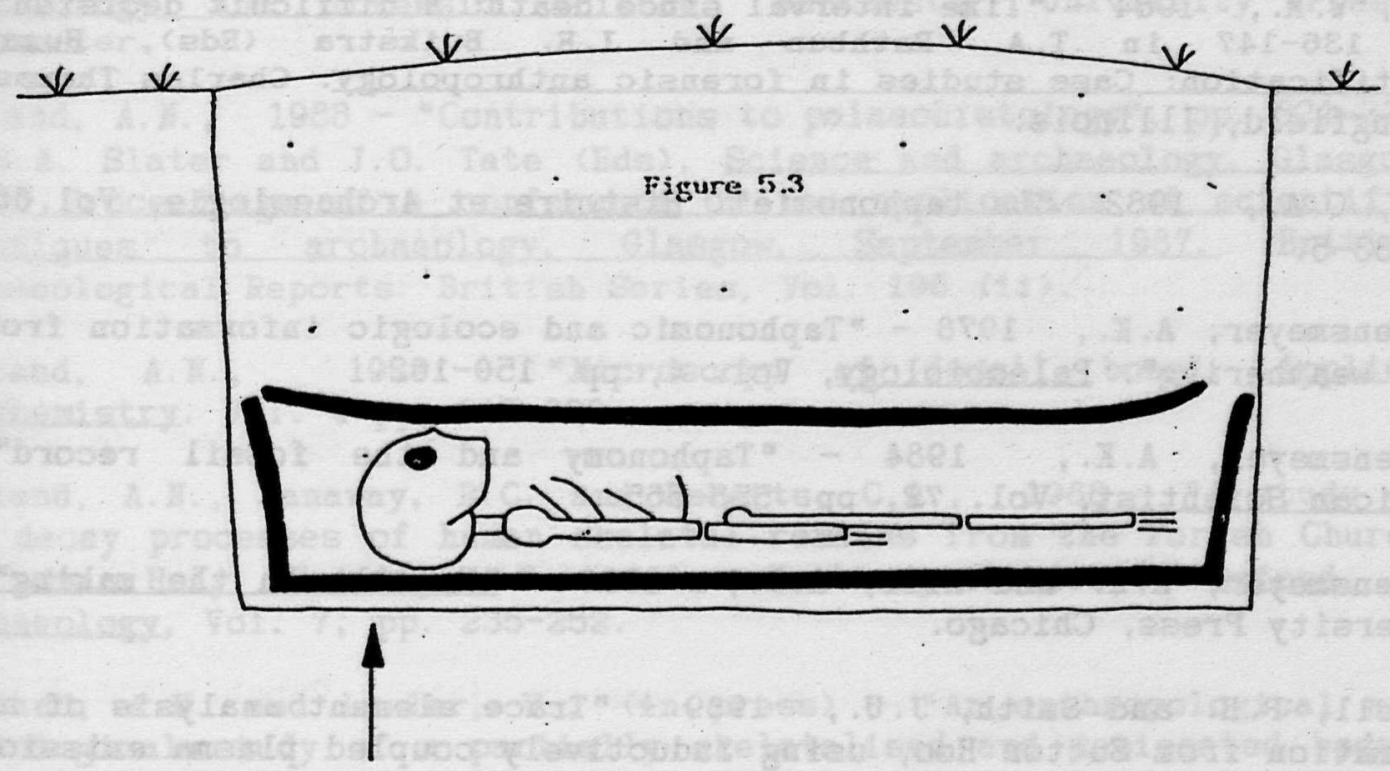

Decomposing body compressed by lid collapse.

OR

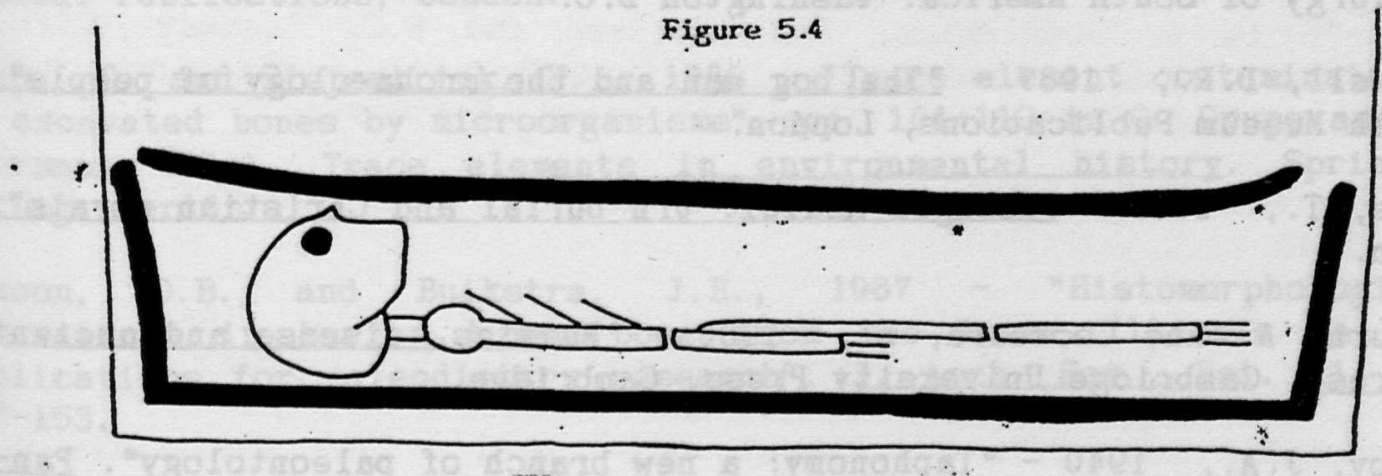

Skeletal collapse before lid 
BIBLIOGRAPHY

Albrethsen, S.E. and Brinch Petersen, E., 1975 - "Grarene pa Bagenbakken Vadbaek". No publisher.

Badone, E. and Farquhar, R.M., 1982 - "Application of neutron activation analysis to the study of element concentration and exchange in fossil bone". I. Radioanalytical Chemistry Vol. 69, pp. 291-311.

Bass, W.M., 1984 - "Time interval since death: a difficult decision", pp. 136-147 in T.A. Rathbun and J.E. Buikstra (Eds), Human identification: Case studies in forensic anthropology. Charles Thomas, Springfield, Illinois.

Baud, C.A., 1982 "La taphonomie". Histoire et Archaeologie, Vol.66, pp. 33-5.

Behrensmeyer, A.K., 1978 - "Taphonomic and ecologic information from bone weathering". Paleoblology, Vol, 4, pp. 150-162.

Behrensmeyer, A.K., 1984 - "Taphonomy and the fossil record". American Scientist, Vol. 72 , pp. 558-565.

Behrensmeyer, A.K. and Hill, A.P., 1980 - "Fossils in the making". University Press, Chicago.

Bethell, P.H. and Smith, J.U., 1989 - "Trace element analysis of an inhumation from Sutton Hoo, using inductively coupled plasma emission spectometry: an evaluation of the technique applied to analysis of organic residues". J, Arch. Scl., Vol. 16, pp. 47-55.

Binford, R.L., 1981 - "Bones, anclent men and modern myths". New York, Academic Press.

Bird, J.B., 1975 - "The Copper Yan: a prehistoric miner and his tools from northern Chile". Dumbarton Oaks Conference on pre-Columbian metallurgy of South America. Washington D.C.

Brothwell, D.R., 1987 - "The bog man and the archreology of people". British Museum Publications, London.

Browne, T., 1658 - "Religio Medic1: Urn burial and Christian morals", London.

Cockburn, A. and Cockburn, E., 1980 - "Yummies, disease and ancient cultures". Cambridge University Press, Cambridge.

Efremov, J.A., 1940 - "Taphonomy: a new branch of paleontology". PanAmerican Geologist, Vol. 74, pp. 81-94.

Evans, E.G., 1962 - "The mummy case. 1. The pathological investigation". Medicine, Science and the Law Vol 2, pp 33-47

Evans, W.E.D., 1963 a - "Adipocere formation in a relatively dry environment" Medicine, Science and the Law, Vol. 3, pp. 145-153. 
Evans, W.E.D., 1963b - "The chemistry of death". Charles Thomas, Springfield, Illinois.

Fourcroy, A.F., 1786 - "Memoirs sur les differents etas des cadavres trouvés 1786 et 1787". Lus à Academie des Sciences, Paris.

Garland, A.N., 1987 - "A histological study of archaeological decomposition", pp. 109-126 in A. Boddington, A. M. Garland and R.C. Janaway (Eds), Death, decay and reconstruction: approaches to archaeology and forensic science. Manchester University Press, Manchester.

Garland, A.N., 1988 - "Contributions to palaeobistology", pp. 321-328 in E.A. Slater and J.O. Tate (Eds), Science and archaeology. Glasgow 1977. Proceedings of a conference on the application of scientific techniques to archaeology. Glasgow, September 1987. British Archaeological Reports. British Series, Vol. 196 (11).

Garland, A.N., 1989 - "Microscopy of fossil bone". Applied Geochemistry. Vol. 4 pp, 215-229.

Garland, A.N., Janaway, R.C. and Roberts, C.A., 1988 - "A study of the decay processes of human skeletal remains from the Parish Church of the Holy Trinity, Rothwell, Northamptonshire". Oxford J. Archaeology, Vol. 7 , pp. 235-252.

Garland, A.M. and Lawler, W., (in press) - "An anthropological and pathological study of a partially skeletalised and desiccated body". Amer. J. of Forensic Yedicine and Pathology.

Gifford, D.P., 1981 - "Taphonomy and palaeoecology: a critical review of archaeology's sister discipline", pp. 365-438 in M.B. Schiffer (Ed), Advances in archaeological method and theory, Vol. 4. Academic Press, New York.

Gresham, G.A., 1973 - "A colour atlas of forensic pathology". Wolfe Medical Publications, London.

Grupe, G. and Piepenbrink, H., 1988 - "Trace element contaminations in excavated bones by microorganisms", pp. 104-112 in G. Grupe and B. Herrmann (Eds), Irace elements in environmental history. Springer Verlag, Berlin.

Hanson, D.B. and Buikstra, J.E., 1987 - "Histomorphological alterations in buried human bone from the Lower Illinois Valley: implications for paleodietary research". J. Arch. Sci., Vol. 11, pp. 247-153.

Hassan, A. A. and Ortner, D.J., 1977 - "Inclusions in bone material as a source of error in radiocarbon dating". Archaeometry, Vol. 19, pp. 131-135. 
Henderson, J, 1987 - "Factors determining the state of preservation of human remains, in A. Boddington, A.N. Garland and R. C. Janaway (eds), Death, Decay and Reconstruction. Approaches to archaeology and forensic science. pp 43-54. Manchester University Press, Manchester.

Herrmann, B. and Newesley, H., 1982 - "Dekompositionsvorgange des Knochens unter langer Liegzeit". I. Die Mineralische Phase. Anthropol. Anz., Vol 40, pp, 19-31.

Janaway, R.C., 1985 - "Dust to dust: the preservation of textile materials in metal artefact corrosion products with reference to inhumation graves". Science and Archaeology, Vol, 27, pp. 29-34.

Janaway, R.C., 1987 - "The preservation of organic materials in association with metal artefacts deposited in inhumation graves", pp. 127-148 in A. Boddington, A.N. Garland and R.C. Janaway (Eds), Death. decay and reconstruction. Approaches to archaeology and forensic science. Manchester University Press, Manchester.

Janssen, W., 1984 - "Forensic histopathology". Springer Verlag, Berlin.

Macleod, W. 1946 - "The massacre of the Ardeatine caves". Journal of the Royal Army Hedical Corps, Vol.87, pp. 10-24.

Mant, A.K., 1950 - "A study of exhumation data". Unpublished K.D. Thesis, University of London.

Mant, A.K., 1953 - "Recent work on post-mortem changes and timing death", pp. 147-162 in K. Simpson (Ed), Lodern trends in forensic medicine. Butterworth, London.

Mant, A.K., 1957 - "Adipocere - a review". Journal of Forensic Medecine, Vol. 4, pp. 18-35.

Mant, A.K., 1987 - "Knowledge acquired from post-War exhumations", pp. $65-78$ in A. Boddington, A.N. Garland and R.C. Janaway (Eds), Death. decay and reconstruction. Approaches to archaeology and forensic science. Manchester University Press, Manchester.

Newesley, H. 1989 - "Fossil bone apatite". Applied Geochemistry, Vol. 4 , pp. 23-45.

Plank, D., Biel, J., Süsskind, A, and Wais, A., (Eds) 1985 - "Der Keltenfürst von Hochdorf". Landesdenkmalamt Baden-Württemberg.

Polson, C.J., Gee, D.J. and Knight, B., 1985 - "The essentials of forensic medicine", 4th edition. Pergamon Press, Oxford.

Race, G.J., Fry, E.I., Matthews, J.L., Wagner, M.J., Martin, J.H. and Lynn, J.A., 1968 - "Ancient Nubian human bones: a chemical and ultrastructural characterisation including collagen". Amer. J. Phys. Anthrop., Vol. 28, pp. 157-162. 
Von Endt, D.W, and Ortner, D.J., 1984 - "Experimental effecte of bone size on bone diagenes1s". J.Arch. Sci., Vol. 11, pp. 247-253.

Waldron, T., 1987 - "The relative survival of the human skeleton: implications for palaeopathology", pp. 55-64 in A. Boddington, A.N. Garland and R.C. Janaway (Eds), Death, decay and reconstruction. Approaches to archaeology and forensic science. Manchester University Press, Manchester.

Walker, N.I., Harmon, B.V., Gobe, G.C. and Kerr, J.F.R., 1988 "Patterns of cell death". Methods and Achievements in Experimental Pathology, Vol. 13, pp. 18-54. 


\title{
OII AND OFF-SITE CONSERVATION OF BOIF
}

\author{
James. A. Spriggs \\ Conservation Laboratories, \\ York Archaeological Trust, \\ Galmanhoe Lane, \\ Narygate, \\ York YO3 $7 \mathrm{DZ}$
}

\section{Intraduction}

It is generally accepted that the quality of the information that can be gained from archaeological remains is inversely proportional to the degree of degradation during burlal. It is often forgotten, though, that the value of these remains is also affected by the way in which they have been treated since the moment of discovery. The process of excavation is possibly the most traumatic experience that any buried object must undergo, closely followed by the methods of cleaning, and other 'hands on' processes. Just as harmful can be the hidden damage by poor packaging, bad handling practises and low grade storage.

Safe storage and handling are dealt with elsewhere in this volume I intend to concentrate here on the problems encountered in the excavation and immediately post-excavation phases, and on how the various types of damage mentioned above may be minimised.

\section{Burial conditions and preservation}

Like any other material, bone will be acted upon by the forces of nature during burial, normally to its detriment. The actual processes of decay are complex and can vary widely depending on the particular combination of physical, chemical and biological factors at play in that particular burial environment. It would seem, however, that the two main contributory factors leading to advanced states of decay in bone are low pH, and repeated cycles of hydration and dehydration. Biological factors ranging from rodents through to microorganisms may also play a significant role, again depending on local conditions. Upon excavation, skeletal material will therefore be found in a varlety of conditions, from 'perfectly preserved' where normal excavation routines and finds processing will be quite adequate for safe recovery, to 'appallingly preserved' where the bone is a mere stain in the ground with scarcely anything physical left worth recovering. In practice, most skeletal material falls somewhere in between the two extremes, and successful recovery may very often require the application of 'first aid' conservation.

Typically, the bone is moist on excavation, and much of $1 t$ is soft. The more heavily calclfied parts, such as the shafts of long bones and cranial vault, will harden considerably on drying, but the area composed of more cancellous tissue, such as long bone eplphyses, the pelvis and the facial area of the skull, will disintegrate on drying and be almost 1 mpossible to recover without the prior application of field conservation techniques (Spriggs and Van Byeren, 1984 pp. 41-2). 
Many of the field conservation techniques applied to skeletal material will involve the use of synthetic resin consolidants, materials for block lifting and special packaging and recording techniques. The archaeologist or anthropologist should first make sure that the correct materials that are required are available to his team, and that those actually involved with the uncovering of the burlals should be experienced in the application of those materials and techniques. Incorrect application of materials can be disastrous, and bad recording worse than useless. On sites where skeletal material in poor condition is anticipated, it is advisable to bring in a trained conservator to deal with the burials, or at least seek their professional advice.

On excavations where a number of burials are likely to be found, a policy should be formulated, by the archaeologist/anthropologist in charge, as to the degree of recording and conservation to be applied to each burial. For example, especially important burlals might merit a range of recording techniques being applied, followed by total lifting 'en bloc' - a time consuming and potentially costly exercise. On the other hand, burials which are much disturbed, and are considered of little relevance may perhaps be gathered up with minimal expenditure of time taken in conservation and recording. Policies governing methodology must necessarily be affected by practical considerations such as time and money but not, hopefully, at the expense of data, which once lost can never be recovered.

\section{Excavation}

In general, skeletal material should be left exposed to the elements for as short a period as possible, especially in extremes of weather or climate. Recording of the skeleton should not necessarily walt until the whole burial is exposed since badly deteriorated bone is best recorded whilst fresh and still slightly damp, rather than later when it might have dried and deteriorated further. Polaroid photography has proved most useful for making swift records of burial details as excavation proceeds. Osteometric data should be made in the ground on bones which are likely to come out in fragments, though it is worth noting that the presence on site of someone with the knowledge to do this properly is a necessary requirement if the measurements are to have any value! Ideally, of course, the more fragile bones will be consolidated as they are exposed, allowing the whole burial to be recorded once it has been fully uncovered.

Every experienced archaeologist will have his own preferred technique for dealing with the excavation of the various elements that make up a burial - grave cut; funerary furniture; skeleton; grave goods; etc. The actual methods are often dictated by the individual clrcumstances, and can be greatly complicated by features such as deep burial cuts, multiple burials and unusual burlal position. There is no standard equipment for excavating burlals, and a wide range of small tools such as plasterers' leaves, dental picks, various sized spoons and small brushes can all be pressed into useful service. When cleaning the last few millimetres of dirt away from the bone surface, 
wooden or plastic tools are recommended as they are less likely to dig into the surface of the bone. Here, modelling tools, tooth picks, tongue depressors and lollipop sticks are all useful additions to the tool kit. Once areas have been exposed and cleaned, it is helpful to keep them covered with weighted polythene to protect them from overrapid drying, wind-blown dirt and other potential mishaps. In particularly bot climates the whole burial should be shaded from direct sunlight for the sake of both the burlal and the excavator, and in colder climates burials under excavation should be protected from the effects of frost.

\section{Consolidation}

There are a number of general maxims that should be adhered to when thinking of using consolidants in the field. These can be summarised as follows. Consolidate only when absolutely necessary; use the minimum amount of consolidant to achieve the desired effect; only use a consolidant that is entirely approprlate for the job at hand and which matches up to the general conservation requirements of reversibility, compatibility, known composition etc; keep clear records of materials used and on which bones and always take the necessary precautions when handling and using chemicals (Sease, 1988 pp. 5-10).

To consolidate damp bone successfully, a thermoplastic resin in water miscible form is required. A number of resins are available as emulsions and colloidal dispersions, the most commonly used being the various types of poly-vinyl acetate (PVA) emulsion. The PVA emulsions are now considered unsuitable for use in hot climates as they tend to soften and have a comparatively large molecule size. The acrylic emulsions and colloidal dispersions, such as the Primal range, are now recommended (Koob, 1984 pp. 99-101) as they are more temperature stable and have a smaller molecule size, allowing them to penetrate denser bone to a greater depth. Typically, a 2-4\% solution is made up with water (assuming the solution is supplied as 100\%) for thicker areas of lamellar bone, anything up to $10 \%$ being used on the softer, thinner and more cancellous parts.

The resin solutions are applied either by brush or dropper depending on the fragility of the bone. Do not allow accumulations of the resin to form on the surface, and allow the bone to dry and the resin to set completely before lifting. Several applications of the resin may be necessary before the bone is strong enough to lift, but each application must be left to dry before applying the next. If too strong a solution is used, or $1 f$ excess consolidant is allowed to dry on the surface, a skin will be formed which will hold any remaining dirt firmly in place and obscure surface detail.

In situations where the surrounding ground is too damp to allow the bone to dry out properly, do not attempt consolidation, but lift the bones using an encapsulation technique if the condition of the bone warrants $1 t$. The bone can be cleaned and consolidated at a later stage. Also, do not consolidate any bone that is destined for any type of chemical analysis or dating. Special samples of bone may need to be taken for these purposes. 


\section{lifting}

Once the exposed surface of the bone is consolidated and dry, the bone can be freed from the soll beneath it in preparation for removal. If the bone is now reasonably sturdy, it may be possible to raise it from the ground, invert it and place it in a padded tray for removal from site. Accurate labelling is essential at this stage to avoid confusion later on. The name of the bone, the side of the body it is from and the burial number should accompany each bone and if the epiphyses are missing or the bone is otherwise damaged so that the orientation is unclear, then a note should be made as to which end is which - distal or proximal. Once off site, the newly exposed surfaces of the bones should be cleaned without delay and consolidated as before, allowing the whole bone to dry thoroughly before final packaging.

More fragile bone may require some support while lifting, and heavy duty aluminium foll has been found useful in this context (Spriggs and Van Byeren, 1984 pp. 44). Pleces of the foll are pre-shaped to fit snugly over the bone whilst still in the ground, and used to handle the bone as it is released from the underlying matrix and turned over. The foil can be kept around the bone as a permanent support after further cleaning and consolidation have taken place, the ends and edges of the foll being turned over to enclose the whole object. A short length of masking tape fixed around one end of the package can make a convenient label.

\section{Encapsulation and block lifting}

There are a number of techniques avallable for lifting fragile or fragmentary bones or assemblages of bones and artefacts. Most of the techniques involve the inclusion of a certain amount of the surrounding soll matrix with the objects being lifted, which may have archaeological implications. The processes can be complicated, time consuming, and may involve the use of potentially hazardous materials. Once out of the ground, the blocks can be heavy and bulky which can cause problems when packing up and arranging transport at the end of the project. It is advisable to seek the aid of a conservator if any major block lifting is anticipated, and a conservator should also be on hand to undertake the delicate task of undoing encapsulated and block-lifted finds once they have arrived back at the receiving institution. It will be sufficient here to refer the reader to the current field conservation manuals detailing techniques and materials (e.8. Watkinson, 1987 pp. 77-84; Sease, 1988 pp. 26-31; Johansson. 1986 pp. 132-137).

The sku11

Being of especial importance to the study of any burial, the skull merits great care in its recovery and handling, especially if still intact. As the skull will normally have become filled with burial matrix, it will be heavy and difficult to move without putting undue stress on some part, possibly leading to breakage and collapse. Additionally, the skull can often be located against the end of a burial cut, or in some other awkward position so compounding the 
difficulties of releasing it from the surrounding earth. In such circumstances, special tools may need to be improvised to cope with the problem. Once freed, the skull should be lifted using both hands to spread the load and avolding stress on the fragile faclal bones or other damaged areas. It should be transferred immediately from the ground into a walting box or bowl lined with crumpled paper or other padding to provide support. Fine cleaning and consolidation of the skul1, and especially of the fragile faclal bones, is best done under better working conditions off-site. The dirt inside the skull should also be emptied out before it dries and becomes hard. Left inside, loose dirt and stones can easily smash a skull during transport. The Foramen magnum is often the only polnt of access to the skull interior, and tools may again need to be improvised to loosen the dirt within.

If the condition of the skull makes it unwise to attempt to lift it unaided, then two or more sheets of thick aluminium foll pressed gently but firmly around it may just provide the extra strength and rigidity that it requires. If the skull is cracked and pieces are loose, lengths of surgical bandage can be tied around it to keep the pleces together. If the mandible is loose, it is a good idea to lift and pack it separately.

\section{Off-site treatment}

Skeletal material needs to be cleaned before it can be studied, and bones from well preserved burlals are normally robust enough to be washed and dried, as described elsewhere in this volume (Stroud). The more fragile bone (which may have been consolidated whilst still insitu) should also receive further cleaning. Very delicate bone can be dry brushed with hogs hair paint brushes; slightly more robust bone which needs further consolidation may be gently washed with soft paint brushes and sponges in a $2-4 \%$ solution of the same emulsion or dispersion used on site. After drying, these bones may be further consolidated by dipping again in a fresh solution of consolidant.

Bones that are in fragments may be refixed using a suitable adhesive, which must match up to the conservation requirements of reversibility etc. Paraloid B72 is now the preferred cholce, and is avallable in crystalline form, or made up in tubes for 1 mmediate use. For techniques of reconstructing bones, see references on pottery reconstruction (e.8. Larney, 1975 pp. 39-42; Sease, 1988 pp. 36-38). Paralaid B72 dissolved in $60 / 40$ acetone/toluene to a $2-3 \%$ wt./vol. solution makes a convenient consolidant for strengthening edges prior to refixing, and for any bone which is dry but requires consolidation.

Bone off-site may occasionally display active damage caused by soluble salts, or be covered with a layer of insoluble concretion, or be rubbery to touch due to total decalcification. To deal with these and other conditions in which bone is occasionally found, refer to a conservator, or to the specialist literature (e.g. Sease, 1988 pp. 5663). 


\section{Packaging}

Packing up skeletons at the end of a project can be a time-consuming task requiring care, patience and a plentiful supply of the appropriate materials. The first requirement is a box of the right size to contain all the bones of a human comfortably, with enough excess space to allow for padding materials. The skull, because of its size and fragility, will normally be packed separately in a smaller container. Skeleton boxes can be obtained pre-fabricated, but are bulky and expensive to transport and store before use. Fold-flat boxes of either card or corrugated plastic overcome these problems, and of course can also be used to store other types of archaeological finds as well.

The bones should be individually wrapped in tissue paper, thin polythene or aluminium fail (if they require the extra support) and each package clearly labelled. They are then packed neatly into their boxes, using wads of crumpled tissue paper or other light springy material as padding to keep the bones apart. Any space left unfilled should be packed out with more crumpled paper to prevent any movement of the contents within. The skeleton boxes themselves may then be crated up in groups, again kept apart by wads of foam rubber, polystyrene, 'bubblewrap' or other similar material to act as a buffer against jarring and shifting during transport. It is most 1 mportant that the bone be completely dry before packaging, and that any polythene materials used should be deliberately pierced to allow humidity levels to equilibriate, should the crate and boxes be exposed to climatic varlations during transport and storage (Sease, $1988 \mathrm{pp}$. 38-47).

\section{Conclusion}

The successful recovery of skeletal data relies on a combination of careful preparation before going into the field and the application of sound policies covering excavation, recording, lifting and packaging. Lessons in such matters can always be acquired through experience, but such experience can be bitter unless the practical assistance of a conservator is sought to complement the skills of the other members of the archaeological field team.

\section{BIBLIOGRAPHY}

Johansson, L-U., 1986 - "Bone and related materials" pp. 132-137 in H. M. Hodges (Ed), In-situ archaeological conservation. Getty Conservation Institute / Instituto Nacional de Antropologia e Historia de Mexico.

Koob, S.P., 1984 - "The consolidation of archaeological bone", pp. 98-102 in N.S. Brommelle, E.M. Pye, P. Smith and G. Thomson (eds). Adhesives and consolidants. The International Institute for Conservation of Historic and Artistic Works. 
Larney, J., 1975 -"Restoration of ceramics", Pp. 39-46 in A. Moncrieff (Ed), Conservation in archaeology and the applied arts. The International Institute for Conservation of Historic and Artistic Works.

Sease, C., 1988 - "A conservation manual for the fleld archaeologist". Archaeological Research Tools Vol. 4. University of California, Los Angeles.

Spriggs, J.A. and Van Byeren, T., 1984 - "A practical approach to the excavation and recording of ancient Maya burials". The conservator, Vol. 8, pp. 41-46

Watkinson, D., (Ed) 1987 - "First aid for finds". Rescue / United Kingdom Institute for Conservation of Historic and Artistic Works.

\section{Naterials}

Primal AC-61, AC-643 (acrylic emulsions), Primal WS-24, WS-50 (acrylic colloidal dispersions) and Paraloid B72 (acrylic resin in solid form) are all avallable from:

Rohm and Haas (UK) Ltd.

Lennig House

2 Mason's Avenue

Croydon

CR9 3NB

Paraloid B72 (acrylic resin) adhesive in tubes from:

H. Marcel Guest Ltd.

Riverside Works

Collyhurst Road

Manchester

M10 7RU

Aluminium foll $(0.5 \mathrm{~mm}$ thick $)$ from:

Star Aluminium Ltd.

97. Penn Road

Wolverhampton

WV3 ODN

Fold-flat boxes e. 8 . of corrugated 'Correx' plastic from:

Lawtons Ltd.

60 Vauxhall Road

Liverpool

L69 $3 \mathrm{AU}$ 
THE PROCESSING OF HUMAN BOHE FROK ARCHAFOLOGICAL SITES

\author{
Gillian Stroud \\ Environmental Archaeology Unit \\ York Archaeological Trust \\ Walled Garden \\ University of York \\ Heslington \\ York \\ YO1 5DD
}

Yuch of the following may strike many readers as obvious; nonetheless my experience and that of my colleagues indicates that our expectations as to the condition in which we receive human skeletal material are not always matched by reality. Ideally, archaeologist and human bone specialist should be in touch right from the start and the method of excavation and processing agreed between them - in reality the specialist is often only contacted after the excavation, sometimes well after.

Although it is generally common practice on lifting an articulated skeleton from the ground to bag up different parts of the body separately, there are still sites where this is not done. Obviously such skeletons can be sorted out by the osteologist, but this adds to the time spent recording the material, especially if a large site is involved. The bones should be bagged with the limbs kept separate, and with right and left sides distinguished where possible. In the case of hands and feet this may sometimes be difficult, or even impossible where for example the hands are crossed over the pelvis. The right and left ribs should also be bagged separately. These of ten break into quite small fragments on lifting, many of which will later be unidentifiable as to side. In cases of multiple rib fractures, for example, or new bone development on the internal surface of ribs, it is of value to know whether only one side of the thorax was affected.

In Britain bones are likely to be damp when lifted, and it is therefore important that any labels put in with them are waterproof and are marked with a waterproof pen. In the absence of such labels, small pieces of Permatrace make a good substitute. As much dirt as possible should be removed at this stage, unless there is the possibility that organic matter may be preserved as a result of exceptional burial conditions.

Assuming that bone is the only tissue to have survived in the ground, then as soon as possible after lifting, the skeletal material should be properly cleaned. The method of cleaning depends very much on the fragility or atherwise of the bone. If abviously in very poor condition, careful cleaning with a dry soft brush may be the only option. Otherwise bone really needs to be washed in order to permit a proper examination of the surface by the specialist at a later date. Brushing alone can obscure slight changes to the surface of the bone.

Washing bone is best carried out in tepid water whlch must be regularly changed - washing in dirty water simply produces dirty 
bones. It is also important not just to wash bones in a bucket of water until there is a couple of inches of sludge in the bottom and then to throw this away when changing the water. Teeth or small pieces of bone may have become detached; consequently a sieve should be used to retrieve any such fragments. In fact the sieve could sit within the washing bowl and the bones be washed over it. Gentle brushing of the bone is normally adequate - scrubbing is generally neither necessary nor desirable - and all surfaces of the bone should be cleaned. Vertebrae in particular are time-consuming to wash properly, but in a complete spine there are approximately 140 articular facets, any or all of which can show arthritic changes of varying degrees. Inadequate cleaning means that accurate recording of pathological changes to these or indeed to any bone surface is impossible.

Two or three exceptions to the above should be mentioned. The first is the dentition. Washing teeth may loosen them, with the risk of subsequent loss, whilst brushing can remove deposits of calculus. Secondly, earth should not be removed from small holes, most specifically the earholes, from which the three small ear bones can be dislodged and possibly lost. Lastly, especial care should be taken when washing the facial bones, since some of the bone around the nose and eyes is thin and fragile.

Once washed, the bones obviously need to dry. This should not take place in direct sunlight or with any kind of forced drying equipment. It is important not to underestimate either the amount of space or the amount of time needed to dry human skeletons - both are considerable. Bones packed away damp will go mouldy, especially if sealed in plastic bags. Once the bones are dry, they should be marked with waterproof ink, common sense dictating a minimum size of fragment below which marking is not necessary.

At this stage the bones are ready for baggging, again in the case of discrete skeletons keeping the separate parts of the body in different bags. Polythene bags of varying sizes are ideal, assuming of course that the bones are quite dry, using the standard practice of a label inside and outside, with the bag loosely tied. Polythene is preferable to paper, which has a tendency to tear.

Boxes should be large enough to take a complete postcranial skeleton comfortably. This may seem blindingly obvious and yet surprisingly boxes are often too small, especially after reconstruction of broken bones has been carried out. A box size of approximately $300 \mathrm{~mm} \times 250 \mathrm{~mm}$ x $500 \mathrm{~mm}$ should take most skeletons easily, whilst a smaller size can be used for complete skulls or for less complete individuals. Where one individual or one context is divided between more than one box, this should be noted on the outside, for example 'Box 1 of 3 ', taking care to label the end of the box rather than the side, so that labels will not be obscured when boxes are stacked or shelved. Inside, the bones should be cushioned by the plastic bags in which they have been placed. Strong boxes will stack easily if necessary, and should not be stored in damp surroundings. 
A final point negds to be made which, while not etrictly speaking related to the processing of bones, is nonetheless of great importance to the specialist prior to and during the recording of the material. This is the provision of adequate site records relating to the excavation of the skeletons - drawings, photographs, the relationship of one context to another. These can be of considerable value. To give an example, an inhumation had been cut by a later one, leaving only the lower legs in situ with the disturbed bones from the earlier grave being thrown back with the fill of the later grave. On excavation, these were given a context number only, relating to the grave fill, while the lower legs and the later burial received skeleton numbers. Without any information from the excavator, the loose bones would simply have been listed under their context number. However, good records supplied with the burials permitted the earlier skeleton to be virtually completely reunited, resulting in additional information with regard to the individual and the site as a whole.

If any conclusion is to be drawn, it is that early communication between osteologist and archaeologist together with timely thought regarding the processing and packaging of the human bones can only be of benefit to both parties, increasing information gained and perhaps saving botb time and money. 


\title{
PHYSICAL AITHROPOLOGY; THE BASIC BOHES
}

\author{
Ann Stirland \\ Institute of Archaeology, London \\ The Cottage \\ Lower Green \\ Woodend \\ Towcester \\ Northants \\ NN12 8SB
}

\section{Sumary}

This paper seeks to increase understanding of the work of the human bone specialist and to promote greater co-operation between the specialist and the archaeologist. An overview of the work of the human bone specialist is presented and the methodology explained. The expectations of archaeologists are enumerated and discussed and the realities in terms of these expectations are defined. Suggestions for closer future interdisciplinary planning and work are made.

\section{Introduction}

In Great Britain the discipline of Anthropology has traditionally Involved the study of people as biological (physical anthropology), and as social (cultural/social anthropology) units. Archaeology has largely been regarded as a separate discipline. In the United States, however, Anthropology has always been a generic term embracing five areas of study. They are:

\section{archaeology}

physical anthropology

cultural anthropology

ethnography

linguistics

Physical anthropology in the United States has included the study of excavated archaeological skeletons, largely native American. Many of the criteria used in the ageing and sexing of human skeletal remains and in the calculation of various indices have been evaluated in the United States using the Terry Collection housed in the Smithsonian Institution (Trotter and Gleser, 1952, 1958), a collection of young American males from the Korean War dead (McKern and Stewart, 1957), and, latterly, large forensic samples from California (Katz and Suchey, 1986).

Recently, another term has been widely adopted, particularly in Great Britain, namely Palaeopathology - the study of ancient disease. This multiplicity of terms has led to some inevitable 'lumpers' and 'splitters' among specialists with people, especially in Britain, regarding themselves as either anthropologists or as palaeopathologists. However, this is a false dichotomy. It is not possible to study pathological lesions in an individual or in a group of skeletons without reference to the basic anthropology. Equally, an anthropological study must include description and discussion of any 
pathological lesions present, and all of this must be set in a proper epidemiological and archaeological context (Steinbock, 1976). We are all, whether from an anthropological or a palaeopathological background human biologists, and a preferred generic term for the work that we do with human skeletal remains is Human Skeletal Biologist.

With very few exceptions, it is extremely difficult to obtain any training in palaeopathology in this country. Physical anthropology, in terms of looking at human rather than animal remains, is almost nonexistent. The United States is still the best place in which to obtain a proper training as a human skeletal biologist and that is a very sorry state of affairs. For although there are sometimes perceived problems in working with skeletons, including the distaste of some archaeologists in having to excavate and handle the material, there are very cogent reasons for the inclusion of the study of the excavated skeletons from any archaeological site in the final report. These are:

1. They are the true remains of the people themselves and any archaeological interpretation is incomplete without them.

2. They are often the remains of 'ordinary' people and a potential sample of an ancient community.

3. Their study can supply a large body of information on the age, sex, physique, diet and nutritional status, disease, trauma, occupational activity and mortality of a group.

4. Such studies allow us to establish patterns in the antiquity of disease and its prevalence in previous populations.

5. The work can be extrapolated into the field of Forensic Science, where unprovenanced human skeletal material from a variety of contexts may be brought to us by the police for identification or for information about the individual concerned. Thus, the study of a group of skeletons allows us to 'flesh' the archaeological bones.

\section{Methodologies}

All human skeletal biologists have their own method of recording a skeleton and of reporting on a group. Over the last few years, however, those of us most closely involved in the work have produced for the C.B.A. minimum standards of recording and of describing pathological lesions. Unfortunately, these standards do not appear to have been published. The sheets illustrated in the following figures are examples of the author's specialist recording sheets, as they are at the present time. As her knowledge increases and requirements change these sheets are amended. However, they do represent a consistent basic record or data bank. For certain sites, and for the purpose of research, they have been adapted for computer input.

Figure 1 has all the necessary archaeological information, a record of the bones present and of the state of the teeth. On commencing work on a skeleton, Figure 1 is completed and it is decided whether the individual is immature or adult. If the former, an attempt is made to 


\begin{tabular}{|l|c|c|l|}
\hline FEFIOD & REF. NO & MUSEUM & LOCALITY \\
\hline ARCHAEOLOGICAL REFS. & XRAY: & FHOTO: \\
\hline SEX: AGE AT DEATH: \\
\hline
\end{tabular}

\begin{tabular}{llllllll|llllllll}
8 & 76 & 5 & 4 & 3 & 2 & 1 & 1 & 2 & 3 & 4 & 5 & 6 & 7 & 8 \\
\hline 876 & 65 & 5 & 3 & 2 & 1 & 1 & 2 & 3 & 456 & 578
\end{tabular}

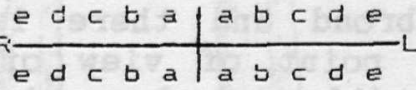

Symbols:

$x=$ A.M. Loss

I = P.M. Loss

$A=$ Abcess

$E=$ Pulp Exposed

$\mathrm{C}=$ Caries

$U=$ Unerupted

$\mathrm{D}=$ Erupting

NF $=$ Not Fresent

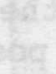

BONES FRESENT:

SKLLL

MANDIELE

VERTEBRAE:

C
L
S
Co.

STERNUM Left
\begin{tabular}{|l|l|l|}
\hline MANUBRIUM & & \\
\hline CLAVICLE & & \\
\hline SCAFULA & & \\
\hline RIBS & & \\
\hline HUMEFUS & & \\
\hline RADIUS & & \\
\hline ULNA & & \\
\hline CARFALS & & \\
\hline METACARPALS & & \\
\hline PHALANGES & & \\
\hline PELVIS & & \\
\hline FEMUR & & \\
\hline PATELLA & & \\
\hline TIBIA & & \\
\hline FIBULA & & \\
\hline TARSALS & & \\
\hline METATARSALS & & \\
\hline PHALANGES & & \\
\hline
\end{tabular}

OT.HER;

Figure 1 
age the individual by the state of eruption of the teeth and the condition of the epiphyses (Figure 2). The epiphyses are at the ends of the long and short bones, the edges of the pelvis and scapula, and the surfaces of the vertebral bodies. During childhood and adolescencethey are attached to the main bone by a cartilaginous plate which allows the bone to grow in length. When growth ceases, the plate ossifies and the ends fuse to the shaft of the bone. These evaluations of immature age will give a range only and never a specific age since there are variations from individual to individual. If the individual is an adult then ageing is much more difficult. It is attempted by using the wear patterns on the molar teeth (Figure 3 ), age changes in males at the pubic symphyses and by the presence of the degenerative conditions of the skeleton which are associated with ageing. As with immature individuals a range and no specific age is produced and, unlike the former, these indices are much less accurate. Recent work at Christchurch, Spitalfields has emphasised these inaccuracies (Margaret Cox, 1988 personal communication). Therefore, the author has recently adopted a new stratagem for ageing adult material. After the age of 25 years, when skeletal maturity is achieved, adults are now placed in the following categories:

Young adult: probably $20^{\prime} \mathrm{s}$

Adult: $\quad$ probably $30^{\prime} \mathrm{s}$ and $40^{\prime} \mathrm{s}$

old adult: probably $50+$

These categories are very broad and there is obviously overlap between the groups. From the point of view of the archaeologist, however, it will still be possible to place skeletons into general groups. We are no longer able to be more specific than this.

Sexing of skeletons can only be accomplished with adult individuals. Morphological differences of the skull and pelvis, between the sexes, are utilised as are differences in size of the heads of the femur and humerus and in the length of the clavicle (Figure 4). In cases where these characteristics on a skeleton are not clearly indicative of one sex, the sexual category is preceded by a ?. In many groups of skeletons a small number of individuals cannot be assigned to either sex and are, therefore, categorised as 'indeterminate'.

A variety of measurements are taken on the skull (Figure 5), and on the post-cranial skeleton (Figure 4) and from these measurements various indices are calculated such as stature, head shape, etc. Dental pathology and variations are recorded (Figure 3 ), as are cranial (Figure 5) and post-cranial (Figure 6) morphological traits. Finally, pathology is recorded and colour-coded (Figure 7 ), and described (Figure 8).

When all the basic data has been collected and analysed, it is put together in a report. This takes the form of a general discussion of the group and its constituents, percentage frequencies of age and sex and a description and discussion of any pathological lesions present. If possible, suggestions may be made about the group and its activities, based on the osseous evidence. 


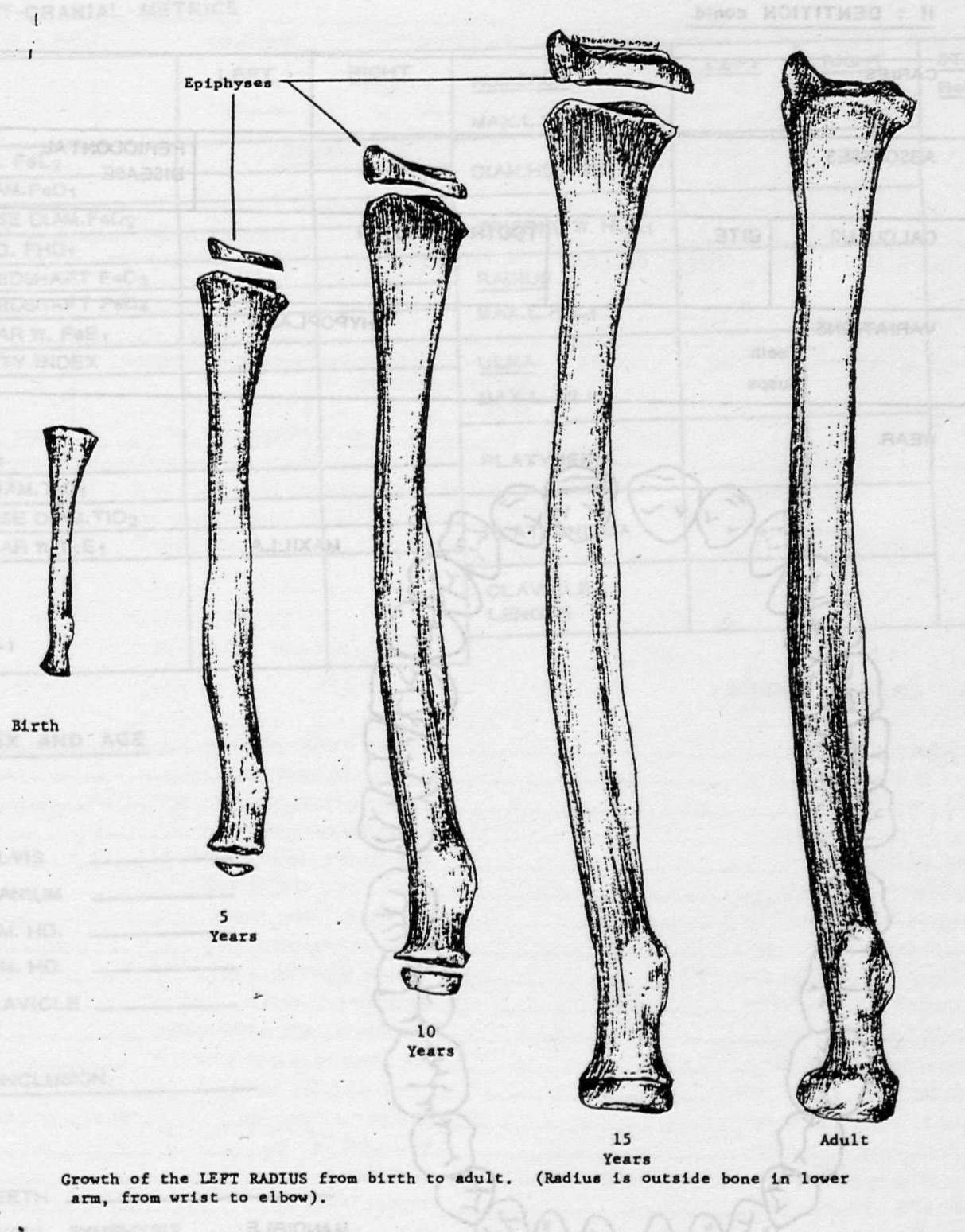

Figure 2 


\section{II : DENTITION contd.}

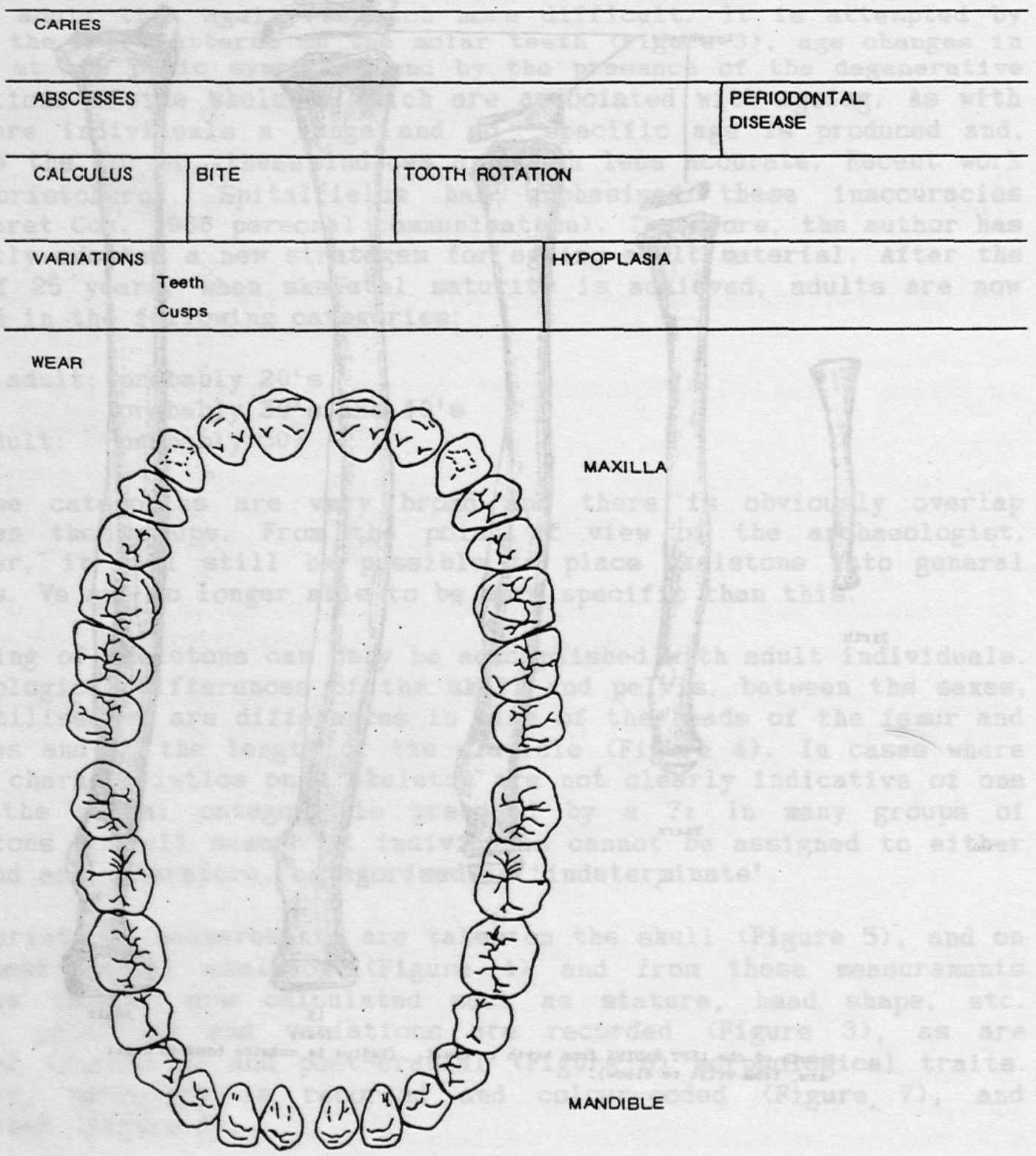

Figure 3. 


\section{BURIAL}

\section{$V:$ POST-CAANIAL METAICS}

\begin{tabular}{|c|c|c|c|c|c|c|}
\hline $\begin{array}{l}\text { FEMUR : } \\
\text { MAXL. FoL }\end{array}$ & LEFT & RIGHT & $\begin{array}{l}\text { HUMERUS } \\
\text { MAX.L.HUL, }\end{array}$ & LEFT & RIGHT & $\begin{array}{l}\text { STATURE } \\
\text { Bone }=\end{array}$ \\
\hline OBLIQUE L. FoL2 & & & \multirow[b]{2}{*}{ DIAM.HD. HHO } & 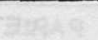 & & \multirow{4}{*}{6734} \\
\hline MIN.A.P.DIAM.FED 1 & & & & & & \\
\hline TRANSVERSE DIAM. $\mathrm{FeD}_{2}$ & & & \multirow{2}{*}{ EPICOND W. HUE 1} & & & \\
\hline DIAM. HEAD. FHD 1 & & & & & & \\
\hline A.P.DIAM.MIDSHAFT FeD 3 & & & \multirow{3}{*}{$\begin{array}{l}\text { RADIUS } \\
\text { MAX.L.RaL, } 1\end{array}$} & $=3 x=\frac{1}{4}$ & $\cdot$ & \multirow{3}{*}{ 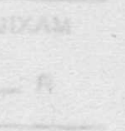 } \\
\hline M.L.DIAM.MIDSHAFT FOO 4 & & & & & & \\
\hline BICONOYLAR W. FOE 1 & & & & & & \\
\hline ROBUSTICITY INDEX & & & ULNA & anses $r$ r h & Oe S17 & Earie \\
\hline TIBIA & . & 2010 & MAX.L. ULLL1 & & & \\
\hline MAX.L.TIL 1 & & & \multirow{2}{*}{ PLATYMERIA } & & & \\
\hline MAX.A.P.DIAM.TID 1 & & & & & & \\
\hline TRANSVERSE DIAM.TID 2 & & & \multirow[b]{2}{*}{ PLATYCNEMIA } & & & \\
\hline BICONDYLAR W.T $T_{1} E_{1}$ & & & & & & \\
\hline FIBULA & & & $\begin{array}{l}\text { CLAVICLE } \\
\text { LENGTH }\end{array}$ & & & \\
\hline
\end{tabular}

\section{VI : SEX AND AGE}

SEX

PELVIS

CRANIUM

FEM. HD.

HUM. HO.

CLAVICLE

\section{CONCLUSION}

AGE

TEETH

PUBAC SYMPHYSIS

EPIPHYSES

CONCLUSION

Figure 4. 
III : CRANIAL MORPHOLOGY

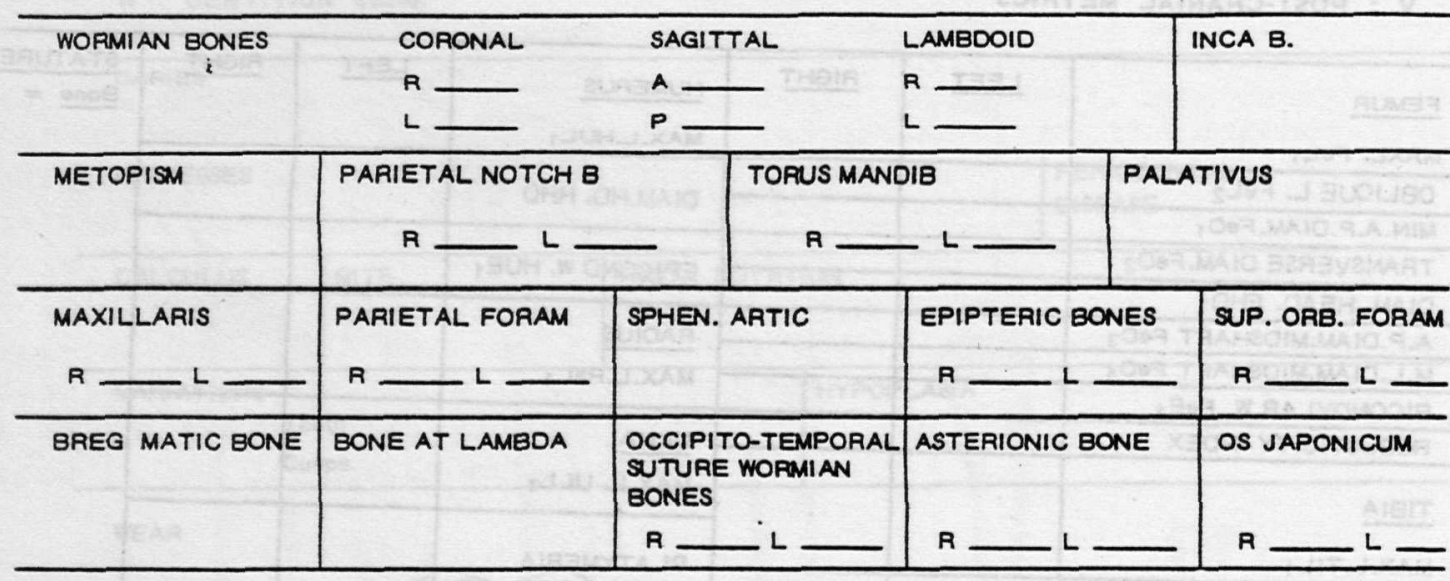

\section{IV : CRANIAL METRICS}

GLAB.OCCIP.L. (L) MAX.B. PYRIF.AP. (NB) MAX.BI-PARIETAL.B. (B)

MIN.FRONT.B. $\left(B^{1}\right)$

BASIO-BREG.HT. (H)

BAS-NASION L. (LB)

NAS-BREG.ARC. $\left(S_{1}\right)$

BREG-LAMBDA ARC $\left(S_{2}\right)$

LMDA-OPISTH.ARC $\left(\mathrm{S}_{3}\right)$

TRANSVERSE BREG.ARC. $\left(T^{1}\right)$

NAS-BREG. CHORD $\left(S^{1}{ }_{1}\right)$

BREG-LMDA.CH. $\left(\mathrm{S}_{2}{ }_{2}\right)$

LMDA-OPISTH.CH. $\left(\mathrm{S}_{3}{ }_{3}\right)$

NAS-ALVEOL.LGTH. $\left(\mathrm{G}^{1} \mathrm{H}\right)$

BAS-ALVEOL.LGTH. (GL)

FACIAL BREAOTH (GB)

PALATE B. (2nd $M)\left(G_{2}\right)$

PALATE LENGTH $\left(\mathrm{G}_{3}^{1}\right)$

MAX.ZYGOM.B. (J) NASAL HT. (HN)

LEAST INTER-ORBITAL BREADTH

BIASTER.BR. (BIAST.B) BI-CONDYLAR WIDTH $\left(W_{1}\right)$ CONDYLE LENGTH (CYL) RAMUS B. (least) (RB ${ }^{1}$ )

SAGIT.HT.MANDIB. $\left(\mathrm{H}_{1}\right)$ FORAM.MENTALIA B. (ZZ) CORONAL B. (CrCr) BI-GONIAL BREADTH (GOGO)

MAX PROJ.L.MANDIB. (ML) CORONOID HT. (CHH)

HEIGHT AT 2NA MOLAR $\left(M_{2} H\right)$ ON ALVEOLAR BREADTH AT $M_{2}$ MASTOID L

TOTAL FACIAL HT.

ORBITAL B. $\left(O_{1}\right)$

HT. OF L.ORBIT $\left(\mathrm{O}_{2}\right)$

FORAMINAL L. (FL)

FORAMINAL B. (FB)

\section{Figure 5.}




\section{BURIAL}

\section{VII : POST-CRANIAL MORPHOLOGY}

\section{Sternum}

Manubrio-corpal synostosis:

Sternal aperture:

Scapula

Os acromiale:

Suprascapular area :

\section{Vertebrae}

Atlas - posterior bridge :

Atlas - lateral bridge:

Sacrum - level of open hiatus :

Accessory sacral/iliac facets: L

Lumbo-sacralisation of a vertebra:

\section{Humerus}

Septal aperture:

Supracondlyar process:

Femur

Third trochanter: $L$

Allen's fossa

Poirier's facet/plaque: L

$R$

Patella

Vastus notch:

Bipartite patella:

Tibia

Squatting facets : R

Talus

Os trigonum:

Talar facet:

\section{Calcaneus}

Calcaneal-facet :

Figure 6. 


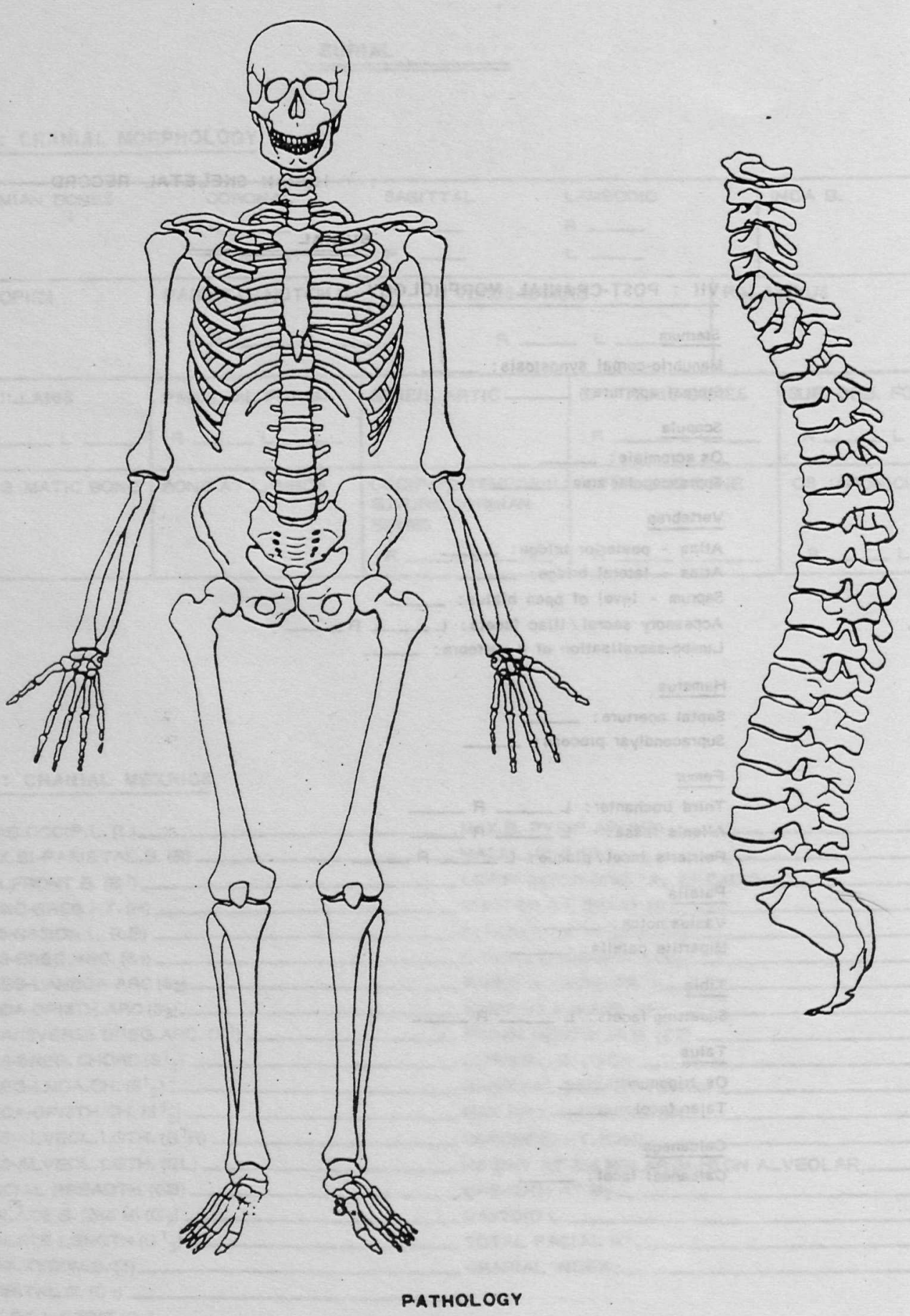

Figure 7 . 
PATHOLOGY PRESENT

BURIAL

SKULL

CLAVICLE

SCAFULA

AF:M

FELUIS

MANUBR IUM

\author{
SF.INE
}

$: \ldots \ldots:$

:

F:IGHT

LEG

$: \ldots \ldots:$

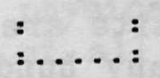

HANDS

FEET

$: \ldots$ :

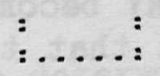

RIBS

STEFNUM

$: \ldots$

STERNUM
: $\ldots \ldots$
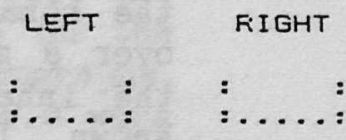

$: \quad: \quad: \quad: \ldots \ldots:$

: $\quad: \quad: \quad: \ldots$ : $\quad$ :

: $\quad: \quad:$ : $\quad$ : $\quad$ :

OTHER $:$
NOTES

Figure 8.
$-$ 


\section{Expectations}

Many field archaeologists have specific expectations of a report by the human skeletal biologist, a situation which can lead to some difficuties. These expectations include:

\section{That a group of skeletons equals a POPULATION}

2. That LIFE TABLES can be constructed for the POPULATION

3. That POPULATION DEMOGRAPHY can be undertaken

4. That STATUS is reflected and can be seen

5. That SEXUAL GROUPINGS may occur

6. That FAMILIAL RELATIONSHIPS can be indicated

7. That CAUSE OF DEATH can be determined

The realities of the report are somewhat different, however. They are:

A group of skeletons does not constitute a POPULATION. It is usually the remains of the people who were buried in a particular cemetery over a given length of time and does not necessarily constitute all the inhabitants of a settlement, even when the settlement site is known. In most archaeological samples, neither the spatial nor the temporal limits of a site are known and, in many, a burial site will have been used over many hundreds of years. Thus, we have no way of knowing when during that time people died. All this being so, it becomes obvious that the construction of LIFE TABLES and the estimation of DEMOGRAPHY become very chancy activities indeed. This is emphasised by the fact that the sex of an individual may be allotted to one of five categories, stature has a standard deviation of at least 1.2 inches either way, and age at death is always given as a range and is probably inaccurate over the age of 25 years. It is also dangerous to make guesses about STATUS from bones per se if we assume that status will be reflected in diet, life-style, etc. While this may well be the case, such things as dietary deficiencies are very difficult to diagnose in dry bone. The evidence for healed childhood rickets is often fairly clear, but the diagnosis of scurvy is contentious and iron-deficiency anaemia still problematical, especially in this country. The archaeologist may feel happy in discussing status based on grave goods; the author would not do so based on the bones. Equally, a problem sometimes occurs when the sexing which has been done elsewhere on the grave goods disagrees with the sexing which has been done on the bones (see Henderson, this volume). Needless to say, sexing based on the bones is far more accurate scientifically. While SEXUAL GROUPINGS may have occurred in the cemetery, unless the skeletal sample is very large and complete it is not possible to say so. The suggestion of genetic or FAMILIAL RELATIONSHIPS has been traditionally based on the expression of morphological traits of the skeleton. Apart from dental variations which are apparently under direct genetic control, however, this is very dangerous ground since it is far from clear how susceptible such 
traits are to environmental pressures of various kinde, from birth stresses to the working environment. Unless there is an arrowhead embedded in the thorax or unless there is documentary evidence as in the case of the Mary Rose, it is usually impossible to determine CAUSE OF DEATH.

In spite of the negative nature of the above comments there are important reasons for studying a group of skeletons and these were discussed in the introduction to this paper. If we remember that all analyses only apply to the particular group of skeletons being studied, which is not a population but only a sample, then much can be learned of the individuals and of the group. The larger the group the more important is this information, and it is poor scientific practice to derive any statistics from, or make any general statements about, a group of less than 50 skeletons. In the case of the very large group with good archaeological provenance, much can be learned and, these days, one seriously questions the morality of expending restricted time and money in working on small groups of poorly preserved and incomplete skeletons.

For the future, field archaeologists and human skeletal biologists should be encouraged to work together at all stages. There should be consultation on recording the material in the ground and on excavation techniques, and the biologist should have the opportunity to visit the site during excavation. Consultation should also take place on the post-excavation preparation of the bones, and good photographs, drawings and plans should always be provided. Finally, we should work towards the provision of basic physical anthropology and palaeopathology in the Yethods element of all archaeological degree courses.

\section{BIBLIOGRAPHY}

Katz, D. and Suchey, J.M., 1986 - "Age determination of the male os pubis". Amer. J. Phys. Anthrop. Val. 69, pp. 427-435

HcKern, T.W. and Stewart, T.D., 1957 - "Skeletal age changes in young American males". Natwick, MA: Quartermaster Research and Development Command, Technical Report EP-45.

Steinbock, R.T., 1976 - "Palaeopathological diagnosis and interpretation". Charles Thomas, Springfield, Illinois.

Trotter, M. and Gleser, G.C., 1952 - "Estimation of stature from long bones of American Whites and Negroes". Amer. J. Phys. Anthrop., Vol. 10. pp. $463-514$

Irotter, M. and Gleser, G.C., 1958 - "A re-evaluation of estimation of stature based on measurements of stature taken during life and of long bones after death". Amer. J. Phys. Anthrop., Vol. 16, pp. 79-123. 


\title{
GREKATIONS: EXPECTATIOIS, METHODOLOGIES AIDD REAL ITIES
}

\author{
Jacqueline I. McKinley \\ Iorfolk Archaeological Unit, \\ Union House, \\ Gressenhall, \\ Dereham, \\ Norfolk NR20 $4 \mathrm{DR}$
}

\section{Introduction}

Iumerous misconceptions appear to be held regarding cremations, like "...but how can you tell anything from a heap of dust?...", a fairly common question from both the layperson and the archaeologist! The main alm of this paper is to attempt to dispel some of the 'cremation myths' by describing exactly what a cremation collection comprises, how information may be retrieved from the collection and what the information may tell us about both the individual and the cremation process itself.

Modern crematoria work between $500-1000^{\circ} \mathrm{C}$. (Jones and Williamson, 1975) depending on the type of furnace being used, the time of day and to a certain extent, the furnace operator. $500^{\circ} \mathrm{C}$. is the minimum temperature necessary to get the body fats burning and maintain combustion until all water and organic components of the body are reduced, leaving the mineralised bone composed of enlarged hydroxyapatite crystals, $\mathrm{Ca}^{70}(\mathrm{PO})^{4} \mathrm{~S}^{\mathrm{O}}(\mathrm{OH})=$. Bone has a $70 \%$ mineral component, the remaining $30 \%$ being mostly water and proteins (Glorleux, 1982). In the crematorium, the coffin is placed within a furnace slightly longer and wider than the coffin itself and about $75 \mathrm{~cm}$ high. The external heat source, in many cases gas jets, are switched on and used only until the body fats are alight, after which combustion is maintained by a regulated oxygen input into the furnace and expulsion of the fumes (which are carefully passed through a series of ducts to minimise odour and smoke). After about 45 minutes at $600-800^{\circ} \mathrm{C}$, most of the soft tissue has been removed except for some of the thicker layers of fat and muscle e.g. around the buttocks, which may have fallen away from the body but would still be burning. The skeleton at this stage would still be held in position by the - Iigaments. All soft tissue must be removed before the bone itself can burn, as oxygen as well as heat must be available. Although at this stage molsture may well be driven out of the bone by high temperature, actual reduction of the other organic components within the bone may be minimal. Obviously, there will be some varlation across the body depending on the amount of soft tissue surrounding individual bones, hence the cremation of the lower legs, for instance, often appears complete before other areas of the body. on:

Cremation usually takes between $1-2$ hours to complete depending

(1) the time of day (the first cremation of the day will take slightly longer as the furnace would be starting from cool), and 
(ii) the individual: a certain amount of body fats are necessary to aid combustion, an emaciated individual would therefore require more external heat and take longer to cremate. On the other hand an obese individual would also take longer as there would be more body fat to dispose of.

Once the cremation is finished an entire skeleton remains, though some of the spongy bone may crumble to dust if very well reduced. The skeleton is quite recognisable, though it has been chemically reduced and altered as a result of dehydration, causing the spongy bone to shrink and the compact bone to twist and fissure. The degree of alteration in the form of the bone may well indicate both speed and completeness of dehydration, and reflect the height of the temperature and possibly even de-fleshing or not of the bone.

The remains are raked out of the furnace compartment where they have been resting on a shelf composed of bricks with about $25 \times 12 \mathrm{~cm}$ spaces in their centres, into a second chamber with increased draught to complete reduction of the bones; they are finally collected in a large metal box in a third, lower chamber. During the raking-out the bone is further broken (being hot and brittle), the fragment size doubtless being influenced somewhat by the size of the spaces the bone has to pass through. The bone fragments collected at the crematorium visited by the author were up to $25 \mathrm{~cm}$ (femur) in length and appeared almost as fragmented as some of the cremations from Spong Hill (Hills and McKinley, this volume). Modern cremated remains are later passed through a 'cremulator' which fragments the bone into the granular form people most often associate with cremations.

The colour of the bone may vary considerably within one cremation, as all the organic components of the bone may not be entirely removed for reasons differing with respect to the individual charge. The skeleton is not merely a supportive structure but is also used for storage of fats and other substances, particularly in the spongy bone, and all such material must be reduced before combustion is complete. The pelvic bones were noted to be still burning long after other areas of the skeleton and on removal were still black. Other parts of the skeleton, notably the metatarsals, were grey/blue though they had stopped burning quite early in the process, perhaps because of the lack of soft tissue to produce combustible fats in the area of the lower leg to aid cremation of the bones.

The quantity of bone recoverable from a modern adult cremation is between $1600-3600 \mathrm{~g}$ dependent on the individual, with an average of c. $3000 \mathrm{~g}$ (i.e. roughly the same welght as a dry-bone specimen).

Obviously, when drawing parallels between modern and ancient cremations there are certain points which must be borne in mind. Firstly, a modèrn cremation takes place in a controlled environment with a regulated temperature and oxygen input; with an ancient cremation pyre there would have been a number of variables that could affect both temperature and oxygen sources, e.g. the weather (wind producing too much or too little draught), and the oxygen could be cut off as a result of coverage by fuel or ash build-up 
Secondly, with respect to fuel, in orematoria the gas jets are maintalned only until the body fats are alight, thereafter the body will continue to burn, kept alight by a regulated flow of oxygen. On a pyre, if a constant high temperature were to be sustained, fuel would need to be added during the hours needed to complete the cremation (c. 7 - 8 hours), or, if the pyre were left, as the Australian aborigines seem to have done in Robinson's 19 th century accounts (H1att, 1969), there would have been a gradual drop in temperature. It is also unlikely that a constant temperature could be maintained across the pyre, the centre being much hotter than the periphery. Pyre debris collecting at the base would have buried any bone there, cut off the oxygen supply and thereby the cremation process. Collapse of the pyre structure would break the bone if it were hot, dry and brittle.

So, although the basic technique of cremation is the same now as in the past, there would have been a number of variables affecting a pyre cremation whose effects may be difficult to explain during examination of the recovered bone; however, these observations at the crematorium may be usefully recalled when examining archaeological cremations.

\section{Cremation identification}

There are obvious Iimitations to identifying cremated remains; it is unlikely that the same amount of information regarding an individual could be recovered from even the most excellent cremation collection as from a complete skeleton, but it is possible to extract far more information than it was once thought. Before the $1960^{\circ} \mathrm{s}$ few excavated cremation collections in this country were retained as it was believed that the bone was unidentifiable!

A note to the excavator: Iffe is made considerably easier for the specialist if they do not recelve great, solld bags of clay with a few scraps of bone and half a ton of pea-grit (small grade gravel)! The bone should be dry, or if necessary, wet sleved (as soon as possible after excavation) through a $2 \mathrm{~mm}$ mesh, no larger, and as much stone and grit removed as possible. Any potential pyre debris such as charcoal and fuel ash slag should be collected and recorded.

Systematic treatment of the cremation collections prior to Identification enables useful information on fragmentation and collection to be galned. Various workers do record in different ways and the system illustrated here is that used by the writer (with thanks to Dr. K. Manchester, for his suggestion of measuring fragmentation using the sieve stack - see below).

Each cremation is passed through a serles of sleves of $10 \mathrm{~mm}$, $5 \mathrm{~mm}$ and $2 \mathrm{~mm}$ mesh sizes, and then weighed producing a percentage fragmentation within each size category. The weight of the cremated bone will give a percentage of the total remains collected from the pyre for burlal, bearting in mind any subsequent disturbance of the site which may have occurred postmortem. The fragmentation percentages may reflect pyre technology (see below) or disturbance of the site: for instance, a tractor crossing the site and crushing an urn would also crush the bone. The maximum fragment size is also recorded. 
The implications of such studies could be wider than just relating to a single site; the information could be used to show different treatment of cremations between various periods when the practice was in use, and/or different areas of the country. Systematic recording is therefore important.

After sieving, identifiable bone is separated, together with any animal bone, grave-goods etc. Fragments of burnt antler or anfmal bone grave-goods may be overlooked by even the most meticulous of finds' assistants if they are not bone specialists because of the similarity with the cremated bone (Hills and McKinley, this volume).

It is not possible to identify exactly every fragment of bone. 20$50 \%$ of a collection is generally identifiable, the majority consisting of small fragments of long bone or joint articular surface. The identifiable bone is separated into four categories - skull, vertebral, upper $1 \mathrm{imb}$ and lower $11 \mathrm{mb}$ - each bone is identified together with any variation in, for example, colour, pathology, adhering grave-goods etc.

\section{Table 1 - Configuration for cremation data-base (wordstar/Spongdat)}

\section{Field Tag. Descriptor}

01

02

03

04

05

06

07

08

09

10

11

12

13

Urn no. I = another no.
Skull
Axial
Upper limb
Lower limb
Pathology
Pathology search field
Bone/degree of burning
Animal bone
Grave-good/bone
age/specifier/sex
No. Individuals/no. urns
Co-ordinates
Y = Yes
N = No.

\section{Sub-field Multiple entry}

N $N$

free text

free text

free text

free text

free text

$\begin{array}{ll}\text { N } & Y \\ Y & Y \\ Y & Y \\ Y & Y \\ Y & Y \\ Y & N \\ Y & N\end{array}$

Within each collection the categories are weighed and represented as a percentage of the total weight of identifiable bone, which may indicate any bias in the areas of the body collected. It must be remembered at this point however, that the percentages represented by each area if the total skeleton were present would be far from equal, due to the bone density and quantity in each category. In an average adult dry skeleton, (roughly the same welght as a total cremation), the percentages would be: skull 18.2\%, axial $23.1 \%$, upper $11 \mathrm{mb} 20.6 \%$ and lower $11 \mathrm{mb} 38.1 \%$. It should also be remembered that certain areas of the body may survive the cremation process better than others and that some bones may thus be more likely to be collected, though not necessarily deliberately (see below). 


\section{Demography}

The number of individuals within a collection is not particularly difficult to deduce but there may be problems.

Weight cannot be used as an indicator, as collection of the entire remains after cremation appears to have been rare; adult collections can range from as little as $200 \mathrm{~g}$ to almost $2000 \mathrm{~g}$ with an average of c. $800 \mathrm{~g}$. There may be complications due to the inclusion of animal bone or disturbance of the collection (Hills and Mckinley this volume). Nor can difference in colour be used to indicate more than one individual; as was illustrated with the specimen from the modern crematorium, it is not unusual to have considerable variation in colour in one cremation.

Only duplication of bones should be used to indicate multiple collections, except in abvious cases of adults interred with immature individuals. Certain bones, especially fragments of the skull, are of distinctive appearance and occur in limited numbers only e.g. mastold processes, the petrous temporal bones, and they are frequently recovered, probably due to the nature of the bone and possibly the mode of collection (see below). Duplication of several of these bones would be a clear indication of multiple burial. There is a danger of contamination, elther during collection from the pyre (assuming a pyre site was used more than once), or more likely, from adjacent burial assemblages on a disturbed site, which is why using single instances of a duplicated bone to indicate multiple burials is unreliable.

It is imperative that a cremation, urned or not, is recorded as completely and as accurately as any other context, with particular attention to associations, and that the information is passed on to the specialist. Contamination from nearby cremations can and does occur and could lead to misinterpretation if the correct information were not provided. Equally, it is possible to have one individual divided between two urns (McKinley, spong Hill case study this volume) and the same need for context information applies.

The numerous methods and pitfalls involved in the ageing and sexing of skeletal remains are dealt with elsewhere in this volume. Obviously, the problems are increased with cremations, primarily due to the incompleteness of cremation collections. Identification of cremations depends on the presence of the useful bones and $1 t$ does not necessarily follow that the larger the collection the easier the identification.

Ageing is relatively easy up to adulthood. Unerupted tooth crowns are frequently recovered intact, being protected from the full force of the fire by their position inside the bone of the mandible or maxilia. Once teeth have erupted, however, the enamel would tend to shatter as it expanded rapidly in the heat of the pyre, hence tooth wear cannot generally be used as an indicator of age with adult cremations. 
The pubic symphyses tend to survive only in about $4 \%$ of collections (Brooks, 1955), the auricular surface of the lilum having a considerably higher survival rate (Lovejoy et. al., 1985), though somewhat more difficult to interpret. Ageing above 25 years (1.e. average age of last epiphyseal fusion), is generally tentatively based on the degree of the various degenerative processes associated with increasing age.

Technically speaking, it should be possible to age cremated material using osteon counts (Singh and Gunberg, 1970; Herrmann, 1977). Although bone will shrink on cremation, the osteon structure remains intact. A preliminary investigation is at present in progress by Neil Garland, (Dept. Pathology, University of Manchester Medical School) to assess the potential of osteon counting with respect to ageing cremated remains. It has been possible to process and impregnate the bone with resin but difficulty has been encountered in producing intact, handground sections. The difficulty is presumably because of the high cremation temperatures altering the natural porosity of the bone and thereby limiting the infiltration of the centre of the bone by the resin. Should the method prove possible to use it would be of invaluable use with ageing adult cremated individuals.

With the methodologies currently available, the writer has found it possible to age, within limits, about $95 \%$ of cremations examined, though this may in some instances be restricted to merely adult or subadult/adult, a figure generally in agreement with other workers in the field (Wahl, 1982, 1988).

Sexing, as with ageing, largely depends on the presence of the appropriate bones in the collection. The writer uses a categorisation of male/female, followed by a ? for probable and ?? for possible, according to the quality and quantity of information available. A single sexually dimorphic feature is not sufficient evidence on which to base the sex of a cremation; there are too many instances of contradictory traits within individuals to consider this adequate.

Chemical analysis (Kiszely, 1974) of bone for the estimation of sex is not possible with cremated bone; the necessary chemicals are generally removed during the cremation process.

The author has found that about $45 \%$ of cremated adults can generally be attributed to a sex but of these only c. $10 \%$ would be in the unquestioned category, about $25 \%$ being in the 'possible' group.

The estimation of stature of cremated individuals contains many pitfalls. Stature estimation from long bone measurements (Trotter and Gleser, 1952, 1958) is not possible, which leaves equations devised for use with the diameter measurements of the major articular heads (Strazalko and Manourier, 1969). Gralla (1964) gives an accuracy of between $\pm 7.5 \mathrm{cms}$ in skeletons of known sex and $\pm 10 \mathrm{cms}$ in those whose sex is not known. The writer, comparing results obtained from using both types of measurements on the same inhumed skeletal remains, found there were several centimetres difference - about 14 inches - between the two estimates. There are, however, numerous problems in attempting to estimate the height of cremated individuals. Firstly, the relevant 
bones have to be present in a complete state; this is rare with both proximal femur and proximal humerus, though in the Spong H1II collections about $5 \%$ had complete radial heads. Secondly, the sex of the individual needs to be known in order to ascertain which of the two sets of equations to use. Finally, there is the problem of shrinkage, which could vary between and within individual cremations, varlations of between 12 and 25\% (Wahl, 1982) belng recorded by different workers. There would seem to be a point beyond which an estimate is so much of an estimate as to be not worth estimating and the writer feels with the methods currently available it may be as well to restrict comment to observations on size and robustness, which would be as informative as estimated stature under the above circumstances.

\section{Ritual and technology}

There is a certain amount of overlap between these two aspects. 'Ritual' encompasses the laying-out of the individual with various grave-goods. By recording the fusion of manufactured grave-goods such as glass and bronze to particular bones and the degree of burning, it should be possible to reconstruct the position of the objects with relation to the body and the pyre. Likewise, with animal bone, by comparing the degree of burning with that of the cremated individual, it should be possible to ascertain the relative position of the animal remains.

Much work has been done on grave good associations (Richards, 1987 and Richards, this volume) and it is not intended to discuss this particular aspect here; however, one point of interest which would appear to have been little considered is the condition of the grave goods. The majority of goods with cremations appear to have been burnt with the body, indicating no doubt the importance of the cremation process, but why not all the goods? Is this accident or design? It is necessary to consider if certain goods are consistentiy unburnt and why that should be so.

One kind of association has been greatly overlooked in past studies, in this country at least, because of the lack of examination of the bones themselves, and that is the inclusion of animal bone in cremation collections; this has proved to be of much importance at Spong H1ll (see Hills and MoKinley, this volume). Although study of the Spong Hill data is not yet complete, it would appear that the 'social' links between type of animal and the cremated individual could be as informative as with the other grave-goods. The age of the animal and the fragments of bone remaining could also indicate the time of year of the ceremony (Gejvall, 1963) and the ritual involved.

Generally, it would appear that only part of the human remains were placed in the urn or pit; this poses other questions - was the deposition of the body a 'token' gesture, a sample of each area of the body being all that was necessary? What happened to the rest of the remalns? Were they merely left on the pyre or were fragments distributed elsewhere? There are obvious variations over both time and space in the quantity and treatment of recovered remains; a comparative study of sites would 111 ustrate these variations and shed 
Iight on the differences in ritual associated with the whole cremation process.

Information about 'pyre technology' may be gleaned from the records of colour, weight, fragmentation and collection. Colour reflects the completeness of cremation, 1.e. how well reduced the bone was (Shipman et. al., 1984). Cremation, as a process, needs heat, oxygen and time to complete; should any of these three be restricted complete cremation may not be achieved, Also, as mentioned when talking about the modern crematorium, a certain amount of body fat is useful to ald combustion (cf. the practice of adding perfumed olls or ghee to cremation pyres in India). Even in the modern crematorium the bones of the feet were greyer than other bones, as they are prone to be less well cremated than other areas of the body (see below).

Before the bone can start to burn, other body tissues such as halr, skin, fats, muscles etc., and lastly ligaments (Evans, 1963), must be removed, though the bone may already have started to heat up and moisture be driven out. The ligaments hold the skeleton together for a long time; at the crematorium, after about 45 minutes the $\mathrm{rib}$ cage was still up-standing though empty and hands and feet have been noted as dropping away from the long bones still articulated.

Once the ligaments are loose, the fire may directly reach the bone; this is also the point at which the bones may part and 80 their separate ways, thereby possibly becoming differentially cremated. If a body were placed at the base of the pyre, oxygen would obviously be unable to reach the underside of the body (Vells, 1960) and pyre debris could soon build up and cut off oxygen further. If the body were centrally placed or above the pyre, oxygen would be easily avallable, but once the ligaments had been burnt (or possibly before that time in the case of the hands and feet - see above) bones could drop through and easily get buried in the wood ash, the smaller bones beling those most likely to get lost. To avoid such problems it would be necessary to stir up the pyre occasionally to allow oxygenation and to return any rogue bone or wood, which would result in considerable movement of the bone. By analysing the colour and condition of the bones, and perhaps grave-good fusion, within a cremation, we should get some indication of the position of the body and the tending of the pyre.

Movement of the pyre during tending would lead to break-up of the hot, brittle, heat-fractured bone, as would the welght of any added wood or falling burnt timbers, i.e. much fragmentation of the bone would take place on the pyre. Presumably, the more efficient the tending, the more complete would have been the cremation and the greater the 'on-pyre' fragmentation?

In the past it has always been understood that the cremated bones were collected individually from the pyre and then deliberately broken, presumably to fit the burial receptacle. As already noted, collection of the total skeletal remains would appear to have been rare and it is likely that much fragmentation would have taken place on the pyre. Many bone collections contain little or no charcoal or other pyre debris (this does depend on the perlod being dealt with and 
to a certain extent the site) and the bones themselves are often very clean and free from any charcoal stains (though fuel ash slag (1) and burnt flint do occur from sites with suitable soils). It would seem therefore, that the bone has generally been deliberately separated.

In order to collect the bones individually from the pyre it would have been necessary first to let them cool, which unless it were to rain would have taken hours! Sorting through the ash from several tons of wood to collect the bones, often including distal phalanges of hands and feet, sesamold bones and even gallstones would also have taken some time (P1ontek, 1976). In Robinson's 1829 accounts of cremations amongst the Aborigines of Australia (Hiatt, 1969), the cremations were generally left overnight after the pyre was $11 t$, the whole ashes raked together the following morning and either pounded to dust or left under a mound (like the German 'Brandschuttensgrab', a burnt mound grave).

It is possible that such a time-consuming method may have been employed, though from some sites where pyre debris is also present in urns or pits there are signs of the deposition being made while the material was still hot. There are other possible modes of collection, however, which may account for the character of bones collected and their condition.

The ashes may have been shovelled up 'en masse' while still hot and elther deposited in water or 'winnowed'. Deposition in water would cool the bone rapidly causing it to fracture along the lines developed in the pyre. The bone, grave goods, large lumps of charcoal and other heavy pyre debris would sink and once the water had been poured off the bone could easily be collected. The 'winnowing' process would have had similar results but without the water.

Such methods would have made collection speedier, and the chances of scoopling up a tiny foot bone as likely as a large chunk of vault, though recovery of the denser and larger bones would still be emphasised. These methods would negate the need for deliberate breakage of the bone in many cases and produce a clean collection from various skeletal areas.

Techniques of collection obviously vary over both time and space.; further investigation of a comparative nature is needed to spread further 11 ght. In this country at least, there are very few pyre sites and no evidence of collection areas or depositions of unwanted bone. Added to this, with potential pyre sites, one thing to watch out for is the greasy smell; pyre debris from Scottish cremations, bones from a Roman cremation cemetery in Baldock and masses of burnt filnt and charcoal from a potential Roman pyre site in Reading all carry the same unmistakeable odour of rancid fat!

Excavation of complete, undisturbed urn or cremation pits may reveal any deliberate order of deposition. This is of especial importance where there has been a multiple burial or if animal bone is present. There is little point in doing this with disturbed cremations as relationships would have been lost. Ideally the bone specialist should excavate but if this is not possible the urn or pit should be 
excavated in labelied spits with a cross-sectional drawing to show angle and position of the bone.

Various points of pathology have been dealt with elsewhere in this volume but the writer would like to make a few points with respect to cremations. Numerous pathological lesions may be caused by a variety of diseases and without a complete examination of the entire skeleton it is not always possible to give a diagnosis; it is, therefore, easy to see why cremations are not exactly most palaeopathologist's favourlte material!

Pathological lesions are often noted in cremations, however, and generally occur in the same order of frequency as in other skeletal material; dental disease, various forms of arthritis, cysts and exostoses are the most common afflictions noted. Some diseased bones may be prone to loss during cremation due to the nature of the lesion, such as osteoporosity where the affected area may collapse and be lost under the various pressures of cremation.

A further frustration attends morphological variations, slight deviations from the normal which may be indicative of genetic relationships. These have been noticed in cremated material and it would be interesting, especially in a large cemetery like Spong Hill, to be able to make more use of such information. Unfortunately, as the same bones are not always recovered from every cremation the approach is of limited application.

\section{Foot Notes}

1. Fuel ash slag is a general hearth slag which may be recovered from any type of hearth where the underlying soil is high in silica (Dr. G. MacDonnell pers.comm.). The main chemical component of the slag is silica oxide, generally between 60-70\%; other components will vary with the site and type of hearth or fuel etc. (Evans and Tylecote, 1967, Henderson et. al., 1987). It has been recovered by the writer in small quantities from cremations of all periods and from England, Scotland and Wales, but most notably from a Bronze Age cist cremation at Holm in Orkney, where large quantities of the slag was recovered with the bone fused to it (McKinley, forthcoming).

\section{Acknowledgements}

Thanks to Neil Garland for his interest and investigation of the histology of cremated bones. Thanks also to Ken Penn and Robert Rickett for their help with writing this paper. 


\section{BIBLIOGRAPHY}

Brooks, S.T., 1955 - "Skeletal age at death: the reliability of cranial and pubic age indicators". Amer. J. Phys. Anthrop, Vol. 13, pp. 567-597.

Evans, W.E.D., 1963 - "The effects of heat on postmortem tissue", pp. 83-85, in W.E.D. Evans (Ed), Chemistry of death. Charles Thomas, Springfield, Illinois.

Evans, R.T. and Tylecote, R.F., 1967 - "Some vitrified products of non-metallurgical significance". Bulletin of the Historical Metallurgy Group, Vol. 119, p. 5.

Gejvall, N.G., 1963 - "Cremations", pp. 379-390 in Brothwell, D. and H1ggs, E. (Eds), Sclence in Archaeology. London, Thames \& Hudson.

Glorleux, F.H., 1982 - "Mineral", pp. 97-106 in L. Cruess (Ed), The Musculo-Skeletal System. Churchill Livingstone, New York, Edinburgh, London and Melbourne,

Gralla, G. 1964 - "Proba Rekonstruckcj1 Vrostu ze szczatkow clatopalnych".

Henderson, J., Janaway, R. and Richards, J., 1987 - "A curious clinker". I. Arch. Se1, Vol. 14, pp. 353-365.

Herrmann, B., 1977 - "On histological investigation of cremated human remains". I. Human Evolution, Vol. 6, pp. 101-103.

Hiatt, B., 1969 - "Cremation in Aboriginal Australia". Mankind, Vol. 7 (2), pp. 104-115.

Jones, E.W. and Williamson R.G., 1975 - "Factors which affect the process of cremations". Cremation Conference Report of the Cremation Society of Great Britain. pp. 77-88.

Kiszely, I., 1974 - "On the possibilities and methods of chemical determination of sex from bones". Ossa, Vol, 1, pp. 51-62.

Lovejoy, C.O., Meindl, R.S., Pryzbeck, T.R. and Mensforth, R.P., 1985 - "Chronological metamorphosis of the auricular surface of the ilium: a new method for the determination of adult skeletal age at death". Amer. J. Phys. Anthrop., Vol. 68, pp. 15-28.

McKinley, J.I., (forthcoming) - "Bronze Age clst cremation from Holm. Orkney".

Pointek, J., 1976 - "The process of cremation and 1ts influence on the morphology of bones in the light of results of experimental research". Archeologia Polski, Vol. 21, pp. 254-280.

Richards, J.D., 1987 - "The significance of form and decoration of Anglo-Saxon cremation urns". British Archaeological Reports. British Series, Vol, 166, Oxford. 
Shipman, P., Forster, G. and Schoeninger, K., 1984 - "Burnt bones and teeth: an experimental study of colour, morphology, crystal structure and shrinkage". I, Arch. Sc1., Vol. 11, pp. 307-325.

Singh, I.J, and Gunberg, D.L., 1970 - "Estimation of age at death in human males from quantitative histology of bone fragments". Amer. J. Bhys, Anthrop., Vol. 33, pp. 373-381.

Strzalko, J. and Manouvier, L., 1969 - "Synthese des recherches polonaises effectuees". Przeglod Antropologiczny, Vol. 35 (1), p. 141.

Trotter, M. and Gleser, G.C., 1952 - "Estimation of stature from long bones of American whites and negroes". Amer. J. Phys. Anthrop., Vol. 10 (4), pp. 463-514.

Trotter, M. and Gleser, G.C., 1958 - "A re-evaluation of stature based on measurements of stature taken during life and of long bones after death". Amer. J. Phys. Anthrop., Vol. 16 (1), pp. 79-123.

Wahl, J., 1982 - "Leichenbranduntersuchungen ein Uberblick uber die Bearbeitungs und Aussage-Moglichkeiten von Brandgrabern". Braehistorische Zeltschrift, Vol. 57 (1), pp. 1-125.

Wahl, J., 1988 - "Suderbrarup". Karl Wachholtz Verlag, Neumunster.

Wells, C., 1960 - "A study of cremation". Antiquity, Vol. 34, pp. 2937. 


\title{
PAGAI SAXOI GEIETERIES: A STUDY OF THE PROBLFHS OF SEXIIG BY GRAVE GOODS AID BOIES
}

\author{
Janet Henderson \\ 7d Compton Road \\ London $\mathbb{N 1} 2 \mathrm{PA}$
}

\section{Introduction}

This paper is concerned with the problems of sexing individuals from pagan Anglo-Saxon cemeteries. It is primarily a response to work on material originally examined by the late Dr. Calvin Wells during the $1960^{\prime} \mathrm{s}$. Two sites were involved: a cemetery on the Portway Industrial Estate near Andover in Hampshire and a pair of cemeteries from Beckford in Gloucestershire. The present author was asked to give a 'second opinion' on the results for sex, on all of the material from Portway and on ten skeletons from Beckford. In each case there were differences between sex as assessed on the grave goods and as indlcated by the bones. As work progressed it became increasingly clear that in some cases the attribution of sex derived from the grave goods, and from the bones, did indeed differ and that there was full agreement between this author and $\mathrm{Dr}$. Wells' analysis. This raised a number of questions. Were the human biologists' results correct? Are grave goods really such a reliable indicator of sex as some archaeologists consider them to be? If both human bialogists and archaeologists are getting it right then why are there disparities? What is to be done about them?

Some progress towards this may be made by looking at the methods currently available for assessing sex on skeletons, some examples of Sites where both grave goods and human bone sexing is adequately reported and examining the attitudes of both human biologists and archaeologists to the problem.

\section{Techniques for assessing the sex of skeletons}

Since methods of assessing sex from grave goods are the province of archaeologists rather than the human biologist they will not be discussed here.

Making an attribution of sex on a human skeleton requires a degree of skill which is not always recognised. Not only does the observer need to know 'how' but also 'why'. Consideration needs to be given to the techniques avallable, to the completeness and provenance of the remains and the age at death of the individual concerned. It is only thus that the observer can hope to gauge the degree of confidence with which any single attribution of sex is made.

What is the importance of an age at death? Simply put there is a general consensus of opinion among researchers that the methods currently available for sexing immature individuals (i.e. those where Skeletal growth and development are incomplete) are insufficiently reliable for attempts at sexing to be justified (see, for example, E1Vajjar and McWilliams, 1978; Krogman, 1962; Stewart, 1979). The effect 
of this is that comparisons between sexing based on grave goods and sexing based on bones is restricted to samples of adult skeletons.

Methods of sexing adults centre on the observation, long recognised by anatomists, of dimorphism between male and female bones. Broadly speaking the male is larger and more robust than the female, whose skeleton is smaller and more gracile. Virtually every bone in the skeleton has, at some time or another, been studied with a view to sexing, with varying degrees of success.

Morphological differences in the skeleton tend to concentrate on three parts: the whole skeleton, the pelvis and the skull and mandible. Although varlabllity is seen, most experlenced observers find that an overall visual assessment of the skeleton is all that is needed to establish sex (Brothwell, 1981).

Metrical analysis is considered by some to be an alternative and by others to be supplementary to morphology. Metric studies of sexual dimorphism in the skeleton have utilised, at one time or another, nearly every bone in the skeleton. Measurements may be single (as in diameters), double (as in indices) or multiple (as in discriminant functions). Bones used have included: the pelvis, femur, humerus, clavicle, sternum, vertebrae, scapulae, talus and calcaneum.

\section{Degree of confidence}

Are attributions of sex based on skeletal material reliable? How do we know that they are correct? Establishing the sex of a skeleton is fundamental to bone studies and the degree of accuracy with which it may be done is crucial. Thus $i t$ is every bit as vital to the human biologist to get it right as it is to anybody else. The three most important factors which will affect accuracy are the observer, the method used and the degree of completeness of the remains.

To take technique first: sex is a continuous variable with a clear bimodal distribution. To put it more bluntly people are either male or female. However, although sex is genetically determined the eventual form of the individual comes under a wide range of genetic and environmental influences, such that some physical features will give a clear indication of sex whereas others may be of little or no use.

In the skeleton the two main influences on sexual dimorphism with which human biologists concern themselves are reproduction and genetically influenced contrasts in size and shape. All techniques for assessing skeletal sex have their origin in these factors. Thus pelvic morphology, for example, has strong links with the reproductive capabilities of the female. Size and shape of bones such as the humerus and femur reflect genetic influences on the overall size and robustness of individuals and the tendency for these to be greater in the male. The degree of confidence with which each may be applied to sexing is a direct outcome of the original cause of the difference. Since form is, amongst other things, a response to function it follows that sexing based on reproductive differences carries greater weight than sexing based on differences in size. 
Various workers have attempted to quantify the degree of confidence with which various bones may be used. Their attention has been directed towards a series of problems including: morphology versus metrics, pelvis versus other bones, multiple assessment as opposed to single and variability between series, in particular between Caucasold, Negrold and Mongoloid groups. Most workers would seem to agree that there is no substitute for a trained, experienced eye, as although the majority of skeletons may be sexed with relative ease there will always be a few marginal cases. The accuracy achieved may be summed up in the following figures:

For the pelvis:

Vashburn (1948)

ischio-pubic index $>90 \%$ index with greater sciatic notch $>95 \%$

Hanna and Washburn (1953) index with notch $>95 \%$

Krogman (1962)

Phenice (1969) pelvis alone $95 \%$ pubic morphology $96 \%$

Other bones:

Krogman (1962)

complete skeleton
complete skull
skull and pelvis
long bones
long bones and pelvis
skull and long bones
skull without mandible
skull with mandible or
other bones
complete skeleton

$98-100 \%$

$92 \%$

$98 \%$

$80-85 \%$

$98 \%$

$95 \%$

Hrdlicka

(In Stewart, 1979)

skull with mandible or

$80 \%$

$96-98 \%$

$96-98 \%$

Ascadi and Nemeskeri

(1970)

whole skeleton

$96.8 \%$

Meindl et al. (1985)

skull and pelvis

$97 \%$

Clearly the bones used are extremely important, hence so much weight being given to completeness of the skeleton. By far the best scores are achieved where either the whole skeleton or the pelvis at least are present. Reduced to long bones or skulls alone, the figure drops below $80 \%$. Fortunately, where inhumations are concerned, in this country at least, it is usually possible to assess sex by more than one method. Where relatively complete skeletons are under analysis rates achieved by experienced observers are probably at the $90 \%$ mark or better. This is illustrated by the series from Christ Church, Spitalfields. Here, some 390 individuals of the total are of known age and sex. Recent work has shown that of these 390 less than 10 individuals were sexed incorrectly using the standard methods currently available. This is an accuracy in the order of $95 \%$ plus 
(Adams and Reeve, 1987). Perhaps even more significant is the fact that most methods of sexing have been established on material other than British and yet in this instance they have been applied with a great degree of success. Hooton summed it up very neatly when he wrote (1946, see Washburn, 1948), " determination of sex from the postcranial skeleton in adults is easy and certain in about $80 \%$ of cases, difficult but possible in another $10 \%$ and quite dubious in the remainder".

What about pagan Saxon samples? It is the present author's experience that for sexing of adults by researchers with a high level of expertise the most important factor is the relative completeness of the remains. This is borne out by work on the samples from Portway and Beckford. For the former all skeletons were examined by both observers but for the latter the present author saw only those individuals where there was a query owing to differences in sexing the grave goods and the bones. Both samples were poorly preserved overall.

Table 1: Sex Results - Human Biologists only

$\begin{array}{lcccr}\text { Site } & \text { n } \text { (sexed) } & \text { differ } & \text { degree } & \text { same } \\ \text { Beckford } & 7 & 3 & 3 & 1 \\ \text { Portway } & 37 & 5 & 6 & 26\end{array}$

Notes: 1) Differences of degree means 'female' as opposed to '?female'

2) The samples used are restricted to sexed adults

Where there were outright differences in the results it could be shown in almost all cases that they were attributable to the poor preservation of the remains. Thus of a total of eight cases of difference, in only two was it felt to be due to the avallability of methods not known in the $1960^{\prime} \mathrm{s}$. The remainder were all attributed to poor bone condition. It may also be emphasised that at Portway the two observers were in general agreement on the greater part of the sample (32 out of 37 ).

What these findings amount to is this. This author is of the opinion that where experienced observers are involved, then by and large a high degree of accuracy is being achieved in sexing archaeological remains. This is confirmed by the results from Spitalfields and strongly indicated by the findings on the two Saxon sites.

\section{Bones versus grave goods}

So far this paper has concentrated on sexing techniques as applied to human skeletal remains. For the remainder, attention will be directed towards how this relates to sexing on grave goods and the implications of the findings. Before this is done one point must be made. Very few sites have been studied and/or published in sufficient detail for analysis. This is the fault both of the archaeologist and human biologist. Where the human biologist is concerned in some cases no individual results at all are given and in others individual results but no comment on the analytical methods used. Unfortunately, 
this leaves the reader with no idea of the degree of confidence that may be placed on the results. As can be seen all too clearly from the reliance placed on grave goods by archaeologists in preference to human bones this is a bad omission and one that needs rectification.

Fortunately, four sites have most of the information necessary for an examination of differences between human bones and grave goods. They are the two sites mentioned already, Sewerby in East Yorkshire and the Buckland cemetery at Dover, Kent. In each case a pagan cemetery is invalved and the results for sexing on grave goods differ in a number of skeletons.

Table 2. Sex results - Bones versus grave Goods

Site

Portway (Cook and Dacre, 1985)

Sewerby (Hirst, 1985)

Buckland, Dover (Evison, 1987)

Beckford (Evison, in prep.)

$\begin{array}{ccc}\text { No. Sexed } & \text { Differ } & \text { Same } \\ 37 & 2 & 35 \\ 15 & 3 & 12 \\ 42 & 12 & 30 \\ 6 & 3 & 3\end{array}$

Hotes: 1) Numbers given for Buckland are smaller than in report. Only data from the grave goods and final bone report used, and only sexed adults included

2) Differences of degree ignored, included as same.

The table shows that whilst in the majority of cases the attribution of sex obtained from the human bones and the grave goods is in agreement, there are, in each sample, a few individuals where this is not true. Various explanations have been put forward by way of explanation of the discrepancles. In two cases at Dover there was disturbance of the graves (hence possible mixing of bone materlal) and in three errors, in the final bone report. For the remaining five and for those at Sewerby doubt has been cast on the validity of the biological sexing, the cultural determination being preferred. Since sex is a biological and not a cultural characteristic of a human being this argument is little short of absurd.

Surely what is far more significant is the statement that:

"These bodies where the bones tell a different story from the grave80ods" (Evison, 1987). 


\section{Conclusion}

This leads back to the questions asked at the outset of this study. Are human biologists correct in their analysis? Yes, in general, they are. Are grave goods really such a reliable indicator of sex as some archaeologists would like them to be? Since, in the majority of cases sexing based on the grave goods and human bones is in agreement then the answer might be yes. However, the four sites illustrated here do show that on some occasions the two do differ. Certainly, caution should be exercised against indiscriminate use of grave goods. There are a number of practices which must come into question in the light of the present evidence. These include use of grave goods in preference to human bones, and use of grave goods to sex those individuals where biological sexing is not feasible.

If both human biologists and archaeologists usually attribute sex correctly why are there disparities? What is to be done about them? Taking the last question first, there needs to be greater co-operation between archaeologist and human biologist such that samples are adequately reported with full details of methods and results given. If necessary, where bone preservation is poor then the human biologist should be given the opportunity to examine the material in situ. It is only by use of a careful methodology that there can be any hope of establishing definitely whether or not it is a genuine finding that in a proportion of cases sexing will differ.

To return to the former question - why are there disparities - is really for archaeologists to answer. Perhaps reference should be made to the comment by the author of the Portway report, faced with the problem that both $\mathrm{Dr}$. Wells and this author were confident in their attribution of male sex to a skeleton which the grave goods indicated as female:

"The suggestion has ... been made that this may have been an unusual, ritual burial".

\section{BIBLIOGRAPHY}

Acsadi, G. and Nemeskeri, J., 1970 - "A history of human life span and mortality". Akademiai Kiado, Budapest.

Adams, M. and Reeve, J., 1987 - "Excavations at Christ Church, Spitalfields 1984-6". Antiquity, Vol. 61, pp. 247-256.

Brothwel1, D.R., 1981 - "Digging up bones. The excavation, treatment and study of human skeletal remains.". 3rd edition. Oxford University Press, Oxford and British Museum (Natural History), London.

Cook, A.M. and Dacre, M., 1985 - "Excavations at Portway. Andover. 1973-5". Oxford University Committee for Archaeology. Monograph 4.

El-Najjar, M.Y. and McWilliams, K.R., 1978 - "Forensic anthropology". Charles C. Thomas, Springfield, Illinois. 


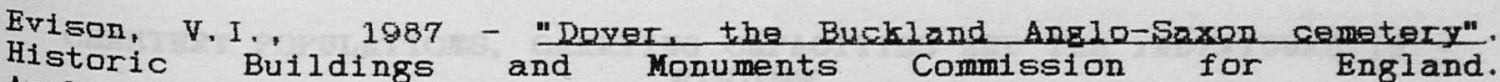

Archaeological Report No. 3. H.B.M.C.E., London.

Hanna, R.E. and Vashburn, S.L., 1953 - "The determination of the sex of skeletons, as illustrated by a study of the Eskimo pelvis". Human. Biology, Vol. 32, pp. 21-27.

Hirst, S.M., 1985 - "An Anglo-Saxon inhumation cemetery at Sewerby. East Yorkshire". York University Archaeological Publications No. 4.

Krogman, W. M., 1962 - "The human skeleton in forensic medicine". Charles C. Thomas, Springfield, Illinois.

Meindl, R.S., Lovejoy, C.O., Mensforth, R.P. and Carlos, L. D., 1985 "Accuracy and direction of error in the sexing of the skeleton: implications for paleodemography". Amer. J. Phys. Anthrop., Vol. 68, pp. $79-85$.

Phenice, T.V., 1969 - "A newly developed visual method of sexing the os pubis". Amer. J. Phys. Anthrop., Vol. 30, pp. 297-301.

Stewart, T.D., 1979 - "Essentials of forensic anthropology". Charles C. Thomas, Springfield, Illinois.

Vashburn, S.L., 1948 - "Sex differences in the pubic bone". Amer J. Phys. Anthrop. Vol. 6, pp. 199-208. 
CEMETERY POPULATIOHS, CARRYIMG CAPACITIES AND THE IMDIVIDUAL II HISTORY

John Bintliff

Department of Archaeological Sciences

University of Bradford

Bradford

BD7 1DP

Introduction

The great French historian Fernand Braudel in his approach to the past that he called STRUCTURAL HISTORY demonstrated the novel insights that can be obtained by studying the world of the past along three different timescales: the LONG TERM of millennia and millions of years, the MEDIUM TERM of several generations to centuries, and the SHORT TERM of events within a year or an individual's lifetime (cf. Bintliff (Ed) forthcoming).

Figure 1

BRAUDEL'S MODEL OF HISTORICAL TIME (Durée) (Structural history)

History of events

SHORT-TERM: $\quad$ ÉVÉTIFITITS

Narrative, Political history

Events

Individuals

Structural history

MEDIUM-TERM: COIJUICTURES

Social, Economic history

Economic, Agrarian, Demographic

Cycles

History of eras, regions, societies

Worldviews, ideologies (mentalités)

LONG-TERM: $\quad$ STRUCTURES DE LA "LOWGUE DURÉE*

\author{
Geohistory \\ "Enabling and constraining" \\ History of civilisations, peoples \\ Stable technologies, worldviews (mentalites)
}

I would like to use this structure to discuss aspects of Burial Archaeology which shed light on some of the processes at work moulding human populations, taking each timescale in turn. 
My example for processes operating in the long term is that of Neanderthal populations in Europe and Vestern Asia. These interesting hominids are actually the first human subspecies known to have regularly practised deliberate burial, and many of the best preserved and studied specimens stem from this practice. The subspecies Homo sapiens neanderthalensis dominates Europe and West Asia from around 75,000 to 30,000 b.p., then disappears rapidly, before an apparently rapidly diffusing population of truly modern humans Homo sapiens sapiens, out of Africa.

Traditional views of this hominid such as that of Boule (1920) linked brutish bodies to similar minds, characterising Meanderthals as sub-human and uncultured. In the 1960's atmosphere of flower power and love thy nelghbour the Neanderthals were reinterpreted as Rousseau's Moble Savages and reinstated as possible ancestors of modern humankind. Type-specimens of exaggerated brutishness were shown to have been crippled by arthritis, and new discoveries such as the Shanidar burial, with its offering of flowers over the corpse, led Solecki and Bordes to picture a sensitive and moral spirit concealed beneath a robust frame (cf. e.g. Solecki, 1971).

Whether or not we see it as offering insight into our present decade, current expert opinion is once again reassessing the Neanderthals. Although the earliest fully human populations of last glacial Eurasia, typified by Cro-kagnon Han, show some Neanderthal traits, they are not close enough for direct descent, and it seems that a massive swamping by genetic novelty led to the disappearance of the Neanderthal type. This is envisaged as a combination of wholesale population replacement in some areas and interbreeding in others.

The important revelation that has developed from this viewpoint is that the long-lived and very widespread Heanderthal populations are not simply another version of ourselves which gradually evolved to fully modern form, closely matched by the progressive elaboration of material culture such as flint technology; nor are they backward brutes on an evolutionary dead-end. Rather they constitute an intriguing mosaic of advanced-looking features, and primitive-looking features, both physically and culturally. Given the long-survival and expansion of the sub-species, it was clearly a very effective lifeform for its times and ecology, yet offering a different physical and cultural repertoire for the population survival game.

Thus as Trinkhaus $(1986 \mathrm{a}, \mathrm{b})$ has recently argued, the great robustness of Neanderthals implies massive energy which correlates with relatively unsophisticated tool types and forms - muscles seem to have replaced technological skill, whereas human groups and contemporary hominids elsewhere used more wit and needed less strength. Hunting techniques appear to have been not very systematic, perhaps requiring more time than that expended by Cro-Kagnon populations, who incidentally employed their leisure in the production of artworks so lacking in Neanderthal contexts. The famous jaws and teeth return to a more primitive size probably because they were used like a third hand; again compensating for the neglected nurture of 
artefact technology? Evidence for shelter suggeste again a lack of sophistication, matched by bodies which show special cald adaptations. Even the curious feature of skulls and braincases frequently exceeding modern dimensions has now been accounted for by longer pregnancies than modern humans, some 11-12 months, producing rapid allometric growth. Cro-Magnons were able to reduce this and make more effective use of infancy via the enhanced social communication within the group.

Rob Foley has argued (1987) that the human evolutionary story now looks more like a series of adaptive radiations rather than an ascending ladder of human descent. Using the technique of Cladistic Analysis (Figure 2) he sees hominid evolution as a mosaic over time and space of long-lived and distinct populations of hominids, living in relative equilibrium with their ecology. Change in human forms and their closely adapted tool technologies is rare and rapid, favouring a Punctuated Equilibrium model. In these examples we have presented interpretations appropriate to Braudel's long-term perspective or Longue Durée where operate the almost timeless constraints on human behaviour set by certain properties of landscapes or by slowly changing technologies and worldviews.

\section{The Medium Tern}

Braudel's medium-term is the timescale most frequently dealt with by archaealogists, the picture given of a site or landscape over several generations or centuries. Permeating past societies are medium-term pressures of which most contemporaries are inadequately unaware. The upward and downward trends in population cycles, agricultural cycles, climatic perturbations, core-periphery effects in political and economic macro-systems. I wish to discuss here three case studies at this timescale from the archaeology of Bronze Age Greece.

\section{(1) Early to Middle Bronze Age Burial in Crete}

Back at the start of the 1970's I spent an enjoyable few weeks working with an archaeological survey of a deserted valley on the south coast of Crete (the Ayiofarango Gorge). Many Minoan Bronze Age sites were found, and one of many contemporary stone tombs or THOLOI excavated. My task was to prepare a Soll Map of the valley, from this derive a Potential Land Use map for the Bronze Age, and then try to fit the Minoan sites into the landscape (Published in Bintliff, 1977a, Bintliff in Blackman and Branigan et. al., 1977b).

When the limited patches of cultivable land were isolated (zones outlined by dotted lines), the Minoan settlement sites showed a clear patterning (Figure 3) which I suggested could be interpreted as a dispersed settlement of small farms and hamlets strung along the valley on or beside islands of $\mathrm{kin}$-group landholdings. Interestingly, the tholos tombs showed the same pattern, suggesting that they marked ancestral holdings for scattered kin-groups. There were even putative small shrines associated with these local landholdings.

I was naturally tempted to a speculative reconstruction of the size of the human populations involved, and tried to use two parameters, 


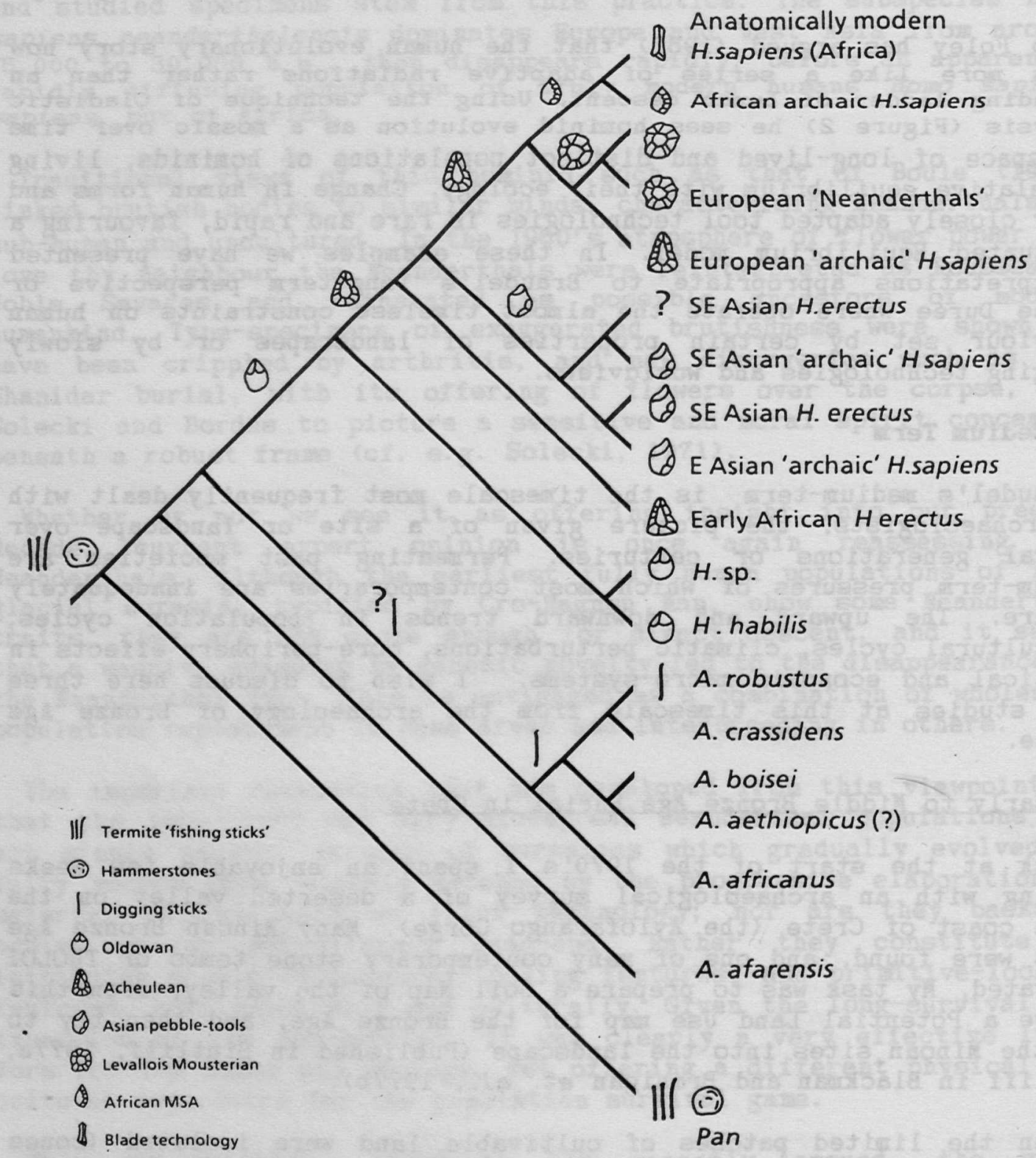

Figure 2. A cladogram of human evolution, emphasizing the divergence of hominid taxa. The stone-tool asemblages associated with each taxon is shown: (from Foley, R., 1987, figure 2). 


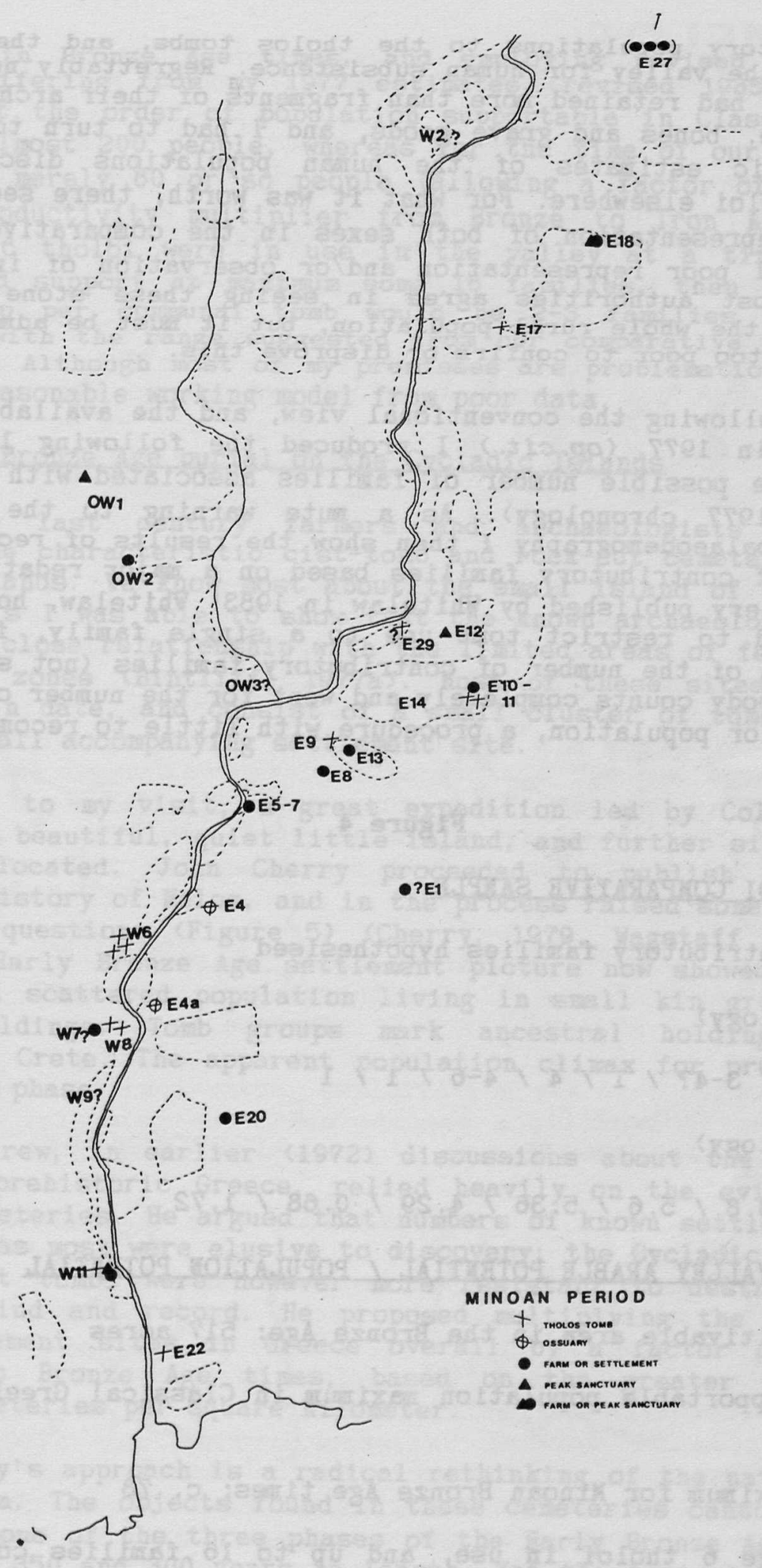

Pigure 3. Minoan Bronze Age site map for the Ayiofarango Valley, Crete. Areas of fertile land outlined by dashes. 
the contributory populations to the tholas tombs, and the carrying capacity of the valley for human subsistence. Regrettably none of the valley tholoi had retained more than fragments of their archaeological deposits, 1.e. bones and grave goods, and I had to turn to the none too scientific estimates of the human populations discovered in excavated tholoi elsewhere. For what it was worth, there seemed to be reasonable representation of both sexes in the comparative samples, and the usual poor representation and/or observation of infants and subadults. Most authorities agree in seeing these stone tombs as communal for the whole rural population, but it must be admitted that the data are too poor to confirm or disprove this.

However, following the conventional view, and the available pottery chronalogy, in 1977 (op.cit.) I produced the following list for 8 tholoi of the possible number of families associated with each tomb (Figure 4: 1977 chronology). As a mute warning to the perpetual problems in palaeodemography I then show the results of recalculating the number of contributory families based on a major redating of the relevant pottery published by Whitelaw in 1983! Whitelaw, however, who really wanted to restrict tomb use to a single family, in his own recalculation of the number of contributory families (not shown here) ditched the body counts completely and went for the number of gifts as a surrogate for population, a procedure with little to recommend $1 t$.

Figure 4

\section{MESSARA THOLOI COMPARATIVE SAMPLE}

Number of contributory families hypothesised

(1977 chronology)

3-4? / 3-4? / 3-4? / $1 / 4 / 4-6 / 1 / 1$

(1983 chronology)

$2.9 / 4.5 / 8.8 / 5.6 / 5.36 / 4.29 / 0.68 / 1.72$

AGIOFARANGO VALLEY ARABLE POTENTIAL / POPULATION POTENTIAL

Potential cultivable area in the Bronze Age: 517 acres

Suggested supportable population maximum in Classical Greek t1mes: c. 194

Suggested maximum for Minoan Bronze Age times: c. 78

If an average 6 tholoi in use, and up to 16 families contributing, average THOLOS social group is 2-3 famlites.

Well, sticking instead with our revised kin-groups for typical tholoi elsewhere (Figure 4: 1987 chronology), we can focus on the Aylofarango Valley data again. I estimate that some 517 acres were 
cultivable in Bronze Age times, and employing revised crop yield figures (differing from my 197 ? estimates, revised 1985). I would suggest that the order of population supportable in Classical Greek times was almost 200 people, whereas for the time of our tombs, the Bronze Age, merely 80 or so people (allowing a factor of 2.5 as an economic productivity multiplier from Bronze to Iron Age). If an average of 6 tholal were in use in the valley at a time, and the valley could support at maximum some 16 families, then the average social group per communal tomb would be $2-3$ families - a figure compatible with the range suggested from our comparative tomb sample shown above. Although most of my premisses are problematic, I believe this is a reasonable working model from poor data.

\section{(ii). Early Bronze Age burial on the Cycladic Islands}

Since the last century farmers and archaeologists have been recording the characteristic cist-tomb and rock-cut cemeteries of the Cycladic Islands. We know most about the small island of MELOS. Here in the 1970 's I was able to show that the known archaeological sites reflected a close relationship with the limited areas of fertile land, and fishing zones (Bintliff, 1977a). Most of these sites are Early Bronze Age in date, and consist of a small cluster of tombs, with or without a small accompanying settlement site.

Subsequent to my visit, a great expedition led by Colin Renfrew invaded this beautiful, quiet little island, and further sites of this kind were located. John Cherry proceeded to publish the fuller settlement history of Melos, and in the process raised some intriguing demographic questions (Figure 5) (Cherry, 1979, Wagstaff and Cherry, 1982). The Early Bronze Age settlement picture now showed even more strikingly a scattered population living in small kin groups beside isolated holdings. Tomb groups mark ancestral holdings, as on contemporary Crete. The apparent population climax for prehistory is also in this phase.

Colin Renfrew, in earlier (1972) discussions about the population density of prehistoric Greece, relied heavily on the evidence from Cycladic cemeteries. He argued that numbers of known settlements were hard to use as most were elusive to discovery; the Cycladic cist tombs and rock cut tombs were however more resistant to destruction and easier to find and record. He proposed multiplying the numbers of known settlement sites in Greece overall by a factor of 2-4 for Neolithic to Bronze Age times, based on the greater density of Cycladic cemeteries per square kilometer.

John Cherry's approach is a radical rethinking of the nature of the cemetery data. The objects found in these cemeteries cannot be dated closer than one of the three phases of the Early Bronze Age, periods of some 600,350 and 300 years in length. Yet the typical grave count of 20 bodies would probably represent no more than a century of use by a single family. A larger social group would imply an even shorter cemetery use.

The obvious conclusion is that we have to divide the known cemeteries by a factor of $3-6$ to see the site pattern at any one time 


\section{MELOS}

- Definite oprobable

A

SURVEY DESIGN

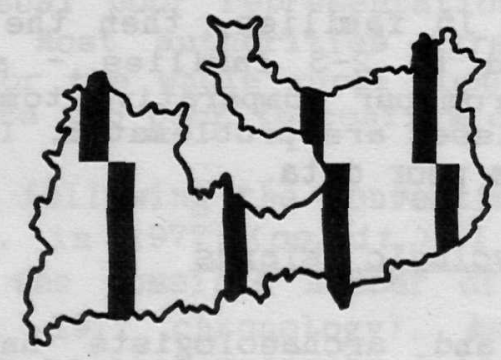

C

NEOLITHIC

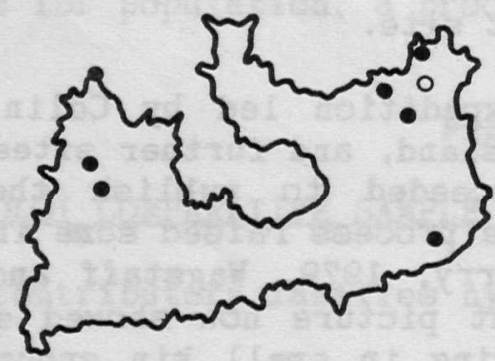

E

MIDDLE BRONZE AGE

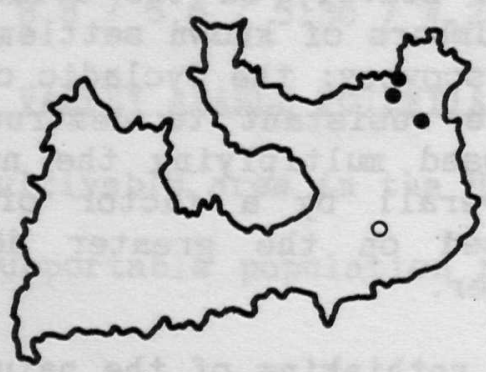

B

MESOLITHIC

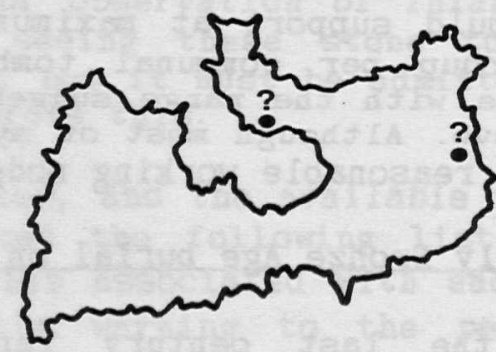

D

EARLY BRONZE AGE

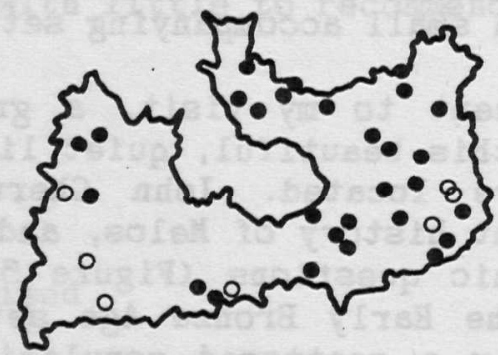

$\mathbf{F}$

LATE BRONZE AGE

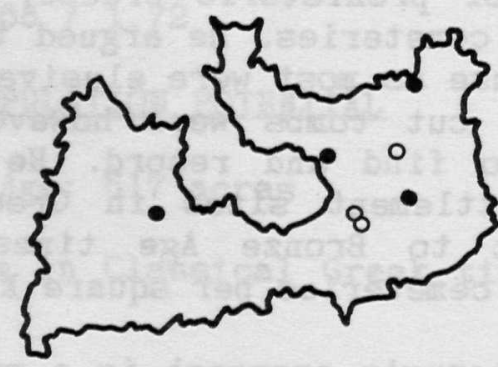

Figure 5 Archaeological sites of prehistoric age on the island of Melos, Greece: (from Cherry,J.F., 1979, figure 1). 
DI Melos. The result is to suzgest that Melos had a population of 40 rising to 90 during different phases of the Early Bronze Age.

Cherry now moves on to a critical problem in population reconstructions: how much data is missing from the archaeological record? He starts from the reasonable claim that during the Middle and Late Bronze Age almost all the island's population have concentrated Into the proto-urban site of Phylakopi in the north-east corner of Melos (Figure 5). He then moves on to highly speculative ground by employing several alternative population growth curves for agricultural populations. His favoured growth curve produces a town population of 740 people by the Middle Bronze Age from a starting population of 80 at the beginning of the Early Bronze Age some 2000 years earlier. That figure matches well with the architectural remains at $\mathrm{Phlakopi}$, and suggests that perhaps half of the early Bronze Age rural sites lie undiscovered by archaeologists.

Independently, I have been grappling with lost sites and lost people from a different data set. In Central Greece the province of Boeotia has been subjected to intensive survey for ten years (Bintliff and Snodgrass, 1985, 1988). Population estimates derived for Classical Greek times from recorded totals of rural and urban archaeological sites, seem to account for only 50-70\% of the sites that should be there to match unusualiy detailed population figures from historical sources for the area in the 4 th century $B C$. The figure for lost sites of Classical Greek date, when we modify it by a further cumulative loss over time back to the Bronze Age, is surprisingly comparable to Cherry's speculative exercise.

The full implications of these palaeodemographic games are not trivial for historical understanding. If the classical historical sources are correct, we estimate that 4 th century Boeotia was being overfarmed prodigiously and catastrophically; if the archaeological sites are taken at face value, exploitation was at a reasonable level. In fact the following centuries witness a collapse of population in Boeotia, reinforcing the hypothesis of agricultural overkill.

\section{(1ii). Late Bronze Age in Mainland Greece}

The Plain of Argos has to be one of the most visually stunning of ali Greek landscapes, and it is heaving with major archaeological sites of every period. In the early $1970^{\prime} \mathrm{s}$, as I walked and bicycled my way around every site and village of the region, I was particularly interested in the network of Late Bronze Age settlements (Figure 6; Bintliff, $1977 b$ for full discussion: Section II. Chapter 2 and Appendix A). They belonged to the Mycenaean civilisation, and included the site of Mycenae itself (Number 1 at the top right hand corner). I tried as shown here to reconstruct the settlement hierarchy of this period. The top centres were occasionally marked by palaces, or one or more extravagant beehive tombs of the Mycenaean THOLOS type (Figure 7). Identifying these was the basis for the territorial cells which are Thiessen polygons around each centre. As for the middle level of settlement, absence of these pretentious features was linked to a smaller settled area and cemeteries containing only the less pretentious tomb types, chiefly the chamber tomb (Figure 7), usually 


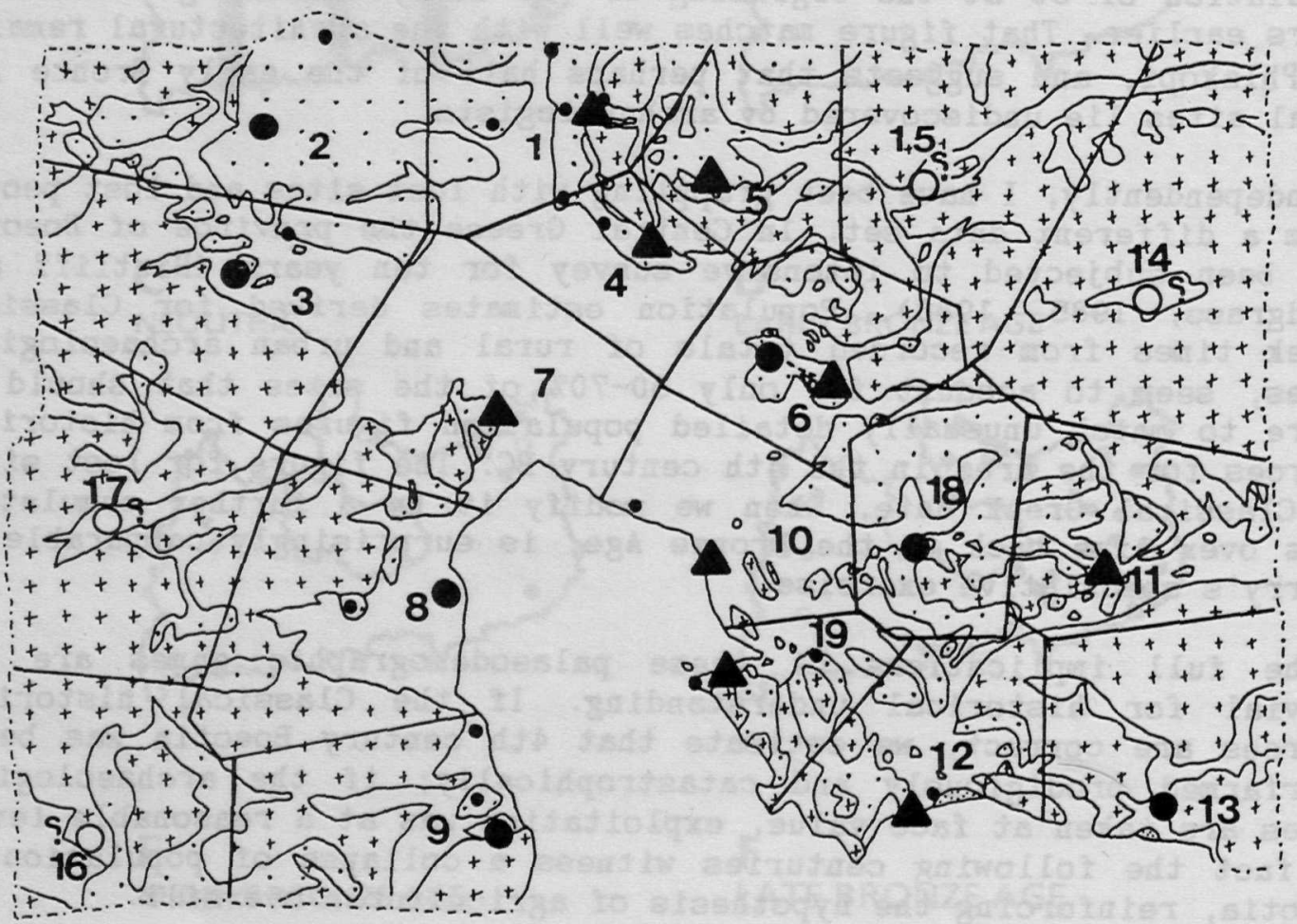

Figure 6 Late Bronze Age (Mycenaean) sites in the Plain of Argos, Greece. Major centres (triangles) form the centre of the Thiessenpolygon cell network representing putative central-place territories. Satellite sites are shown as major or minor settlements by large or small circles. 

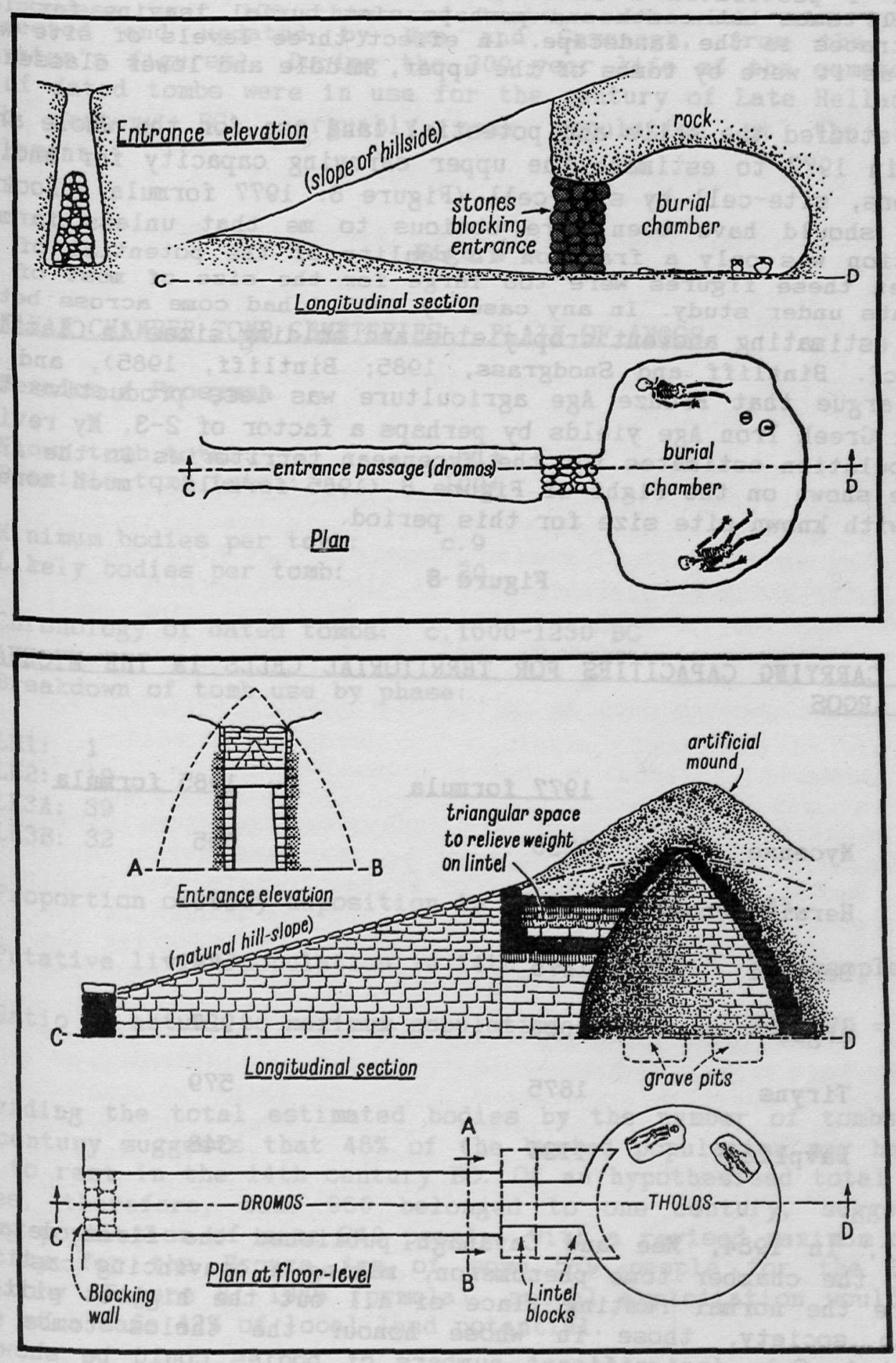

Figure 7 The two major types of burial monument in Late Bronze Age (Mycenaean) Mainland Greece, the Chamber Tomb (upper diagram) and Tholos Tomb (lower diagram). Double picture of stone chamber and tholos tombs of Mycenaean age: (from Lord William Taylour the yycengeans, Thames and Hudson 1964, figures $30 \& 43$ ). 
rock cut. I postulated a lowest rank of site where there were no monumental tombs but earth and perhaps cist burial leaving far less obvious traces in the landscape. In effect three levels of site were typified as it were by tombs of the upper, middle and lower classes.

Having studied the soils and potential land use for the whole area, I. tried in 1977 to estimate the upper carrying capacity for ancient populations, site-cell by site-cell (Figure 8: 1977 formula). Looking back, it should have been more obvious to me that unless farming exploitation was only a fraction in reality of the potential of the land, then these figures were too large for the size of most of the settlements under study. In any case by 1985 I had come across better data for estimating ancient crop yields and holding sizes in Classical Greece (cf. Bintliff and Snodgrass, 1985; Bintliff, 1985), and was also to argue that Bronze Age agriculture was less productive than Classical Greek Iron Age yields by perhaps a factor of 2-3. My revised upper population estimates for the Mycenaean territories in the Argos Plain are shown on the right of Figure 8 (1985 formula), much more in keeping with known site size for this period.

\section{Figure 8}

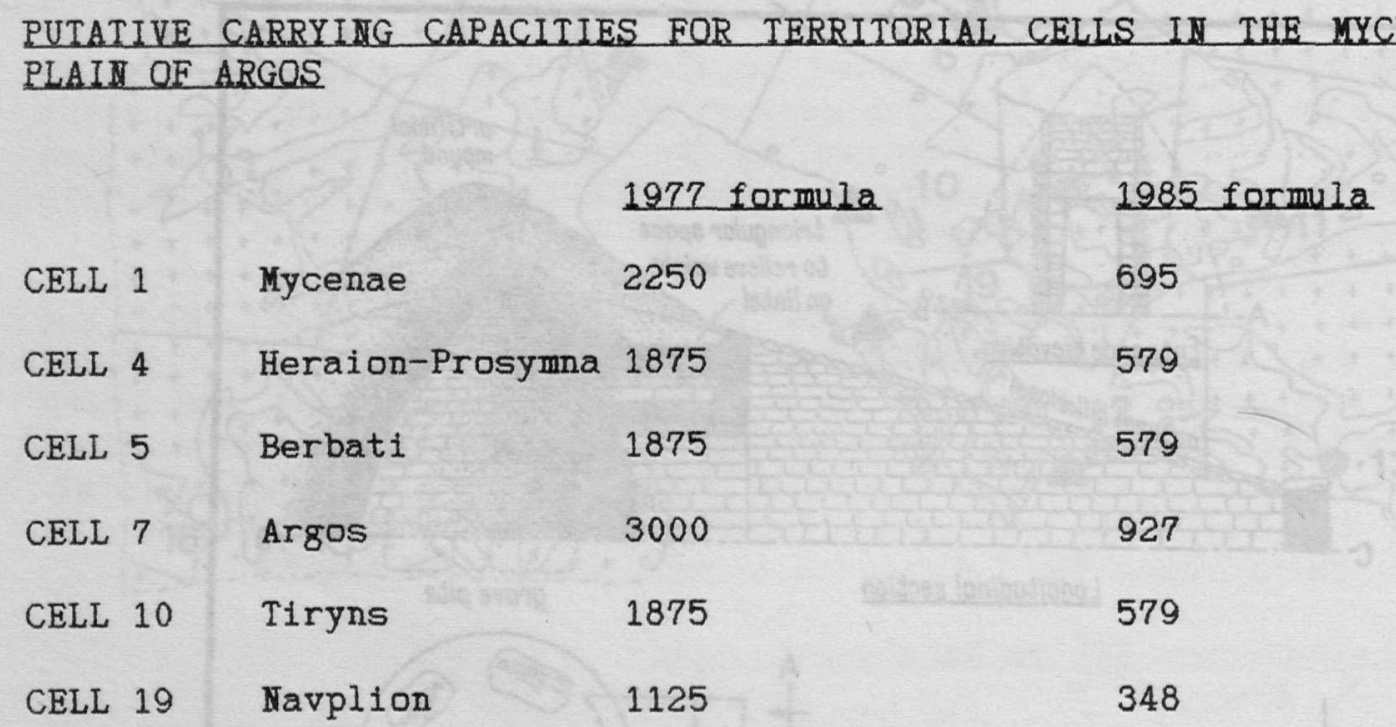

However, in 1984, Mee and Cavanagh published the first detailed study of the chamber tomb phenomenon, making a convincing case that they were the normal resting place of all but the highest elite in Mycenaean society, those in whose honour the tholos tombs were constructed. Only insignificant numbers of bodies could be shown to have gone into other, simpler forms of burial. Their conclusions open up the possibility of obtaining at least a general order of magnitude for the populations actually living at particular Mycenaean sites whose chamber tomb cemeteries have been explored.

Examination of two sites in the Plain of Argos from this viewpoint will reveal both the problems and potential of this data. Firstly, (Figure 9) the major centre of PROSYMNA (site number 4 on Figure 6) 
may poseses over 100 chambered tombs, each with some 20 bodies (corrected and updated by Mee and Cavanagh, from the original excavator's figures). During the 300 year iffe of the cemetery some $76 \%$ of dated tombs were in use for the century of Late Helladic IIIA (14th century BC), arguably peak population at the adjacent settlement.

Figure 9

\section{UYCENAEAI CHAMBER TOMB CEMETERIES - PLAIN OF ARGOS}

\section{(1) Heraion / Prosyma}

Known tomb total:

Possible tomb total:

Minimum bodies per tamb:

c. 9

Likely bodies per tomb:

c. 20

Chronology of dated tombs:

c. $1600-1230 \mathrm{BC}$

Breakdown of tomb use by phase:

LH1: 1

LH2: 19

LH3A: 39

LH3B: 32

Proportion of body deposition in LH3A:

$48 \%$

Putative living population in 14 th century BC: 240 people

Ratio of actual to maximum population:

Dividing the total estimated bodies by the number of tombs in use per century suggests that $48 \%$ of the buried population may have been laid to rest in the 14 th century BC. Of an hypothesised tatal of 2000 bodies, therefore, some 960 belonged to one century, suggesting a living population of some 240 people. With a revised maximum carrying capacity for the Bronze Age of some 579 people for the PROSYMMA territory (Figure 8: 1985 formula), actual exploitation would appear to be at a safe $42 \%$ of local land potential.

A second example from the Argos Plain (Figure 10) NAVPLION (site number 19 on Figure 6) gives a very different picture however. The chambered tomb total may be as high as 500 and the implied buried population 10,000. If we use a similar ratio of use for the 14 th century $B C$ as at PROSYMNA, peak use may reflect a living population at that time of some 1200 people. My carrying capacity estimate (Figure 8) is now a mere 348 people, implying that at this time the population was at $345 \%$ of $10 c a l$ resource capability. 
(2) Mavplion

Likely tomb total:

500

Putative buried population: $\quad 10,000$

If $48 \%$ of body deposition is in LH3A (14th century BC) living population at peak could be 1200 people.

Navplion maximum carrying capacity:

348 people

Ratio of actual to locally-supportable population: $1200 / 348=345 \%$

A local solution would be to suggest that the Navplion cemetery was used for burial by populations in neighbouring territories. But since they usually have their own cemeteries, this is special pleading. A more promising solution is to remind ourselves that although Navplion possesses a fertile arable hinterland, it also lies on the sea (Figure 6) and therefore its working population in Mycenaean times will have lived from fishing and commerce as well as local agriculture. In fact, these figures, if of the right order, would imply that most of the population was supported outside of the settlement's territory.

\section{The Short Term}

Braudel's history of the short term emphasises the experience we as individuals have of events, from year to year and during conscious lifetimes. Recently a growing number of archaeologists have criticised our interpretations of the past (most notably Ian Hodder in his 1986 book Reading the Past), for, amongst other things, ignoring the role of the individual in both experiencing and creating the human past.

It seems to me that Palaeopathology and the wider study of Burial Archaeology have a very special role to play in enlightening us about an individual's lifetime experience. For one thing we can usually focus on the physical individual in the past through burial archaeology in a way that settlement excavation rarely permits. And wherever bodily preservation permits detailed measurement we have the potential to observe not only the broad characteristics of that individual in bodily proportion, age and sex, but specific marks of that individual's life experience such as diet, disease, frequency of childbirth, pressures of work and frequency of injury.

If thus we can see one profitable way forward in the so-called PostPositivist Archaeology of the 1980's (Bintliff, 1988), it is still my own conviction that generalisations about the past should be our main goal. In this respect what should interest us is the relationship between the individual lifetime experience and that of his or her community, then of that community's lifetime experience to that of population groups at ever-wider geographical scales. Palaeopathology has indeed gone a long way in this direction with statistical comparisons of cemetery populations, and some exponents of the social 
analysis of burial assemblages (e.z. Randsborg, 1975) have explored aspects of cultural variability. Settlement archaeology has clearly a long way to go just to catch up!

I would like to conclude this paper with a final case study in burial archaeology that deals with shared or divergent lifetime experience within a regional community.

\section{The Iron Age cemeteries of Hallein and Hallstatt, Austria}

The discovery and exploration of these famous Austrian Early Iron Age cemeteries began during the last century. Both are large (Figure 11) with Hallstatt probably comprising well over 2000 burials, and both are in upland locations where the local salt and copper mines were clearly more important than farming and grazing. Not surprisingly therefore, these cemeteries are far wealthier in grave goods than typical cemeteries almost anywhere else in temperate Europe (Figure 12), and most authorities are agreed that this wealth accrued to the local communities concerned through the widespread trade in the salt they mined in the immediate vicinity of the cemeteries. Understandably, there has been a long-standing interest in the nature of the social organisation of these early industrial and commercial communities.

In 1958 Kromer Identifed in the Hallstatt cemetery three distinct 'classes', using grave goods and a claimed imbalance in the age and sex ratios: a warrior protector group, a technical/commercial group, and the heavy-labour mining population. Such a pronounced role differentiation suits the traditional view of these sites as marking the beginning of the capitalist division of labour and the modern type of economy.

However, a series of subsequent studies have quite undermined Kromer's reconstructions of this saltmining society (cf. the detailed discussion in Bintliff, 1984: Chapter 7). It now seems clear that both cemeteries are likely to represent natural populations from the region. However, during the Iron Age individual burials were assigned to one of several discrete clusters of burials within each cemetery, and these clusters in turn were used in parallel or overlapped in use with each other. Each cluster shows a broad spectrum of age, sex and relative wealth. As climatic conditions and the lack of permanent settlement evidence argue strongly for seasonal use of both cemetery/mining locations, it is suggested that each burial cluster represents a social group with a separate hamlet or village residence in agricultural districts down in the lowland zone. Each cemetery therefore incorporates the dead of several small settlements cooperating in seasonal upland mining.

Study of the mining zones has given further demographic indications: at Hallein it is suggested that some 50 men worked 5 seams, to which we would add a processing and off-site workforce, plus families for both groups: in all several hundred people. Hallstatt gives clearer burial numbers, suggesting a living community of some 450 people. 


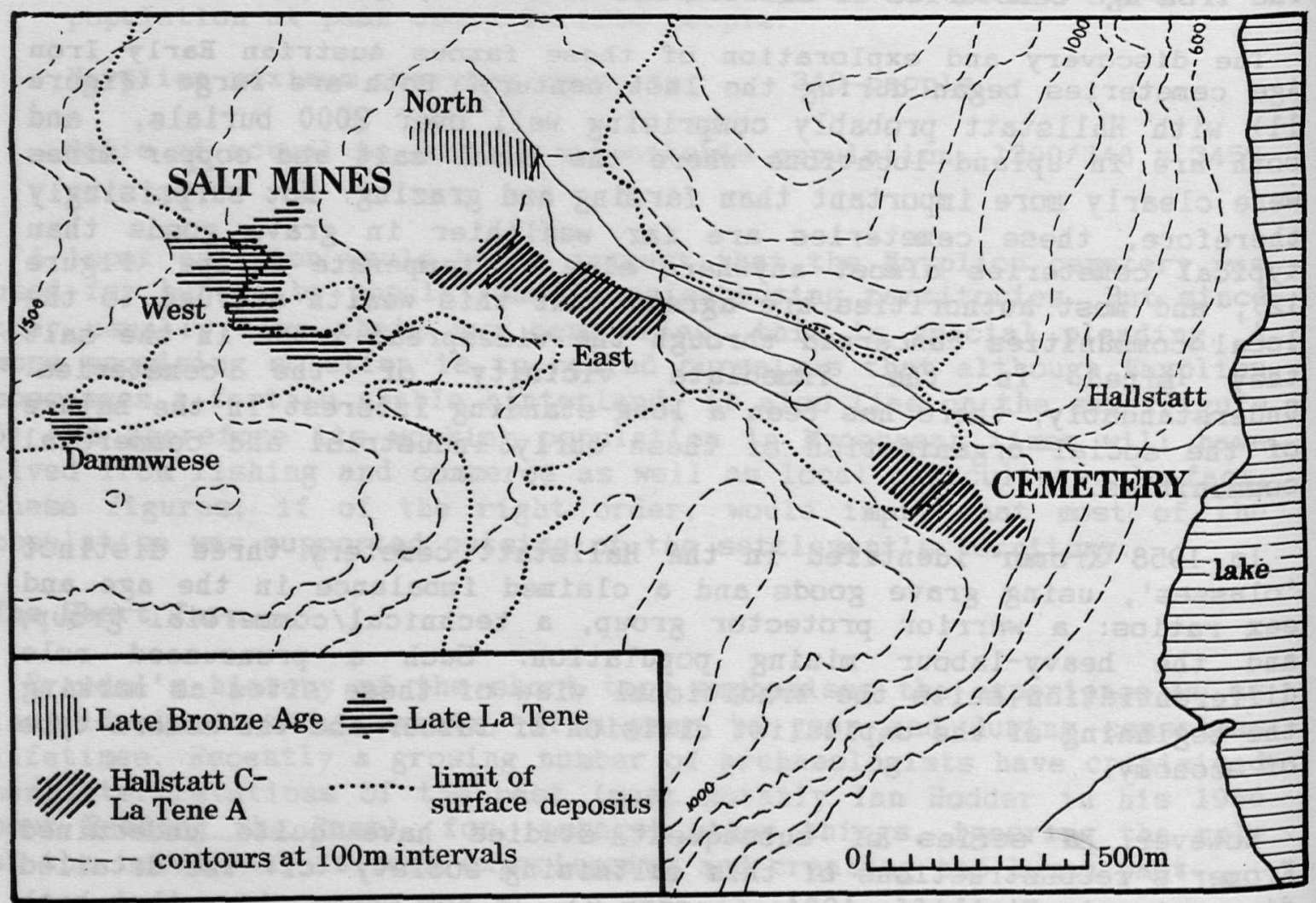

\section{Hallstatt}

Figure 11 Location map of the later prehistoric salt mines and cemetery at Hallstatt in Austria: (from John Collis The European Iron Age, Batsford 1984, figure 18). 


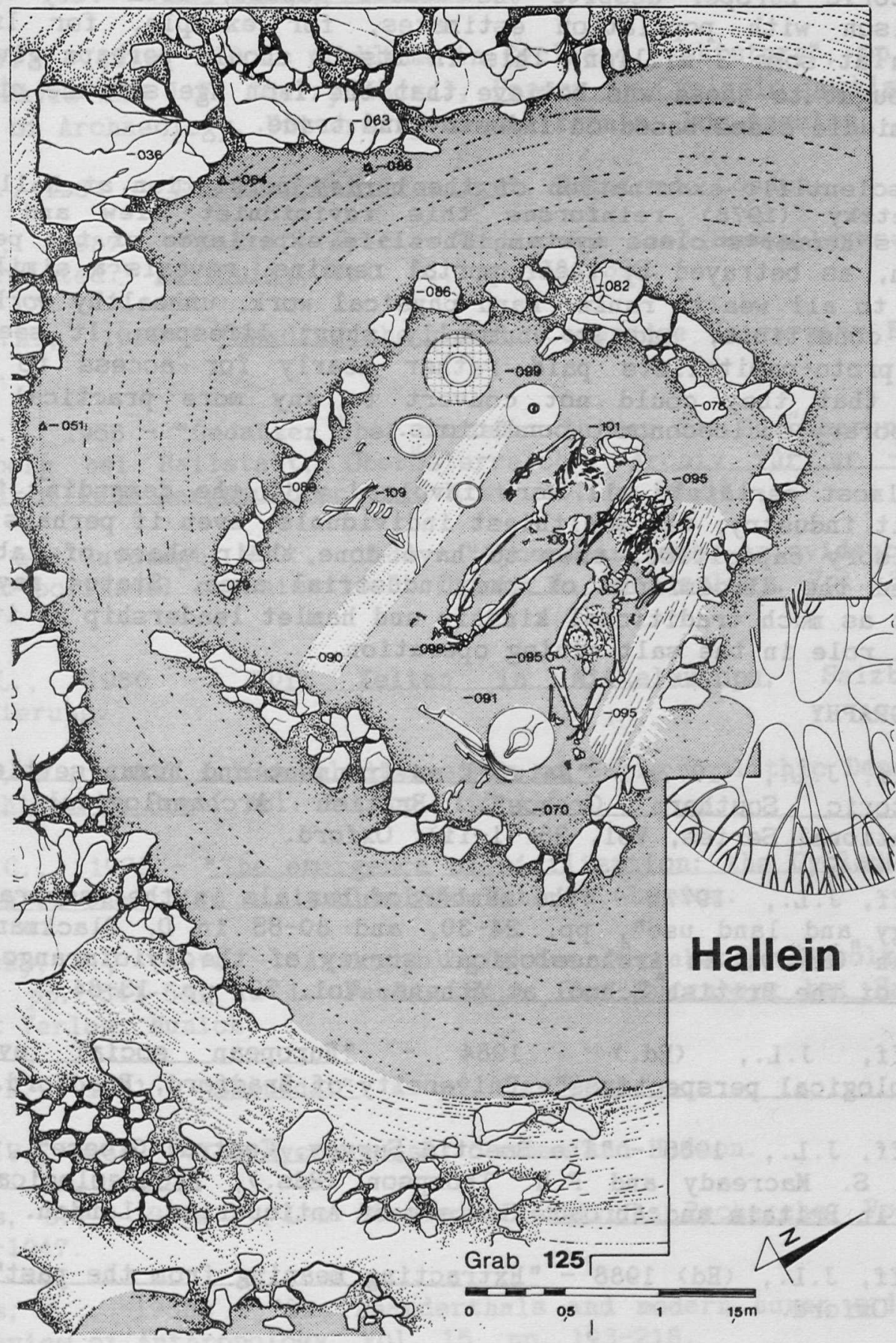

Figure 12 A typical wealthy burial mound excavated at the Iron Age cemetery of Hallein in Austria: (from L. Pauli ed. Die Kelten in Mitteleuropa, Salzburger Landesregierung 1980, p 176, figure 31). 
The more recent picture, then, is of rural populations from adjacent lowlands exploiting the salt deposits in the warmer times of the year. The numbers involved at two of the most important industrial sites in prehistoric Europe, despite the wealth gained, seem very small in comparison with population estimates, for example, for Iron Age Britain at some 2 million. This in itself should perhaps give pause for thought to those who believe that the Iron Age saw the rise of a large middle class based on industry and trade.

The scientific examination of the buried population at Hallein by Schwidetzky (1978) reinforces this revisionist view and further destroys Kromer's class system. The life experience of the people of Hallein, as betrayed by their mortal remains, reveals a similar life common to all wealth ranks: hard physical work, unhealthy working and living conditions, and an unusually short lifespan. It seems that these proto-capitalists paid rather dearly for access to display wealth that they could not convert to any more practical use in contemporary socioeconomic conditions.

So almost certainly all were involved with the demanding tasks of the salt industry; the wealthiest individuals, even if perhaps in more supervisory capacities, seem to have done their share of labour and suffered the discomforts of the industrial area. Status may indeed reflect as much traditional kinship and hamlet leadership as it does a special role in the salt mining operation.

\section{BIBLIOGRAPHY}

Bintliff, J.L., 1977 a - "Natural environment and human settlement in Prehistoric Southern Greece". British Archaeological Reports, International Series, Vol. 28 (i-ii). Oxford.

Bintliff, J.L., $1977 \mathrm{~b}$ - "The number of burials in the Messara tholai, Pedology and land use", pp. 24-30, and 80-83 in D. Blackman and K. Branigan (Eds.), An Archaeological survey of the Aylofarango Valley. Annual of the British School at Athens, Vol, 72, pp. 13-84.

Bintliff, J.L., (Ed.) 1984 - "European social evolution: archaeological perspectives". University of Bradford, Bradford.

Bintliff, J.L., 1985 - "The Boeotia Survey, Central Greece", pp. 196216 in S. Macready and F.H. Thompson (Eds.), Archaeological Field Survey in Britain and Abroad. Society of Antiquaries, London.

Bintliff, J.L., (Ed) 1988 - "Extracting meaning from the past". Oxbow Books, Oxford.

Bintliff, J.L., (Ed,) forthcoming - "The Annales School and Archaeology."

Bintliff, J.L. and Snodgrass, A.M., 1985 - "The Boeotia Survey, a preliminary report: the first four years". J. Field Archaeology, Vol. 12 , pp. $126-161$. 
Bintliff, J,L, and Snodgrass, A.M., 1988 - "Mediterranean survey and the city". Antiquity, Vol. 62, pp. 57-71.

Boule, M. , 1920 - "Les Hommes Fossiles". Masson, Paris.

Cherry, J.F., 1979 - "Four problems in Cycladic prehistory", pp. 2247 in J. Davis and J.F. Cherry (Eds.), Papers in Cycladic prehistory. Institute of Archaeology, University of California, Los Angeles.

Coll1s, J., 1984 - "The European Iron Age", Batsford, London.

Foley, R., 1987 - "Hominid species and stone-tool assemblages: how are they related?" Antiquity, Vol. 61, pp. 380-392.

Hodder, I.A., 1986 - "Reading the past". Cambridge University Press, Cambridge.

Kromer, K., 1958 - "Gedanken über sozialen Aufbau der Bevölkerung auf dem Salzberg bel Hallstatt, Oberösterreich". Archiv für ur - und frühgeschichtliche Bergbauforschung, Mitt. 13, pp.39-58.

Mee, C.B. and Cavanagh, W.G., 1984 - "Mycenaean tombs as evidence for social and political organisation". Oxford J. Archaeology, Vol. 3, pp. 45-64.

Paul1, L., 1980 - "Die Kelten in Mitteleuropa, Salzburger Landesregierung.

Randsborg, K., 1975 - "Social dimensions of Early Neolithic Denmark". Proc. Prehistoric Soc., Vol. 41, pp. 105-118.

Renfrew, C., 1972 - "The emergence of civilisation: the Cyclades and the Aegean in the third millenium BC". Methuen, London.

Schwidetzky, I., 1978 - "Anthropologie der Dürrnberger Bevälkerung, Beitrag", pp. 541-581 in L. Paull (Ed.), Der Dürrnberg bel Hallein II. Beck Verlag, Munich.

Solecki, R., 1971 - "Shanidar". Knopf, Hew York.

Taylour, W., 1964 - "The Mycenaeans", Thames and Hudson.

Trinkhaus, E., $1986 a$ - "Les néandertaliens". La Recherche, Vol. 17, pp. 1040-1047.

Trinkhaus, E., 1986b - "The neanderthals and modern human origins". Annual Review of Anthropology, Vol. 15, pp. 193-218.

Wagstaff, J.M. and Cherry, J.F., 1982 - "Settlement and population Change", pp. 136-155 in C. Renfrew and M. Wagstaff (Eds.), An 1sland polity. The archaeology of exploitation in Melos. Cambridge University Press, Cambridge. 
Whitelaw, T.M. 1983 - "The settlement at Fournau Korifi, Myrtos and aspects of Early Minoan social organisation", pp. 323-345 in 0 . Krzyszkowska and L. Nixon (Eds.), Ninoan society. Proceedings of the Cambridge Colloquium 1981. Bristal Classical Press, Bristol. 


\title{
CORPUTERS AND BURIAL ARCHAEOLOGY
}

\author{
J.D. Richards \\ Department of Archaeology, \\ University of York, \\ Micklegate, \\ York, \\ Y01 $1 \mathrm{JZ}$
}

\section{Introduction}

The computer is fust a tool - some would say useful; some dangerous. But its rightful place should be no more elevated than that of the trowel or the wheelbarrow, the camera or the microscope. Indeed, it could be argued that 1 ts use should not be considered a fit subject for academic debate, any more than one might expect significant contributions on "The wheelbarrow and burial archaeology" or "The dumpy level and modelling mortuary behaviour". Where the use of a tool is considered routine there seems little justification for discussing $1 t$.

There could, however, be two reasons for discussing the application of computers to burial archaeology.

Firstly, it could be that the computer is a novel tool and its use is not yet routine, and that there is still room for the computer evangelist to spread the word about the joys of late night programming in FORTRAY. There may be some truth in this but the other papers in this volume confirm the hope that computers are now being widely employed in burial archaeology.

The second reason could be that the 1 mpact of the computer is not simply to allow more archaeology to be done more quickly but to change actively the nature of the archaeology that is done. This, I will argue, is the case. Indeed, I contend that archaeological investigation is not just theory-led; to some extent it is also technology-driven. The introduction of a new item of technology, by making certain forms of recording and analysis possible, influences the theoretical interests of the discipline (see Richards, 1986). This Is certainly true of the application of computers to burial archaeology where the quantity of data has defied traditional approaches.

In this paper I shall look firstly at what is made possible by the introduction of computers. Secondly I shall say a little about methodology, although just as I would not dare describe how to use a wheelbarrow I will not presume to waste the reader's time by describing what a computer is or what it does (see Richards and Ryan, 1985 for a summary and further references). Thirdly, turning to the realities, I shall describe some results from my own analyses of burial using computers, and finally discuss some of the limitations. The application of computers to human skeletal analysis will not be described; the emphasis here will be upon the application of computers to burial as a cultural phenomenon. 
Expectations of computers

More perhaps than any other item of technology, computers have the power to raise false expectations. This is partly the result of High Street sales hype, partly of computer mystique and of mistaken 1deas of artificial intelifgence, owing more to science fiction than science fact. Computers can do things that human beings can't - despite increases in average life expectancy the human capacity for tedium is still fairly restricted. But they can only do things which human beings can define. Thus their potential is ilmited by our ability to define a sequence of operations required to perform a given task.

In order to examine the role of the computer it is important that we ask why we are looking at burials at all. A general danger of computers is that style can come to dominate content. Just as laserprinting can lend authority to a note scribbled on the back of an envelope so $1 t$ is with all aspects of computer work. The medium must not be allowed to take precedence over the message, and a particularly trendy form of computer analysis performed just because "the software was there". The technology may influence the theory but it cannot determine $1 t ;$ we must always keep the goals of our work to the forefront.

I assume that, as archaeologists, we are interested in the patterning in material culture arising from aggregated human behaviour. Our aim is to describe and explain that patterning. Our principal expectation of the computer, therefore, is that it will help us explore novel and existing ways of investigating patterning in burials.

As archaeologists we generally recover up to four components of a burial: the grave structure or container (including tombs, coffins and cremation vessels), the skeletal remains, and two categories of artefact: those which were physically associated with the corpse (such as dress fastenings) and became incorporated in the burlal fill almost by accident, and those which can be identified as deliberately selected grave goods added to the burial by the mourners. Patterning may be detected in the associations between any two or more of these categories.

Patterning can also exist on three different levels: between and within cemeteries, and within individual burials. The computer can help detect patterning at each level.

Firstly, there may be patterning at a landscape level, or in the relationship between cemeteries and other landscape features (including both human and environmental aspects). The nature of the burial rite may also be seen to vary regionally, in the treatment of the corpse or the types and quantities of cultural artefacts included with the burial. Secondly, there may be patterning within the cemetery, in the layout and relationships of the individual burials. Thirdly, there may be patterning within an individual burial. This includes not just the presence or absence of specific 1tems but also their spatial arrangement within a grave. Confronted with such a 
wealth of material in which to look for patterning the main problem is what to record and analyse.

With burlals we are generally dealing with a large number of individual cases, a cemetery, with limited variation between the burlals. It is usually straightforward to devise a coding system defining a series of attributes which are common to each burial. The difficulty comes in defining what to record and where to draw the Iine. There are, in theory, an infinite number of attributes which might be measured. In practice, what we choose to record will be a result of our research goals, our understanding of human behaviour from our archaeological training and our assumptions about what may be significant.

The general rule in recording any archaeological material must be to record in as much detail as possible at the highest scale of measurement possible. Thus, for example, if we can measure the orlentation of a grave in degrees we should not reduce $1 t$ to cardinal compass points. Similarly, if we can record the number of artefacts in each grave we should not record them as rich, average and poor. The computer can always be used to deduce such groupings at a later stage, If they turn out to be meaningful.

The importance of training and accepted wisdom in this classification process should not be underestimated. A group of untutored first year undergraduates were given a set of plans of graves and lists of their contents, and simply told to "devise a coding system which adequately described them". Most 1gnored the presence or absence of individual types of artefact and simply counted up the total number of objects. On the other hand the students described in minute detail which individual bones were present, oblivious to the effects of post-depositional disturbance and decay.

\section{Nethodologies}

Having recorded the burlals it is then necessary to identify which computer techniques might be employed to detect patterning.

The traditional method is to use statistical aids to describe patterning and search for associations. Generalised statistical packages now come in many shapes and sizes for all types of computer. There is even a cemetery statistics package, funded by the S.E.R.C., developed at the Institute of Archaeology in London, and available over JANET, the university electronic network (Hodson and Tyers, 1988). All statistical packages must be used with care unless one's research is to hasten the depletion of the Amazonian rain forests. When told to cluster, a clustering program will do fust that whether or not the data can really be grouped. Similarly, a test for association between each attribute and every other attribute is bound to turn up some significant results by the laws of probability. For this reason one should work within a deductive rather than inductive framework.

Database management systems can also help in the recognition of patterning in the data. A good database system allows the user simply 
to browse through the data, perhaps checking an idea before submitting it to some form of statistical test. Techniques of database design mean that the data can be stored just once but that many different specialists, each with their own requirments of the data, can each maintain their own model of the data organisation. But it is essential that the possible needs are planned from the start of a project, that the database is built up as the project progresses, and that it is budgeted for from the start.

Increasingly, techniques of EDA (or Exploratory Data Analysis) are being adopted. Data is seen as consisting of a "rough" and a "smooth" component. The rough element will frequently be meaningless background noise. The task of the analyst is to 1solate the smooth element as objectively as possible. Descriptive statistics may be of less value than visual and graphical means of detecting patterning. Three dimensional computer graphics may help in discovering trends in the data (Reilly and Richards, 1988).

Finally, techniques of Geographic Information Systems (GIS) may be used to explore the relationship between burials and other landscape features. A GIS is a type of database in which spatial data of different types can be held in different layers, cross-referenced by $x$ and $y$ co-ordinates, such as Ordnance Survey national grid coordinates (Harris, 1986). This technique enables us to exploit the mass of information about the distribution of burials already held in computerised national and county sites and monuments records.

\section{Realities}

In considering the realities it may be helpful to look at an example from my own research on Anglo-Saxon burlal (Richards, 1987).

This study started from a general theory about material culture and mortuary behaviour which it was proposed to apply to Anglo-Saxon cremation burial. The theory led to a number of hypotheses about Anglo-Saxon burial, which were refined into testable hypotheses. A method was defined and a test applied, thereby confronting the data.

(i) The general theory was that of structuralism, as derived from anthropology, and the works of archaeologists interested in the area, in particular those working on mortuary symbolism.

(11) The hypothesis proposed was that the Anglo-Saxons used symbols to make statements about the 1dentity of their dead, in particular, that the form and decoration of a cremation urn was related to the identity of the occupant, and might be read like a memorial gravestone, if only we could understand the code.

(1ii) This may be translated into a testable hypothesis that grave goods and. skeletal types will not be randomly distributed through types of pots, but that particular grave good classes, and particular age and sex groupings will be found to be associated with particular styles of pottery. 
(iv) The method used was to define types of pot and types of grave goods, and utilise skeletal information where avallable. Of the three, classifying the pottery was the most difficult. The process could never be completely objective, but subjectivity could be reduced by describing form and decoration at as fine a level as possible, rather than pre-selecting attributes.

As has already been noted, the advantage of the computer is at least that it allows disagreement. Assumptions have to be clearly stated and are there for others to see and criticise.

The help of the computer was then enlisted in deciding which attributes were significant, that is, meaningful to the Anglo-Saxons. A pilot sample of $c .500$ vessels from three recent excavations was recorded at as detailed a level as possible, and then the computer was used to test which attributes of form and decoration were correlated with either grave goods or skeletal groupings.

(v) On this basis the method could then be redefined for the full sample of 2440 vessels from 18 sites, including old and new excavations. Only those attributes which had been found to be correlated with other features were now recorded. The initial hypotheses could then be tested against the total sample.

(vi) This is not the place to describe the results in any detail, but it may be helpful to give a few examples.

Firstly, for burlals where the age of the deceased could be Identified from skeletal remains, it was demonstrated that the size of a cremation vessel was directly in proportion to the age of the occupant, although the relative status of the deceased has also to be taken into account. Adult females, for example, are not generally burled in such tall vessels as adult males. From this it should be possible to provide a rough age, within a definable margin of error, for the occupant of vessels where no skeletal remains survive, or were recorded, being particularly those from older excavations.

Secondly, the use of incised decoration was demonstrated to be closely tied to the identity of the deceased. Nearly every motif was slgnificantly correlated with at least one class of grave good. Again then, aspects of the decoration of a pot can be used to predict details of the social identity of the deceased, even when the presence or absence of grave goods has not been recorded.

The arrangement of the incised decoration, including both the number of motifs, and thelr layout, appear to be less important as an Indicator of the identity of the deceased. S1milarly, the average number of lines used in a motif also appears to be irrelevant in marking the occupant. All these attributes seem to be related to the identity of the potter, rather than that of the deceased.

Thirdly, cremation grave goods do not appear to be directly correlated with either age or sex groupings. For 188 urns which contained sexed skeletal remains and at least one of 19 possible classes of grave goods, only 3 grave good types were sex-11nked at 
above the 0.1 significance level and only one above a 0.05 level. These were miniature shears and tweezers, correlated with males, and ivory, correlated with females - and each of these 3 did occur with both male and female cremations. No other items, including brooches, glass beads and spindlewhorls were sex-linked.

On the other hand the form and decoration of vessels were significantly correlated with many classes of grave good. Some objects which were found to be especially associated with particular classes of vessel could now be identified to be deliberate grave goods, rather than artefacts which had been incorporated in the burial by accident. Worked flints, for instance, were common in narrow-necked vessels. So were miniature tweezers and shears.

The overall impression was of society with a highly complex iconography and finely divided but well defined social roles, of which biological age and sex formed just two components. In order to disentangle that complexity, the use of the computer was seen as being essential. The multiple variables of such a large sample could not have been tackled by manual methods.

\section{Linitations}

Finally, I was asked to look at some of the limitations of applying computers to burials. I don't wish to dwell here upon the pragmatic limitations of acquiring the funding to buy a computer, or finding the trained staff to use one. These are doubtless real problems but if the value of the computer can be demonstrated then I believe these problems can be overcome.

Rather, it is important to consider some of the theoretical difficulties in using computers to detect patterning. These are largely problems arising from the quality of the data. It may be that the wrong variables have been recorded, or that the sample size is too small, or there may be too much background nolse preventing the detection of patterning. There are, of course, a host of depositional and recovery transforms which act as filters between patterning as transmitted by past human behaviour and the patterning as percelved by us. I have argued elsewhere that it is possible to use the computer to quantify the scale of some of these distortions, and that each variable should have an associated flag indicating the degree of confidence with which it can be believed - equivalent to the probable, likely and possible of the skeletal blologist. By taking into account the research interests and theoretical frameworks of previous generations it is possible to make use of quite low quality data.

For instance, the reliability of the identification of a site as an Anglo-Saxon cemetery - rather than Roman or Medieval - will be directly related to the date of discovery. Confidence factors may therefore range from $75 \%$ of those graves with weapons recorded in the Meaney gazetteer (1964) to $99 \%$ of those discovered today. Certainty as to site location may be as high as $90 \%$, but confidence that a site has been completely excavated may be as $10 \mathrm{w}$ as $25 \%$. Confidence in the number of graves recorded will vary: perhaps $90 \%$ of those with grave goods will have been recorded, falling to $25 \%$ of those without. The 
rellability of the number of objecte found within a grave will be very low for organic objects for old excavations, say $5 \%$, rising to only $25 \%$ for modern excavations. Figures for inorganic objects may be considerably higher - perhaps $90 \%$ for rich items, and $75 \%$ for poorer items such as iron blades.

By computerising these probabilities, modelling techniques may be used to reconstruct original populations, within a quantifiable degree of accuracy. Falrly low quality old data (of which we have lots for Anglo-Saxon England) can then be utilised (see Huggett and Richards, forthcoming).

I would nevertheless argue that in order to exploit the maximum potential of computerised pattern recognition we need high quality data, with large sample sizes, and wherever possible skeletal data to help interpret patterning.

\section{BIBLIOGRAPHY}

Harris, T.M., 1986 - "Geographic information system design for archaeological site information retrieval", pp. 148-61 in Computer Applications in Archaeology. Birmingham.

Hodson, F.R. and Tyers, P., 1988 - "Data analysis for archaeologists: the Institute of Archaeology packages", pp 31-41, in S.P.Q. Rahtz (Ed), Computer and quantitative methods in archaeology, 1988. British Archaeological Reports, International Series Vol.446. Oxford.

Huggett, J. and Richards, J.D., (forthcoming) "Inhumation and cremation; the computer at work".

Meaney, A.L., 1964 - "A gazeteer of early Anglo-Saxon burial sites" London.

Reilly, P. and Richards, J.D., 1988 - "New perspectives on Sutton Hoo: the potential of 3-D graphics", pp. 173-185, in C.L.N. Ruggles and S.P.Q. Rahtz (Eds), computer and quantitative methods in archaeology, 1987 British Archaeological Reports. International Series, Vol. 393. Oxford.

Richards, J.D., 1986 - "Computers in archaeological theory and practice", pp. 51-55 in J.A. Bell, G.R. Lock and P. Rellly (Eds), Sclence and Archaeology, Vol. 28.

Rlchards, J.D., 1987 - "The signiflcance of form and decoration of early Anglo-Saxon cremation urns". British Archaeological Reports. British Series, Vol. 166. Oxford.

Richards, J.D. and Ryan, N.S., 1985 - "Data processing in archaeology". Cambridge. 
COMPUTERISED RECORDIIG AND ATALYSIS OF EXCAVATED HUMAT DEITAL REMAINS

Wilbert Bouts and Tjeerd Pot

Hinthamerstraat 153

5211 MK's-Hertogenbosch

The Netherlands

\section{Introduction}

Each excavated human dentition can be considered as a personal archive. It contains information on endogenous and exogenous processes Whose effects accumulated during iffe. These can be read and interpreted. The information which can be retrieved from the dentition pertains to two periods:

A. THE PREFUNCTIOHAL PERIOD : (PRE-) ERUPTIVE INFORMATION

$$
\begin{aligned}
& \text { Physiological } \\
& \text {-morphology } \\
& \text {-developmental stage }
\end{aligned}
$$
a. of the Jaws
b. of the teeth

B. THE FUHCTIONAL PERIOD: POST-ERUPTIVE INFORYATION

\section{Physiological}

-attrition

-occlusal, proximal

-alveolar resorption

\section{Pathological \\ - developmental disturbances \\ -eruptive disturbances}

Pathological

-caries

-peri-apical bone lesion

-antemortem tooth loss

- alveolar resorption

-trauma (abrasion, fracture)

- dental calculus

The primary task of palaeo-odontological research is to extract the above data from the excavated human dentitions, to interpret them and to present these interpretations in a meaningful manner to the archaeologist. The data represent the interaction between the (growing) dentition on the one hand, and on the other exogenous biological, biochemical and mechanical factors of wear and deterioration. Seen in the light of this dynamic equilibrium they contribute to a better understanding of everyday life, feeding patterns, and activities in which the dentition is used. Moreover, they can give information on the age at death of the individuals and thus on the demography of ancient populations.

For this purpose, the original data as well as their interpretations must be made accessible. However, the large amount of dental material which can be produced by excavation is difficult to handle and to analyse in a standardised manner. The expertise of highly specialised scientists is required to evaluate the dentitions and the skeletal remains. Statistical analysis of the data is often time-consuming; it is necessary to extract the data from their records and to rearrange 
them, introducing amongst athers the risk of errors and inconsistencies. Moreover, differences in method between the various scientists often preclude comparisons between their respective results.

The use of automated database systems for this type of research would offer new opportuntties for more elaborate analyses and comparisons, while maintaining direct control over the original data records. If the registration and recording of the primary skeletal data is performed by a trained scientist, their subsequent analysis can be performed in co-operation with a statistician and the archaeologist. In this way, a true multidisciplinary approach is realised.

\section{Automated registration}

As a first step in this direction, the graphical registration of dental data was introduced (Perizonius and Pot, 1981). To facilitate a detailed recording of the existing teeth and jaw bone, and to score physiological and pathological phenomena, a dental data form was designed. On this form, caries, attrition and periapical bone lesions can be recorded by pictograms, numbers and symbols. In this way the general dental status of each individual can be appreciated at first glance. However, the completion of such a form proved to be a laborious and tedious task, and for publication, the entire form had to be redrawn by a skilled graphical artist.

In addition, this method does not solve the above mentioned problems of data retraction for statistical analysis and mutual comparability of the applied methods.

For an efficient registration and recording, a combination of the graphical forms and a database system should be used. With the original data form in mind, a new one was designed, which would allow automatic registration of the visualised data in an alphanumerical database (Figure 1). For this purpose, a graphical programme was developed, which acts as a bi-directional translator of the graphical input and the appropriate codes in the database. The programme, intended for use on IBK-PC/XT/AT and true compatibles, is written in Turbo Pascal 4.0, occuples about $260 \mathrm{~K}$ of memory, and is compatible with the various graphical standards currently available. A demonstration version, without the database facilities, can be delivered upon request.

The programme enables the researcher to record the data from the jaws and teeth in a way which closely resembles the earlier designed form and adds extra possibilities for automated selection and other database functions, as well as the automated production of cameraready forms. To achieve this goal, the input of data 15 based on a graphical representation as it was in the hand-completed form (Figures 1 and 2).

Several alterations, necessary for automated processing of the data are introduced in the new form. As a result of these modifications the number of registrable qualifications is increased. Most of the symbols 


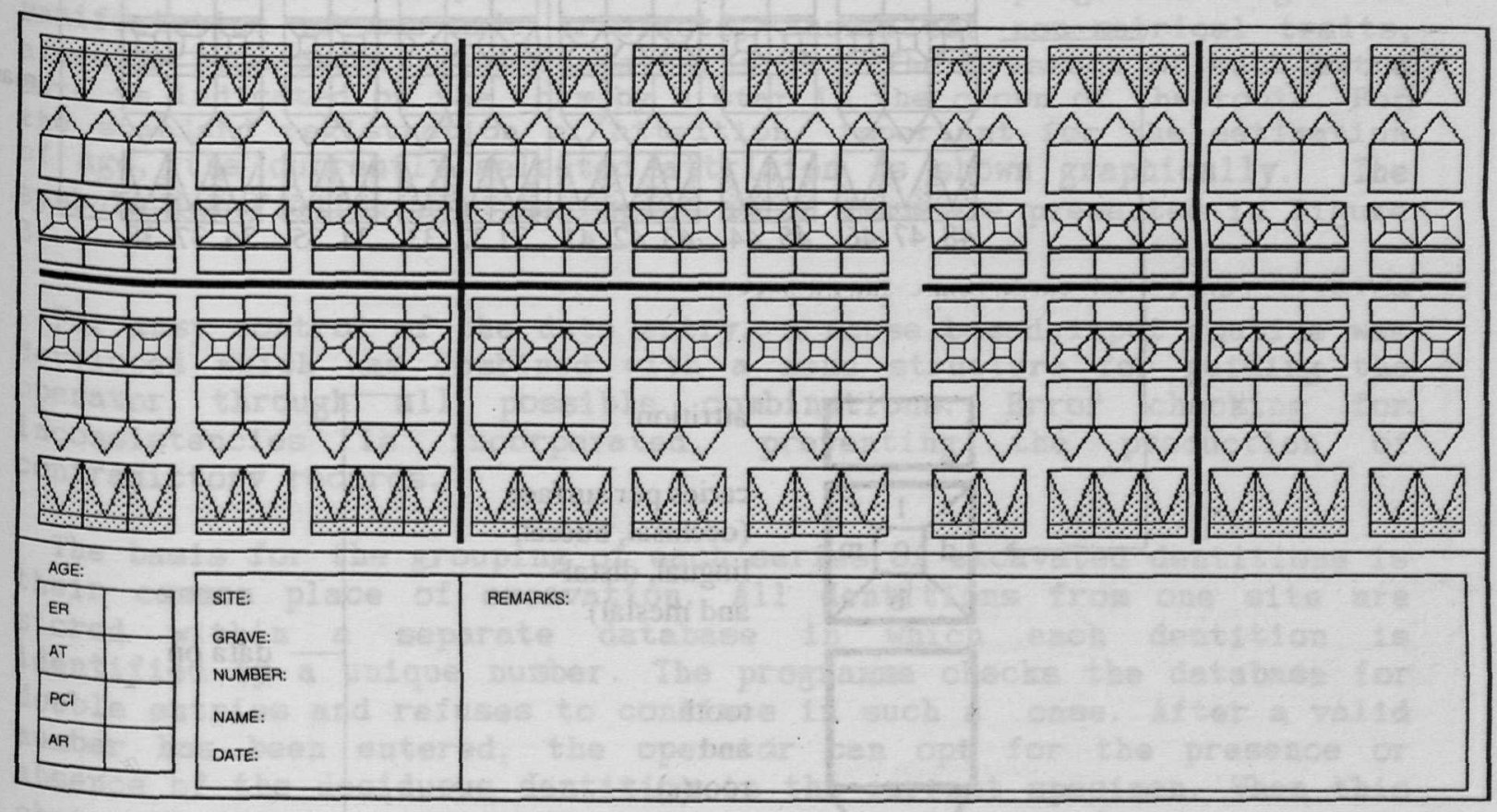

\footnotetext{
Higure 1 The blank form for the registration of both the deciduous and loft permanent dentition; as it appears on the screen. In the lower dot colum the characteristics can be indicated on which the age a) Volnation is based (eruption, attrition, PC1-index (see below) or -olar resorption).
} 


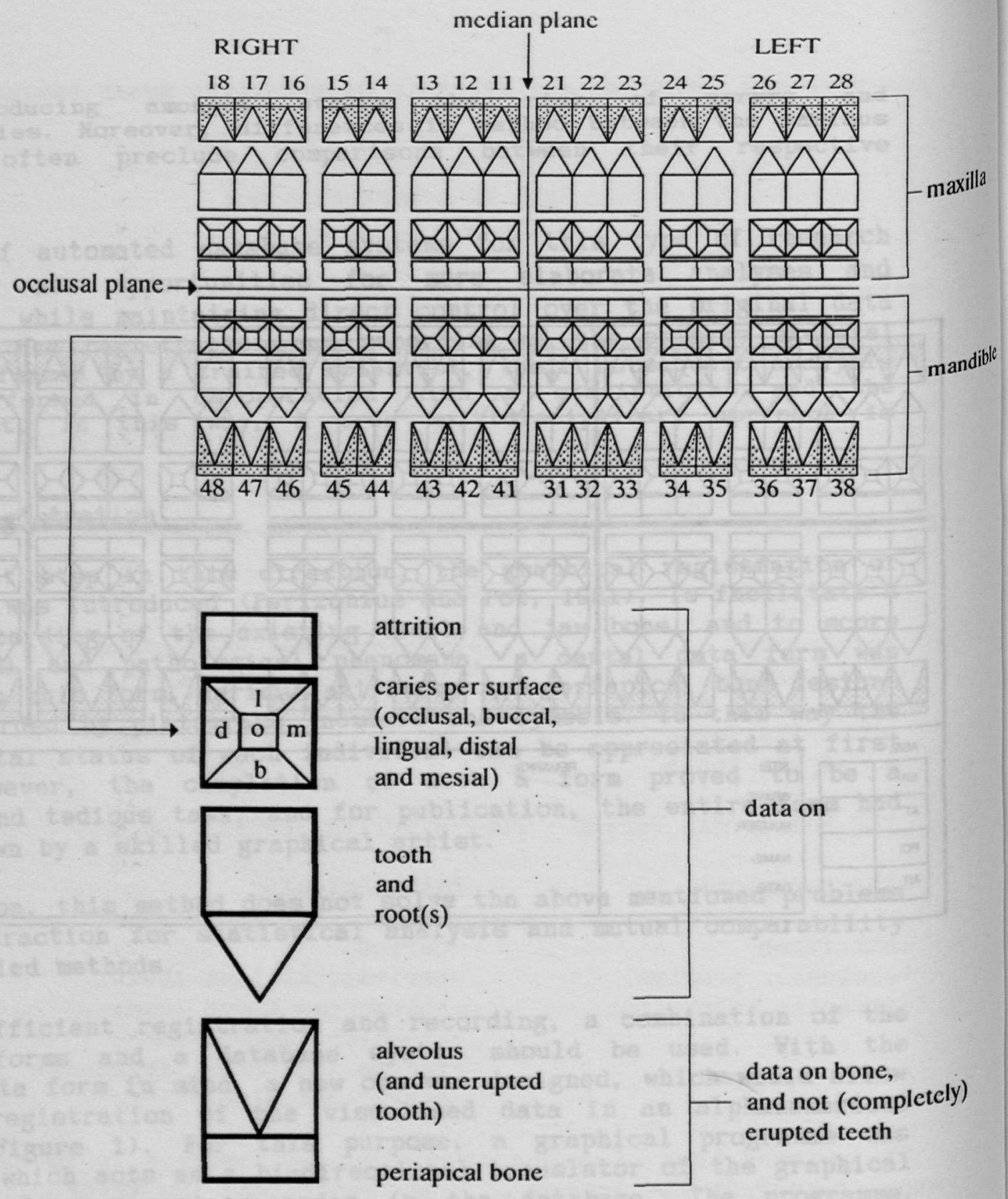

Figure 2 The key to the dental registration form. 
were left as they were, but the possibility of inserting data on calculus, and extra space for a separate recording of data on tooth roots and unerupted elements have been added. As an additional effect this produced the opportunity to record the alveolus in a visually more understandable way. Furthermore, the possibility was included to record extra data for every individual tooth. This special data option provides the opportunity to add new classifications to the database which are not incorporated in the standard programme e.g. the manifestation of man-made artefacts, anomalies, non-metrical traits, alveolar resorption, fissure patterns etc. The presence of such extra data is indicated on the form by a star in the crown of the tooth. For the standard registration of attrition, important for the estimation of age, the currently selected attrition is shown graphically. The symbols for filling out the registration form are presented in Figure 3.

For easy control of the data entry, a mouse based input routine was developed which was combined with a menu structure for guiding the operator through all possible combinations. Error checking for inconsistencies is incorporated, preventing the production of contradictory records.

The basis for the grouping of each series of excavated dentitions is their common place of excavation. All dentitions from one site are stored within a separate database in which each dentition is identified by a unique number. The programme checks the database for double entries and refuses to continue in such a case. After a valid number has been entered, the operator can opt for the presence or absence of the deciduous dentition in the current specimen. When this choice has been made, data entry can start by selection of the individual dental elements, either by cursor control from the keyboard or by mouse selection. The element of choice is selected and copled Onto a work area. At this stage, the operator can select several Options: tooth data, bone data and extra data. Once a selection has been made, the next level of the menu is displayed, which now shows the various types of data which can be recorded (Figure 4).

All options can be selected by the cursor or by mouse movements from the individual menus. They can also be entered directly from the keyboard. Data are stored internally in a temporary buffer, which can be written into the database using the file utility menu. The database format is either a compressed internal format for optimal disk space preservation, or a dBase III compatible ASCII file format for external use of the database contents. Routines for conversion between both formats are provided.

Additional information on every dentition can be stored in a note Which cannot be used for indexing the database. After the dentition data have been stored in a file, the file can be viewed on the basis of the identification numbers, or sequentially, by manual control of the pages. The entries in the database can be marked and copied into a hew file, thus enabling the operator to make manual selections of the registered dentitions. 
data on crupted teeth

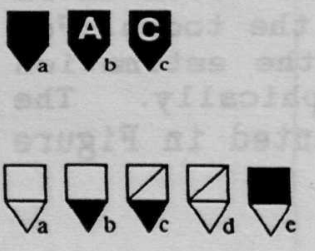

ts) absent

a. cause unknown

b. by ante-mortem tooth loss

c. congenitally

a. tooth \& root(s) present

b. element present without root(s)

c. fractured element without root(s)

d. fracured element with root(s)

e. only root(s) present

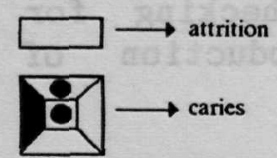

24 scale (see fig 6)

unassessable

$\square$ surfaces without caries

[D carious surface

surface not assessable
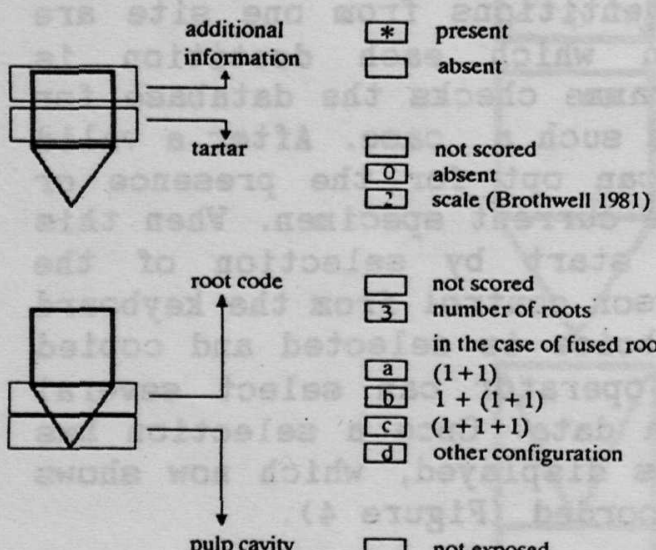

$\square$ not scored

number of roots

in the case of fused roots:

a $(1+1)$

[b] $1+(1+1)$

[c] $(1+1+1)$

[d] other configuration

pulp cavity

not exposed

exposed data on bone and

not (completely) erupted tecth

bone absen

open alveolus present

(post-mortem tooth loss)

no alveolus present

(ante-mortem tooth loss

or congenitally absence)

$\nabla$

observed not (completely) erupted element

27 assumed not (completely) erupted element

7 loose not (completely) erupted element

- periapical bone absent

periapical location observable, lesion absent

[0. periapical location observable, lesion present

periapical location invisible (usually because the tooth could not be removed from the alveolus) a completely erupted tooth

Figure 3. The picture-symbols for filling out the registration form. 


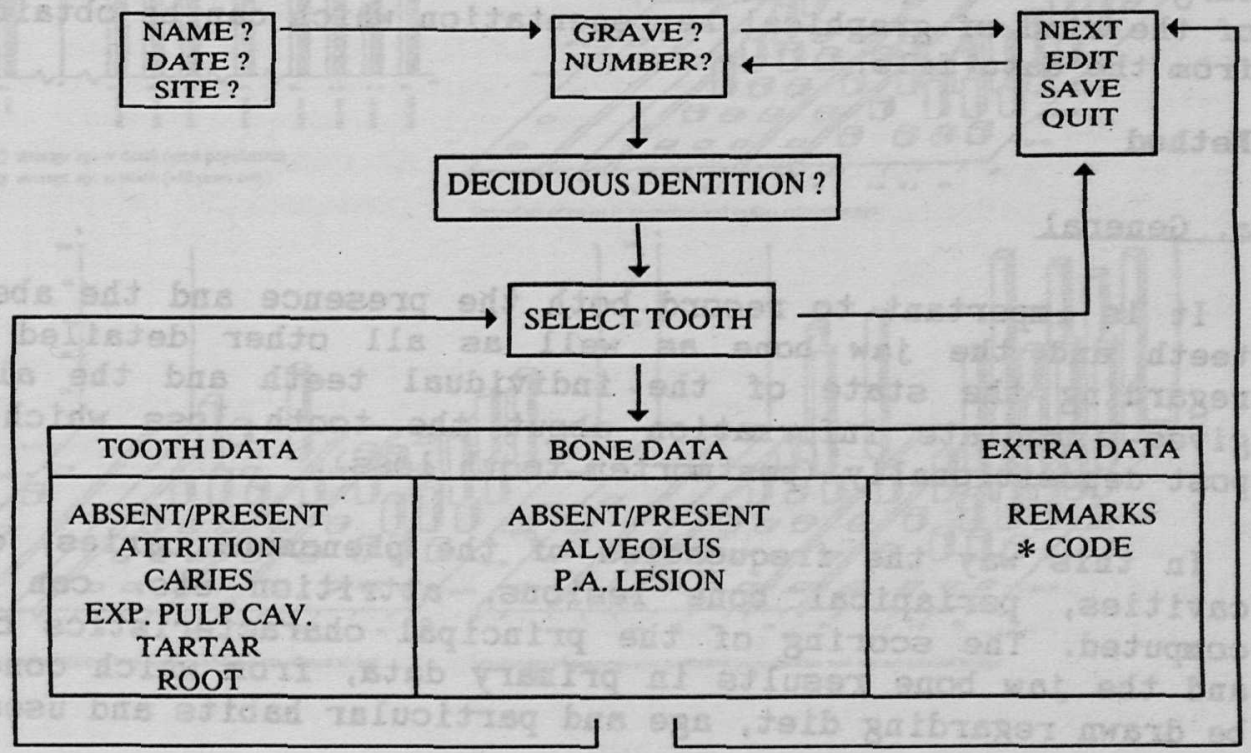

Figure 4. Flow chart of the registration procedure. 
Statistical and graphical possibilities

The dBase III compatible ASCII file format enables the user to enter data from the file into most current statistical and graphical computer programmes e.g. SPSSPC+, SAS, LOTUS, Harvard Graphics, Microsoft Chart etc. In this way the analysis and mutual comparison of large dental samples becomes possible. In Figure 5 an example is given of the kind of graphical representation which can be obtained directly from the data file.

Nethod

\section{a. General}

It is important to record both the presence and the absence of the teeth and the jaw bone as well as all other detailed information regarding the state of the individual teeth and the alveoli. This gives immediate information about the tooth loss which took place post-depositionally (postmortem tooth loss).

In this way the frequencies of the phenomena carles, exposed pulp cavities, periapical bone lesions, attrition etc. can be reliably computed. The scoring of the principal characteristics of the teeth and the jaw bone results in primary data, from which conclusions can be drawn regarding diet, age and particular habits and uses.

In the following section the standards will be described for scoring attrition, caries, peri-apical bone lesion and dental calculus in order to obtain a uniform system. In the subsequent paragraph the interpretation of the collected data in terms of age estimation will be explained.

\section{b. Attrition}

At a certain time the erupting teeth (or elements) will meet their antagonists and finally the complete dentition is arranged into occlusion.

As a result of mastication the teeth will start to wear down. Under normal circumstances this is a continuous and progressive process and the amount of attrition can be viewed as a reflection of the extent of the functional period of the tooth.

When an excessively high rate of attrition is observed for one (or a few) specific element(s), usually an exogenous cause ather than mastication can be suggested. In such a case the phenomenon is called abrasion. An excessively low rate of attrition, on the other hand, is the result of disturbances in the articulation initiated by for example, painful caries, inflammation, antemortem tooth loss etc. In the latter case the attrition process is disturbed or completed.

Brothwell (1981) designed a method for scoring attrition which is based on his investigation of Neolithic to Medieval British skulls. However, in this system, which is widely used, only molar attrition is 


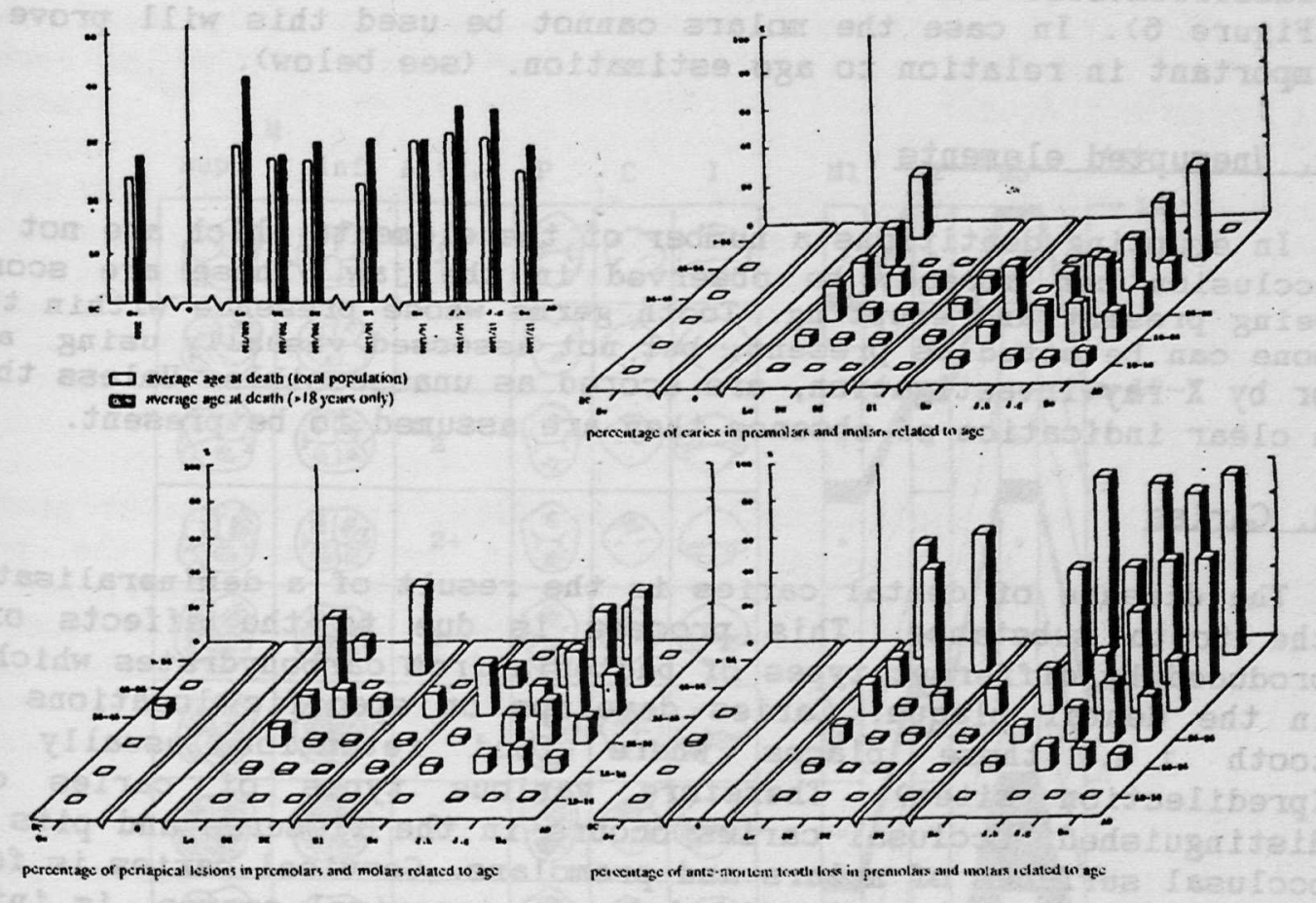

Figure 5 Graphical representation of the data which can be retracted from the database: some comparisons between Dutch populations ranging from $3300 \mathrm{BC}$ to $1850 \mathrm{AD}$ (in diachronical order). 
taken into consideration. Therefore, the authors added attrition classifications for the other dental elements into our new scheme (Figure 6). In case the molars cannot be used this will prove to be important in relation to age estimation. (see below).

\section{c. Unerupted elements}

In erupting dentitions a number of the elements whlch are not yet in occlusion can already be observed in the jaw. These are scored as being present and erupting. Tooth germs whose presence within the jaw bone can be noted as present, but not assessed visually using a probe or by $X$-ray investigation, are scored as unassessible. Unless there is a clear indication of absence they are assumed to be present.

\section{d. Caries}

The disease of dental caries is the result of a demineralisation of the tooth substance. This process is due to the effects of acid produced by different types of bacteria from carbohydrates which occur in the dental plaque. Caries develops on specific locations on the tooth i.e. those places where food retention usually occurs (predilection sites). Therefore various types of caries can be distinguished. Occlusal caries occurs in the fissures and pits of the occlusal surfaces of molars and premolars. Cervical caries is found at the gingival margins. The third type, approximal caries, is initiated on the contact areas of adjacent teeth.

Morphological and functional differences between the various dental elements are causes of differences in caries susceptibility between them. A comprehensive study of this structural phenomenon is in progress.

Dental caries manifests itself in several ways. Initial lesions present themselves as merely opaque white spots in the still intact enamel surface (Pot et al., 1977). Postmortem decomposition while in soil can result in features which are very difficult to distinguish from initial caries.

In the course of the continuing carious process, these sub-surface lesions will result in the formation of a cavity with a discontinuity in the enamel surface.

Caries can be scored per element and per predilection site as being either present or absent. Because of the above possible confusion with postmortem decomposition we advise scoring only clear cavities which have obviously originated at predilection sites. In the case of incipient carious lesions, when decalcification has started but there has been no formation of cavities, caries should be scored as absent.

\section{e. Exposed pulp cavities and periapical lesions}

Bacterial infection of the tissues in the pulp cavity of a tooth can be seen as the result of a deep carlous process, excessive attrition or trauma. Once the bacteria succeed in penetrating into the pulp cavity, 

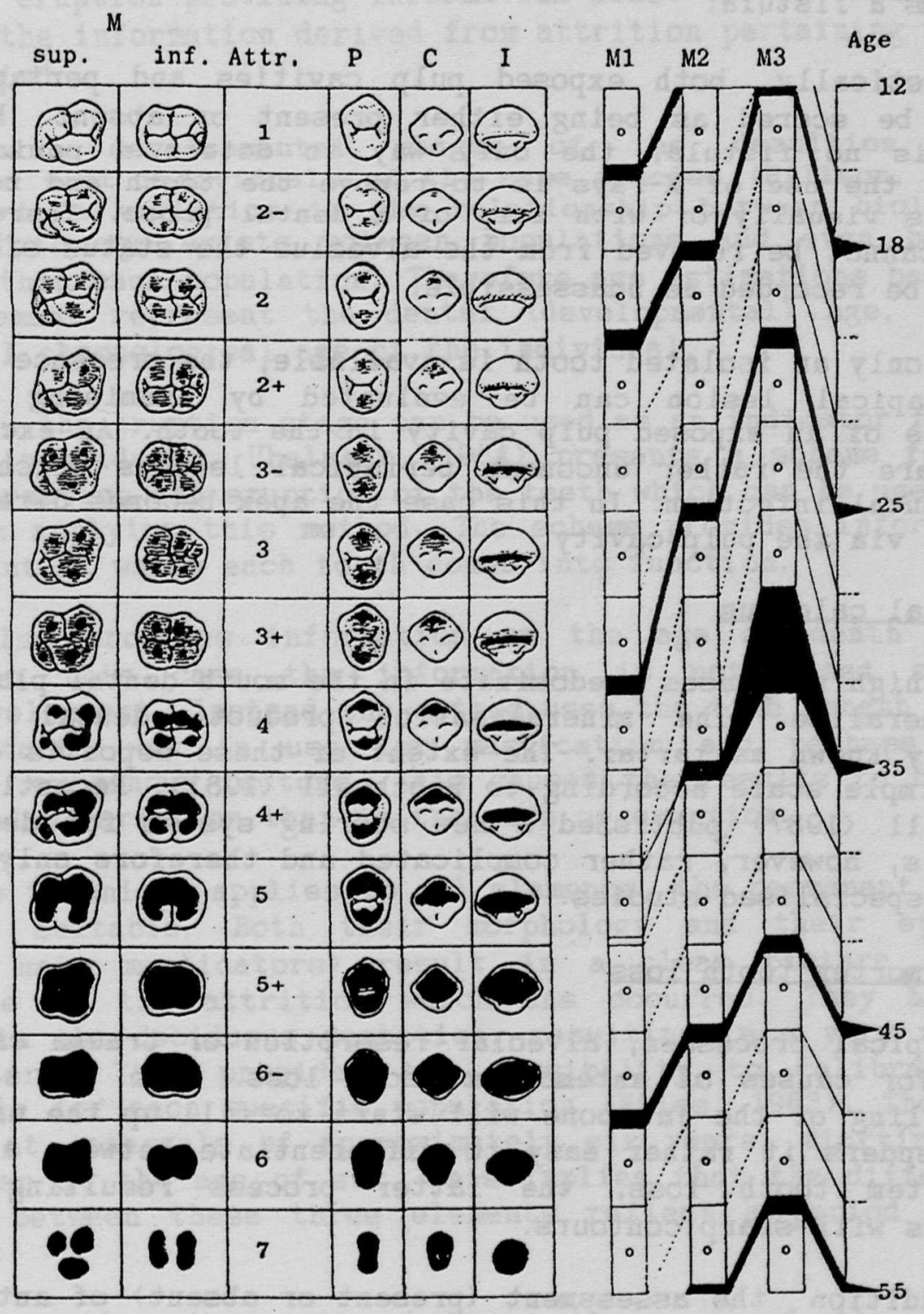

Figure 6. The attritional scale in relation to age. The recorded rate of attrition must be connected horizontally to the particular molar on which it has been observed. From thereon the diagonal paths indicate the most probable age at death of the individual. Attrition evaluations pertaining to the premolars, canines and incisors can be used to calculate the PCI - index. 
the inflammation spreads rapidly towards the apex of the root. Here it may affect the surrounding jaw bone, resulting in an expanding globular cavity in the bone around the apex. If the process continues for some time, the cavity may reach the surface of the jaw bone where it forms a fistula.

Theoretically, both exposed pulp cavities and periapical lesions should be scored as being either present or absent. However, when there is no fistula, the only way to detect a periapical lesion without the use of $X$-rays is to remove the tooth and to inspect the alveolus visually or with help of a dental probe. Therefore, when a tooth cannot be removed from the alveolus the status of the jaw bone has to be recorded as unassessible.

When only an isolated tooth is available, the presence or absence of a periapical lesion can be evaluated by examining the possible presence of an exposed pulp cavity in the tooth. An exception to the above are the rather uncommon periapical lesions which result from periodontal infection. In this case the apex becomes directly infected and not via the pulp cavity.

\section{f. Dental calculus}

When high $\mathrm{pH}$ phases predominate in the mouth dental plaque can start to mineralise. The mineralisation product, dental calculus, is commonly known as tartar. The extent of these deposits can be scored on a simple scale according to Brothwell (1981). Recently, Dobney and Brothwell (1987) published a new scoring system for dental calculus which is, however, rather complicated and therefore only suitable for highly specialised studies.

\section{g. Antemortem tooth loss}

Periapical processes, alveolar resorption or trauma can be seen as the major causes of antemortem tooth loss. Once the tooth is lost, remodelling of the jaw bone will start to fill up the empty alveolus. This renders it rather easy to differentiate between antemortem and postmortem tooth loss, the latter process resulting in an open alveolus with sharp contours.

In addition the assessment (present or absent) of antemortem tooth loss cannot in all instances be made with certainty. In a number of cases a distinction between the congenital absence of the dental element (see below) and the presence of an underlying, but not yet visible tooth-germ can only be made by $x$-ray investigation. In those cases the cause of the apparent absence of the element should be scored as unknown.

\section{h. Congenital absence}

In some cases the germ of a certain element has never been formed in the jaw bone. This is called congenital absence; this condition can only be assessed with certainty by $\mathrm{X}$-ray investigation. 


\section{Age estimation}

Both dental eruption and dental attrition are sources of information pertaining to the age at death of the individual. They are mutually complementary, eruption providing information about the pre-functional period, while the information derived from attrition pertaining to the functional period.

The subsequent developmental stages of the dentition occur consistently in most individuals of the same species (Hillson, 1986). However, a certain variation in the relationship between biological and chronological age exists between populations and even between individuals within each population. Therefore age estimations based on dental development represent the dental (developmental) age, rather than the actual chronological age of the individual.

Nevertheless, the eruption stage can be used as an indicator for the age of young individuals. Ubelaker (1984) presents a scheme for the sequence of formation and eruption of the teeth which can be used as a reference when applying this method. The scheme provides information about the moment at which each tooth comes into function.

Attrition also provides information on the age at death of an individual. In this case the information is not based on its biological development. Instead the method uses the time length during which every tooth was in use for mastication and perhaps other purposes, i.e. exogenous factors. This causes the results to be more subject to random variation than in the case of eruption.

Although the technique applies to all elements, the permanent molars are the most suitable. Both their morphology and their specific function (as main masticators) result in a clear picture of the occlusal plane of the attrition which has occurred. They have no predecessors in the deciduous dentition, resulting in a very regular eruption pattern. This provides the possibility to calibrate the attrition scale for each specific population (Miles, 1963). The three molars erupt at intervals of approximately six years, starting with the first molar at the age of six. This implies that the differences in attrition between these three elements reflect a period of six years of wear.

The chronological relationship between the wear of the various molars makes it possible to estimate for each population (and theoretically even for each individual) the pace with which the attrition process has proceeded. All age estimations on the basis of this attribute should be viewed within the light of this approximate pace of the attrition in the populations in question. It is dependent on the individual's feeding patterns and the specific use which may have been made of the dentition etc. In future research the authors will attempt to design a method to adapt the age categories in Figure 6 with reference to the average attrition rate in the material studied.

The M1, being the first molar to erupt, is more $11 k e l y$ to be affected by disease, for example caries, than the others, resulting in 
the risk of an early loss of the element. The MB is the most variable between individuals in its presence or absence, morphology and eruption time. It is therefore also less suitable as a generally applicable element for age estimations on the basis of attrition.

As a consequence, the 2nd malar is the preferred element for this purpose. Age estimations are best based on the mean of the individual attrition rates of the 2 nd molars. However, these may be absent or not possible to use, or because their degree of attrition is anomalously high or low (see above under attrition) or because they are braken or carious. In such a case the other molars have to be used (Figure 6 ).

In this stage of the research it is not possible to define exactly the conditions for the use of either the N2 or the other molars, or how the cholce between using $M 1$ or $M 3$ should be made. Furthermore, not all attrition stages could be defined precisely around the 35 years age category. One of our research projects is a reappraisal of the age categories in the scheme using a collection of skeletons of known age and sex, recently excavated in the Netherlands.

Using the scheme of Brothwell, or using our own scheme but limiting the assessment of the attrition rate to the molars, renders a serious bias to the age estimations. More specifically, the absence of all molars, as well as an abnormal attrition pattern of these elements, would imply the elimination of the individual from the age sample. As a result, this would lead to selective exclusion of the older individuals from the age sample because, more specifically, these people are liable to have lost one or several molars in life. Moreover, the older individuals have the highest attrition rates, leading to open pulp cavities and periapical lesions. Both biases would lead to a reduction of the estimated mean age of the sample.

In view of the above the original scheme was expanded to include the incisors, canines and premolars (Figure 6). The degree of attrition of these elements is summed and averaged to calculate the so-called PCIindex (Pot, 1988). This index allows an age estimation in those cases where the molars are absent or cannot be used due to abnormal circumstances. To this end the PCI-index value of all individuals with complete dentitions in the populaion is determined and related to their 'H2 age'. From these data the average 'M2 age' per PCI class can be determined. These average 'K2 ages' give an indication of the age of the individuals in the respective PCI classes, which can be used for the specimens with incomplete dentitions i.e. lacking molars.

The above method shows that both dental eruption and attrition are important indicators of the individual age at death. However, they should always be evaluated in relation to the complete picture provided by all dental data of the individual in question. This implies that no reliable age estimation can be based on the attrition figure of a loose tooth, where there is no information on, for example, the presence or absence or the pathological condition of its antagonist or its neighbours. 
The complete picture represents the frozen stage of the dynamic process of dental development and decay at the time of death and it is only in relation to that setting that an attrition figure for an individual tooth can be correctly evaluated.

\section{Conclusions and future research}

The automated registration of dental data provide improved possibilities for their efficient and accurate analysis. A number of Dutch populations, ranging from $3300 \mathrm{BC}$ to $1850 \mathrm{AD}$ have already been examined. An example of the results of that analysis is presented in Figure 5. A future publication will be dedicated to the statistical analysis of those results. An attempt will be made to establish the presence or absence of systematic differences in carles susceptibility between the various (groups of) elements. Moreover, an attempt will be made to quantify the reliability of age estimations; that reliability is dependent upon the (im)possibility of making observations on the various (groups of) elements and upon their presence or absence in the excavated dentitions. Furthermore, there is a plan to investigate the possibility of defining a uniform scoring procedure in the case of absence of the most informative dental elements (the 2nd molars) and of designing a method to adapt the age estimations with reference to the average pace of the attrition process in a specific population. Finally, by using a recently excavated Dutch sample with known age and sex, the age categories will be reassessed in the scheme of Figure 6.

\section{Acknowledgements}

This text has gained considerable clarity through the critical review kindly provided by Dr. T.S. Constandse-Westermann. The authors wish to thank Ir. H.A. Verhoeven for the many hours spent in coding of the program used and for his useful suggestions with regard to data processing.

\section{BIBLIOGRAPHY}

Brothwell, D.R., 1981 - "Digging up bones. The excavation, treatment and study of human skeletal remains". 3rd edition. Oxford University Press, Oxford and British Museum (Natural History), London.

Dobney, K. and Brothwell, D.R., 1987 - "A method for evaluating the amount of dental calculus on teeth from archaeological sites". L. Arch. Sc1., Vol. 14 , pp. 343-351.

Hillson, S., 1986 - "Teeth." Cambridge Manuals in Archaeology. Cambridge University Press, Cambridge.

Miles, A.E.W., 1963 - "Dentition in the estimation of age". I. Dental Research, Vol. 42, pp. 255-263. 
Perizonius, W.R.K, and Pat, TJ., 1981 - "Dirchronic dental research on human skeletal remains excavated in the Netherlands. I: Dorestad's cemetery on "the Heul'". Berichten van de Rijksdienst voor het Qudheidkundig Bodemonderzoek, Vol. 31, pp. 369-413.

Pot, Tj., 1988 - "Een gebitsonderzoek van het 18e-eeuwse grafveld St. Janskerkhof 1984". Kroniek Bouwhistorisch en Archeologisch Onderzoek's-Hertogenbosch, Vol. 1, pp. 125-149.

Pot, Tj., Purdell-Lewis, D.J., and Groenevald, A, , 1977 - "The origin and behaviour of white spot enamel lesions". J. Dental Research, Vol. 56 , pp. 6-18.

Ubelaker, D.H., 1984 - "Human skeletal remains; excavation, analysis. interpretation". National Kuseum of Natural History, Washington D.C. 
TEETH: SOIE CURRETT DEVELOPIETTS IT RESEARCH

\author{
Dr S. Hillson \\ Inst1tute of Archaeology. \\ University College \\ 31-34 Gordon Square \\ London \\ WC1H OPY
}

\title{
Ancient teeth as aterial for study
}

Although much work on burled human remains concentrates on the bones, teeth have some significant advantages as raw materials for study. They are tougher than the bony skeleton, often remaining well preserved even in hostile conditions of burlal. Dental tissues usually survive little changed, showing fine detalls of microscopic structure and allowing detalled histological studies to be carried out. Such studies have potential for improved age determination and as an aid to the diagnosis of dental pathology. Other advantages come from the peculiar biology of teeth, which are not strictly part of the skeleton and have their own physiology and developmental processes, rather different to those of bone. Many age-at-death estimation methods are based upon teeth. Their complex growth history is preserved within their microscopic structure because, unlike bone, dental tissues do not turn over and they preserve the traces left during their formation. Studies of dental development allow the 8rowth rate of children in past populations to be studied in a detall which would otherwise be impossible. Teeth are also the only mineralised parts of the body which were actually in contact with the outside world during the life of the people whose remains are being studied. They were licked by the tongue, they were bathed by the saliva and they touched every particle of food which passed the lips. The harsh environment of the mouth leaves recognisable traces of wear and dental studies offer unrivalled opportunities for reconstructing the diet, particularly from the complex array of diet-related diseases which affect the teeth and the bone of the jaws.

There are too many recent developments and new possibilities for study to be covered in one short paper, so I will concentrate upon two areas which I consider to be of particular interest. The first of these involves the study of microscopic structures inside the teeth and the tissues that form them; structures which are controlled by the internal rhythms of growth and ageing. The second area concerns developments on the surface of the crown and neck of the tooth, the parts which are exposed to the full force of the environment in the mouth.

\section{Kicroscopic layering in dental tissues \\ Dental tissues}

Three dental tissues are found in human teeth. Hard, pearly white enamel coats the crowns of the teeth. Even the fresh enamel of a newly extracted tooth is almost entirely composed of mineral, with tiny crystals arranged in bundles called prisms (Figure 2). In some 
circumstances, the enamel caps of the teeth crowns may be all that remains of a body on an archaeological site. A second tissue, dentine, makes up the main internal bulk of the tooth. Fresh dentine contains more organic matter than enamel, in the forms of reinforcing protein fibres, cells and a cocktail of other components. It is generally less well preserved than enamel because this organic matter is lost (Beeley and Lunt, 1980), to be replaced by secondary minerals deposited from percolating ground water. Even so, it is often better preserved than bone and yields up details of 1 ts microscopic structure when appropriate techniques are used. The third dental tissue, cement, coats the surface of the tooth roots in man. Fresh cement contains somewhat more organic matter than dentine - it is similar in composition to bone - and is again not so well preserved as enamel in archaeological specimens. Nontheless it is often possible to see the main elements of its structure under the scanning electron microscope, particularly its characteristic layering (Figure 1). Ancient cement, dentine and bone may all be riddled with canals excavated by the invasions of mycelium - producing microorganisms, which obliterate many features of their structure (Werelds, 1961; Poole and Tratman, 1978; Hillson, 1988) and it is necessary to select carefully the techniques of microscopy which are used to study them.

\section{Techniques of Study}

Modern dental histology uses a wide variety of microscopes and methods of specimen preparation. Different methods may be better than others at showing particular aspects of structure. With archaeology, there is also the question of different types of preservation. Dental enamel, even in ancient specimens, produces good results with most techniques. it may be cut and polished into thin sections which can be examined under the polarising microscope (Schmidt and Ke11, 1971) to show patterns in the orientation of 1 ts tiny crystals, and gaps in between their packing in a way that no other methods can. Etched surfaces of enamel may also be examined under the scanning electron microscope, which is the best way of showing the prisms (Figure 2) and crown surface features (Figure 5). The latter may also be investigated non-destructively by taking casts with dental impression materials. These impressions, or replicas made from them, are then examined under incident 11 ght (even a basic low-power stereo microscope) or the scanning electron microscope (Bromage and Dean 1985; Beynon, 1987). Dentine and cement usually present more difficulty because their preservation varies a great deal. Often, they do not section easily and, even if sectioned, may be too opaque for polarised light microscopy. In these circumstances, scanning electron microscopy of fractured, etched surfaces may be successful (Hillson, 1988). Another possibility is microradiography - where a thin section is placed directly upon a photographic emulsion and exposed to $\mathrm{X}$-rays. The resulting negative is then examined under a transmitted light microscope. This technique is used widely in dental histology, but has yet to be applied to archaeological teeth. It has, however, been used with success on ancient bone (Martin et. al. 1985). 
Layers in dental tissues

Much of the interest in histological studies of human teeth lies in the layered structures which are found in all three tissues. Once laid down during the growth of the tooth, these layers remain unless tissue is destroyed by pathological processes, wear or loss of teeth. Bone, by contrast, is constantly being broken-down and replaced during Ilfe - the process of tissue turnover which obliterates traces of the growth process. Layering in human enamel and dentine represents short-term growth rhythms with a wavelength of days and weeks. It yields information about the biology of childhood and may help to calibrate other age-at-death estimation methods for young individuals. Layering in cement by contrast appears to represent seasonal and annual rhythms. It seems to have most potential for estimating ageat-death in adult individuals, particularly in older adults, whose age is usually difficult to estimate from archaeological remains.

\title{
Cement layering and age estimation in man
}

\begin{abstract}
There is a huge literature (summaries include Klevezal and Klelnenberg, 1967; Morris, 1972; Perrin and Myrick, 1980) on the relationship between cement layer counts and chronological age in a wide variety of mammals. Counting of "cement annulations" has been applied especially widely in marine mammals - toothed whales, seals and sealions. Recently, a similar relationship between layer counts and age had been found in the higher primates (Wada et. al., 1978; Stott et. al., 1980; Yoreda, 1982; Kay et. al., 1984), including man (Stott et. al., 1982; Naylor et al., 1985). Some of the results are remarkable, including good correspondence in individuals of 70 years or more. Before any age estimation method is applied generally, it must be tested rigorously, and an extensive study has been carried out (Charles et. al., 1986; Condon et. al., 1986) using repeated counts of cement layers in human teeth by different observers of specimens prepared from teeth extracted from individuals of known age. Cement layers are notoriously difficult to count, but the investigators found that they could be recorded at least as repeatably as the observations used in age estimation from the pelvis. The accuracy of ages estlmated from layer counts was also at least as good as the other methods available.
\end{abstract}

The technique is still not without problems. The physialogy of cement layering in man has been little investigated and so the blological basis of the method is not well established. Not all teeth are necessarily suitable. Some specimens show layering better than others. Different parts of the root surface may yield different results and so the plane of sectioning used in preparing specimens is Important. Condon et al (1986) noticed that teeth extracted from Individuals with periodontal disease had a wider margin of error in age estimation than those extracted from people in which the condition was not diagnosed. It is unfortunate that most older adult (the range where the technique would be of most value) individuals in archaeological collections show evidence of periodontal disease. In addition, the techniques of microscopy which were most successful in samples of freshly extracted teeth would not be suitable for all archaeological specimens. Charles et. al. (1986) demineralised their 
specimens, fallowed by staining with haematoxylin; a method which has been found to show cement layers well in a wide variety of different mammals. It is, however, variably successful in archaeological specimens because it relies upon the survival of sufficient organic material in the cement to produce a stain reaction after demineralisation. Enough organic material survives in specimens from some sites for sections to be prepared in this way, but many specimens may be destroyed completely by demineralisation (discussed in Hillson, 1986). Further experimentation with techniques of microscopy is needed before the technique can be applied universally, but none of this prevents cement layer counting from being a potentially valuable addition to the range of techniques available in an area of the study of human remains which is notoriously difficult.

Enamel layering as a srowth record: non-destructive techniques of study

Both enamel and dentine show microscopic layering clearly in man. At the finest level, there are layers which were formed for each day of tissue growth during childhood. Superimposed over this is a layering with a cycle of several days. In the case of enamel this coarser layering represents about a week of growth (usually between 7 and 10 days, with an average of about 8 ). Enamel has a number of advantages over dentine as the tissue for study in archaeology. Its better preservation means that microscope preparations are usually more successful in showing the layers. In addition, the growth layering of enamel is apparent at the surface of the tooth crown and so can be studied without the time consuming and destructive sectioning which is required to study dentine. For these reasons, most work has concentrated on enamel.

In enamel, the roughly weekly layering finds physical expression in thin sections under the polarising microscope as dark, fuzzy lines called the brown striae of Retzius (Figure 3 ). These striae mark aut the stages of enamel growth (Figure 4), starting with a series of dome-shaped increments, stacked up one side outside another until they form the highest points of the tooth crown. The domes are succeeded by sleeve-shaped increments which overlap one another down the sides of the crown, and the visible part of the crown outside is made up almost entirely of the outer edges of these layers. Only the very tip of the buried dome-like increments shows in the unworn tooth, right at the highest point of cusps or ridges. The edges of the sleeve-like layers cause a fine rlppling of the crown surface which may be seen even under quite modest magnification, and the outlines of the layer edges can be followed as shallow furrows around the circumference of the tooth (Figures 4 and 5). These surface expressions of layering are called perikymata and counts of perikyma furrows on an unworn crown correspond well with the number of brown striae in the sleevelike growth region underneath. Dally layers in the enamel cannot be seen at the crown surface and are most successfully investigated by the polarising microscopy of thin sections, where they are called cross striations. The same layering is belleved to cause a regular bulging of the prisms (Figure 2) which can be seen by scanning electron microscopy. Counts of cross striations between brown striae are usually constant throughout the teeth in a dentition and are very 
seldom lese than 7 or more than 10. In fact, the great majority of counts fall on the average value of about 8 (Bullion, 1987; Dean, 1987). Most studies, therefore, assume an 8 day spacing for perikymata and, even though there is no way in which this can be checked at the tooth surface, counts of perikymata do seem to provide a reasonable basis upon which to determine the time taken for different parts of the tooth crown to grow.

Perikymata can be studied on the crown surface itself, using either incldent light microscopy or the scanning electron microscope. It is usually more convenient and less destructive, however, to take Impressions of the crown surface using a varlety of dental and other flexible impression materials. These are examined directly (Figure 5), or may be used as moulds for the production of epoxy resin casts which reproduce the original surface in microscopic detall (Beynon, 1987). Perikymata can be counted on photomicrographs, but a recent development (H1lison and Jones, 1989) is a computer-interfaced instrument for counting perikymata and measuring their spacing directly from impressions or casts. This rapidly records detalled crown profiles (Figure 6) and allows the spacing of perikymata to be studied statistically.

The spacing of the perikymata decreases in a regular progression down the side of the crown. They may be over $100 \mu m$ apart (and just visible to the naked eye) near the cusps and about $30 \mu \mathrm{m}$ apart nearer the neck of the tooth where the crown joins the roots. The details of this progression vary between classes of teeth and are responsible in part for the differences in crown geometry between them. There are, however, disturbances to this regular sequence which lead to defects that can be seen clearly with the naked eye and felt by running a probe over the crown surface. These defects have been studied widely (e.8. Commission on Oral Health, Research and Epidemiology, 1982) and relate to a variety of growth-disturbing factors such as periods of detary deficlency, fever-generating infectious diseases and other conditions (Pindborg, 1982). They are very common in both archaeological and modern teeth (White, 1978; Goodman et. al., 1980; 1984; Hillson, 1986), and are usually known as enamel hypoplasta. Each defect is believed to represent an episode of disturbance which Dccurred to the individual during the growth of his or her teeth, and all teeth whose sleeve-type reglons were being formed at the time usually show evidence of the same episode. In detail, the defects are seen to be local variations in the spacing of perikymata (Figures 5 and 6) which cumulatively cause a grooving or pitting of the crown surface. It is possible to count the number between defects. Thus, each tooth crown has its own perikymata/defect sequence and, because defects occur on all teeth being formed at the same time, it is possible to match sequences between teeth. This can now be done statistically (Bullion 1987; Hillson and Jones, 1989) and opens up a number of possibilities:

1. It is possible to match up teeth from one individual with some precision. This may be useful when the remains of several individuals are mixed up in the same burial. 
2. An extended perikymata/defect sequence can be built up by matching between teeth, covering a major part of the period of formation of the dentition. In many cases, this may represent a period from about 1 to 5 or more years of age.

3. Perikymata/defect sequences can yield estimates of the age at which particular parts of the crown were being formed, where the average age at which the dome-type region of the crown was completed is known for a tooth in the sequence (Bullion, 1987).

4. The growth rate of the dentition can be followed through childhood, together with a record of disturbances to growth during the period. This gives an extraordinarily detailed glimpse of the biology of ancient human populations which will be directly comparable with data gathered from modern day populations.

5. The information on dental growth rate will also make it possible to calibrate the widely used age at death estimation techniques which are based on tooth formation and eruption. (e. 8. Gustafson and Koch, 1974).

Perikymata counting can only be applied successfully to teeth which are not too worn and so is best used on juveniles and young adult material. Appropriate equipment and techniques are still in an early stage of development but, in my opinion, there is considerable potential for applications in archaeology.

\section{Dental Caries}

\section{Dental plaque and calculus}

When the crown surface emerges into the mouth by the process of dental eruption, it is gradually colonised by communities of microorganisms. These are glued to the surface largely by adhesives which are manufactured by the microorganisms themselves. Microorganisms, adhesives and other constituents together make up the deposits known as dental plaque which are found on all teeth, even the most diligently cleaned, and which are the focus of another area of research activity in archaeology. The soft plaque deposits presumably decompose shortly after death, but fossilised plaque is a very common find on teeth from archaeological sites. It is known as dental calculus or tartar and archaeological teeth often show extensive deposits. Prime areas for calculus accumulation are the lingual (tongue) side of the lower incisors and the buccal (cheek) side of molars. The plaque fossilisation process in fact occurs during iffe, when long-standing plaque deposits are mineralised by the crystallisation of calcium phosphates from the saliva. This mineralisation starts within the cell walls of the microorganisms themselves and the shapes of the organisms are often clear in scanning electron micrographs of archaeological samples of calculus (Dobney and Brothwell, 1986). It is possible to recognise filament, rod and coccal forms similar to the microorganisms which characterise living plaque, although identification to species, which is usually based upon physiological criteria, is unlikely ever to be possible. Whilst 
calculus is firmly attached to the teeth in life and resists stubbornly any attempt to clean it off, it is often less well attached to archaeological specimens. Teeth and jaws need very careful cleaning if their pathological record is to be saved, and it may well be best to leave this to the specialist.

\section{Diet and Plaque}

Calculus does not replace a plaque accumulation completely and even on extensive deposits, there is always a surface layer of living plaque. The microorganisms of plaque scavenge the food that passes through the mouth and the ecology of our plaque communities is very much related to our diet. Varying mixtures of carbohydrates (both starches and sugars), proteins and fats are presented to the plaque surfaces as food is bitten, chewed, sucked, mixed with saliva and swallowed during the meals and snacks of the day. The molecules of starches, proteins and fats are rather too long to diffuse readily into the plaque and are not thought to figure largely in the nutrition of the microorganisms inside. Sugars, however, have small enough molecules to diffuse into the plaque, and are important in the metabolism of many microorganisms. In addition to the sugars which are already present in the food as it comes into the mouth, some sugars are released from the breakdown of starches by the enzyme anylase, which is present in saliva. These must also diffuse into the plaque, but the initial breakdown process probably ensures that sugar comes from this source rather more slowly. Sugars are fermented by the microorganisms to release the energy that they require for life, but also to release acid waste products. This takes place surprisingly quickly and it has been found that a sweet drink can lower the $\mathrm{pH}$ of plaque from around 6.8 (nearly neutral) to 5.5 in as little as two minutes. The $\mathrm{pH}$ gradually climbs back towards neutrality over the next half hour. As different meals are eaten during the day, the plaque $\mathrm{pH}$ fluctuates up and down in a way that depends upon the proportions of carbohydrate in the diet, their type (sugar or starch), the adhesion of the food to the teeth and plaque (and therefore the time available for diffusion), the spacing of meals and the form and location of plaque deposits. A pH of 5.5 is low enough to dissolve tooth mineral and, during the low $\mathrm{pH}$ phases, mineral is lost from the crown underneath the affected plaque deposit. When the $\mathrm{pH}$ climbs back towards neutral, tooth mineral recrystallises in these damaged areas, supplied from a store of dissolved calcium phosphates which is maintained in the saliva. A balance is kept in this way between loss and replacement of mineral. At particular sites on the crown, where the plaque above is frequently in a state of low $\mathrm{pH}$, there is a net loss of mineral and eventually the area of demineralisation is visible to the naked eye - the characteristic lesion of dental caries. At first, this is only a change to the colour or translucency of the enamel, but eventually a cavity is formed which may deepen until it penetrates the pulp of the tooth, in some cases leading to an infection of the pulp which causes the loss of the tooth. Carious lesions have been found in human teeth (both Homo sapiens and other hominid species) throughout the archaeological record (Hillson, 1986). They are also present in the teeth of wild primates other than hominids and the pathological processes which cause carles have been at work for many millions of years. 
Dental caries has been a major focus of interest recently and there have particularly been developments in the areas of diagnosis and epidemiology.

\section{Techniques of caries diagnosis}

There are considerable difficulties in defining standards for the diagnosis of caries, even in the clinical situation, with living patients. This is partly because caries is a continuous process. The first damage can only be seen in thin sections of tooth crowns, under the microscope. By the time an opaque, or coloured spot is seen on the crown surface, considerable loss of mineral has already occurred. A cavity represents rather a late stage in the process. The progress of carlous lesions can be halted or reversed at any stage - spots or cavities may remain "dormant" for years and some repair themselves without a dentist's intervention. It is therefore rather difficult to make a precise diagnosis of the state of a carious lesion without making a microscope section of the tooth - and this is clearly impossible in living patients and impractical in large collections of archaeological specimens. Radiography may not be particularly helpful in this respect, because it too first shows a lesion only at about the 'white or brown spot' stage. Furthermore, as a standard dental radiograph is an image produced from the whole thickness of the crown, the precise definition of small areas of mineral loss is difficult. Additional difficulties arise from the position of the lesion on the crown (Figure 7). Lesions develop very commonly in the contact area between neighbouring teeth and these can be very difficult to see, particularly when teeth are closely packed. Another very common site for the development of lesions is in the fissures which run between the cusps of the cheek teeth. Dental carles may proceed deep in these fissures without leaving a sign at the visible surface until the enamel of the crown is so undermined that it collapses to make a large open cavity. Radiography may be particularly valuable in these circumstances.

Archaeological dental remains do have some serious disadvantages as raw material for the study of caries. They are freqently fragmentary and incomplete. Tooth crowns may be broken, individual teeth may have been lost postmortem and whole jaws may be absent. The conditions in which teeth have been buried often cause a variety of changes - there may be localised loss of tissue and deposition of new minerals which mask or even mimic the changes of dental caries. Microorganisms may cause enamel and dentine destruction after death and burial, sometimes resembling even the histological changes of dental caries very closely (Poole and Tratman, 1978). Particular care is clearly needed with archaeological material for all these reasons, but there are considerable advantages as well as disadvantages. Archaeological specimens may be examined much more closely than teeth in a living patient. The teeth are often loose in their sockets and this allows them to "be manipulated, and sometimes extracted, for careful examination. The jaws can in any case be orientated better than living mouths underneath a strong light source, and they are more amenable to routine study under a lower power reflected light microscope, which allows very careful scrutiny. Techniques such as the use of ultraviolet illumination are also more practicable and 
there is no limit to the number of radiographs that can be taken: the small size of the specimens allows them to be placed inside an $X$-ray machine of the completely shielded type which minimises risk to the operator. Against this, it should be noted that there is often insufficient funding in archaeological projects for routine dental radlography, but the closer surface examination which is possible with dry teeth and jaws may make this less critical, and the heavy wear on many ancient teeth obliterates the problematical fissure area for which radiography would otherwise be indispensible. In addition, there is no reason why sectioning and microscopic examination of teeth should not routinely be carried out to confirm diagnoses, although this would again be subject to the limits of funding.

Further work is needed on postmortem change to teeth, but there are considerable opportunities for detailed studies of dental caries in the large collections of material which are readily avallable in museums and current excavations. 
The study of epidemiology

The epidemiology of dental caries in living human populations is usually studied by indices of the "dmf" type. Several different indices are in use, but in all of them numbers of decayed, missing and filled teeth are counted for each individual examined. A dmf index can then be calculated for the group under study. Most of such studies have emphasised the importance of sugar in the diet, particularly sucrose. Although there must be detailed differences between individuals in a population, the "caries experience" of the population as a whole can be quite closely related to its overall sucrase consumption (Newbrun, 1982; Sheiham, 1983). Most sugars are thought to increase caries rate (some more than others), but the level of starch consumption does not seem to be so important, presumably because sugars are more slowly released from this source. Dietary proteins and fats are seen as carbohydrate-diluting factors in the diet, because they appear to play little part in the metabolism of plaque microorganisms. Calculus and caries represent opposites in the balance of plaque $\mathrm{pH}$ and mineral deposition versus mineral loss. For this reason, it is expected that a population with a high carles rate would have a low calculus rate (and vice versa), even though individuals in the population may well have both caries and calculus in their mouths. This effect has been noted in archaeological material (Hillson, 1979) and may be another way of investigating the plaque biology which underlies the epidemiology of caries.

It is now apparent that the aetiology of carious lesions varies between different sites of the tooth (Figure 7). The biology of the plaque in a fissure, together with the way in which carious lesions may develop, is quite markedly different to those of, say the contact area of the crown, or the exposed surface of a root. There are few studies of living populations which separate out different sites of carious attack, but several archaeological studies (Moore and Corbett, 1971; 1973; 1975; Corbett and Moore, 1976; Lunt 1974: Whittaker et. al., 1981) have done this and are showing contrasts between collections of different date which suggest that dietary factors may have a role in controlling the site of attack (Hillson, 1986).

The principal difficulty with archaeological material is that dmf type indices are not suitable. Even in living people, teeth may be missing for reasons which have little directly to do with dental caries, such as injury or periodontal disease. Similarly, fillings are not solely a treatment for dental caries and there 15 the additional problem of how to count complete artifical crowns. In archaeology there is the further difficulty of missing and damaged teeth, and incomplete or lost jaws. It is better for archaeological purposes to count up the numbers of potential carles sites "at risk" which can be contrasted with the number of sites that actually have a detectable carious lesion present in them. This makes no assumptions about the missing teeth, although it still assumes that the preserved potential caries sites in each individual mouth represent the original caries experience of that mouth. The difficulty with this is that comparable studies of living populations are not available and it may be necessary to carry out studies based upon modern dental records for this purpose. 
In spite of these difficulties, epidemiological studies of dental caries and other plaque-related conditions hold out considerable hope for reconstruction of the major components of the diet in ancient populations.

Dental carles and the microscoplc layered structures of teeth are Just two areas selected from a wide array of possibilities for the study of ancient human dental material. I believe that this field would amply repay a greater concentration of research effort and resources.

\section{BIBLIOGRAPHY}

Beeley, J.G. and Lunt D.A., 1980 - "The nature of the biochemical changes in softened dentine from archaeological sites." I. of Arch. Sci., Vol. 7, pp. 371-377.

Beynon, A.D., 1987 - "Replication technique for studying microstructure in fossil enamel". Scanning Microscopy, Vol. 1, pp. 663-669.

Bromage, T.G. and Dean M.C., 1985 - "Re-evaluation of the age at death of Plio-Plestocene fossil hominids". Nature, Vol. 317, pp. 525-528.

Bullion, S.K., 1987 - "Incremental structures of enamel and their applications to archaeology". Unpublished PhD thesis, University of Lancaster.

Charles, D. K., Condon, K., Cheverud, J.M. and Buikstra, J.E., 1986 "Cementum annulation and age determination in Homo sapiens. I. Tooth variability and observer error". Amer. J. Phys. Anthrop., Vol. 71, Pp. 311-320.

Commission on Oral Health, Research and Epidemiology, 1982 - "An epidemiological index of developmental defects of dental enamel. (D.D.E. Index)". International Dental Journal, Vol. 32, pp. 159-167.

Condon, K., Charles,,D.K., Cheverud, J.M. and Bulkstra, J.E. 1986 "Cementum annulation and age determination in Homo sapiens. II Est1mates and accuracy". Amer. J. Phys. Anthrop., Vol. 71, pp. 321330.

Corbett, G.B., and Moore, W.J., 1976 - "Distribution of dental caries in ancient British populations IV: The 19th Century". Caries Research, Vol. 10, pp. 401-414.

Dean, M.C., 1987 Growth layers and incremental markings in hard tissues; a review of the literature and some preliminary observations about enamel structure in Paranthropus bolsei. I. Human Evolution, Vol. 16, pp. 157-172.

Dobney, K. and Brothwell, D.R., 1986 - "Dental calculus: 1ts relevance to ancient diet and oral ecology", pp. 55-82 in E. Cruwys and R.A. Foley (Eds), Teeth and Anthropology. British Archaeological Reports. International Series, Vol. 291, Oxford. 
Goodman, A.H., Armelagos, G.J. and Rose, J.C., 1980 - "Enamel hypoplasias as indicators of stress in three prehistoric populations from Illinols". Human Biology, Vol.52, pp. 515-528.

Goodman, A.H., Lalla, J., Armelagos, G.J. and Rose, J.C., 1984 "Health changes at Dickson Mounds, Illinois (AD 950-1300)", pp. 271306 in M.N. Cohen and G.J. Armelagos (Eds), Palaeopathology at the origins of agriculture. Academic Press, New York and London.

Gustafson. G. and Koch, G., 1974 - "Age estimation up to 16 years of age based on dental development". Odontologisk Revy. Vol 25, pp. 297306.

Hillson S.W., 1979 - "Diet and Dental Disease". World Archaeolog Vol. 11, pp. $147-162$.

Hillson, S.W., 1986 - "Teeth". Cambridge Manuals in Archaeology, Cambridge.

Hillson, S.W., 1988 - "The scanning electron microscope and the study of ancient teeth", pp. 249-260 in S. Olsen (Ed), Scanning electron microscopy in archaeology. British Archaeological Reports. International Series, Vol. 452, Oxford.

Hillson, S.W. and Jones, B.K., 1989 "Instruments for measuring surface profiles: an application in the study of ancient tooth crown profiles". L. Arch. Sel, Vol. 16, pp. 95-105.

Kay, R.F., Rasmussen, D.T. and Beard, K.C., 1984 - "Cementum annulus acounts provide a means for age determination. Macaca mulatta (Primates, Anthropoidea)". Folia Primatologia, Vol. 42, pp. 85-95.

Klevezal, G.A. and Kleinenberg, S.E., 1967 - "Age determination of mammals from annual layers in teeth and bones". Academy of Sciences, U.S.S.R., translated in 1969 by the Department of the Interior and National Science Foundation, U.S. Department of Commerce, Clearinghouse for Federal Scientific and Technical Information. Springfield, Illinois.

Lunt, D.A., 1974 - "The prevalence of dental caries in the permanent dentition of Scottish prehistoric and Medieval populations". Archives of Oral Biology, Vol.19, pp. 431-437.

Martin, D.L., Goodman, A.H. and Armelagos, G.J., 1985 - "Skeletal pathologies as indicators of quality and quantity of diet", pp. 227229 in R.I. Gilbert and J.H. Mielke (Eds), Analysis of Prehistoric Diets. Academic Press, New York.

Moore, W.J. and Corbett, M.E., 1971 - "The distribution of dental caries in ancient British populations: I Anglo-Saxon period". Caries Research, Vol.5, pp, 151 - 168

Moore, W.J. and Corbett, M.E., 1973 - "The distribution of dental caries in ancient British populations: II Iron Age, Romano-British and Medieval periods". Caries Research, Vol.7, pp. 139-153. 
Moore, W.J. and Corbett, M.E., 1975 - "The distribution of dental carles in ancient British populations: III The 17th Century". Caries Research, Vol.9, pp. $163-175$.

Morris, P., 1972 - "A review of mammalian age determination techniques". Mammal Review, Vol.2, pp. 69-104.

Haylor, J.W., Miller, W.G., Stokes, G.N. and Stott, G.G., 1985 "Cemental annulation enhancement: a technique for age determination in man". Amer. J. Phys. Anthrop., Vol.68, pp. 197-201.

Newbrunn, E., 1982 - "Sugar and dental caries: a review of human studies". Science, Vol. 217, pp. 418-423.

Perrin, W.F, and Myrick, A.C. (Eds) 1978 - "Growth of odontocetes and Sirenians: problems in age determination". Proceedings of the International Conference on Determining Age of Odontocete ceteans (Sirenians), La Jolla, California September 5 - 191978. International Whaling Commission, Cambridge.

Pindborg, J.J., 1982 - "Aetiology of developmental enamel defects not related to fluorosis". International Dental Journal, Vol.32, pp. 123134.

Poole, D.F.G. and Tratman, E.K., 1978 - "Post-mortem changes in human teeth from late Upper Palaeolithic/Mesolithic occupants of an English limestone cave". Archives of Oral B1ology, Vol.23, pp. $1115-1120$.

Schmidt, W.J. and Ke11, A., 1971 - "Polarization microscopy of dental tissues". Pergamon Press, Oxford.

Sheiham, A., 1983 - "Sugars and dental decay". Lancet, Vol.1 (8319), pp. $282-284$

Stott, G.G., Sis, R.F. and Levy, B.M., 1980 "Cemental annulation as an age criterion in the common marmoset (Callithrix facchus)". J. of Kedical Primatology, Vol.9, pp. 274-285.

Stott, G.G., Sis, R.F. and Levy, B. M., 1982 "Cemental annulation as an age criterion in forensic dentistry". I. of Dental Research, Vol.61, pp. 814-817.

Wada, K., Ohtaishi, N. and Hachiya, N., 1978 - "Determination of age in the Japanese monkey from growth layers in the dental cementum". Brimates, Vol.19, pp. 775-784.

Werelds, R.J., 1961 - "Observations macroscopiques et microscopiques sur certains alterations post-mortem des dents". Bulletin du Groupement Internationale pour la Recherche scientifique en Stomatologie, Vol.4, pp. 7-60.

Wite, T.D., 1978 "Early hominid enamel hypoplasias". Amer. J. Phys. Anthrop., Vol.49, pp. 79-84. 
Whittaker, D.K., Molleson, T., Bennett, R. B., Edwards, I., Jenkins, P.R. and Llewelyn, J.H., 1981 - "The prevalence and distribution of dental caries in a Romano-British population". Archives of Oral Biology, Vol.26, pp. 237-245.

Yoreda, M., 1982 "Growth layers in dental cementum of Saguinus monkeys in South America". Primates, Vol. 23, pp. 460-464. 


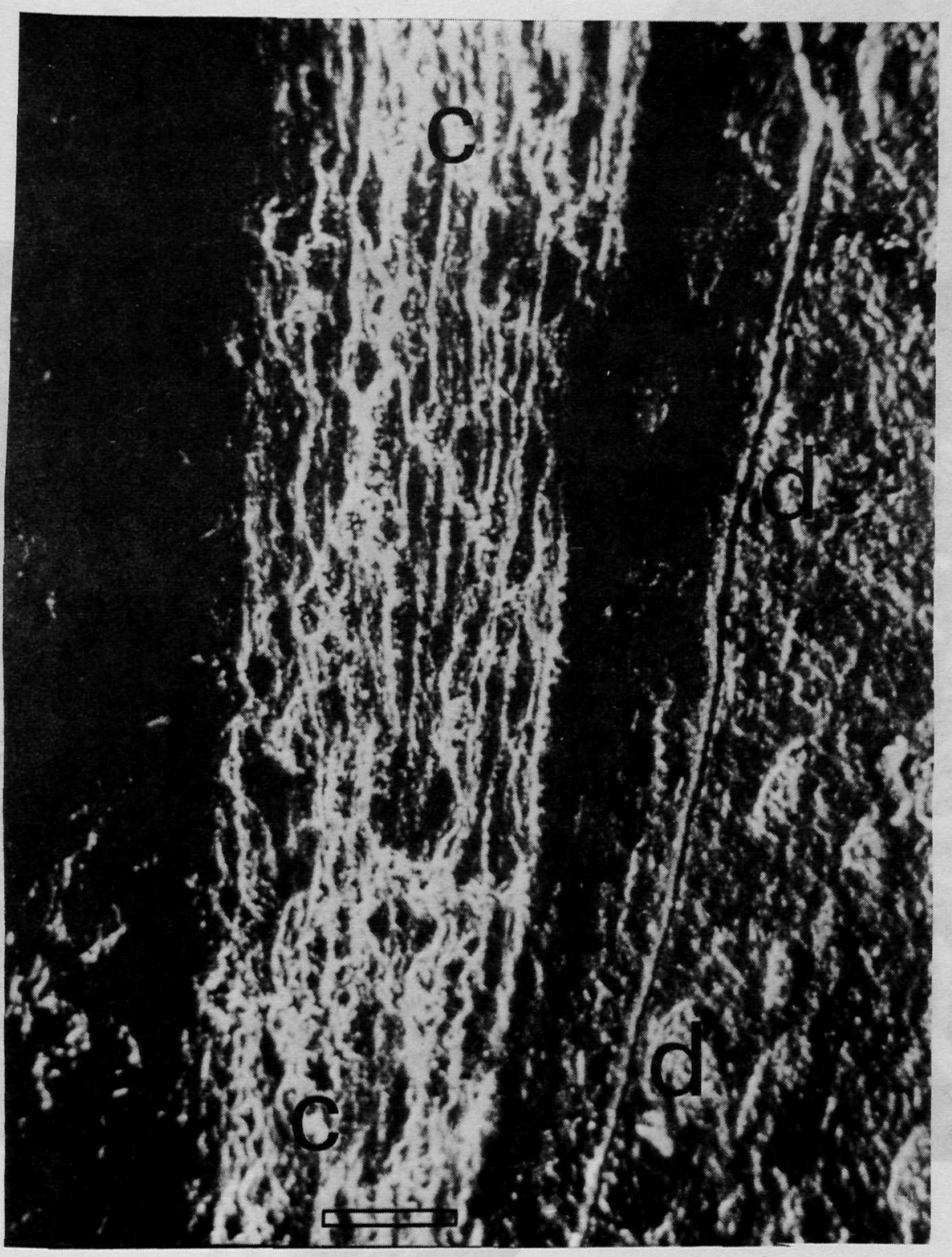

Figure 1: Cement layering in a human permanent second molar tooth from Kerma, Nubia (1720-1550 BC). The cement is seen in section and marked " $c$ ", and the dentine of the root is marked "d". The dark band to the left of the photograph marks the other surface of the root. Radial section of root, polished, etched and then sputter coated with gold. Cambridge Instruments 54 scanning electron microscope operated in secondary electron mode. Scale bar represents c. $58 \mu \mathrm{m}$. 


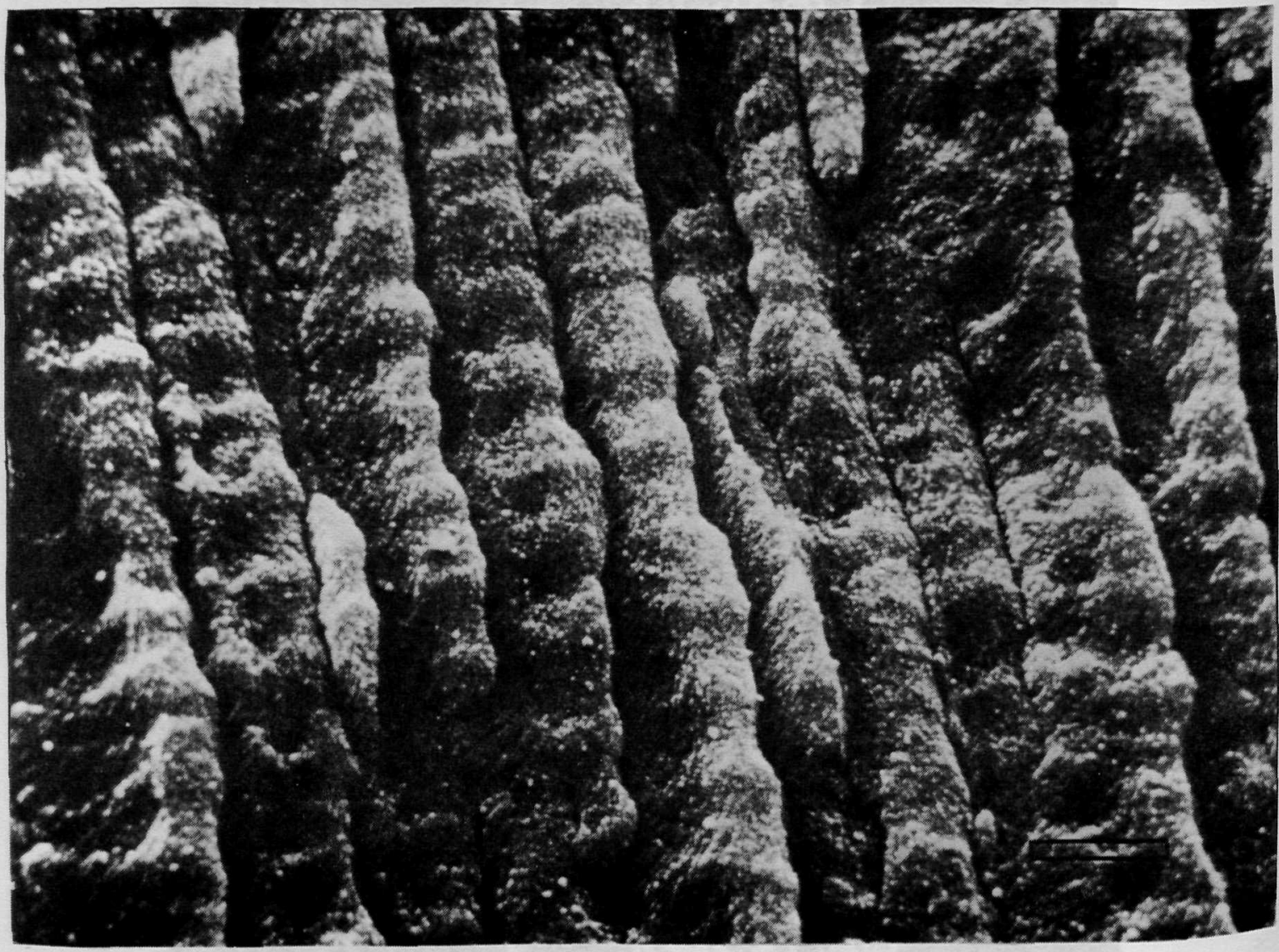

Figure 2: Prisms in the enamel of a human permanent molar from Medieval York. The dally layering of the prism cross striations is seen in this electron micrograph as a slight, regular bulging of the prism sidès. Fractured surface, etched and then sputter coated with gold. Cambridge Instruments 54 scanning electron microscope operated in secondary electron mode. Scale bar represents c. $5 \mu \mathrm{m}$. 


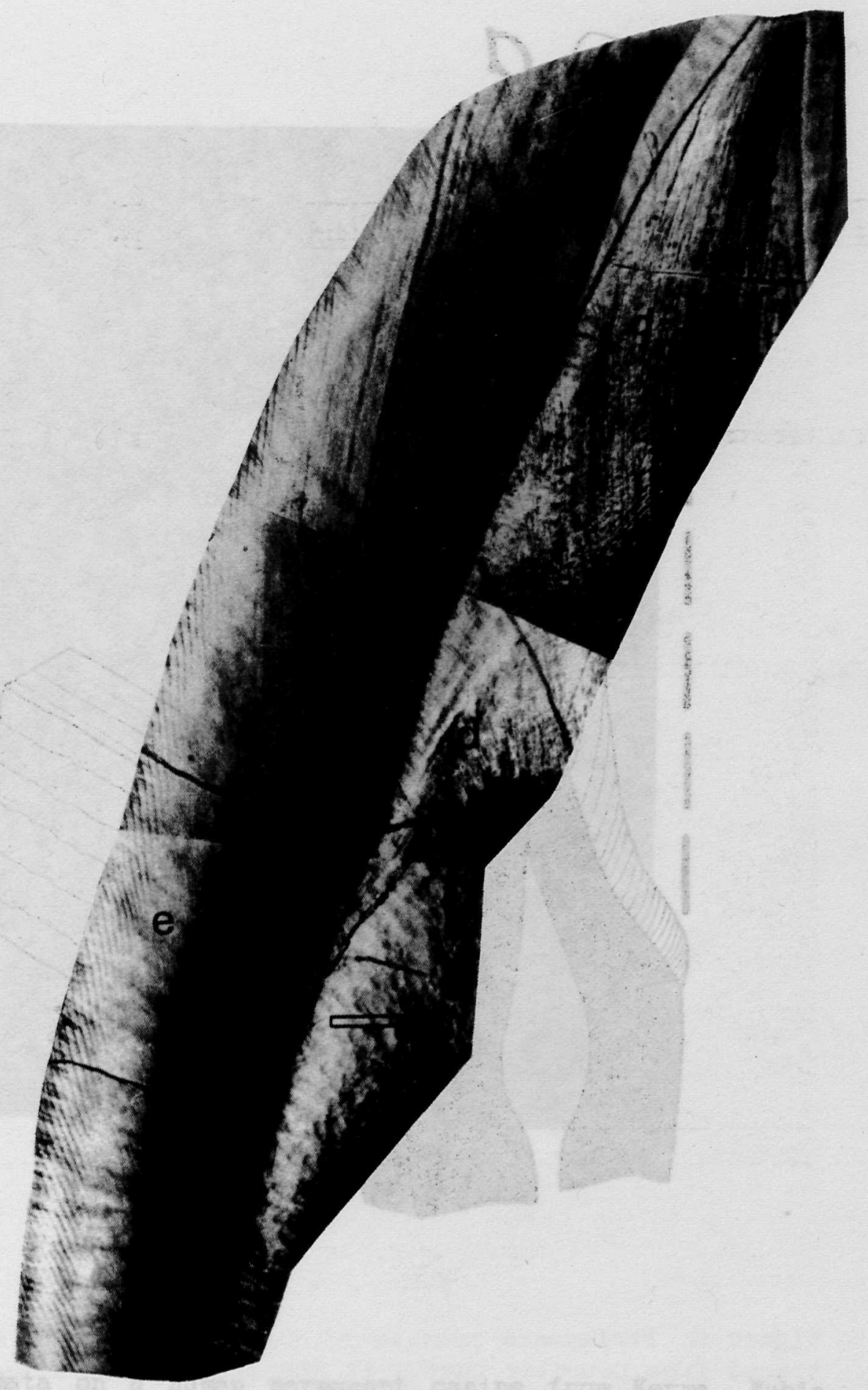

Figure 3: Section through the enamel of a crown fragment of a human permanent canine from Kerma, Nubia (1720-1550 B.C.). The enamel layer is marked " $e$ " and the underlying dentine of the crown is marked " $d$ ". At the top of the photograph, the tip of the crown has been worn away during life. Brown striae of Retzius can be seen running diagonally across the enamel thickness. This figure is a composite, made up from a serles of photomicrographs fitted together. Ground and polished thin section. Transmitted light microscope, viewed in plane polarised light. Scale bar represents c, $330 \mu \mathrm{m}$. 


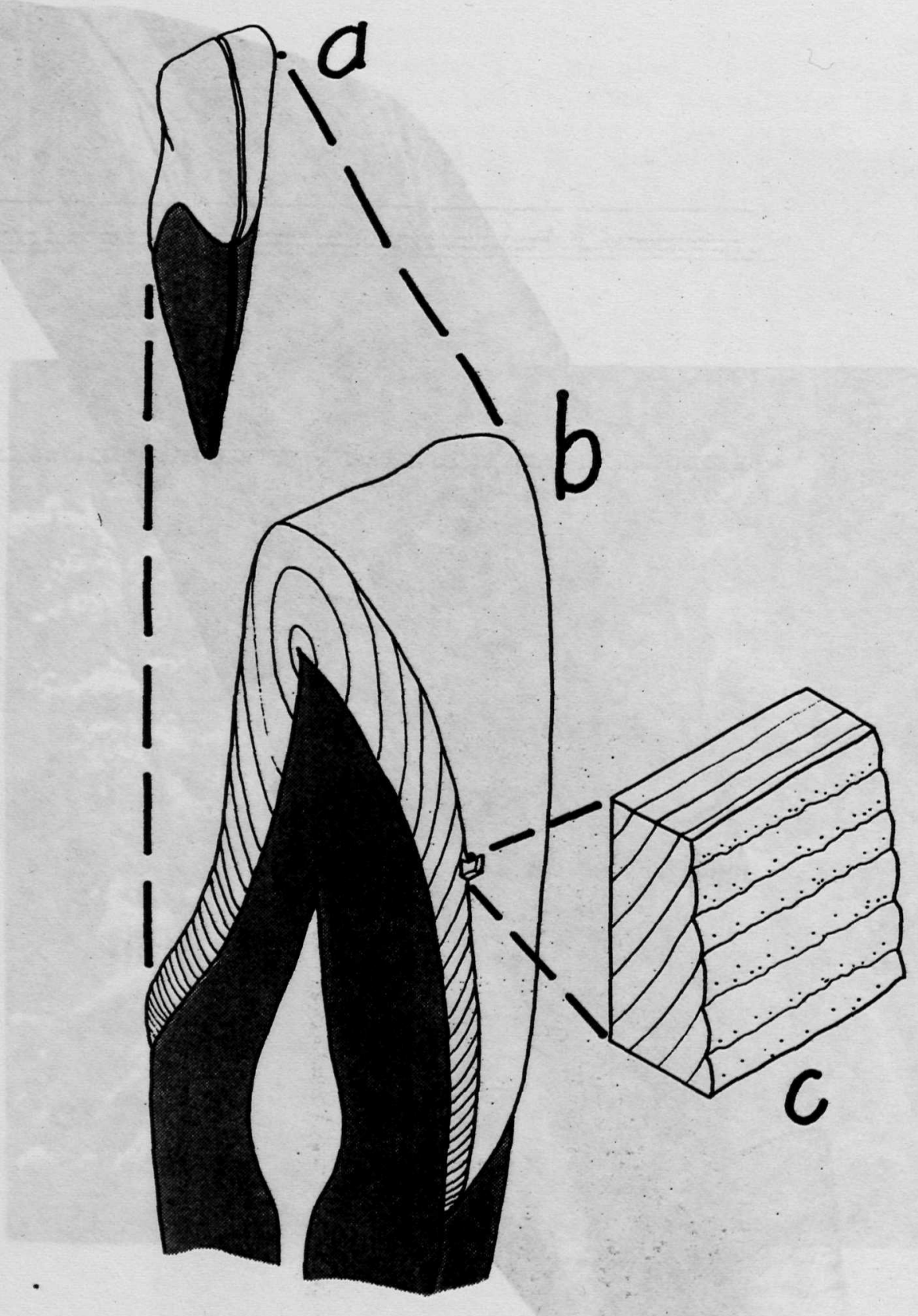

Figure 4: The organisation of brown striae of Retzius and perikymata in a hypothetical human upper incisor. "a" shows the line of section. " $b$ " shows the trend lines of the brown striae in the enamel of the crown - the trend only, because brown striae are very much more finely spaced than can be shown at this scale. The total height of the crown shown in "b" is around $1 \mathrm{~cm}$. " $c$ " is an enlarged block of the crown surface, representing a height of about $180 \mu \mathrm{m}$. It shows the brown striae rising up to meet the trough of the perikymata which run along the surface. 


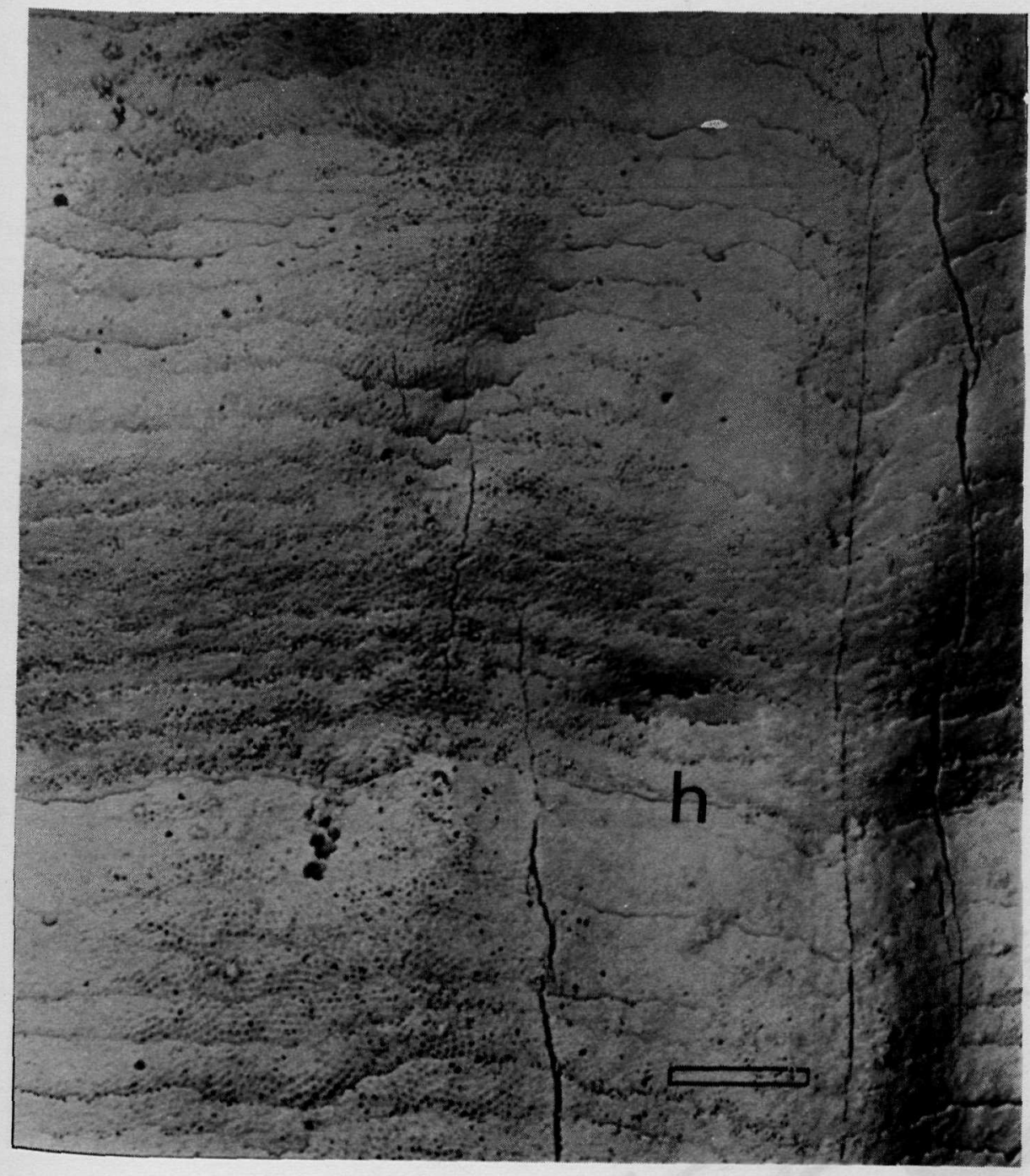

Figure 5: Perikymata on a human permanent canine from Kerma, Iubia $(1720-1550 \mathrm{BC})$. The grooves of the perikymata run roughly horizontaly across the photograph. The large groove mark " $h$ " is a minor defect of the type classified as enamel hypoplasia, caused by variation in the spacing of the perikymata. Impression of the crown surface, taken with Coltene President light body dental 1 mpression material, sputter coated with gold. Hitachi $S 570$ scanning electron microscope, operated at $15 \mathrm{kV}$ in secondary electron mode, using an inverted video setting so that the image appears as a positive - as it would if the crown surface 1 tself were belng observed. Scale bar represents $100 \mu \mathrm{m}$. 


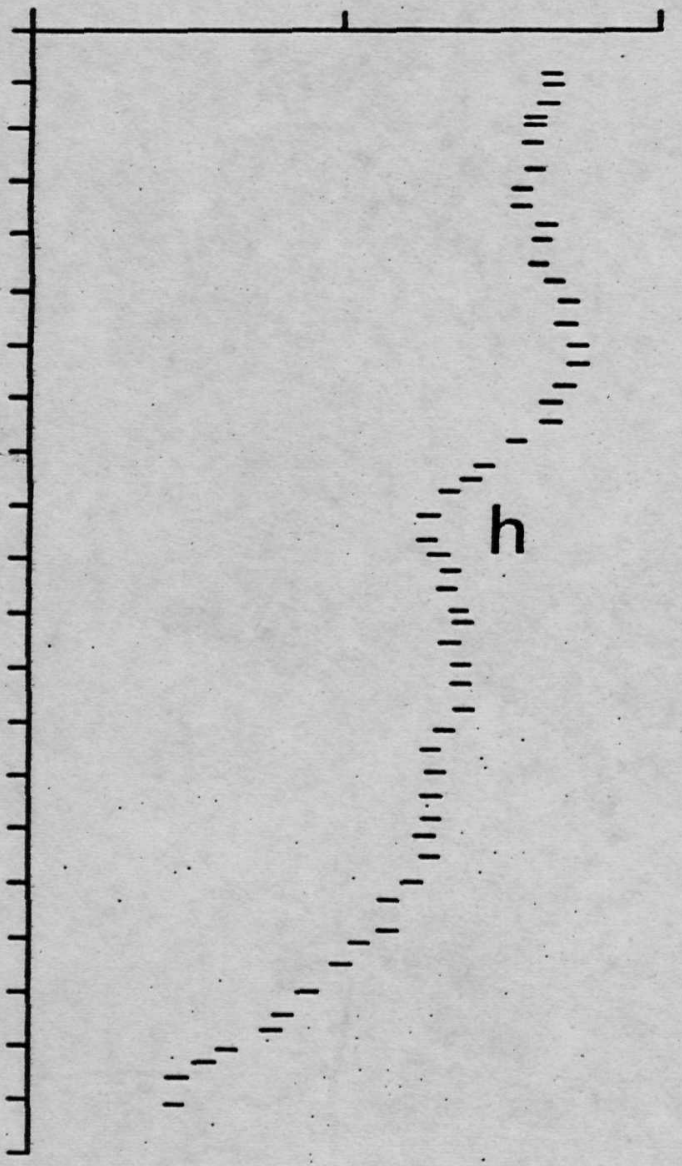

Figure 6: Perikymata profile of the crown surface shown in Figure 5 , traced from computer output of the crown surface measuring instrument developed by Hillson and Jones (1989). The divisions along the axes are at $100 \mu \mathrm{m}$ intervals (i.e. the horizontal scale is exaggerated relative to the vertical), and the right-hand ends of each of the ticks in the plot represent the grooves of individual perikymata. The prominent dip marked " $h$ " corresponds to the band of hypoplasia also marked " $h$ " on Figure 5 . 


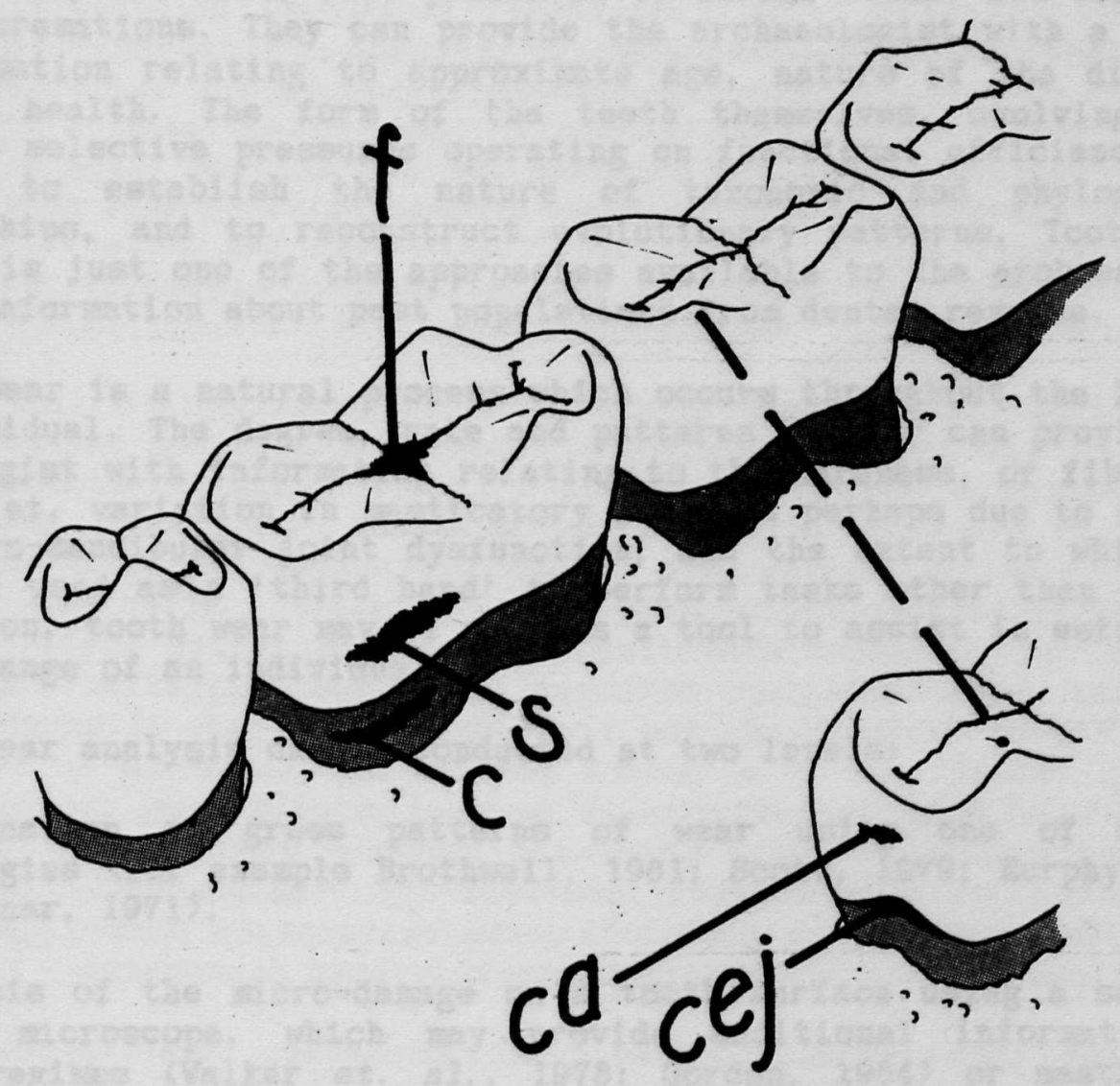

Figure 7: Some sites of dental caries initiation in a mandibular cheek tooth row; " $f$ " marks a fissure site, "s", a smooth crown surface site, "c", a site on the cement of a root surface, "ca", a contact area site and "cej", a site along the cement-enamel junction at the base of the crown. 

TOOTH VEAR AID THE ARCHAFOLOGIST

The role of human tooth wear in archaeological research

\author{
Elizabeth Cruwys, \\ Scott Polar Research Institute, \\ Lensfield Road, \\ Cambridge \\ CB2 1ER
}

Introduction

Teeth constitute the hardest material in the human body, and because of this, they are often well preserved in burial sites, and sometimes even in cremations. They can provide the archaeologist with a wealth of information relating to approximate age, nature of the diet and state of health. The form of the teeth themselves, evolving as a result of selective pressures operating on functional efficlency, can be used to establish the nature of taxonomic and phylogenetic relationships, and to reconstruct evolutionary patterns, Iooth wear analysis is just one of the approaches available to the archaeologist to gain information about past populations from dental remains.

Tooth wear is a natural process which occurs throughout the life of the individual. The degree, rate and patterns of wear can provide the archaeologist with information relating to the hardness, or fibrosity, of the diet, variation in masticatory patterns perhaps due to disease or tempora-mandibular joint dysfunction, and the extent to which the teeth are used as a 'third hand' to perform tasks other than eating. In addition, tooth wear may be used as a tool to assist in estimating the age range of an individual.

Iooth wear analysis can be conducted at two levels:

1. Examination of gross patterns of wear using one of several methodologies (for example Brothwel1, 1981; Scott, 1979; Murphy, 1959; 1968; Kolnar, 1971).

2. Analysis of the micro-damage on a tooth surface using a scanning electron microscope, which may provide additional information on dietary regimes (Walker et. al., 1978; Gordon, 1984) or masticatory movement (Ryan, 1979, a and b). However, a quantitative and objective method of assessing micro-damage still needs to be developed, and caution advised when interpreting results (Gordon, 1982).

The aim of the present paper is to present data from elght ethnically and culturally diverse peoples to 11 lustrate how tooth wear may be interpreted to provide information on past populations. The populations include historic and modern British and Inuit (Eskimo) groups. However, the processes and development of tooth wear is highly complex, and considerable individual variation is present to further complicate the picture. Perhaps the simplest way to define interacting aetiological factors of tooth wear is in terms of cause and effect. Factors which cause tooth wear include diet, uses of the teeth as a 'third hand' (i.e. holding objects between the teeth), methods of oral hygiene, artificial filing for cultural reasons and certain acid attacks. Factors which affect wear include the age and sex of the 
individual, the number of teeth present, and their size, shape and location in the dental arch, oral and general health, the state of the occlusion, bite force potential, timing and sequence of eruption, size and shape of the dental arch, deviations from the 'normal' masticatory process, dental trauma and the physical and biochemical structure of the teeth (to name but a few). It is not possible to examine tooth wear in relation to all these factors in a short paper, and so only diet, age, disease and cultural factors are examined here. To a certain extent, this is made easier by some of the modern individuals in the study, where specific aetiological factors can be isolated from medical history interviews.

Briefly defined, tooth wear is the progressive loss of dental tissue throughout the life of an individual. It may be differentiated into three distinct types, although in practice it is often extremely difficult to isolate one of these wear types in the individual since they normally occur simultaneously, and often mask each other. However, in some cases, the evidence for one or other type of wear is overwhelming, and can provide the archaeologist with a rare insight into individual habits. The distinction between the different types of wear is therefore a valid one for archaeological analysis, and the three terms should not be used interchangeably.

Attrition: wear caused by tooth-tooth contact. This includes the meeting of the teeth during normal chewing and during swallowing. In groups eating a hard diet, or using their teeth in extensive nonmasticatory function, attrition may be masked by abrasion. However, in certain cases, attrition may become pronounced when the teeth are persistently honed or ground together ('bruxism'), often as a response to stress or anxiety. This frequently occurs during sleep, and may affect the whole dentition, although more often only affects a certain combination of teeth ( $1 . e$, the front or back teeth). Although bruxism is often thought to be a modern phenomenon, there is no reason to suppose that some individuals in ancient populations did not grind their teeth during their sleep and produce unusual wear patterns. Although difficult to identify conclusively, the presence of bruxists in skeletal groups is a possibility to be borne in mind if all other explanations of unusual wear patterns have been discounted.

Abrasion: physical wear caused by objects other than the teeth. This includes food and other extraneous agents introduced into the mouth during its use as a 'third hand', such as pins, nails, pens or pipestems. The Inuit are noted especially for frequent and extensive use of their teeth in day-to- day life; Merbs (1968) and Pedersen (1949) note the softening of frozen hides, preparation of seal sinew for sewing, tying and tightening dog traces and constructing cross bows with the teeth. Tooth brushes, floss, picks and dentifrices may also cause abrasion.

Erosion: chemical attacks, usually acidic. These attacks are thought to originate from three sources: dietary (such as citrus fruits and juices, some alcoholic drinks and some spices); regurgative (caused by frequent and recurrent bouts of vomiting, a symptom of such conditions as hiatus hernia and certain upper digestive tract disorders); and industrial / atmospheric (severe erosion has been observed in zinc 
oxide factory employees in industrialised societies). Although the latter category is unlikely to occur in most skeletal populations, dietary and regurgitative erosion may be present; as yet, examination of erosion facets in past groups has been generally neglected. Erosion facets are distinct from attrition and abrasion, due to their smooth surfaces, 'cupping-out' of occlusal and incisal surfaces, and thin, brittle enamel on the Iingual surfaces of anterior teeth where the tooth has been eroded away (Smith and Knight, 1984).

\section{Haterial and Nethods}

The historic and modern Inuit and British populations in the study were chosen because they have little in common as regards culture, diet, environmental pressures and genetic affinity. The differences occurring in wear patterns on the teeth therefore, cannot be ascribed to common aetiologies. The modern populations were included because they are of known age and sex, and medical histories were avallable so that specific wear could be attributed to probable aetiologies.

Some 2696 individuals were included in the present study and were comprised as follows:

$\begin{array}{ll}\text { British } & \text { Anglo-Saxons } \\ & \text { Romano-British } \\ & \text { Kodern } \\ \text { Inuit } & \text { Canadian } \\ & \text { Canadian } \\ & \text { East Greenland } \\ & \text { East Greenland } \\ & \text { Vest Greenland }\end{array}$

422 skeletons
313 skeletons
459 models (dental casts)

71 skeletons

649 models (modern)

163 skeletons

160 models (modern)

459 skeletons

British: the skeletal populations, dating from c. 300 B.C. until c. 1200 A.D., were in all probability eating a fairly coarse diet with cereal staples. The modern group (taken from models stored in dental clinics and Dental Schools in Leeds, Newcastle-upon-Tyne and Bradford) were known to be eating contemporary soft Vestern foods.

Inuit: the diet of the historic and the modern groups of East Greenland Inuit consists mainly of meat (sea mammals, caribou and birds) and fish. This would be mostly consumed raw, often still frozen, or bolled. Fruit and vegetable matter would only be avallable in the summer months. The modern Canadian population are eating a combination of traditional foods and imported shop foods (Mayhall, 1970). Canned and packeted foods are also available, along with sugar, processed flour, and tea and coffee.

The skeletons in the study were given approximate age ranges using non-dentally based criteria suggested by Bass (1981), Stewart (1979), Brothwell (1981) and the Workshop of European Anthropologists (1980). Exact chronological age and sex was available for the modern material from dental and anthropological records.

Molnar's (1971) method of recording the degree of wear on the occlusal and incisal dental surfaces was used, with an additional 
stage added at the beginning so that a small enamel facet could be distinguished from enamel loss over two or more cusps (Cruwys, 1988).

\section{Results and Discussion}

Diet

Previous studies have suggested that the degree of wear varies between different dietary regimes, so that traditional meat and vegetable, cereal diets cause heavy wear (Taylor, 1975; Smith, 1972; Davies, 1972), opposed to the slight degree of wear caused by a Western diet. Hylander (1977) and Luke and Lucas (1983) suggest that food preparation techniques are more responsible for abrasion than the hardness of the diet itself; Taylor's (1975) comparison of dietaryrelated wear rates in indigenous Polynesian groups suggests that both factors may be at work simultaneously. Taylor showed that there was more extensive wear on the teeth of Maoris / Morioris, who were eating tough fibrous foods with high levels of contaminants from cooking methods and wind-blown particles, than on the teeth of Tongans, who were eating softer foods with little contamination. As a tool for identifying the precise nature of the diet of a population therefore, it would seem that gross tooth wear is inapproriate.

The rate of wear on the first molars of British, Greenland Inuit and Canadian Inuit where exact chronological age was known is shown in Figure 1. It seems ilkely that the different hardness of the diets of the three groups is largely responsible for the variation. Figure 2 shows the dentitions of two individuals of similar chronological age from two different populations; the disparity in the degree of wear on all teeth is immediately apparent. Other teeth were 11 kewise plotted, and show similar patterns - with the East Greenland Inuit (eating purely traditional foods) showing the fastest rates of wear and the British, (eating the softest foods) the slowest. Rates of wear also vary between individual teeth, so that in the East Greenland population, for example, upper central incisors show a much greater rate of wear than any molars (Figure 3). It is likely that this is due to anterior tooth use in non-masticatory function. These differences within the mouth suggest it is inappropriate to use combinations of different types of teeth to form 'tooth wear indices'. Wear is better assessed from individual teeth, or tooth series although right / left differences tend not to be significant in the absence of pathologies or unilateral tooth loss.

\section{Ageing}

Perhaps one of the most valuable uses of tooth wear for the burtal archaeologist is its potential for estimating age ranges. The chief advantages are the accessibility of teeth, quick application of tooth wear parameters in the field, and the fact that there is no need to section or destroy the material. However, although charts are available offering broad estimates of age through varying degrees of tooth wear, it must be remembered that since the abrasive qualities of the diets in different populations vary, so do the resulting rates of tooth wear. Ageing from tooth wear is therefore population specific. This is clearly evident from Figures 1, 2 and 3. 


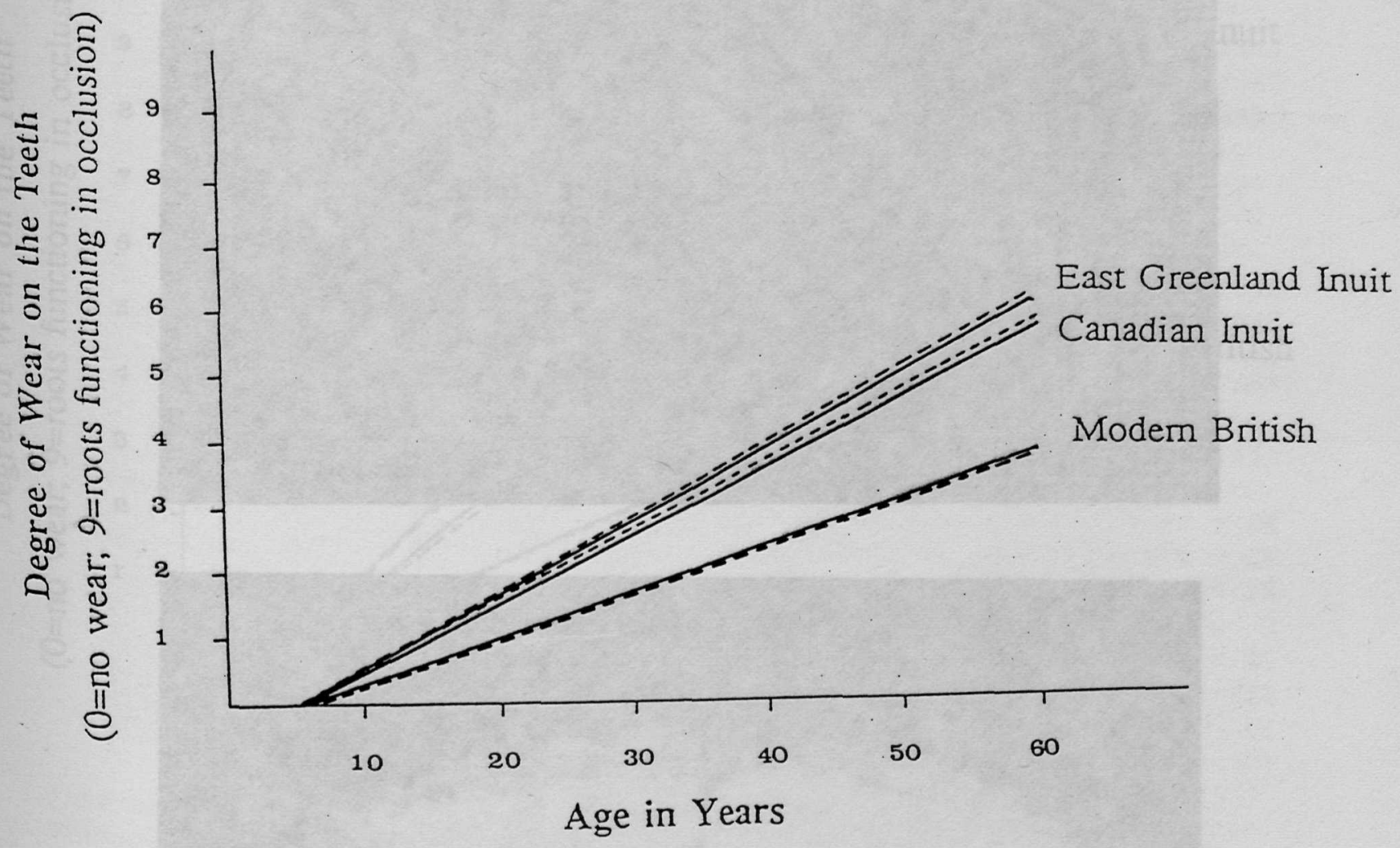

Figure 1: A comparison of the rate of wear on the first molars of British, East Greenland Inuit and Canadian Inuit (upper teeth unbroken line; lower teeth - dotted line). 

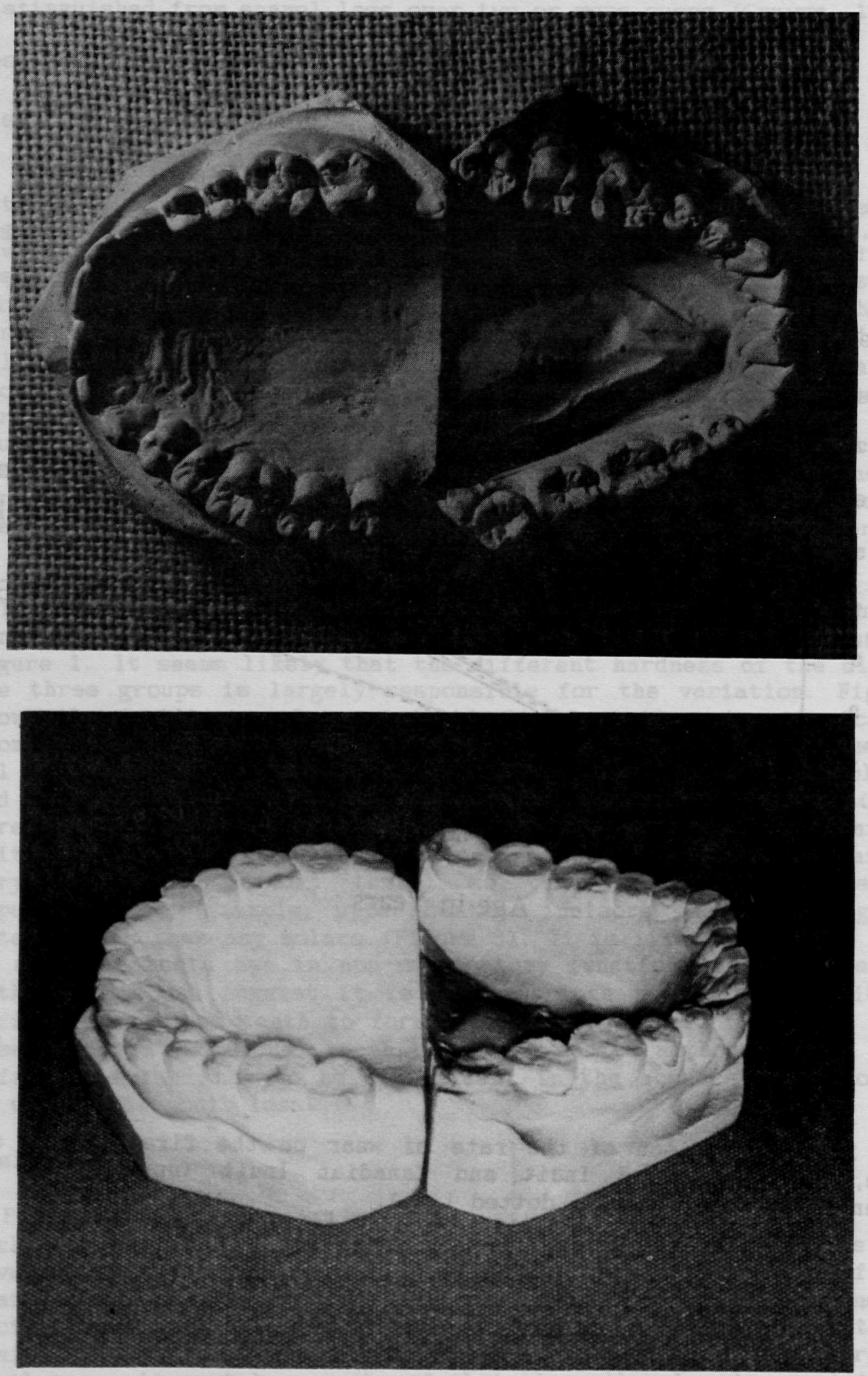

Figure 2: The dentitions of two individuals of similar chronological age from a: the modern British population ( 30 year old male), $b$ : the modern East Greenland population ( 35 year old male). 


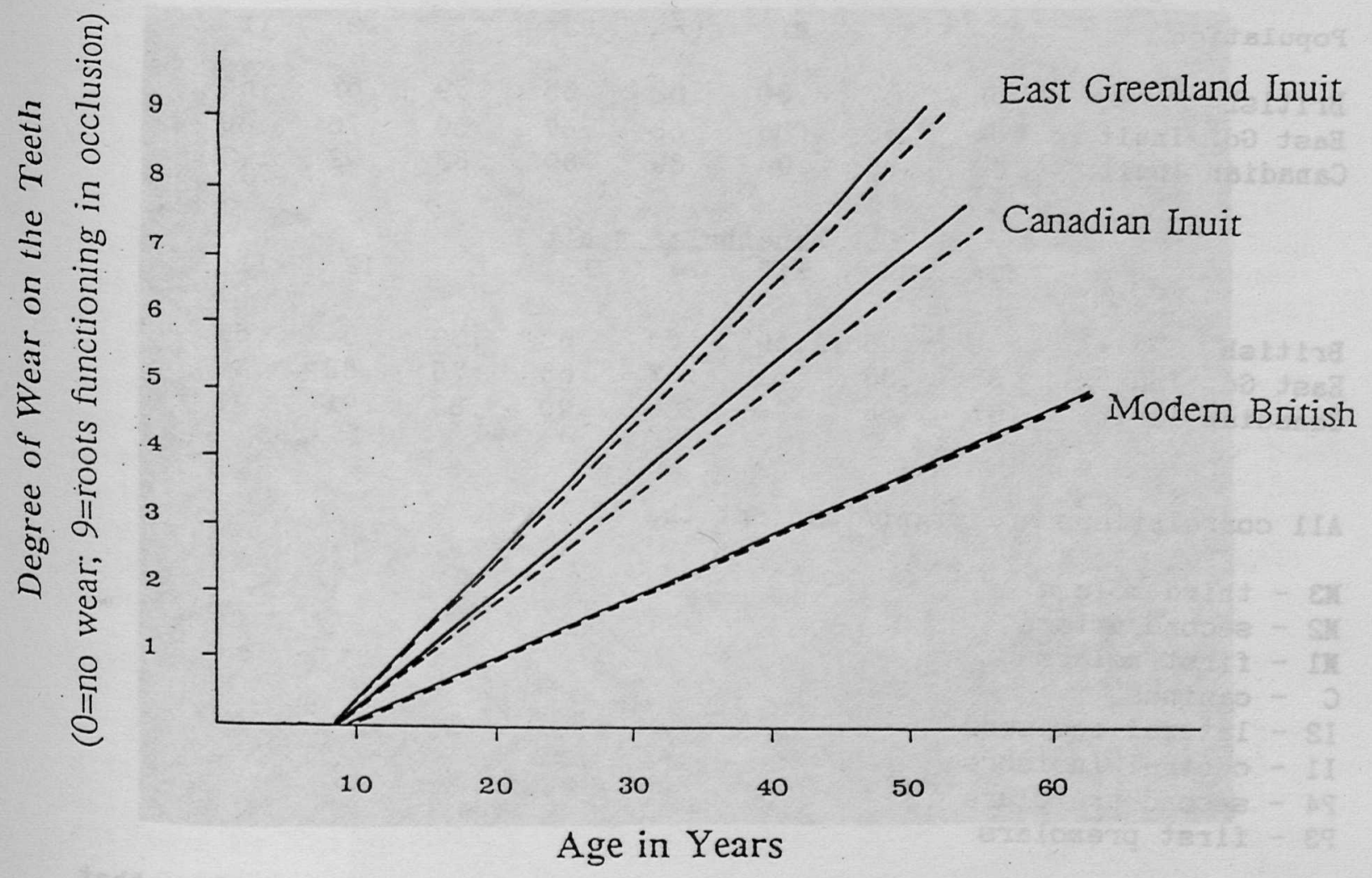

Pigure 3: A comparison of the rate of wear on the central incisors of British, East Greenland Inuit and Canadian Inuit (upper teeth unbroken line; lower teeth - dotted line). 
Table 1

Ion-parametric correlation coefficients showing the strength of the relationship between age and the degree of wear on the occlusal $l$ incisal surfaces of the teeth (individuals of known chronological age)

\section{Maxillary teeth}

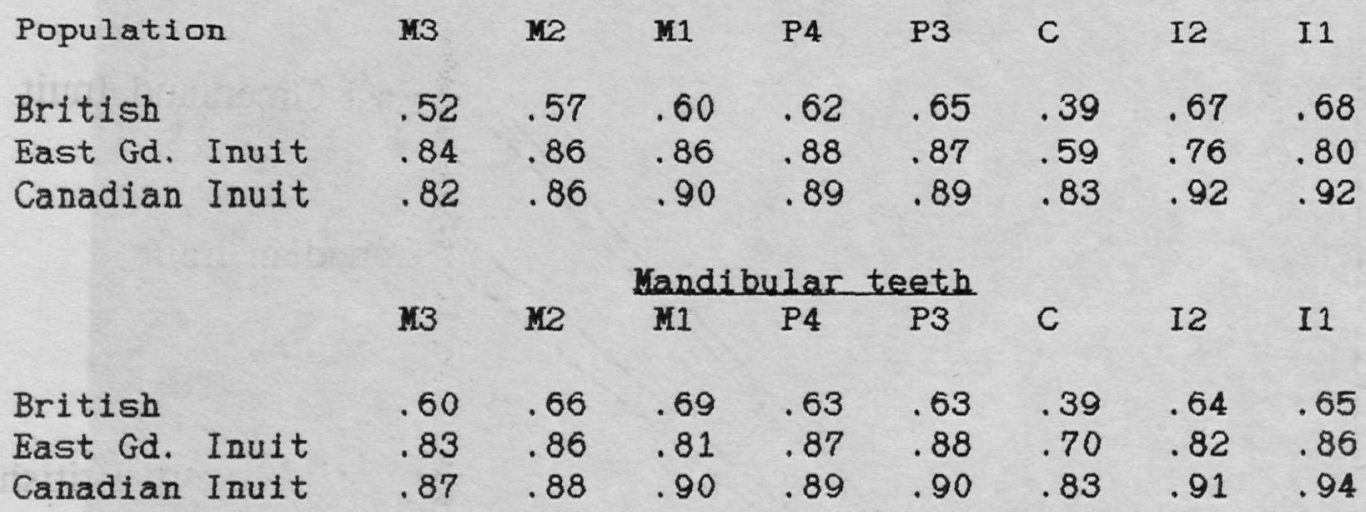

All correlations are significant at the $5 \%$ level

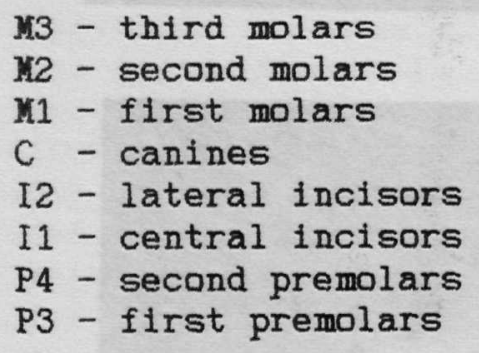

The non-parametric correlation coefficients in Table 1 show that throughout all three populations, there is a strong positive relationship between tooth wear and chronological age. This is especially evident in the Canadian population - notably for the incisors. In all three populations, the lowest correlations are for the canines and third molars. A possible reason for this is that the late eruption of the third molars, and their variable morphology and occlusion may affect wear rates. The canines tend to wear quickly in modern populations, but again, much depends on occlusion and the frequency of use of the canines as a 'third hand'. Overall, however, the relationship between the two variables is good.

There was considerable variation in the rates of wear within each population, particularly in the modern groups, where 'third hand' tooth use'tends to be more habitual than general practice. Perhaps it is a function of modern populations that the absence of an abrasive diet accentuates wear caused by other tooth uses and abuses so that some teeth in some individuals show greater wear than others. Inevitably, many factors combine to show variation in wear, even within individuals of the same chronological age in the same 


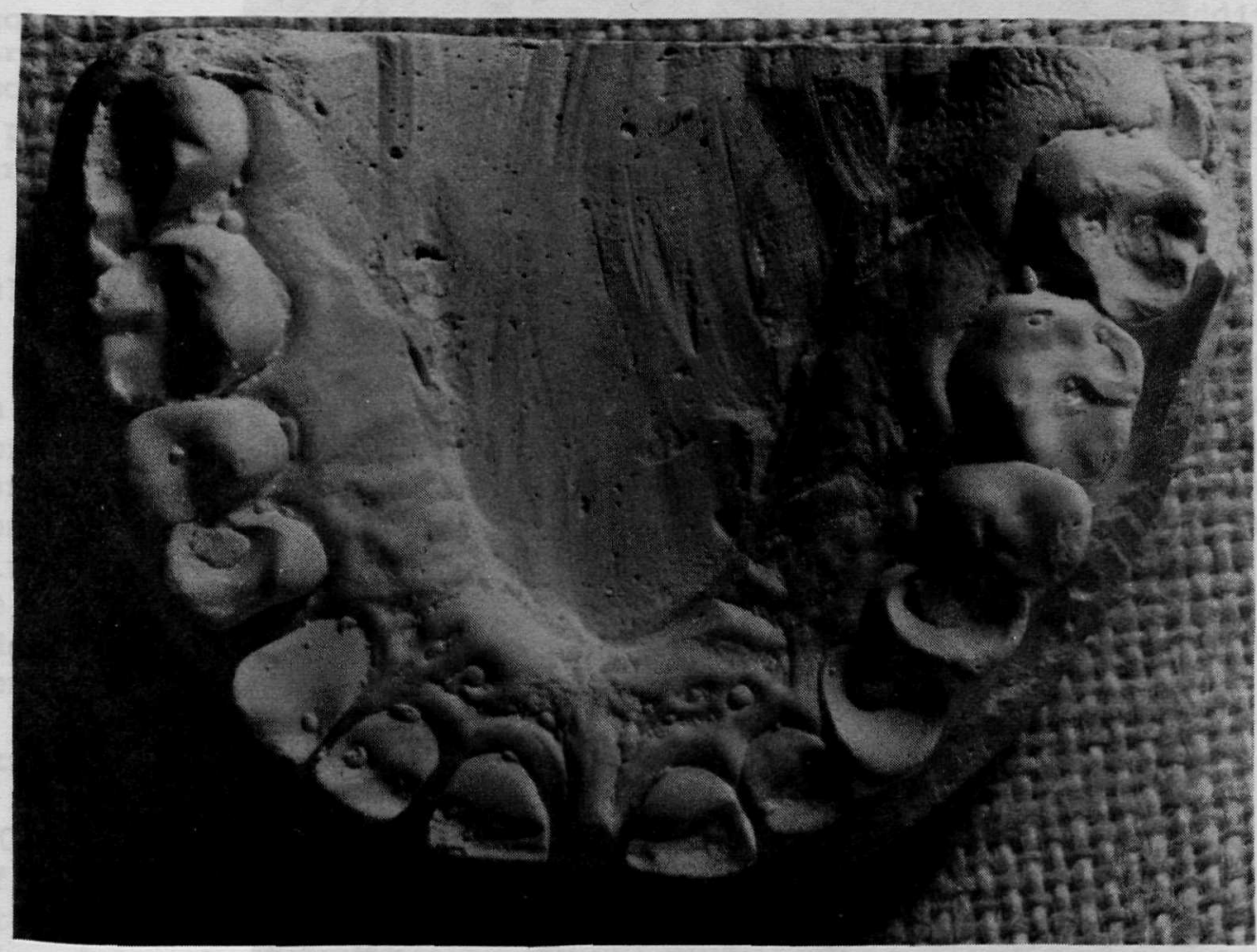

Figure 4a: An 18 year old female anorexic patient (British) showing Intra-oral effects concomitant with chronic regurgitation (disparate wear between the upper and lower teeth and a 'cupping' out of the lingual surface of the anterior teeth. Also there is a distinct groove in the upper incisors where the softened dental tissues have been abraded by the harder lower teeth 


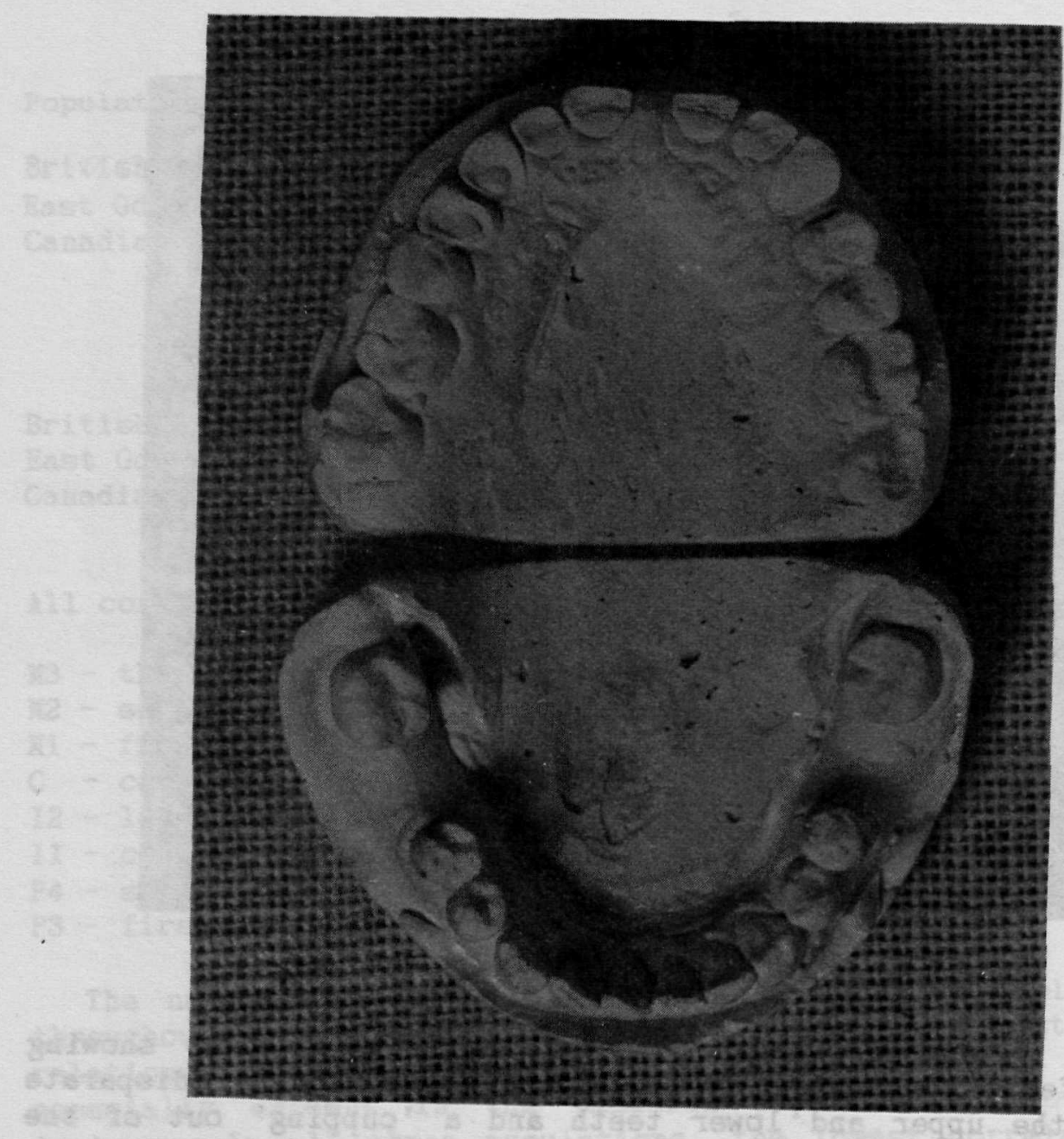

Figure 4b: A young Anglo-Saxon female showing similar wear patterns to those modern patients known to be suffering from chronic regurgitation. 
population. Intrapopulation variation is discussed in greater detall in Cruwys (1988).

\section{Disease}

Often, variation in the pattern of tooth wear may occur as a result of dental disease. A missing or decayed tooth, or an abscess, may result in a shift of chewing from one side to another. Thus in cases where there is a definite preference for one side in wear, pathological or abnormal conditions may be responsible. In addition, severe attrition on particular teeth is often indicative of bruxism. Although bruxism may be a relatively recent phenomenon in oral health, the possibility of finding an individual with bruxist wear patterns in an archaeological population should not be ruled out.

As yet, analysis of regurgitative erosion in archaeological populations has not been undertaken, although it would seem likely that acid erosion from gastro-intestinal disorders or other diseases may have occurred. Figure $4 \mathrm{a}$ shows the dentition of a modern patient with extensive regurgitation erosion. It is possible that the AngloSaxon in Figure $4 \mathrm{~b}$ may also show some evidence of erosion due to regurgitation. This would suggest that acid erosion is a valid line of investigation in past populations, and could be used to assess the health status of an individual. Research in progress has found that some 14 of 422 Anglo-Saxons, and 17 of 313 of Romano-Britons show evidence of severe erosion, although the precise aetiology remains uncertain.

\section{Cultural factors}

Cultural influences on the teeth are perhaps one of the most difficult areas to identify, because they are so varied. The effect of cultural practices on tooth wear fall into two categories: practices followed by the entire community, or a large section of it, (such as hide-chewing in the Inuit groups) and individual habits. Wear associated with behavioural practices is generally confined to the anterior teeth, and accasionally the premolars. This is simply because the anterior teeth are more conveniently situated for non-masticatory function.

At the population level, hide-chewing was $11 k e l y$ to have been the most major cause of the wear on the anterior teeth of the Greenland Inuit populations in the current study. Evidence for this is mostly ethnographic (Merbs, 1968; Pedersen, 1949; De Poncins, 1941; Victor, 1938). That there is continued wear after occlusal contact is lost (see Figure 5) would suggest that abrasional, rather than attritional. factors are responsible. Pedersen (pers. comm.) observed grooves running in a mesio-distal direction on the anterior teeth of East Greenland females. These are thought to be caused by seal sinew preparation. The technique involved is to take a length of seal sinew and draw it across the teeth to render it pliable for sewing. Facets of this nature were observed in many Inuit women from Greenland, although none were observed from the Canadian Inuit in the present study. 


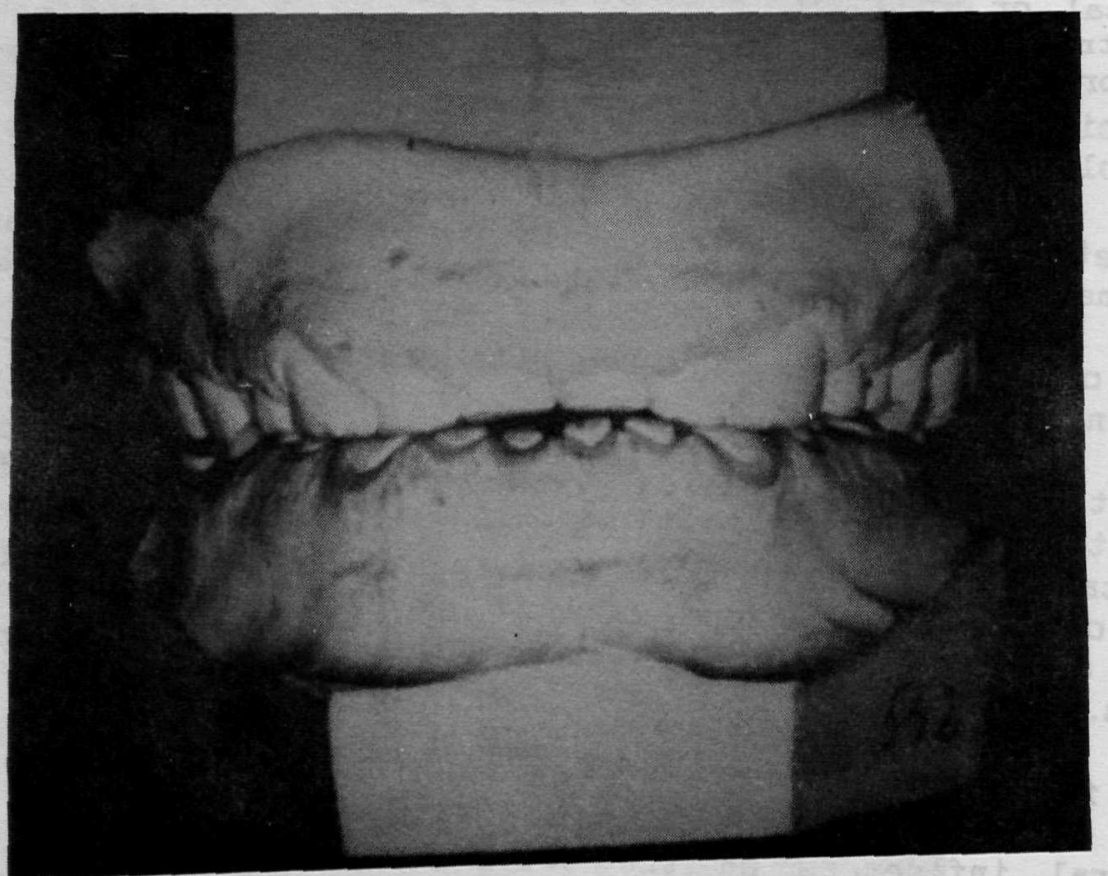

Figure 5: An old Inuit female from East Greenland showing extensive wear, and an ability to produce contact between the anterior teeth. 


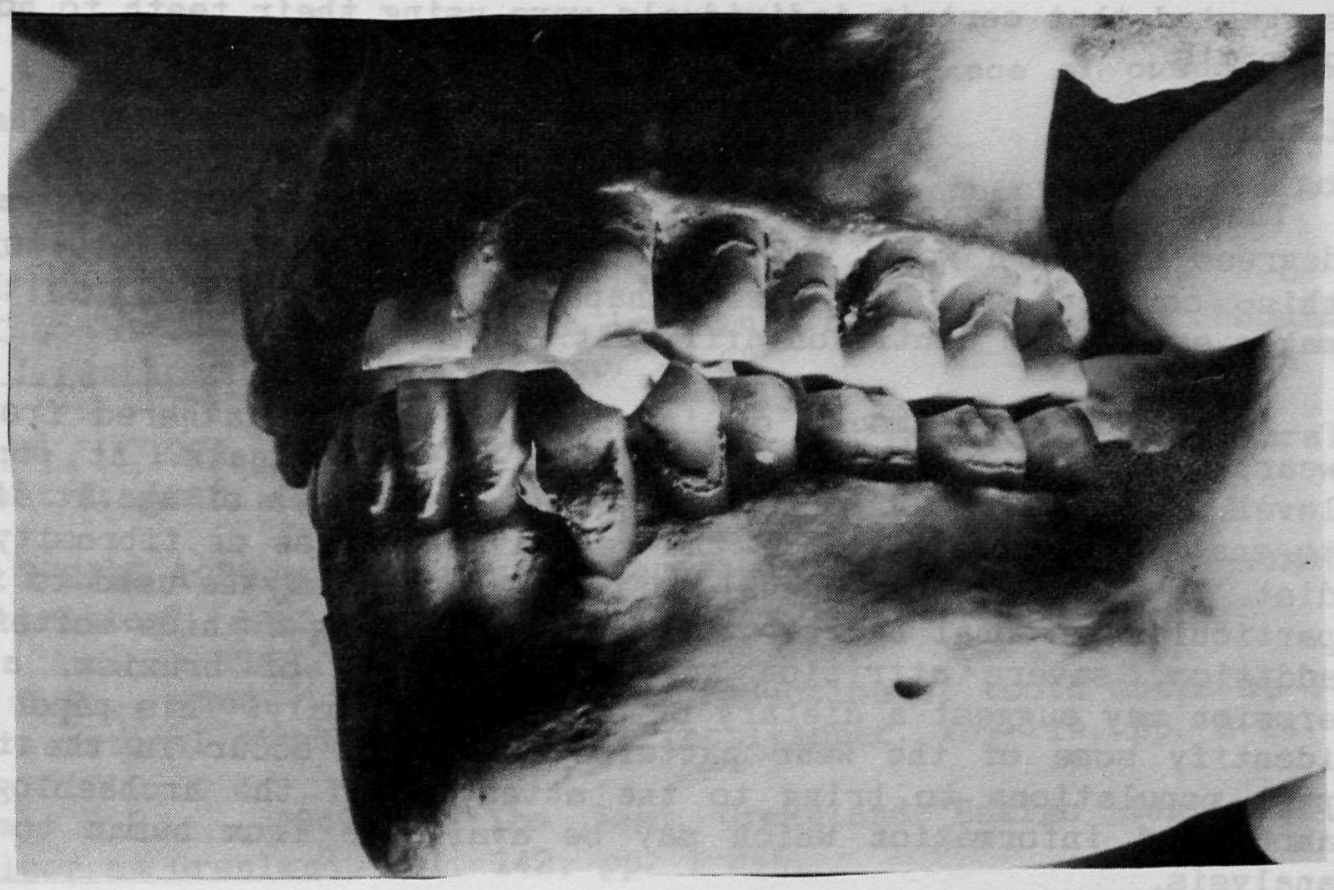

Figure 6: A circular facet between the canines and lateral incisors thought to have been caused by persistant abrasion with a pipe-stem. 
In terms of individual habits, the circular facet in the individual in Figure 6 suggests the prolonged use of an abrasive pipe-stem. A similar facet occurred on the left side of the dentition in the same individual, indicating the pipe was held between the teeth on both sides of the mouth. In the Anglo-Saxon population, some 9 individuals showed evidence of notches in their anterior teeth, suggesting perhaps some vocational babit (Cruwys et. al., in press.). No other early British or Inuit groups showed evidence of these patterns, and it is suggested that certain individuals were using their teeth to hold pins or nails.

\section{Conclusions}

There are many factors which may influence the patterns, rates and degrees of tooth wear, and produce variations in the results. It is this, coupled with the size, shape and state of oral health which makes each human dentition different.

A considerable amount of information can be gathered from tooth wear, both from population data and in individuals. At population level, tooth wear may be used to produce estimates of age at death, or to enable interpretation of the relative hardness or fibrosity of the diet. In individuals, unusual patterns of wear my be used to indicate particular personal habits, such as pipe smoking or hide softening. In addition, severe attrition may be indicative of bruxism, and acid erosion may suggest a dietary or digestive anomaly. This paper aims to identify some of the wear patterns which may occur in the teeth of past populations to bring to the attention of the archaeologist the amount of information which may be available from human tooth wear analysis.

\section{BIBLIOGRAPHY}

Bass, W. M., 1981 - "Human Osteology". Archaeological Society, Missouri.

Brothwell, D.R., 1981 - "Digging up bones. The excavation, treatment and study of human skeletal remains". Oxford University Press, Oxford and British Museum (Natural History), London.

Cruwys, E., 1988 - "Iooth wear patterns in modern human populations". Unpublished PhD Thesis. Department of Physical Anthropology, University of Cambridge.

Cruwys, E., Robb, N. and Smith, B.G.N., (in press.) - "Notching in the anterior teeth of a population of Anglo-Saxons".

Davies, D.M., 1972 - "The influence of teeth, diet and habits on the human race". Heinemann Medical Books, London.

De Poncins, K., 1941 - "Kablooma". Reynal, New York.

Gordon, K.D., 1982 - "A study of microwear on chimpanzee molars: implications for microwear analysis". Amer. J. Phys, Anthrop., Vol. 59. pp. 195-215. 
Gordon, K. D., 1984 - "Hominid dental microwear: complicatione in the use of microwear analysis to detect diet". J. Dental Research, Vol. 63, pp. 1043-1046.

Hylander, W., 1977 - "Horphological changes in human tooth and jaws in a high attrition environment", pp. 301-330, in A. A. Dahlberg and T.M. Graber (Eds), Orofacial growth and development. Mouton Press, The Hague.

Luke, D.A. and Lucas, P.W., 1983 - "The significance of cusps". J. Oral Rehabilitation, Vol. 10, pp. 197-206.

Mayhall, J.M., 1970 - "The effects of culture change upon the Eskimo dentition". Arctic Anthropology, Val. ?, pp. 117-121.

Merbs, C., 1968 - "Anterior tooth loss in Arctic populations". South Vestern J. Anthropology, Vol. 24, pp. 20-32.

Molnar, S., 1971 - "Human tooth wear, tooth function and cultural variability". Amer. J. Phys, Anthrop., Vol. 34, pp. 175-189.

Kurphy, T.R., 1959 - "Changing patterns of dentine exposure in human tooth attrition". Amer. J. Phys, Anthrop. Vol. 17, pp. 167-178.

Kurphy, T.R., 1968 - "The progressive reduction of tooth cusps as it occurs in natural attrition". Dental Practitioner, Vol. 19, pp. 8-14.

Pedersen, P.O., 1949 - "The East Greenland Eskimo dentition". Keddelelser om Gronland, Vol. 142, pp. 1-244.

Ryan, A.S., 1979a - "A preliminary scanning electron microscope examination of wear striation direction of primate teeth". J. Dental Research, Vol. 58, pp. 525-530.

Ryan, A.S., 1979b - "Wear striation direction on primate teeth: a scanning electron microscope examination". Amer. J. Phys. Anthrop., Vol. 50 , pp. 155-168.

Scott, E.C., 1979 - "Dental wear scoring techniques". Amer. J. Phys. Anthrop., Vol. 51, pp. 213-218.

Smith, B.G.N. and Knight, J.K., 1984 - "A comparison of patterns of tooth wear with aetiological factors". British Dental J., Vol. 157, pp. $16-19$.

Smith, P., 1972 - "Diet and nutrition in the Natufians". Amer. J. Phys. Anthrop., vol. 37, pp. 233-238.

Stewart, T.D., 1979 - "Essentials of forensic anthropology". Charles C. Thomas, Springfield, Illinois.

Taylor, R.M.S., 1975 - "The significance of tooth wear in Polynesians - a review". J. Dental Association of South Africa, Vol. 30, pp. 241244 
Victor, P-E., 1938 - "My eskimo 11fe". Hamish Hamilton, London.

Walker, A., Hoeck, H.N. and Perez, L., 1978 - "Microwear of mammalian teeth as an indicator of diet". Science, Vol. 210, pp. 908-911.

Workshop of European Anthropologists, 1980 - "Recommendations for age and sex diagnosis of skeletons". Iournal of Human Evolution 9: 517 549 . 


\title{
DEMTAL CARIES AID IUTRITIOHAL STRESS IN EMGLISH ARCHAEOLOGICAL CHILD POPULAT IOIS
}

\author{
E. O'Sullivan, S.A. Williams, M.E.J. Curzon \\ Department of Child Dental Health \\ University of Leeds \\ Leeds LS2 9LU
}

\section{Summary}

This study aimed to determine whether there was any association between dental caries prevalence involving the primary dentition and cribra orbitalia in archaeological populations. The periods covered range from pre-Roman to late Mediaeval times. The skeletal remains of 221 children were examined, of whom 100 had orbital material available. Of these, only children with all first primary molars present were included, and carles diagnosis was restricted to these teeth only for the purposes of comparison.

Data from 50 children were ultimately available for analysis. A statistically significant association was found between caries prevalence and cribra orbitalia. The findings suggest that nutritional stress is an associated factor in caries aetiology in children.

\section{Review of the literature}

The examination of dental structures forms an important part of the assessment of human archaeological material, as teeth are usually the best preserved part of skeletal remains. Nany studies on the dental state of past populations have been carried out, but relatively few have provided detailed information concerning the deciduous dentition (Wells, 1975). This may be due to the sparsity of juvenile remains, or to the general poor state of juvenile compared with adult skeletal material.

In living populations, levels of dental carles experience are best expressed as the average number of decayed, missing and filled teeth per Individual (H1lison, 1986). In archaeological work, however. samples may be small and teeth may be lost or scattered and so modern epidemiological methods are inappropriate. Many archaeological studies have reported simply on numbers and proportions of carious teeth without specifying tooth types, but this can lead to bias as proportionately more multi-rooted posterior teeth are usually avallable for examination. It is more appropriate to obtain tooth-type studies and, for example, state the carles prevalence for the molar teeth separately from the carles prevalence of anterior teeth (James and Miller, 1970). This also allows similar studies to be compared.

James and Miller (1970) studied a group of Mediaeval English children and recorded that $7.5 \%$ of primary 1 ncisors and canines, and $16.5 \%$ of primary molars were carious. Moore and Corbett (1973) recorded the state of primary molars, in children from Saxon ( 5 th-10th centuries), Medieval ( $11 \mathrm{th}-15 \mathrm{th}$ centuries) and $17 \mathrm{th}$ century England, and found that $5.3 \%, 7.1 \%$ and $20 \%$ respectively were carious. Similarly, Williams and Curzon (1985) reported that $3 \%$ of primary 
canines and incisors and $15 \%$ of primary molars were affected among a Mediaeval child population from the Scottish Border country.

The aetiology of dental caries is related to the composition, frequency of intake and texture of the diet, the types of bacterial flora present, the buffering capacity of the saliva and the structure of the teeth (Nikiforuk, 1985). A number of studies, notably Moore and Corbett (1978), have recorded changes in caries experience of English populations with changing diets, but this is only one aspect of caries aetiology. There are both pre-eruptive and post-eruptive factors (McDonald, 1985), and even nutrients in the diet can affect caries susceptibility of teeth in both ways.

According to Russell (1963), the populations with fewer nutritional deficiencies tend to be those having greater problems with dental carles, but McDonald (1985) points out that this is not necessarily true for the primary dentition. The occurrence of dental caries in several pre-Industrial countries is more severe in the primary than the permanent dentitions.

Nutritional stress may be an associated factor. Children recovering from third degree malnutrition in Guatamala had more dental caries in the primary dentition than those who were less malnourished (Sawyer and Nwoku, 1985). In the United Kingdom, lower weight percentile values (indicative of a fallure to thrive) were found to be associated with higher levels of decay (Miller et. al., 1982; Villiams et al., 1988).

In archaeological populations, porotic hyperostosis and cribra orbitalia provide useful tools for investigating nutritional stress (Manchester, 1983; Stuart-Macadam, 1985). Cribra orbitalia is reported to occur with greater frequency in children than adults (StuartMacadam, 1985). The aetiology of anaemia has received support from recent radiographic studies (Stuart-Macadam, 1987), although the severity of the anaemia does not always correspond with the severity of the bone changes.

Stuart-Macadam (1985) has found a significant association between cribra orbitalia and hypoplasia in adults and juveniles from a RomanoBritish site. However, it was not stated whether the condition was restricted to observations of the permanent teeth alone. The author considered that children stressed nutritionally and systematically might be susceptible to cribra orbitalia defects and hypoplasia due to a range of conditions or insults creating both conditions. It is possible that they may also be more at risk to dental caries development.

The aim of the present study was therefore to determine for individual children within an archaeological group, whether there was an association between dental caries involving first primary molars and cribra orbitalia. 


\section{Haterials and methods}

The original sources of the remains were various burial sites in England, the largest quantities derived from Dorset and Winchester Cathedral Green. The dates for the remains studied were divided into six broad archaeological periods from Prehistoric to late Mediaeval times. The skeletal material was examined at the Department of Archaeological Sciences at the University of Bradford and in the Department of Palaeontology of the British Museum (Natural History), London. Only the remains containing some primary teeth were examined.

For each individual, a separate dental chart was completed. The dentition was examined and charted according to the system recommended by the World Health Organisation (WHO, 1987). All surfaces of the teeth were examined under strong light with the ald of a dental explorer. Only undoubted cavities, with obvious cavitation or where stickiness or softness were encountered were recorded as carious (WHO, 1987).

In those cases where there was sufficient cranio-facial material avallable in good condition, an examination was made for 'cribra orbitalia'. If present, it was classified according to the severity:

Slight

Moderate

fine, pin-point apertures

Severe

larger, but still isolated apertures

larger apertures, which have become confluent resulting in a resemblance to bony trabeculae (Brothwell, 1981)

For comparative purposes, only chlldren with all four first primary molars present were included, and caries diagnosis involving these teeth was then related to the presence and severity of cribra orbitalia in the same individual.

Prior to commencement of the main study, several calibration exercises were carried out on juvenile remains, in order that diagnostic criteria were precisely defined. A high level of agreement was achieved and any specific problems anticipated and resolved.

\section{Results}

A total of 221 juvenile skeletal remains yielded dental material for the study. Table 1 shows the period, location and number of individuals examined in each respective archaeological period. Only material from five children had completely intact dentitions involving no postmortem loss. 
Table 1

Period, location and number of remains studied

$\begin{array}{lll}\text { Period Source Dates } & \text { Io. Individuals }\end{array}$

Prehistoric Various U.K. $\quad 3000$ B.C. -600 B.C. 15

Roman Dorchester.

Chester.

Berks. ,

Gloucs.,

Stratford

55 B.C. -410 A.D. 65

Early

Anglo-Saxon

Winchester, Kent,

Somerset $\quad 5$ th -6 th century 26

Late

Anglo-Saxon Berks., N. Hants.,

N. Yorkshire $9 t h-11$ th century 73

Early

Medieval

N. Yorkshire, Oxon.

11 th -12 th century 9

Late

Medieval E. Yorkshire,

Winchester $13 t h-15 t h$ century 33

TOTAL

221

The determination of age for each individual was made according to the state of the dental development. The largest group (48\%) was represented by the late primary dentition (aged 2-5 years), and the early mixed dentition (aged 6-9 years) made up $35 \%$ of the sample. The largest number of teeth avallable for examination were molars, as many primary anterior teeth were elther exfoliated naturally prior to death, or were lost postmortem due to their small size and single simple root shape. The total number of first primary molars available for examination and the number found to be carious is given in Table 2. 
Table 2

Number of primary first molar teeth examined and number (\%) found to be carious for each period

\section{Eirst primary molars}

\section{Present Carlous \%}

Period

Prehistoric

Roman

Early Anglo-Saxon

Late Anglo-Saxon

Early Medieval

Late Medieval

$\begin{array}{rrr}38 & 4 & 11 \\ 172 & 28 & 16 \\ 59 & 6 & 10 \\ 186 & 16 & 9 \\ 22 & 0 & 0 \\ 54 & 11 & 20\end{array}$

TOTAL

65

12

The presence and severity of cribra orbitalia in the different periods is recorded in Table 3 . The majority of individuals in whom orbital bone had remained intact had some degree of defect. The largest group exhibited a mild degree, but $73 \%$ of the children were affected to some extent, and all age groups were involved (Table 4).

Table 3

Brevalence of cribra orbitalia in each period

\section{Cribra orbitalia}

\section{Period No. Remains Ione Mld Mod. Severe Iot assessable}

Prehistoric

$$
15
$$

65

Early A/S

Late $A / S$

Early Med.

Late Med.

26

73

9

33

$\begin{array}{rr}3 & 3 \\ 12 & 16 \\ 4 & 1 \\ 8 & 11 \\ 0 & 5 \\ 0 & 2\end{array}$

3
6
2
12
2
2

6
28

18

39

$\begin{array}{lllllll}\text { TOTAL } & 221 & 27 & 38 & 27 & 8 & 121\end{array}$

\footnotetext{
A/S Anglo-Saxon

Med. Medieval

Not assessable (1nsufficient skull material to examine for cribra orbitalia)
} 
Table 4

Severity of cribra orbitalia according to age of individual

\section{Cribra orbitalia}

$\begin{array}{lccccc}\begin{array}{l}\text { Age } \\ \text { (years) }\end{array} & \begin{array}{l}\text { Number } \\ \text { (at risk) }\end{array} & \text { Slight } & \text { Yoderate } & \text { Severe } & \text { Total } \\ 0.5-2 & 8 & 1 & 1 & 2 & 4 \\ 2-4 & 16 & 11 & 1 & 1 & 13 \\ 4-6 & 22 & 8 & 8 & 1 & 17 \\ 6-8 & 23 & 10 & 5 & 3 & 18 \\ 8-10 & 23 & 8 & 8 & 1 & 17 \\ 10-12 & 6 & 2 & 2 & - & 4\end{array}$

In all, skull material for 50 children was available for comparison with the orbital area intact and four first primary molars present. of those 13 with caries present, cribra orbitalia affected 3 only slightly or not at all, but 10 were affected to a moderate or severe degree. Of the 37 in whom no caries was recorded, cribra orbitalia affected 28 only slightly or not at all, compared with 9 who had moderate or severe involvement. The association between caries prevalence and cribra orbitalia was found to be highly statistically significant ( $P<0.005)$, according to the Fisher Exact Test.

\section{Discussion}

In the present study, the level of dental carles recorded was similar to that reported by previous investigators. Of the first primary molars among the children of the late Mediaeval period in this study, $20 \%$ were carlous. This may be compared with values of $16 \%$ (James and Miller, 1970), 7\% (Moore and Corbett, 1973) and 15\% (Williams and Curzon, 1985) when both primary molar tooth types were combined by previous authors. The similarity of the results of the present study to those previously published in comparable populations tends to confirm the reliability of this finding. Cribra orbitalia affected $73 \%$ of children in the present study compared with a simllar value of $65 \%$ for juveniles (aged 2 to 10 years) examined by StuartMacadam (1985). The ranges reported previously among juveniles varied between $26 \%$ and $83 \%$. Stuart-Macadam (1985) commented that there was a probability that proportionately more anaemic children were dying than those who were not anaemic, and that this should be taken into account when observing the higher prevalence of cribra orbitalia in children compared with adults. If dental carles is positively associated with cribra orbitalia, as in the present study, children who die could also have had more caries than the surviving population.

Most nutritional disease is the result of a combination of malnutrition and infection acting synergistically (Scrimshaw and Suskind, 1976). Malnutrition can be secondary to gastro-intestinal disease, including acute or chronic diarrhoea and severe parasitism. In children, it can also result from localised infection, such as otitis media and pharyngitis (Scrimshaw and Susirind, 1976). Loss of body weight may also be accompanied by complex losses of zinc, 
magnesium, potassium and sulphur. Serum iron also drops with a resultant iron deficlency anaemia. Malnutrition also affects antibody formation, tissue integrity and inflammatory responses. A decrease in T-cell production occurs in protein/calorie deficiency, and phagocytic function is decreased. A cycle of repeating infectious episodes may then be set up.

Pre-eruptive influences may be important, and affect the structure of teeth. An infant stressed nutritionally may be more prone to hypoplasia (Sweeney et. al., 1971) and carles (Sawyer and Iwoku, 1985). The stress may have been of longstanding, commencing possibly pre-, peri- or post-natally.

Post-eruptively, the caries process will be influenced by the bacteria in plaque, the buffering capacity of saliva, and the composition, frequency of intake and texture of the diet. All these effects may be modified by infection and malnutrition. Dental caries is multifactorial in origin and it is important not to anticipate simple answers in terms of diet alone. The association with cribra orbitalia in the present study, and the considerable weight of evidence from animal and human studies point to a possible role of nutritional stress.

It would be valuable to discover whether there is also an association between cribra orbitalia and caries in the permanent dentition in older children and young adults. Future research may indicate that a similar association exists involving the permanent teeth.

The results of this study suggest that dental caries levels found in archaeological material in children could overestimate the true level of the disease in surviving populations. This may be particularly true among groups where a substantial number are also affected by cribra orbitalia. Consequently, the possibility of bias in reporting the level and extent of dental carles among young children in archaeological populations should not be ignored.

\section{BIBLLIOGRAPHY}

Brothwel1, D.R., 1981 - "Digging up Bones". 3rd edition. Oxford University Press, Oxford and British Museum (Natural History), London.

Hillson, S., 1986 - "Teeth". Cambridge, Cambridge University Press.

James, P.M.C. and Miller, W.A., 1970 - "Dental conditions in a group of Medieval English children". British Dental J., Vol. 128, pp. 391396.

Manchester, K., 1983 - "The archaeology of disease". Bradford University Press, Bradford.

McDonald, J.L., 1985 - "Dietary and nutritional influences on dental Carles", pp. 151-160 in R.L. Pollack and E. Kravitz (Eds), Nutrition in Oral Health and Disease. Lea and Febiger, Philadelphia. 
Milier, J, Vaughan-Williams, E, Furlong, R, and Harrison, L, , 1982 - "Dental caries and children's weights". L. Epidemiol. Commun. Health, Vol. 36, pp. 49-55.

Moore, W.J. and Corbett, E., 1973 - "The distribution of dental caries in ancient British populations. II Iron Age, Romano-British and Medieval periods". Caries Research, Vol. 7, pp. 139-153.

Moore, W. J. and Corbett, E., 1978 - "Dental carles experience in man; historical, anthropological and cultural diet-caries relationships, the English experience", pp. 3-19 in N.H. Rowe (Ed), Diet, Nutrition and Dental Caries. University of Michigan School of Dentistry.

Nikiforuk, G., 1985 - "Understanding dental caries: I etiology and mechanisms, basic and clinical aspects". Karger, Basel.

Russell, A.L., 1963 - "International nutrition surveys: a preliminary finding". J. Dental Research, Vol. 42, p. 233.

Sawyer, D.R. and Nwoku, A.L., 1985 - "Malnutrition and the oral health of children in Ogbomosho, Nigeria". J. Dent. Child, Vol. 52, pp. 141-145.

Scrimshaw, N.S. and Suskind, R. M., 1976 - "Interactions of nutrition and infection". Dental clinies of North America, Vol. 20, pp. 461-471.

Stuart-Macadam, P., 1985 - "Porotic hyperostosis: representative of a childhood condition". Amer. J. Phys. Anthrop., Vol. 66, pp. 391-398.

Stuart-Macadam, P., 1987 - "Porotic hyperostosis: new evidence to support the anaemia theory". Amer. J. Phys. Anthrop. , Vol. 74, pp. 521-526.

Sweeney, E.A., Saffir, A.J. and Deleon, R., 1971 - "Linear hypoplasia of deciduous teeth in malnourished children". Amer. J. Clin. Nutrition, Vol. 24, pp. 29-31.

Wells, C. 1975 - "Prehistoric and historic changes in nutritional disease and associated conditions". Progress in Food and Nutrition Science, Vol. 1 (11), pp. 729-779.

Williams, S.A. and Curzon, M.E.J., 1985 - "Dental carles in a Scottish Medieval child population". Caries Res., Vol. 19 (2), p. 162.

Williams, S.A., Curzon, M.E.J. and Barker, A., 1988 - "Growth parameters and carles experience in young children". Caries Res. (In press).

World Health Organisation, 1987 - "Oral health Surveys: baste methods". 3rd edition. Geneva. 


\title{
A HODEL FOR ASSESSIMG HEALTH PATTERIS FROY SKELETAL REIAINS
}

\author{
Valerie Higgins \\ Department of Archaeology and Prehistory, \\ University of Sheffield \\ Sheffield \\ S10 2TN
}

\section{Introduction}

This article will present a theoretical model to assess health patterns from skeletal remains. It was developed in order to study two sroups of skeletons from an archaeological excavation at San Vincenzo al Volturno in central southern Italy. Both groups were from low status burials; one was from the late Roman period and one was from the early Medieval period. The principal aim of the research was to determine if the rural population of this area had suffered a decline in health from the late Roman to the early Medieval period.

The collapse of the Roman empire inspired many contemporary accounts of the destruction of urban life, widespread disease, death and famine. The following from Procopius is a typical example,

"And most of the people were so overcome by their hunger that if they happened upon a bit of grass anywhere, they would rush to it with freat eagerness, and kneeling down would try and pull it from the 8round. Then finding themselves unable to do so because all their strength had left them, they would fall upon the grass and their outstretched hand and die. And no-one ever laid them to earth, for there was in fact not a man to concern himself about burying them" (Procopius, History of the Vars VI. $\mathrm{xx}$ ).

There have been many historical debates concerning the effect of the decline of the Empire on the society of the time. Of the effect on urban life there can be little doubt; it was catastrophic. Less is known of the effects on the countryside and opinions are divided. It has been suggested that it might have been beneficial option as the clties were parasites on the countryside, producing little and consuming much. Another school of thought suggests that the economies of rural and urban areas were inextricably linked, and the decline of one inevitably led to the decline of the other. The recovery of the skeletal remains from San Vincenzo al Volturno, was an opportunity to compare a rural population through time and to examine these theories.

The skeletons consisted of two groups from an excavation of a Medieval monastery. Despite the positioning of the graves, in fact neither group represented the monastic population. The first group was from a late Roman graveyard and probably represented the workers of a large villa estate of the 5 th century A.D. (Hodges, in press). It is estimated that approximately $45 \%$ of the graveyard was excavated yielding 84 individuals. The second, later group was from a very large graveyard on the hillside above the monastery. It is believed that these represent the lay workers of the monastery who would have farmed the land (Coutts, in press). The graveyard covers most of the hillside 
and it is estimated that between $3 \%$ and $16 \%$ was excavated yielding 69 individuals.

San Vincenzo al Volturno is situated in the Apennine mountains at an altitude of 547 metres. It has always been in an essentially rural environment. The agricultural system consists of small family farms. Until very recently, alternative sources of employment were limited, and all members of a family would work on the family farm. It was unusual to employ anyone on the farm who was from outside the family except for temporary periods, such as at harvest time. Thus, until very recently, it could be described as a traditional European peasant economy. During the late Roman and early Medieval periods the situation would have differed somewhat, though the essential structure would have been similar. The burials from the later Roman group are most likely to represent the agricultural workers of a villa rustica of the late Roman period (Hodges, in press). The early Medieval burials are most likely to be the familia foris or outer family of the monastery. The familia foris could marry and have children. They usually worked the monastic land in family groups and paid for their tenancy either by tribute or service (Horn and Born, 1979, p.341).

Sociological studies of peasant societies reveal many recurring features that are caused by the restriction imposed by running a family farm. The most important feature of peasant societies is that the family unit is also the working unit, and therefore, each member of the family is related in an economic as well as a social sense (Galeski, 1971, p. 122; Thorner, 1971, p. 205). Economic factors influence, or even dominate, social relationships. The economic viability of the peasant system is dependent to a very great extent on their ability to control their families, and hence their future workforce. Studies of peasant communities reveal a delicate, if unconscious, balancing act between maintaining economic viability, and carrying out social obligations. The ratio of the producing and nonproducing members of the community must be contained within strict limits; children must be supported until they reach an age where they can contribute to the output; old people who can no longer work must be supported until they die; the physically and mentally 111 must be supported for all their natural iffe. The fundamental solidarity of the family cannot be converted to any other type of group relationship, nor undermined by individual relationships. It manifests itself both in assistance rendered to, and control exerted over, any member of the group by any other member representing the group as a whole (Thomas and Znaniecki, 1971, p. 27).

Kany apparently disparate features of peasant society originate froll the necessity to control social relationships to achieve economic ends. Marriage is usually an arranged affair, and suitability is determined to a large extent by the economic compatibility of the partners, rather than individual preference (Gamst, 1974, p. 53). Marriage is regarded as being vitally important for the welfare of the community, and single status for adults is not tolerated except under unusual circumstances (Handlin, 1967, p. 458). The marriage of the eldest son is critical to the future of the family. The bride, as the future head of the domestic household is particularly carefully chosen. She might be expected to bring in a dowry sufficient to set up 
the younger brothers, and add to the dowries of the daughters. No marriage is an isolated affair, but all are economically connected (Handlin, 1967, p. 460).

"The whole familial system of attitude involves absolutely the postulate of marriage for every member of the young generation unless handicapped. A person who does not marry within a certain time, or an old man who does not die at a certain age, provokes an attitude of unfavourable astonishment" (Thomas and Znanlecki, 1958, p. 107 ).

Once married the couple will be expected to produce a family to guarantee the future workforce. The average age of marriage is related to the needs of the workforce; if there is a need to increase labour the age at marriage will be reduced, and if there is a need to reduce the working population it will be increased (MacFarlane, 1978, p. 28). Computer simulations have shown age at first marriage to be the single most important factor determining household size (Saller, 1987, $p$. 31). A fine balance must be achieved; the future workforce must be ensured, but the ratio between the producing and non-producing members of the community must be maintained. Thus, it is expected that conception will not be a haphazard affair, but will tend to be structured by socioeconomic forces. Control of social relations, reproduction and behaviour, are part of the response to the overlying need to maintain the status quo. The rationale behind this is easily understood.

"Nature was the major determinant of peasant economic life - the smallness of peasant resources magnified its impact. The difference between a good agricultural year, and a bad one was the difference between prosperity and famine if not death" (Shanin, 1971 p. 32).

This description is not intended as a blueprint for all peasant societies at all times, but there are certain factors that will have influenced the community under study. The necessity to control the population is likely to have been a factor in this environment which will always have been marginal from an agricultural point of view (Hayes, in press). The following model for assessing health patterns is based primarily on biological processes, but also incorporates some of the aforementioned social and cultural aspects. It uses nonspecific indicators of stress and attempts to Iink them. If all nonspecific indicators have stress as a common aetiology then the incidence of each indicator should be related in some way to the incidence of the other indicators. A model is suggested in Figure 1 based on this assumption.

\section{The Yodel}

The model is divided into two sections: the physiological processes taking place, and the potential skeletal manifestations that can result. Skeletal manifestations are an indirect reflection of stress patterns; the direct effects of stress on the living population leave no trace. The relationship between physiological processes and sikeletal manifestations can potentially be complicated by environmental, genetic and cultural factors. For a model of stress to have any credibility, it must be based primarily on the living 


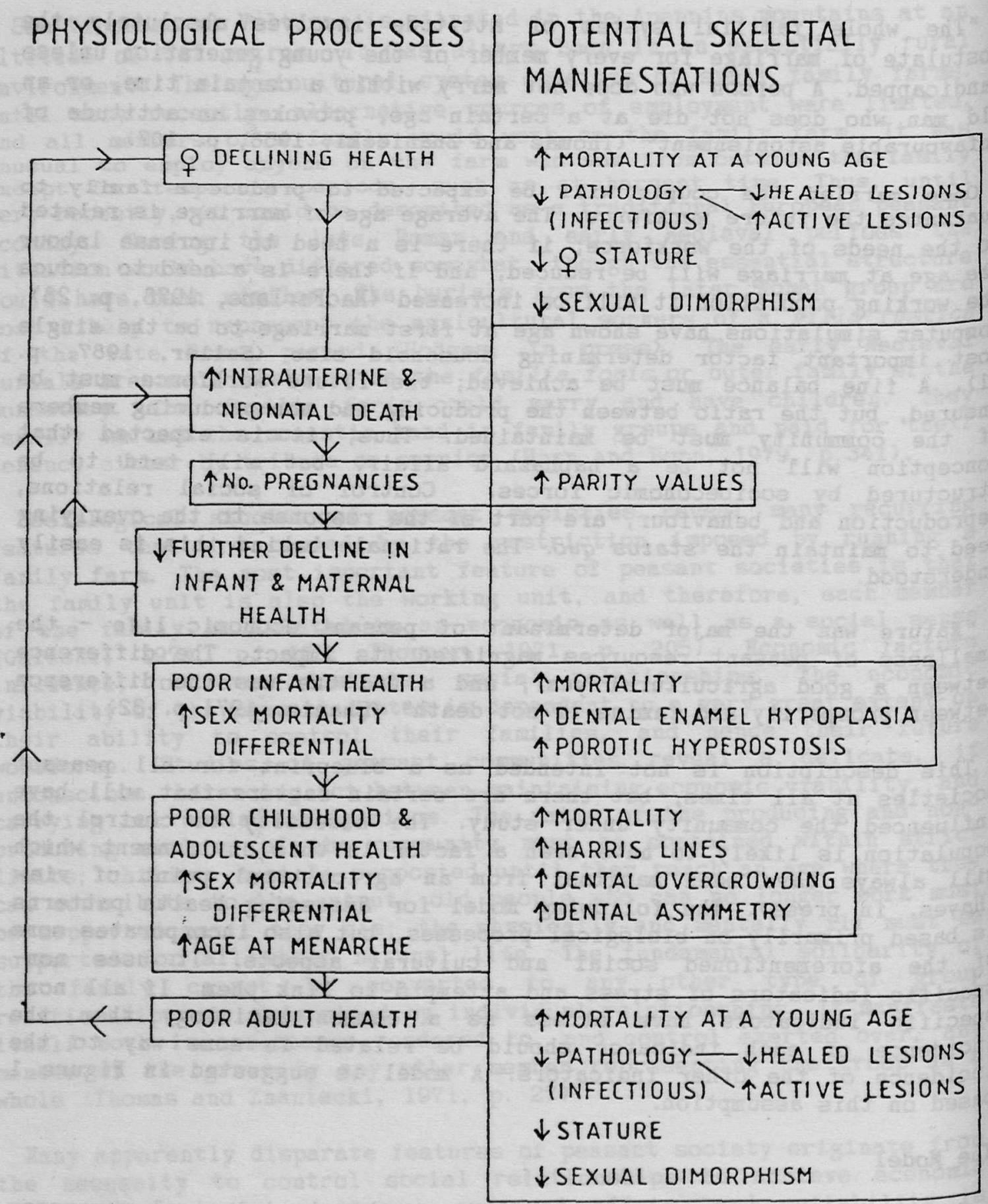

Figure 1

$-178-$ 
population; from this we can then extrapolate secondarily to the archaeological remains.

The model has as its starting point the health status of females of reproductive age and contains the following points:

1. A decline in the health status of females of childbearing age will have a deleterious effect on the health status of the foetus. This will lead to higher levels of intrauterine and neonatal death.

2. An increase in intrauterine and neonatal death will lead to an increase in the number of pregnancies.

3. An increased number of pregnancies will, in itself, further impair the health status of females.

4. A decline in maternal health will impair the health status of infants.

5. Low health status in infancy will predispose the child to low health status in childhood.

6. Low health status in childhood will predispose the individual to low health status in adulthood.

7. Low health status amongst the adult population will mean that females of reproductive age are affected, and thus the effect will be intergenerational.

These points will be elaborated upon below. This model is proposed as an aid to interpretation, and not intended to be deterministic. Poor infant health does not automatically lead to poor childhood health, and poor childhood health does not invariably result in poor adult health. What is suggested here is that these will be trends within the population as a whole. Similarly, it is quite possible for robust infants and children to become sickly adolescents and adults. Wat is being proposed is that on a population level, this is less likely to occur than if their health is impaired during their early years.

\section{The relationship between maternal and foetal health}

\section{2) Physiological processes}

That the standard of maternal health directly affects the health of the foetus and newborn child has been demonstrated in modern clinical situations, laboratory experiments and anthropological fieldwork. In the modern clinical environment it is difficult to measure overall standards of health except by subjective assessment, and it has tended to be inferred indirectly from height. The use of height to indicate health is acceptable providing its limitations are recognised. This is discussed in the section on stature.

A post-war survey in Glasgow showed a marked difference between the rates of infant mortality in private hospitals, and those in public 
hospitals, despite the lack of facilities and older maternal age of patients at the former (Baird, 1952, pp. 562-3). The author cited attributed this entirely to the poor health of the mothers in the public hospitals as witnessed by their height, and his subjective assessment of their overall level of health (Baird, 1952, p. 565). In a major survey of infant mortality conducted over the whole of Britain several years later, Butler and Bonham (1963, p. 278) attributed the disparity they found in infant mortality between higher and lower socio-economic groups to the poor state of health of the latter during the depression of the $1930^{\circ} \mathrm{s}$ when the mothers were born. This sample demonstrated that the proportion of babies born at the optimal gestation time, and the optimal birthweight, fell progressively with decreasing maternal height (Butler et. al., 1969, p. 51); a Japanese study came to the same conclusion (Gruenwald et. al., 1967, p. 1026). Thomson (1959, p. 157 ) wrote:

"whatever the nature of the delivery, the foetus of a short woman has a lower vitality, and is less likely to be well-grown and survive than that of a tall woman".

Small maternal size, relative to the average for a specific, ethnically homogenous population, is usually the result of chronic undernutrition, and $i t$ is this that reduces placental size in the foetus, which in turn reduces the area available for nutrient exchange, thus restricting the growth of the foetus (Winick, 1970, p. 526; Lechtig et. al., 1975, p. 201; Laga et. al., 1972, p. 31). It should be emphasised that it is the chronic nature of the maternal condition, rather than merely acute malnutrition during pregnancy that is important (Campbel1, 1975, p. 275; Naeye et. al., 1973, p. 501; Alberman, 1976, p. 421). Naeye (1980, p. 4) has suggested that foetal growth is affected if the mother weighs less than $43.6 \mathrm{~kg}$ at the start of her pregnancy. Federick and Anderson (1976 p.349) found low maternal weight to be the most important factor associated with spontaneous abortion, apart from previous reproductive history. This is echoed by Vaughan (1968, pp. 140-1) who found that women with a poor diet had three times the risk of premature labour as the controls.

Low birthweight can be the result either of the baby being born early, or being born at full-term, but underdeveloped. The former will increase neonatal mortality because of the difficulties immature babies experience in adjusting to an extra-uterine life; the latter will increase stillbirths because the foetal stores are too depleted to survive labour (Gruenwald, 1964, p. 162; 1969, p. 169, Alberman, 1976, pp. 417-8; Bakketig and Hoffman, 1981, p. 17). Women with poor health status have an increased risk of both these possibilities (Butler et. al., 1969, p. 51). Intrauterine growth retardation is followed by a lag in growth after birth (Gruenwald et, al., 1967, p. 1028); this in itself will compromise the health of the baby during its early months. Foetal malnutrition leads to a reduction of immunoglobulin $\mathrm{G}$ and lymphocytes which impairs resistance to disease (Ferguson et, al., 1974, p. 721; Chandra, 1975 p. 453). Other maternal factors which influence health are the age of the mother, and her parity. 
A disadvantage of the clinical situation is that every case is due to a unique combination of factors, and one cannot control or isolate certain factors to determine their influence. Therefore, one cannot very easily prove cause and effect. One has to look to animal experiments in which the environment can be controlled for information of mechanisms at a cellular level.

Experiments by Widdowson and McCance (1964, p. 327) on rats showed that altering the state of nutrition could have a permanent effect on the foetus if imposed during critical periods of development. Winick demonstrated in the laboratory that maternal undernutrition retarded cell division in the placenta in early foetal life, and if imposed later affected cell size; this Impaired cell division in all argans of the foetus (Winick, 1970, p. 539). Wigglesworth (1964, p. 11) concluded from his experiments in rats that foetal stunting results if the maternal nutrient pool is reduced through malnutrition, or reduction of utero-placental blood flow. The relationship between small foetus and malnutrition has also been demonstrated in primates (Hill et. al., 1971, pp. 77-81) and pigs (Adams, 1971, p. 352; Viddowson, 1971 pp. 337-9).

Anthropological fieldwork can provide data from areas where medical intervention is absent or minimal. A long term study in Guatemala was carried out on the health of a rural population who had received little medical attention (Mata et. al., 1967, pp. 112-126; 1972 pp. 257-264, 1974, pp. 561-6; 1976, pp. 303-315). On the evidence of height, weight and skinfold thickness, the maternal population was found to be suffering from chronic malnutrition, and many of the features suggested by clinical data were evident; $34 \%$ of babies had birthweight below 2501 grams (the commonly accepted clinical definftion of low birthweight); $7 \%$ were pre-term (Mata et. al., 1976, pp. 309-313). Both premature and low weight (for gestational age) babies had a poorer survival rate during the neonatal period, whereas premature infants thrived after the post-neonatal period and the lower weight infants had a poor survival rate through the second and third years of life.

\section{b) Patential skeletal manifestations}

1. There will be an increase in mortality at a young age amongst females.

2. There will be an overall decline in the number of pathological lesions. There will be an increase in the number of active lesions relative to the number of healed lesions. In comparison to soft tissue, bone is very unreactive. A bone lesion represents a chronic condition that has been persisting for some time. The appearance of a lesion signifies that the body has already put up a long period of resistance to the disease. Immuno-compromised individuals will be more likely to die before a skeletal reaction sets in, than persons whose resistance is greater. This is an entirely theoretical viewpoint for Which there is little evidence either to support or deny from previous published data. It was included in an attempt to link non-specific indicators of stress with conventional pathological data. It was felt that the prevalence of infection might in some way be related to the 
overall health status of the individual. Dental caries was not included in this category because of the other factors which have a strong influence on its appearance, such as diet.

3. There will be a decline in female stature. The relationship between stature and health will be discussed below in more detail. 2. The relationship between aternal health and the number of
pregnancies

\section{a) Physiological processes}

The loss of a child is likely to increase rather than reduce the number of pregnancies for two reasons; firstly in archaic populations lactation would have been an important contraceptive; secondly, in rural agricultural societies children are often highly desired as an important addition to the workforce.

Pregnancy stimulates the pituitary glands to produce the hormone prolactin which has a number of functions, the most important of which is to stimulate the mamary glands to produce milk. One of its other functions is the inhibition of ovulation, clinically manifest as postpartum amenorrhoea which renders the woman infertile during pregnancy and lactation (Mackay et. al., 1983, p. 80). Before the advent of modern milk substitutes this was of vital importance to the well-being of the infant who might otherwise have to be weaned before he/she was physiologically capable of digesting other food. The age at which an infant is weaned varies culturally and individually, and this will affect the spacing of pregnancy. The death of a baby will reduce the levels of prolactin which will also remove post-partum amenorrhoea; as a result the woman will become fertile again.

Studies among modern populations (Leridon, 1977, p.94), and from historical documents of French and German villages from the $16 \mathrm{th}$ to the 19th centuries (Knodel, 1975, p. 7), suggest that if an infant survived its early years to complete weaning, then subsequent pregnancy is delayed by approximately one year. The effect of high infant mortality on the birth rate has also been observed in anthropological fieldwork (Millard, 1982, p.147). Many societies have a taboo on sexual intercourse following pregnancy, known as the postpartum sex taboo; such a custom has been recorded in 17 th and 18th century Europe (Leridon, 1977, p.94). This may have evolved in response to the observation that pregnancies too close together were injurious to the health of the infant who had to be weaned too early.

As well as purely physiological reasons, there will be social and economic reasons for a woman to want to concelve again quickly after the loss of a foetus or infant. For many years it was considered that our own 20th century society was the only one that had ever controlled childbirth. This idea was fostered by the ethnocentric view that all societies want to limit population growth, and therefore family planning revolves entirely around contraception. But as Malinowski (1967, p. 74) wrote, " there is not a single instance on record of a primitive culture in which the process of gestation is left to nature alone". All societies have a vast range of social customs, taboos. 
charms and herbal medicines to enhance or prevent gestation and contraception. For many societies it is the timing and spacing of births, rather than the ultimate number, that is the first priority (Mclaren, 1984, p.7). In peasant societies the production of children may, or may not, be a happy social event, but it is definitely an economic priority if the future workforce is to be maintained and the farm remain a viable economic unit. However, pregnancies too close together will result in too many non-productive mouths to feed, so a balance must be achieved. Prabably the most significant factars governing rate of pregnancy are the social customs regarding marriage, and in particular age at first marriage.

How far contraceptive measures were employed amongst the late Roman and early Medieval rural population is unclear. The urban Roman population were certainly aware of a wide range of contraceptive devices. These included application of cedar gum, vinegar, brine and olive oil, and the use of plugs or pessaries which were soaked in honey, alum, white lead or olive oil. The use of olive oil or sticky substances lowered the risk of conception by reducing the motility of the sperm; alum, vinegar and brine are highly spermicidal, and were recommended by 20 th century pioneers in family planning such as Narie Stopes (Hopkins, 1965, pp.134-5). We can only speculate as to how far the information was disseminated to the rural community.

Abortion has probably been more widely practised than literary sources would suggest. It is often an exclusively female process, of which the male population is unaware, and there is often an element of secrecy attached to it. In non-modern societies the most common abortion techniques are mechanical and consist of internal probing, pummelling the stomach and violent exercise. The major problems associated with primitive abortion are haemorrhage and infection which may ultimately lead to sterility (Abernethy, 1979, pp. 50-51).

Mortality, both accidental and deliberate, amongst the infant population is an important factor governing the spacing of the next pregnancy in non-modern societies. Infanticide was widely practised in the early Roman Empire. It was practised less frequently in the later Empire, and only sporadically by the barbarians (Russel1, 1985). The fairly lenient penances exacted by the Church for it (op. cit. p. 159) suggests that it was not regarded too seriously, which leads one to wonder whether it might have been secretly practised more frequently than documentary evidence suggests. When infanticide does occur it is rarely evenly divided between the sexes; female babies are more frequently murdered than male babies.

\section{b) Potential skeletal manifestations}

1. Increase in parity values. Scars of parturition have been well documented and potentially could be a valuable source of information about parity levels in well preserved pelves. They were not recorded in this series. 
3. The relationship between an increased number of pregnancies and aternal health

\section{a) Physiological processes}

In a woman already suffering from poor health or undernutrition, pregnancy and lactation will further deplete her reserves, and will increase the possibility of spontaneous abortion, stillbirth and neonatal death in the future. This has been demonstrated in modern demographic studies (Ascadi Associates, 1985, p. 1 and Figures $3 a$ and $3 \mathrm{~b}$ ), and in an archaeological population (Cook, 1979, p.111). Clinically it has been noted that successive neonates or undernourished mothers show increasing signs of antenatal retardation (Naeye et. al., 1973, p. 501; Naeye, 1980, p. 4).

\section{b) Potential skeletal manifestations}

There are no skeletal manifestations resulting from these processes.

4. The relationship between maternal health status and the health status of infants

\section{a) Physiological processes}

1. Prematurity, low birth weight and/or poor neonatal health have important consequences later in life. As far back as 1862 the relationship between birth weight and future health was appreciated (Little, 1862). Since that time there have been numerous clinical studies that have demonstrated the adverse effects of low birth weight on later physical, neurological and intellectual development (Hardy, 1973, pp. 973-4; Gruenwald et. al., 1967, p. 1028; Fancourt et. al., 1976, p. 1437; Alberman, 1976, p. 425; Fitzhardinge and Steven, 1972 , p. 681). It has been suggested that this is the result of stress at a critical period of growth during the phase of active cell division which results in a deficit in the final number of cells. This is nonreversible whereas stress suffered at other periods may be compensated for by catch-up growth (Fancourt et. al., 1976, p. 1437; Winick, 1967, p. $390 ; 1968$ p. 352).

2. Increase in the sex mortality differential. Males are biologically more vulnerable than females and this results in a sex mortality differential (SMD). The SKD is lowest in modern western countries that have good sanitation levels and also amongst high-mobility, low density band organisations that have a low level of parasitic infection (McKee, 1984, p. 95). Conversely, it will be higher under conditions of poor sanitation, sedentism and high population density in the absence of high standards of hygiene. Although there are many cultural practices that favour one sex over the other, these should be seen as a response to the biological determinants, rather than as a cause of SND. That SWD has primarily a biological origin is demonstrated by the survival rates amongst foetuses, where there is no possibility of cultural practices playing a part. At the moment of conception the sex ratio is at least 120 males to 100 females (McMillen, 1979, pp. 89-90). However, by the end of the gestation period, the higher mortality amongst male foetuses has reduced the 
ratio to 105-6:100 (Teitelbaum, 1972). Biochemical analysis of blood samples from women who ultimately produced male foetuses had higher levels of immunoglobulins in general, and in particular immunoglobulin $G$, which is related to gastrointestinal infections and can cross the placental barrier. Levels were even higher if the mothers were also poor, $i 11$ educated or badly nourished (Super, 1984, p. 86). Nales were generally more susceptible to adverse conditions of any kind whether it be biological, such as high levels of pathogens or parasites, environmental such as malnutrition, or geographical, such as high altitude (Stevenson and Bobrow, 1967, p.,198). Males are more susceptible to infection at all ages, but the difference is most marked in the newborn (Davie, 1969 p.326, Washburn et. al., 1965, p. 62).

The cause of higher mortality amongst males is unknown, but there are two factors which are most likely to be implicated. Firstly, for the first few weeks all embryos start on a female path, and it is only after testosterone has been secreted at about six weeks that the embryo becomes male. This affects many aspects of development from Overall morphology to the organisation of the central nervous system. Secondly, it is believed that the second $x$ chromosone gives additional genetic protection (Super, 1984, p.85). The $Y$ chromosone carries information mainly relating to the development of primary and secondary sex characteristics, whereas the $X$ chromosone carries information that controls many biological responses including imunological responses (McKee, 1984, p.93).

\section{b) Potential skeletal manifestations}

1. Increased infant mortality.

Epidemiological studies (Gordon et. al., 1967, pp. 121-144) have Shown that infant mortality has such a profound influence on the crude death rate of a population, that it is a measure of population fitress. There are three important stress-related periads for the neonatal and postnatal infant:-

1) Birth to one month. During this period death is usually from the effects of prematurity or birth injuries, congenital anomalies, atelactasis, and immediately acquired infections.

11) One to twelve months. During this period death is usually the result of infectious disease such as bronchitis, pneumonia, otitis media or gastroenteritis.

iii) One to four years. During this period the frequency of infectious disease begins to decrease and the frequency of malnutrition increases. The critical period from the point of synergistic effects of nutritional deficiency and infectious disease is six to twenty-four months (Mensforth et, al., 1978, p.12).

2. Increased levels of dental enamel hypoplasia.

The cells responsible for forming enamel are ameloblasts and the process of enamel formation is known as amelogenesis. Amelogenesis 
involves two stages; the first is matrix production in which the organic matrix is laid down; the second is maturation in which the amelogenin of the first stage of matrix production is gradually replaced by apatite (Hillson, 1986, p.114). If the matrix production is disturbed growth may cease causing a macroscopic defect to become visible on the surface of the tooth; this is known as dental enamel hypoplasia (Hillson, 1986, p.129).

Dental enamel hypoplasia is particularly archaeologically visible because once it has formed and been fully calcified, it cannot be remodelled; after the formative cells have receded and lost their connection with the matrix itself the enamel surface is unalterable (Massler et. al., 1941, p.35). Therefore, it is a record only of stress occurring during the formative stage of enamel development, and stress suffered subsequently will not be recorded. Thus it is an indicator of infant and childhood health stress only. Both clinical observation and laboratory experimentation indicate that it is a nonspecific response that may be caused by a variety of stressors including fever, growth disruptions, infectious disease, nutritional deficiencies and intoxicants (Kreshover, 1960, p. 161 and p. 166; Kreshover and Clough, 1953, pp. 574-5; Shafer et. al., 1983, p. 53).

\section{Increased levels of poratic hyperostosis.}

Porotic hyperostosis (also known as osteoporotic pitting and spongy hyperostosis) consists of skull lesions of a sieve-like appearance, and variable in size, that most frequently occur in the superior portion of the orbits, forehead portion of the frontal bone, on the parietal bones above the temporal line and on the occipital bone. Characteristically, the diploe is expanded and the skull is thicker at that point with the outer layer of bone being very thin (Huss-Ashmore et. al., 1982, p. 414). The lesions found in the orbits are known by the name of cribra orbitalia.

The relationship of this condition to anaemia has been acknowledged, but there is less agreement on the type of anaemia it results from. It was originally observed in conjunction with hereditary anaemias, and was therefore believed to have been caused by them (Angel, 1966. pp. 760-3). Eng (1958, pp. 263-8) was one of the first to postulate its relationship to iron deficiency anaemia. Since that time many authors have supported this view (e.8. Mosely, 1965, p. 141; Steinbock, 1976 , pp. 244-8; Hengen, 1971, pp. 57-75; El-Najjar et. al., 1975, p. 919; Carlson et. al., 1974, pp.405-10; Lallo et. al., 1977, pp. 479-481; Mensforth et. al., 1978, pp.1-59). The distribution of porotic hyperostosis is too widespread and too common to be solely the result of relatively rare hereditary anaemias that are geographically restricted. Although the possibility of hereditary anaemia being the cause cannot be dismissed, it has been suggested that the appearance of porotic hyperostosis in the absence of other skeletal changes is due to iron deficiency anaemia (Britton et. al., 1960, p. 626). Mensforth et. al. (1978, pp. 1-59) looked at the distribution of porotic hyperostosis on an age-specific basis, and found that there was a strong correlation with the age-specific distribution of hypochromic, microcytic iron deficiency anaemia in infants and children. Iron deficiency anaemia is a frequent accompaniment of other 
rarer types of anaemia and this may account for its association with
them.

Iron deficiency anaemia usually affects infants between the ages of 6 and 24 months, and disappears spontaneously between 2 and 3 years. In modern societies it is very common, and frequently occurs in the absence of clinical symptoms; however, in developing societies it is more severe and contributes significantly to patterns of infant and child mortality and morbidity (Mensforth et. al., 1978, p. 13). Certain prenatal factors will affect the amount of iron available; length of gestation is probably the most important, but maternal iron stores and waste through haemorrhage are also important (Mensforth et. 1., 1978, p. 14). Babies will receive negligible quantities of iron from their diet until they are weaned, and for the first few months of life they are dependent on the iron stores they were born with, which are proportional to their body weight. As premature and low birth weight infants have an accelerated growth rate, their supplies of iron are usually not sufficient to allow for catch-up growth and, hence, they are prone to iron deficiency (Gairdner et. al., 1955, pp.203-11). Veaning is also a period of particular stress for infants. Their nutrient requirements are outstripping the nutritional value of milk alone, and frequently they will first be fed on food such as cereals which not only have little iron content themselves, but can also prevent full absorption of dietary iron.

Although a direct association between iron deficiency anaemia and porotic hyperostosis has not yet been demonstrated, the distribution patterns show great similarity. Iron deficiency anaemia is relatively common as a result of both nutritional inadequacy and poor absorption due to other physiological conditions. Modern epidemiological studies sugfests that it can be used as an index of the nutritional health of a population. Mensforth et. al. (1978, p. 2) found porotic hyperostosis to be strongly associated with patterns of infant and child mortality and morbidity, and concluded that it played an important role in selection and fitness. Iron content of food varies tremendously depending on how $i t$ is grown and prepared and the rate of absorption is also related to the overall spectrum of the diet (Martinez-Torres and Layrisse, 1974, pp. 51-70). Also not all iron is equally beneficial; haem iron is more easily absorbed than ferrous which is more easily absorbed than ferric iron (Turnbull et. al., 1967, pp.1897-1907). Generally speaking, meat products contribute more iron in an absorbable form than vegetables (Martinez-Torres and Layrisse, 1971, pp. 531-9).

Chronic infection of bacterial or viral origin interferes with ironbinding and erythrocyte life span to produce "anaemia of infection" (Scrimshaw et. al., 1968, p. 50; Lallo et. al., 1977, p. 471). An increased prevalence of iron deficiency anaemia has been found in association with adoption of maze agriculture (Goodman et. al., 1984, p. 297; Rose et. al., 1984, p. 406). This is due to the effect of cereal on iron absorption and probably also the effects of high parasite levels and higher levels of infectlous disease associated with an increase of sedentism. 
Both clinical and experimental studies have highlighted specific groups as being particularly vulnerable. Important risk factors are the rate of growth and physiological blood loss. Groups who need a lot of iron are, for example, women of reproducing age and young children. Both anthropological (Lallo et. al., 1977, p. 48; Stuart-Macadam, 1985 , p. 396) and clinical studies (Agarwal et. al., 1970 p. 636, Burko et. al., 1961 p.450; Britton et. al., 1960, pp. 621-8, Lanzkowsky, 1968 pp. 16-29) have demonstrated the increased prevalence of porotic hyperostosis in children, but so far no such evidence has been published to show an increase in prevalence in females. This has led some observers to believe that it can only form in childhood when bone marrow hyperplasia can produce porotic hyperostosis because the bone is thin and not fully mineralised (Lanzkowsky, 1968, pp. 25-6; El-Najjar et. al., 1975, p. 923; Stuart-Macadam, 1985, p. 392). Therefore, its presence in adult skulls is a remant of a childhood condition rather than being due to an attack of anaemia just prior to death (Stuart-Macadam, 1985, p. 397). However, there are some unpublished data from Australia and the South Pacific which clearly show a higher prevalence in females (Webb, pers. comm.), and therefore cast doubt on this. This point cannot be more fully illuminated until more evidence is published, and therefore on the basis of the published evidence porotic hyperostosis has been used here as an indicator of childhood stress only.

5. The relationship between low health status in infancy and low health status in childhood

\section{a) Physiological processes}

\section{Infant health affects childhood health.}

As has been mentioned above, low birth weight will predispose an individual to poor health in infancy

\section{Likely to lead to an increase in age at menarche.}

The onset of puberty in females is more closely related to maturation than age. For menstruation to commence and continue a critical weight and a certain ratio of fat must be attained (Frisch, 1975, p. 318). Poor nutrition will delay the onset of menarche.

\section{b) Potential skeletal manifestations}

\section{An increase in childhood mortality}

\section{An increase in Harris lines}

Harris's lines, also known as transverse lines, lines of radiopacity, lines of arrested growth, or bone scars, are horizontal lines that appear in the long bones after periods of temporary growth arrest. They may occur on any of the long bones but are most common in the distal tibia followed by the proximal tibia, distal femur, distal radius and metacarpals (Steinbock, 1976, p. 43). Although Harris (1926, pp. 785-806, 1931, pp. 561-88 and 622-400) and Ascada (1924, Pp. 43-95) are attributed with first bringing them to widespread academic 
attention in the 1920's and 1950's, Harris acknowledges that the phenomenon has been described in the 19th century (1931, p. 561). Since then there has been a wealth of literature devoted to the subject. If the bone is sectioned they can be seen as lines of thickened trabeculae, but they are usually assessed by means of $X$-rays where they appear as radiopaque lines.

The mechanism by which these lines form is a two stage process, and has been determined by means of laboratory experimentation (Park, 1954, pp. 269-81, 1964 pp. 815-62). The first stage in the process is the cessation of growth. During this phase the mature cells and the trabeculae that formed immediately prior to the stress are resorbed, and the immature cells are left to form a thin disc of epiphyseal Cartilage called the primary stratum (Park, 1964, pp. 818-9). Due to the immaturity of these cells the primary stratum is completely resistant to penetration by capiliaries and osteoblasts, and as a consequence bone cannot be laid down, and 1 t therefore acts as a barrier to further growth. At this stage the cells are very shrunken and thin, and cannot be easily distinguished from the mesenchymal cells of the supporting tissue of the bone marrow (Park, 1964, p. 822). In the second phase of the process, after the stressor has been removed, the body is ready to begin growing again; the thin transverse line of the primary stratum begins to thicken. As the osteoblasts recover they begin to lay down bone once more, but initially this is only on the inferior surface, as the cells on the superior surface are still too immature to accept new bone. This causes the trabeculae to become arranged horizontaliy rather than vertically. The immature cells take 4-9 days to mature (Steinbock, 1976, p.46), after which time bone can be laid down in the normal fashion. Thus, it can be seen that Harris's lines will reflect only a certain type of stress - that is a period of acute stress followed by a normal, or near normal, recovery. They will not reflect chronic stress, or stress which was not followed by a period of recovery. Some have felt the term ' lines of arrested growth' to be a misnomer because what is seen on $X$-rays is only the stage of recovery and this makes assessment problematic.

\footnotetext{
Harris's lines are age specific, and can only be produced when the bone is subject to longitudinal growth i.e. from birth to about 14 years in boys, and 12 years in girls; studies in modern Western populations suggest that they occur most frequently in infancy (1 to 4 years for boys, and 1 to 3.5 years for girls) during the period of Childhood infections (Gindhart, 1969, pp. 18-19).
}

As with all non-specific indicators of stress, Harris's lines vary in their presence, and stressors of the same severity may produce different responses between individuals, or even in the same individual at different times. It has been estimated that taking all possible stressors into account they will appear in approximately $25 \%$ of occasions (Gindhart, 1969, p. 20). The incidence tends to be higher in males than females (Gindhart, 1969, p. 20), probably reflecting the higher biological vulnerability of males. Comparisons with dental enamel hypoplasia suggest that Harris lines occur more frequently than hypoplastic lines and will be produced by insults that are insufficient to cause a line of hypoplasia. As will be seen below it 
is generally the case that bone will be more easily influenced by stress than dental tissues.

Probably the biggest single problem with assessing the significance of Harris's lines is that they can be resorbed. It has been suggested that most lines are resorbed within ten years, though females tend to preserve lines longer than males (Gindhart, 1969, p. 20). The process of remodelling has been studied by Garn et. al. (1968, pp. 58-89) who concluded that denser lines (presumably relating to length and severity of insult) persist longer, and that resorption works equally in all parts of the bone, though the latter statement appears to be contradicted by the preservation of partial lines that do not completely traverse the bone. The inability to quantify the number of lines lost has led many anthropologists to abandon using thell altogether, or to use them only as supporting evidence for other stress indicators (Huss-Ashmore et. al., 1982, p. 435).

\section{Dental overcrowding.}

When a human being is subjected to stress, bone will respond more quickly and more severely than dental tissues, which are more resilient. This principle has been mentioned above when comparing the incidence of Harris lines and dental enamel hypoplasia. Thus the teeth will keep growing at a faster rate than the bone, and dental overcrowding will result. Teeth will be malaligned and rotated out of their normal position, molars will be impacted and malocclusion can occur (Widdowson and McCance, 1964, p. 330). Furthermore, although other parts of the body may recover after a period of stress, teeth that are rotated or 1 mpacted do not alter (Widdowson and McCance, 1964 , p. 330). This factor has not received the same degree of attention as other stress indicators, and it should be interpreted with caution.

\section{Dental asymmetry.}

Bilaterally, symmetrical organisms will try to produce an organism or anatomical part that is perfectly symmetrical, but in practice this is rarely achieved. Any form of stress or disturbance can prevent this from occurring, because there is a decrease in co-adaptation which results in an increase in the phenotypic manifestation of developmental noise (Bailit et. al., 1970, p. 627). Thus, fluctuating asymmetry, i.e. one which does not favour either side has been used as a measure of stress levels during growth (Mather, 1953, p. 299; van Valen, 1962 , p. 137). Animal experiments in which rats were fed on malnourished diets showed asymmetrical growth to be one of the associated effects (Winick et. al., 1973, p. 191).

Theoretically, any bilateral part of the body can be measured, but in practice the dental arcades are the most commonly used in physical anthropology. Dental asymmetry has been demonstrated to increase as a result of noise, heat, cold, nutritional and environmental stress, and also inbreeding which produces a greater degree of homozygosity which effectively limits the developmental environment by reducing the number of alternative pathways available for the synthesis of a particular protein (Doyle and Johnstone, 1977, p. 132; Perzigian, 
1977, p. 86; Bader, 1965, p. 299). Dibennardo and Bailit (1978, p. 93) have emphasised the complexity of factors involved in dental asymmetry, and have warned against simplistic interpretation of its aetiology. In their research on a Japanese population they found many factors other than environmental stress to be implicated. Certainly genetic factors, gender and maternal parity are important considerations. However, many of the other factors implicated such as gestational age, socioeconomic status and foetal size are indirect measurements of environmental stress in themselves. Therefore, it is not surprising that they should correlate well with dental asymmetry.

\section{The relationship between health status in childhood and adulthood}

\section{a) Physiological processes}

1. As has been mentioned above relative low birth weight will predispose an individual to poor health in infancy.

\section{Intergenerational effect.}

The fact that the level of maternal health affects the health of the foetus, and that the health of the foetus directly affects the health of that individual in later life, means that there is an intergenerational effect on health patterns. As has been mentioned above, a survey of infant mortality in Britain in the $1960^{\prime} \mathrm{s}$ concluded that the high rate of infant mortality seen amongst low socio-economic groups was due to the poor state of health of the mothers, who were born during the years of the depression (Butler and Bonham, 1963, p. 278).

\section{b) Potential skeletal manifestations}

1. An increase in mortality at a young age

2. Decline in infectious pathology.

This has already been discussed above

3. Decline in stature

There is a large body of evidence to demonstrate the relationship between stature and stress in general, and nutrition in particular; there is probably an equal volume of literature demonstrating the genetical control of stature. As with all biological processes it is obviously a product of both factors, but the genetic component is possibly more important, and more controversial than is the case with any other stressors used in this model.

Studies carried out in several modern day populations to assess the degree of genetic control have produced widely varying results. For example, a South American population showed a correlation of 0.437 by path analysis (Rao et. al., 1975, p. 515), whereas a Morth American population gave a widely different correlation of 0.78 (Paganini-Hill et. al., 1981, p. 66). Each population will vary according to its individual circumstances, and it is impossible to generalise about the 
relative importance of genetic versus environmental factors or to extrapolate from one population to another. One reason for believing that the genetic component might be of less importance in this sample is that, most peasant communities are highly inbred and marry within a group of neighbouring villages.

It has been emphasised previously that the effects of stress will be dependent not only on the severity and duration of the stressor, but also on the timing of the insult. Stress occurring during certain periods can be readily compensated by catch-up growth, whereas stress incurred during other periods produces other effects that can never be reversed. Generally speaking, episodes of stress that are short in duration, mild in impact, or those that occur late in childhood can be reversed. However, there are notable exceptions to this generalisation, and the evidence with regard to stature shows a more complex pattern. Laboratory experiments in which very young animals were starved, showed that on return to uninhibited feeding, most animals underwent a period of catch-up growth, but that they still failed to reach the size of the control group. Slightly older, but still immature animals who were starved, not only completely recover the size differential, but in some cases surpassed the size of the control group (Widdowson and McCance, 1964, p. 327 ).

Evidence from human populations produces similar results regarding the rate of ossification. In a widespread survey involving a sample of 10,000 people from the lower socioeconomic groups in Central America, it was demonstrated that stress imposed in childhood could retard skeletal maturity by up to $30 \%$, whereas stress imposed during adolescence could retard by only $10 \%$ or less. However, the data for stature were the total reverse of the findings for skeletal maturation. Stature was not retarded by more than $10 \%$ in childhood, but stress imposed during adolescence could result in retardation of up to $30 \%$ (Frischanco et. al., 1970, p. 130). Thus, it is suggested that ultimate stature will be decreased because maturation will continue although growth will be retarded; therefore, by the time ossification is complete insufficient growth will be attained. On the other hand it can be demonstrated that there is a racial influence, not only on the ultimate height attained, but also on the patterns of growth which has to be set against purely environmental factors (Johnstone et. al., 1976, p. 473).

The controversy over whether stature is, or is not, a genuine reflection of environmental stress, centres on the relationship between growth and maturity. If, as has been suggested above, they work independently and even inversely then stature will be affected by stress. However, there is also a considerable body of evidence to show that improved environmental conditions leads to early ossification, and that prolonged stress can result in a longer period of growth. If this is the case, then the ultimate stature attained may be only marginally affected. Adult height is not only the result of the rate of growth as it is also influenced by the duration of growth; childhood rate of growth may have little ultimate bearing on adult stature (Falkner, 1958, p. 9). A comparison of the heights recorded for males during childhood, and then again at the ages of 19 and 25 during their military career was undertaken in Holland using records 
dating back to 1820 . The difference in stature attained at the age of 25 showed little change, but the height differentials during childhood and at 19 were considerable. In a modern western population mast males have achieved their adult stature by the age of 19 , whereas in the 19 th century many continued growing after this point to register a marked increase in height by the age of 25, and quite possibly carried on growing after that as well (Oppers, 1963 cited in Widdowson and HcCance, 1964 , p. 326). This has also been recorded in a third world population; a study of a Columbian population undergoing nutritional stress demonstrated that males were still growing in their 27 th year (Stini, 1971, p. 1025).

In using height as a non-specific indicator of stress it should be appreciated that it is essentially only reflecting the more robust members of the community. Assessment of stature depends on the individual having achieved adulthood, and therefore the most vulnerable members of the community will not be represented as they Will have died by this stage. There is a high correlation between patterns of mortality and patterns of growth (McGregor et. al., 1961, p. 1665).

As has been discussed above there is a synergistic effect between nutrition and infection. Infections, even minor ones, can seriously hamper growth and affect size. This has been well demonstrated in modern agricultural situations. In recent years much effort has been put into producing infection-free herds, not only because of the reduced mortality this brings, but also because of the increase in size; with the development of virus free herds, pigs reached the required weight of 200 pounds in only 160 days compared with 210 days previously (Widdowson and McCance, 1964, p. 328). Human populations have provided similar, though less quantifiable results. It has been demonstrated that nutritional stress results in reduced bone formation both enchondral and appositional, poor calcification and diminished trabecular patterns (Jha et. al., 1968, p. 1111). Anything that results in a reduction of protein is particularly important because osteoblasts have a higher protein turnover and a well developed rough endoplasmic reticulum (Jha et. al., 1968, p. 1116). Attempts to find an association between stature and the number of Harris lines have not proved conclusive. Two reports have claimed an inverse relationship (Perzigian, 1977, p. 86; Blanco et. al., 1974, p. 46) and one a positive relationship (Goodman and Clark cited in Huss-Ashmore et. Ql., 1982 , p. 439). This may be because of the problem of estimating resorbed lines, or possibly because stature records a different type of growth retardation, possibly a chronic condition that would not produce a Harris line.

4. A decline in sexual dimorphism.

The principle underlying the use of sexual dimorphism as a stress indicator has been stated above; namely that males have increased biological vulnerability and will be more severely affected by a stressor than females subjected to the same degree of stress. As a result of this, growth will be retarded more in males than females, and the normal differences in body size between the sexes will be reduced, thus sexual dimorphism will decrease. It has been suggested 
that, as well as possessing congenital advantages, females also acquire enhanced immunological responses during childhood and adolescence from hormones secreted by the thymus gland. Females appear to be better able to cope not only with infectious disease but also with degenerative and neoplastic diseases (Stini, 1985, p. 212).

Although the theory behind the principle is far from new, there is by no means universal agreement that the variability in sexual dimorphism is a reflection of environmental stress, and many support a genetic basis as the predominant control. There have been several studies of modern populations that have demonstrated that males are generally more labile in response to environmental stimuli; adverse conditions affect males more than females, but they also respond more sharply to improving conditions (Acheson and Fowler, 1964, p. 32; Stini, 1969 p. 425, 1971, p. 1024). Whilst this can be demonstrated quite easily in living children, there is less agreement as to whether this ultimately affects the degree of sexual dimorphism in the adult after growth has ceased. As has been mentioned above, duration of growth is equally as important as rate, and patterns of growth do not have a direct relationship with patterns of maturation. In a South American population it has been shown that stress leads to a loss of muscle tissue and decreased sexual dimorphism in circumferential measurements of musculature, but the same study did not show decreased sexual dimorphism in stature, merely an increase in the duration of male growth (Stini, 1971, pp. 1025-7).

The data from modern population studies have been interpreted in conflicting ways; for example, Tobias (1975, p. 301) interpreted his evidence as supporting sexual dimorphism as a stress indicator; Eveleth ( 1975, p. 38) takes the opposite viewpoint, and sees sexual dimorphism as being predominantly genetically based. Stini (1972, p. 121) has suggested that whilst it is predominantly genetically controlled, it can be used as a stress indicator if applied to the same population through time.

Cultural practices reflecting the relative status of males to females are likely to be of overwhelming importance in the manifestation of sexual dimorphism. Differential feeding and weaning of males and females can have severe health consequences. Sexual d1morphism of circumferential measurements may be related to occupation, and thus will reflect labour divisions within the society.

\section{Conclusion}

This article has presented a theoretical model to assess health in a rural agricultural society. It is predominantly biologically based, but has also incorporated social and cultural factors. As I hope I have made clear, none of the indicators used is tatally reliable. Dental enamel hypoplasia and age at death are probably the most reliable indicators. Stature, sexual dimorphism, cribra orbitalia and porotic hyperostosis are less reliable than dental enamel hypoplasia and age at death, but have been fairly extensively studied, though not all studies have reached the same conclusions. Dental asymmetry and overcrowding have been studied less extensively as stress indicators. and their reliability is unknown. The use of Harris's lines as a 
stress indicator is particularly problematic. Taking the number of pathological lesions as an indicator is entirely speculative. It is hoped to be able to provide a statistical assessment of this model in the future, and to reach some conclusions regarding the consistency of each indicator.

\section{Acknowledgements}

This research was funded by the Science and Engineering Research Council. Figure 1 was drawn by Barry Vincent. I am indebted to Dr P. Bumsted of the Department of Anthropology, University of Auckland and Dr A. Goodman of the School of Natural Sciences, Hampshire College, Amerst for their comments on this work in the early stages.

\section{BIBLIOGRAPHY}

Abernethy, V., 1979 - "Population pressure and cultural adjustment". Human Sciences Press, New York.

Acheson, R.M. and Fowler, G.B., 1964 - "Sex, socio-economic status and secular increase in stature". British J. Preventive Medicine, Vol. 18, pp. $25-34$

Adams, P.H., 1971 - "Intra-uterine growth retardation in the pig. II Development of the skeleton". Biology of the Meonate, Vol. 19, pp. $341-353$.

Agarwal, K.N., Dhar, N., Shah, M. N. and Bhardway, O.P., 1970 "Roentgenologic changes in iron deficiency anaemia". American J. Roentgenology, Val. 110, pp. 635-7.

Alberman, E., 1976 - "Factors influencing perinatal wastage", pp. 415-432 in R. W. Beard and P.W. Hathanielsz (Eds), Fetal physiology and medicine. W. B. Saunders Co. Ltd., Philadelphia.

Angel, J.L., 1966 - "Porotic hyperostosis, anemia, malarias and marshes in the prehistoric eastern Mediterranean". Science, Vol. 153, pp. $760-3$

Asciada, T., 1924 - "Ueber die Entstehung und pathologische Bedeutung der im Rontgenbild das Rohrenknochens am Diaphysenende zum Vorschen Kommenden paralien Querlinienbildung". Mitteil. Med-Fakult Kyushu Univ., Vol. 9, pp. 43-95.

Ascadi Associates, 1985 - "Family planning and the well-being of women and children". International Planned Parenthood Federation.

Bader, R.S., 1965 - "Fluctuating asymmetry in the dentition of the house mouse". Growth, Vol. 29, pp. 300

Bailit, H.L.P., Workman, P.L., Niswander, J.K. and MacClean, C.J., 1970 - "Dental asymmetry as an indicator of genetic and environmental stress in human populations". Human Blology, Vol. 42, pp. 626-638. 
Baird, D., 1952 - "Preventive medicine in obstetrics". New England I Kedicine, Vol. 246, pp. 561-568.

Bakketeig, L.S. and Hoffman, H.J., 1981 - "Epidemiology of preterm birth: results from a longitudinal study of births in Norway", pp. 1746 in M.G. Elder and C.H. Hendricks (Eds), Preterm labor. Butterworth International Kedical Reviews. Obstetrics and Gynecology 1. Butterworths, London.

Blanco, R.A., Acheson, R.M. , Canosa, C. and Saloman, J.N., $1974-$ "Height, weight and lines of arrested growth in young Guatemalan children". Amer. J. Phys, Anthrop., Vol. 40, pp. 39-48.

Britton, H. A., Canby, J.D. and Kohler, C.M., 1960 - "Iron deficiency anemia producing evidence of marrow hyperplasia in the calvarium". Pediatrics, Vol. 25, pp. 621-628.

Burko, H., Mellins, H.Z. and Vatson, J., 1961 - "Skull changes in iron deficiency anemia". Amer. J. of Roentgenology, Vol, 86 (3), pp. 447-452.

Butler, N.R. and Bonham, D.G., 1963 - "Perinatal mortality". E. and S. Livingstone, London.

Butler, N.R., Goldstein, H and Alberman, E., 1969 - "Maternal factors affecting duration of pregnancy, birthweight and foetal growth", pp. 47-71 in N.R. Butler and E. Alberman (Eds), Perinatal problems. E. and S. Livingstone, London.

Campbell, S., 1975 - "Fetal growth", pp. 271-301 in R.W. Beard and P.W. Nathanielsz (Eds), Fetal physiology and medicine. W. B. Saunders Co. Ltd., London.

Carlson, D.S., Armelagos, G.J. and van Gerven, D.P., 1974 - "Factors influencing the etiology of cribra orbitalia in prehistoric Nubia". I Human Evolution, Vol. 3, pp. 405-410.

Chandra, R.K., 1975 - "Fetal malnutrition and postnatal immunocompetence". Amer. J. of Diseases of Children, Vol. 129, pp. 450-454.

Cook, D.C., 1979 - "Subsistence base and health in prehistoric Illinois Valley: evidence from the human skeleton". Ledical Anthropology, Vol. 3, pp. 109-124.

Coutts, C.M., in press - "The hilltop cemetery", in R. Hodges (Ed), San Vincenzo al Volturno: excavation and survey 1980-1986. British School at Rome, London.

Davie, R., 1969 - "The first follow-up of the children born in the control week", pp. $321-330$ in N.R. Butler and E. Alderman (Eds), Perinatal problems. E. and S. Livingstone, London. 
Dibernnardo, R. and Bailit, H.L., 1978 - "Stress and dental asymetry in a population of Japanese children". Amer. J. Phys. Anthrop., Vol. 48 , pp. $89-94$

Doyle, W. and Johnstone, 0., 1977 - "On the meaning of increased fluctuating dental asymmetry: a cross-populational study". Amer. J. Phys. Anthrop., Vol. 46, pp. 27-134.

El-Najjar, M.Y., Lozoff, B. and Ryan, D.J., 1975 - "The paleoepidemiology of porotic hyperostosis in the American southwest: radiological and ecological considerations". Amer. J. Roentgenology, Vol. 125 (4), pp. 918-924.

Eng, L.L., 1958 - "Chronic iron deficiency anemia with bone changes resembling Cooley's anemia". Acta Hematologica, Vol. 19, pp. 263-268.

Eveleth, P.B., 1975 - "Differences between ethnic groups in sex dimorphism of adult height". Annals of Human Biology, Vol. 2, pp. 3539.

Falkner, F., 1958 - "Some physical measurements in the first three years of $11 \mathrm{fe} "$. Archives of Disease in Childhood, Vol. 33, pp. 1-9.

Fancourt, R., Campbell, S., Harvey, D. and Horman, A.P., 1976 - "A follow-up study of small-for-dates babies". British Yedical J., Vol. 1. pp. 1435-1437.

Fedrick, J. and Anderson, A.B.M., 1976 - "Factors associated with spontaneous pre-term birth". Brit. J, of Obstetrics and Gynaecology, Vol. 83 , pp. $342-250$.

Ferguson, A.C., Lawlor Jr. G.J., Neumann, C.G., Loh, W. and Stiehm, E.R., 1974 - "Decreased rosette-forming lymphocytes in malnutrition and intra-uterine growth retardation". I. of Pediatrics, Vol. 85, pp. $717-723$.

Fitzhardinge, P.M. and Steven, E.M., 1972 - "The small-for-date infant. 1. Later growth patterns". Pediatrics, Vol. 49, pp. 671-681.

Frischancho, A.R., Garn, S.M. and Ascoli, W., 1970 - "Population differences in skeletal maturation and its relationship to growth in body size". Amer. J. Phys. Anthrop., Vol. 33, p. 130.

Frisch, R.E., 1975 - "Critical weight, critical body composition and the maintenance of menstrual cycles", Pp. 319-352 in E.S. Watts, F.E. Johnston and G.W. Lasker (Eds). Biosocial interrelations in population daptation. Mouton Publishers, The Hague.

Gairdner, D., Marks, J. and Roscoe, J.D., 1955 - "Blood formation in infancy. Part IV The early anemia of prematurity". Archives of Diseases of Childhood, Vol. 30, pp. 203-211.

Galeski, B., 1971 - "Social organisation and rural social change", Pp. 115-137 in T. Shanin (Ed), Peasants and peasant societies. Penguin, London. 
Gamst, F, C., 1974 - "Feasante in complex society". Holt Fhinehart and Winston Inc., New York.

Garn, S.M., Silverman, F.N., Hertzog, K.P. and Rohan, C.G., 1968 "Lines and bands of increased density: their implication to growth and development". Kedical Radiography and Photography, Vol. 44, pp. 58-89.

Gindhart, P.S., 1969 - "The frequency of appearance of transverse lines in the tibia in relation to childhood illnesses". Amer. J. Phys. Anthrop., Vol. 31, pp. 17-22.

Goodman, A.H., Lallo, J., Armelagos, G.J. and Rose, J.E., 1984 "Health changes at Dickson Mounds, Illinois (AD 950-1300)", pp. 271305 in M.N. Cohen and G.J. Armelagos (Eds), Paleopathology at the origins of agriculture. Academic Press, New York.

Gordon, J.E., Wyon, J.B. and Ascoli, W., 1967 - "The second year death rate in less developed countries". Amer. J. of Medical Sclence, Vol. 254, pp. 121-144.

Gruenwald, P., 1964 - "Infants of low birth weight among 5000 deliveries". Pediatrics, Vol. 34, pp. 157-62.

Gruenwald, P., 1969 - "Stillbirth and early neonatal death", pp. 163183 in N.R. Butler and E. Alderman (Eds), Perinatal problems. E. and S. Livingstone, London.

Gruenwald, P., Funakawa, H., Mitani, S., Nishimura, T. and Takeuch1, S., 1967 - "Influence of environmental factors of foetal growth of man". Lancet, Vol. 1, pp. 1026-1028.

Handlin, O.E., 1967 - "Peasant origins", pp. 456-478 in G. Dalton (Ed), Iribal and peasant economies. University of Texas Press, Austin.

Hardy, J.B., 1973 - "Birthweight and subsequent physical and intellectual development". New England J. Nedicine, Vol. 289, pp. 9734.

Haris, H.A., 1926 - "The growth of the long bones in childhood with special reference to certain bony striations of the metaphysis and to the role of vitamins". Archives of Internal Medicine, Vol. 38, pp. $785-806$.

Harris, H.A., 1931 - "Lines of arrested growth in the long bones in childhood: correlation of histological and radiographic appearances in clinical and experimental conditions". British J. Radiology, Vol. 4, pp. 561-588 and 622-640.

Hayes, P., in press - "The environmental setting", in R. Hodges (Ed), San Vincenzo al Volturno 1: Excavation and survey 1980-1986. British School at Rome, London.

Hengen, O.P., 1971 - "Cribra orbitalia: pathogenesis and probable etiology". Homo, Vol. 22, pp. 57-75. 
Hi11, D.E., Myers, R.E., Holt, A.B., Scott, R. E. and Cheek, D.B., 1971 - "Fetal growth retardation produced by experimental placental insufficiency in the rhesus monkey. II Chemical composition of the brain, liver, muscle and carcass". Biology of the Heonate, Vol. 19, $p$. $68-82$

Hillson, S., 1986 - "Teeth". Cambridge Manuals of Archaeology. Cambridge University Press, Cambridge.

Hodges, R., in press - "The late Roman villa at San Vincenzo", in R. Hodges (Ed), San Vincenzo al Volturno 1: Excavation and survey 19801986. British School at Rome, London.

Hopkins, K., 1965 - "Contraception in the Roman empire". Comparative Studies in Society and History, Vol. 8, pp. 125-151.

Horn, E. and Born, W., 1979 - "The plan of St Gall". University of California Press, Berkeley, California.

Huss-Ashmore, R., Goodman, A.H. and Armelagos, G.J., 1982 "Iutritional inference from paleopathology", pp. 395-474 in M. B. Schiffer (Ed), Advances in archaeological method and theory. Volume 5. Academic Press, London.

Jha, G.J., Deo, M.G. and Ramalingaswami, V., 1968 - "Bone growth and protein deficiency". Amer. $J$, of Pathology, Vol. 53, pp. 1111-1121.

Johnstone, F.E., Wainer, H., Thissen, D. and MacVenn, R.B., 1976 "Hereditary and environmental determinants of growth in height in a longitudinal sample of children and youth of Guatemalan and European ancestry". Amer, J. Phys. Anthrop., Vol. 44, pp. 469-476.

Knodel, J., 1975 - "The influence of child mortality on fertility in European populations in the past: results from individual data". U.N. W. H. O. Working Paper No. 7 for World Population Year. New Delhi.

Kreshover, S., 1960 - "Metabolic disturbances in tooth formation". Annals of the New York Academy of Sciences, Vol. 85, pp. 161-167.

Kreshover, S. and Clough, O., 1953 - "Prenatal Influences in tooth development". J. of Dental Research, Vol. 32, pp. 565-572.

Laga, E.M., Driscoll, S.G. and Kunro, N.H., 1972 - "Comparison of placentas from two socioeconomic groups. 1. Morphometry". Rediatrics, Vol. 50 , pp. 24-32.

Lallo, J.W., Armelagos, G.J. and Mensforth, R.P., 1977 - "The role of diet, disease and physiology in the origin of porotic hyperostosis". Human Biology, Vol. 49 , pp.471-483.

Lanzkowsky, P., 1968 - "Radiologic features of iron deficiency anemia". Amer. $J$, of Diseases of Children, Vol, 116, pp. 16-29. 
Lechtig, A., Yarborough, C, Delgado, H, , Mortorell, R., Klein, R.E., Bemar, K., 1975 - "Effect of moderate maternal malnutrition on the placenta". Amer. J. of Obstetrics and Gynaecology, Vol, 123, pp. 191201.

Leridon, H., 1977 - "Human fertility". University of Chicago Press, Chicago.

Little, W.J., 1862 - "On the influence of abnormal parturition, difficult labour, premature birth and asphyxia neonatomen on the medical and physical condition of the child especially in relation to deformities". Transactions of the London Obstetric Society, Vol. 3, pp. 293-344.

MacFarlane, A., 1978 - "The origins of English individualism". Basil Blackwel1, Oxford.

MacKay, E.V., Beicher, N.A., Cox, L.V. and Wood, C., $1983-$ "Illustrated textbook of gynaecology". W. B. Saunders Co., Sydney.

Malinowski, B., 1967 - "Sex, culture and myth". 2nd Edition. Dell, London.

Martinez-Torres, C. and Layrisse, M., 1971 - "Iron absorption from veal muscle". Amer. $J$, of Clinical Nutrition, Vol. 24, pp. 531-539.

Martinez-Torres, C. and Layrisse, M., 1974 - "Interest for the study of dietary absorption and iron fortification". Forld Review of Nutrition and Dietetics, Vol. 19, pp. 51-70.

Yassler, M., Schour, I. and Poncher, H.G., 1941 - "Developmental pattern of the child as reflected in the calcification pattern of the teeth". Amer. J. of Diseases of Childhood, Vol. 62, pp. 33-67,

Mata, L.J., Urrutia, J.J. and Garcia, B., 1967 - "Effects of infection and diet on child growth. Experience in a Guatemalan village", pp. 112-126 in G.E.W. Wolstenholme and C.M. O' Connor (Eds), Nutrition and infection. Little Brown, Boston.

Mata, L.J., Urrutia, J.J., Caceres, A, and Guzman, H. A., 1972 - "The biological environment in a Guatemalan rural community", pp. 257-264 in Proceedings Hestern Hemisphere Nutrition Congress III. Futura Publishing Company Inc., New York.

Yata, L.J., Urrutia, J.J., Kronmal, R.A. and Joplin, C., 1974 "Survival and physical growth in infancy and early childhood by birthweight and gestational age. Study in a Guatemalan Indian village". Amer. J. Diseases of Children, Vol. 129, pp. 561-566.

Mata, L.J., Kronmal, R.A., Urrutia, J.J. and Garcia, B., $1976-$ "Antenatal events and postnatal growth and survival of children in a rural Guatemalan village". Annals of Human Biology, Vol. 3, pp. 305315. 
Mather, K., 1953 - "Genetic control of stability in development". Heredity, Vol. 7 , pp. 297-336.

MeGregor, I.A., Billewicz, W.Z, and Thompson, A. M., 1961 - "Growth and mortality in children". British Medical J. Vol, 2, pp. 1661-1666.

McHenry, H.M. and Schultz, P., 1976 - "The association between Harris lines and enamel hypoplasia in prehistoric Californian Indians". Amer. J. Phys. Anthrop. Vol. 44, pp. 507-512.

McKee, L., 1984 - "Sex differentials in survivorship and the customary treatment of infants and children". Medical Anthropology, Vol. 8 (2), pp. 91-108.

McLaren, A., 1984 - "Reproductive rituals". Methuen, London.

McMillen, M., 1979 - "Differential mortality by sex in fetal and neonatal deaths". Science, Vol. 204, pp. 89-90.

Mensforth, R.P., Lovejoy, C.O., Lallo, J.W. and Armelagos, G.J., 1978 - "The role of constitutional factors, diet and infectious disease in the etiology of porotic hyperostosis, and periosteal reactions in prehistoric infants and children". Medical Anthropology, Vol. 2, pp. $1-59$.

Hillard, A.V., 1982 - "Child mortality and lactation contraception in Kexico". Kedical Anthropology, Vol. 6(3), pp. 147-164.

Hosely, J.E., 1965 - "The paleopathologic riddle of "symmetrical osteoporosis" ". Amer. J. of Roentgenology, Vol. 95 (1), pp. 135-142.

Naeye, R.L., 1980 - "Factors in the mother/infant dyad that influence the development of infections before and after birth", in CIBA Foundation, Perinatal Infection. Excerpta Medica 1980. New York.

Naeye, R.L., Blanc, W. and Paul, C., 1973 - "Effects of maternal nutrition on the human fetus". Pediatrics, Vol. 52, pp. 494-502.

Paganini-Hill, A., Martin, A.O. and Spence, K.A., 1981 - "S-leut anthropometric traits: genetic analysis". Amer. J. of Phys. Anthrop., Vol. 55, pp. 55-67.

Park, E.A., 1954 - "Bone growth in health and disease". Archives of Diseases in Childhood, Vol. 29, pp. 269-281.

Park, E.A., 1964 - "The imprinting of nutritional disturbances on srowing bone". Pediatrics, Vol. 33, pp. 815-862.

Perzigian, A.J., 1977 - "Fluctuating dental asymmetry: variation among skeletal populations". Amer. J. Phys. Anthrop. Vol. 47, pp. 81-
88 .

Procopius, 1979 - "History of the Wars. Book VI". Translated by H. B. Dewing. Harvard University Press, Cambridge, Massachusetts. 
Rao, D.C., Machean, C.J., Mortan, N.E. and Yee, S., 1975 - "AnalysiE of family resemblance. V. Height and weight in north-east Brazil". Amer. $J$, of Human Genetics, Vol. 27, pp. 509-520.

Rose, J.C., Burnett, B.A., Blaeuer, M. W. and Nassaney, M.S. , 1984 "Paleopathology and the origins of maize agriculture in the lower Mississippi Valley and Caddoan culture areas", pp. 393-426 in M. I. Cohen and G.J. Armelagos (Eds), Paleopathology at the origins of agriculture. Academic Press, New York.

Russell, J.C., 1985 - "The control of late ancient and Medieval populations". American Philosophical Society, Philadelphia.

Saller, R.P., 1987 - "Mens age at marriage and its consequence in the Roman family". Classical Philology, Vol. 82, pp. 21-34.

Scrimshaw, N.S., Taylor, C.E. and Gordon, J.E., 1968 - "Interactions of nutrition and infection". World Health Organisation Monograph Series No. 57. Geneva.

Shafer, W.G., Hine, M.K. and Levy, B.M., 1983 - "A textbook of oral pathology". 4th edition. W.B. Saunders Company, Eastbourne.

Shanin, T., 1971 - "A Russian peasant household at the turn of the century", pp. 30-36 in T. Shanin (Ed), Peasants and peasant societies. Penguin, London.

Steinbock, R.T., 1976 - "Paleopathological diagnosis and interpretation". Charles Thomas, Springfield, Illinois.

Stevenson, A.C. and Bobrow, M., 1967 - "Determinants of sex proportions in man, with consideration of the evidence concerning a contribution from $X$-linked mutations to intrauterine death". J. of Medical Genetics, Vol. 4, pp. 190-221.

Stini, W.A., 1969 - "Nutritional stress and growth: sex differences in adaptive response". Amer. J. Phys. Anthrop., Vol, 31, pp. 417-426.

Stini, W.A., 1971 - "Evolutionary implications of changing nutritional patterns in human populations". American Anthropologist, Vol. 73, pp. 1019-1030.

Stini, W.A., 1972 - "Malnutrition, body size and proportion". Ecolos of Food and Nutrition, Vol. 1 (1), pp. 121-126.

Stini, W.A., 1985 - "Growth rates and sexual dimorphism in evolutionary perspective", pp. 191-226 in Gilbert and Mielke (EdS), The analysis of prehistoric diets. Academic Press, New York.

Stirling, P., 1971 - "A Turkish village", pp. $37-48$ in T. Shanth (Ed), Peasants and peasant societies. Penguin, London.

Stuart-Macadam, P., 1985 - "Porotic hyperostosis : representative of a childhood condition". Amer. J. Phys. Anthrop., Vol. 66 pp. 391-399. 
Super, C.M., 1984 - "Sex differences in infant care vulnerability". Kedical Anthropology, Vol. 8 (2), pp. 84-108.

Teitelbaum, M., 1972 - "Factors associated with the sex ratio in human population", pp. 90-109 in G. Harrison and A. Boyce (Eds), The Structure of human population. Oxfard University Press, Oxford.

Thomas, W.I. and Znaniecki, F., 1958 - "The Polish peasant in Europe and America". Dover Publications, New York.

Thomas, W.I. and Znaniecki, F. 1971 - "A Polish peasant family", pp. $23-9$ in $T$. Shanin (Ed), Peasants and peasant societles. Penguin, London.

Thomson, A.M., 1959 - "Maternal stature and reproductive efficiency". Eugenics Review, Vol. 51, pp. 157-162.

Thorner, D., 1971 - "Peasant economy as a category in economic history", pp. 202-218 in T. Shanin (Ed), Peasants and peasant Secieties. Penguin, London.

Tobias, P., 1975 - "Anthropometry among disadvantaged peoples: Studies in southern Africa", Pp. 287-308 in E.S. Watts, P.E. Johnstone and G.W. Lasker (Eds), Biosocial interrelation in population adaptation. Mouton Publishers, The Hague.

Turnbull, A.F., Cleton, C.A., Finch, L., Thomson, S., Martin, J., 1967 - "Iron absorption. IV The absorption of hemoglobin iron". J. of Clinical Investigation, Vol. 41, pp. 1897-1907.

Van Valen, L., 1962 - "A study of fluctuating asymmetry". Evolution, Vol. 16, pp. 125-142.

Vaughan, D.H., 1968 - "Some social factors in perinatal mortality". Brit1sh J. of Preventive and Social Medicine, Vol. 22, pp. 138-145.

Washburn, T.C., Medearis, D.N. and Childs, B., 1965 - "Sex differences in susceptibility to infections". Pediatrics, Vol. 35, pp. $57-64$

Viddowson, E.M., 1971 - "Intra-uterine growth retardation in the pig. I Organ size and cellular development at birth and after growth to maturity". Blology of the Neonate, Vol. 19, pp. 329-340.

Viddowson, E.M. and McCance, R.A., 1964 - "Effects of nutrition and disease on growth". British Dental J., Vol. 117, pp. 326-330.

Wig8lesworth, J.S., 1964 - "Experimental growth retardation in the

fetal rat". J, Pathology and Bacteriology, Vol. 88, pp. 1-13.

Winick, M., 1967 - "Cellular growth of the human placenta". L. of Pediatrics, Vol. 71 , pp. 390-395. 
Winick, M., 1958 - "Changes in nucleic acid and protein content of the human brain during growth". Pediatric Research, Vol. 2, pp. 352355.

Vinick, M., 1970 - "Fetal malnutrition". Clinical Obstetries and Gynecology, Vol. 13, pp. 526-541.

Vinick, M., Brasel, J.A. and Velasio, E.C., 1973 - "Effects of prenatal nutrition on pregnancy risk". Clinical Obstetrics and Gynaecology, Vol. 16, pp. 184-196. 


\title{
CHEIICAI AUALYSIS OF SHADOW BURIALS
}

\author{
Philip Bethell \\ Sutton Hoo Research Trust \\ Birmingham University Field Archaeology Unit \\ P. 0. Box 363 \\ Birmingham \\ B15 2TT
}

\section{Introduction}

The term 'shadow burlals' is used here to describe a phenomenon encountered by archaeologists over many years, (known by various names such as silhouette, body stain, pseudomorph, etc.), which appears in a varlety of forms ranging from 3-dimensional 'sandmen' uncovered at Sutton Hoo (see Bethell and Carver, 1987), to amorphous stains on the floors of neolithic burial chambers (Biek, 1957). They share the common factor of almost complete skeletal destruction, leaving only organic residues of the body's decay. It is these residues which have been the subject of chemical analysis, as archaeologists have sought to gather information from material which, of course, defies conventional interpretation. Included in these investigations of shadow burlals must be those burials where all visible traces of the body have disappeared, as this instance can legitimately be regarded as an extreme of the shadow burlal phenomenon (e.g. Barber, 1982). This paper will describe a number of analyses of degraded burials, and thelr purpose; trace the chronological development of such studies; and relate more recent work carried out on material from the AngloSaxon burial site at Sutton Hoo. It is an attempt to give archaeologists without chemistry training an 1 dea of the type of analyses which have been done, and the reasoning behind them, and to offer pointers towards the best way of carrying out such studies in the future.

\section{Historical Examples}

It seems appropriate to begin with Sutton Hoo, as the enigma of the original discovery - the 'royal' ship-burial without a body - has spawned endless speculations as to whether or not there was an interment with the treasure. A number of chemical investigations have taken place on material from the ship mound in an attempt to resolve that question, starting with that of Hughes between 1948 and 1951 (Barker, 1950; Barker et. al., 1975). As no soll samples had been taken from the burial chamber during the original excavation, it was declded to examine the grave goods, especially the iron ones, under the premise that any dissolved phosphate ions in the ground water would react with the iron objects and form an insoluble ferric phosphate compound. Thus any notable enhancement of ferric phosphate recovered from the grave goods would have come from a large, dissolving source of phosphorus, 1.e. a skeleton. The technique employed was a simple qualitative test producing an ammonium phosphomolybdate precipitate, followed by a simple volumetric titration for the quantitative measurements. The analysis suggested that there had been sources of additional phosphorus (1.e. additional 
to the natural background level) in the burial chamber, but it was not conclusive proof of a body being there.

An example from the U.S.A. was provided by Ralph Solecki, who excavated a Native American burial mound, and found human remains in a poor state of preservation. The mound also contained grave-like features with no visible traces of burial (Solecki, 1951). Solecki had 30 samples of soil analysed, from features with known burials: apparently empty features; from different soils in the mound; and from different levels. Control samples were also included. The analysis consisted of available phosphorus and $\mathrm{pH}$ measurements, and detailed soll description. The phosphorus determination, based on a $2 \%$ citric acid extraction, showed an enhancement in the 'empty' features. indicating that they originally contained a source of phosphorus, and hence these were probably burials. Also, samples of "loose powdery gray soil resembling hearth sweepings" (Solecki, ibid, 255) were found to contain a high proportion of phosphorus, and were deemed to be cremation deposits. Thus Solecki used this very basic analysis to suggest that the mound contained a greater density of burials than the excavation evidence showed.

A.H. Johnson examined an amorphous stain from the floor of a Scottish neolithic chambered tomb. With a view to proving whether or not it was the residue of an inhumation (Johnson, 1956). He analysed a number of samples of soil for total phosphorus, using a colorimetric method (McGregor, 1950). He contrasted the results with those of an available phosphorus measurement, and warned against assessing anything other than total phosphorus. He did find an enhancement of phosphorus in the central area of the floor, but this did not coincide exactly with the limits of the stain, and Johnson rightly pointed out that the retention mechanisms of the two types of deposit are different. He concluded that bones were the likely source of the enrichment, although no visible traces of bone remained.

A more complex examination of a prehistoric shadow burial was made by Leo Biek, of material from a Hampshire round barrow (Biek, 1957). Unfortunately, only 5 soll samples were analysed, for manganese content and total phosphorus, and the analytical technique was not recorded. The phosphorus showed little variation across the area of the grave, but the manganese appeared enhanced in the stain area, over the levels in the grave edges. This led Biek to suggest that manganese accumulated where organic matter had been situated. He also suggeted that future workers may attempt the " 'development' of aluminium 'Silhouettes' not visible to the naked eye".

Ballymacdermot court cairn, in Northern Ireland, was the subject of a chemical investigation in the 1960's, when it was found to contain only a few minute fragments of bone. The analyst, F.W. Gay (1964), delved into the 1920's for his inspiration, and used Arrhenius' $2 \%$ citric acid method to extract the available phosphorus from a number of soil samples (Arrhentus, 1929). Using ammonium molybdate in sulphuric acid, and stannous ( $t i n)$ chloride in hydrochloric acid, a blue solution was produced, the colour intensity of which was measured using a colorimeter. The depth of colour in the solution is directly related to the concentration of extracted phosphorus in the sample. 
Gay was able to distinguish differfig phosphorus levels in the different chambers of the tomb; between the chamber deposits and the external controls; and between various layers within the inner chamber. He concluded that the highest concentrations of phosphorus in the innermost chamber indicated the actual site of burial, and that a lesser enhancement in the outermost chamber supported the excavator's contention that this was not used for primary burial, but functioned as an antechamber. Different phosphorus concentrations within the stratigraphy of the inner chamber appeared to indicate at which level the interments took place. It is noteworthy that Gay pointed out flaws in the methodology, in that different soils have different levels of extractability, and this reinforces Johnson's point (above) concerning the usefulness of measuring available rather than total phosphorus.

The above examples can be grouped together on a number of criteria. Firstly, they were all attempts to prove the presence of inhumed bone, where no visible trace, or only amorphous (presumably) organic stains, remained at the supposed site of burial. They also have in common a reliance on the measurement of phosphorus, the exception being the analysis reported by Biek (1957) which also looked at manganese. The choice of phosporus as a body indicator is not surprising - it is a major constituent of bone, and has strong retentive properties in most solls. However, the overrriding flaw that the quoted examples share is a lack of investigation of the medium in which the phosphorus enhancements were noted, and of the mechanism by which they were retained in that medium (1.e. the soli). Another big drawback is the Inconsistency of analytical method employed - some workers measured total phosphorus, and others avallable/labile phosphorus. The number of samples analysed varied considerably, as did the wet chemistry analytical techniques.

This is not to decry the efforts of those earlier analysts, but awareness of their weaknesses is essential for such work to improve in usefulness. Indeed, many of the examples contain provisoes from the analysts. The consensus of opinion to be gleaned is that there are inherent dangers in relying on the measurement of available phosphorus alone, and that total phosphorus content is preferable; and that much fuller analysis of the background is required. Phosphorus does not exist in isolation, but is a constituent of an organic residue; it is part of the dynamic soil system in which it is deposited. It is a better understanding of this whole system, and the processes of decay in operation, which is necessary for reaching some kind of universal comparability of results.

It is not possible fully to elucidate here the advantages and disadvantages of total versus avallable phosphorus measurement, but suffice it to say that different solls have very different characteristics of phosphorus retention - 1.e. the proportion of phosphorus which can be easily extracted will vary with other criteria, and may not necessarily reflect with accuracy the actual content of the element in that particular soil. A fuller discussion of this subject will appear in a forthcoming paper (Bethell and Máte, in press). The realisation of the importance of understanding the phenomenon as part of a wider system was apparent in the late $1960^{\circ} \mathrm{s}$. 
at least to Biek, who wrote, "In general, it will be clear that a detailed knowledge of the basic geological and pedological background is essential if uncertainty is to be reduced to the minimum (Biek, 1969 , p.121). The uncertainty referred to is that of actually relating the 'soil silhouette' to the original object. In this paper, Biek was talking about the residues of all classes of organic material, and where skeletal evidence was concerned, was cautious about the use of phosphorus analysis. The examples examined above were all more or less successful - but the reasons why the experiments worked in those instances, and the question whether other people had negative results with the same methodology, were not investigated. It is not intended to labour this point, but it is important to understand how the growth in awareness of the need for a more scientific approach to archaeology, and the development of new analytical techniques, has affected more modern examples of this type of analysis. This is reflected by McCawley and McKerrell (1972), who examined the use of phosphorus analysis in identifying the presence of bodies (amongst other things). These authors looked at the phosphorus cycle in the soil, the different retentive properties of different soils and other features, in an attempt to standardize the approach to such analyses.

\section{Nore recent examples.}

Returning to Sutton Hoo, the analyses conducted on the material from this site in the early $1970^{\prime} s$ were somewhat more elaborate than those carried out in the late $1940^{\prime} \mathrm{s}$. During the re-opening of the ship burial by the British Museum in 1966-67, a number of soil samples were taken from the burial chamber and examined. These samples were taken either from around the remaining in-situ iron rivets, or where these were missing, on a superimposed grid. Analysis showed that there was a general enhancement of phosphorus over the natural background level in the area of the burial chamber, and a few areas of distinctive enrichment detected. 'Creamy fragments' also found and analysed, turned out to contain high levels of phosphorus, along with calcium, barium and iron (Barker et. al., 1975). A direct-current arc emmission spectrographic method was used for this qualitative analysis, and a suite of other techniques was used for the quantitative work- the colormetric method of Murphy and Riley (1962) was the basis for the phosphorus analysis, and atomic absorption spectrometry was used for measuring the concentrations of other elements.

An important aspect of this whole analysis was the comparison made with material from other sites. The absolute levels of phosphorus were compared with those from other sites, although not much could be concluded. More interestingly, an analysis of a 'shadow burial' from another site was conducted, to establish what the residue of an aciddecayed body might contain. This was undertaken on a burlal from the Anglo-Saxon cemetery at Mucking, Essex, which had decayed to a "silhouette... and a few disintegrated fragments of bone" (Barker et. al., 1975, p.564). Mucking was chosen because the soil conditions were similar to those at Sutton Hoo - an acidic free-draining sand/gravel (although the Essex site was slightly less acidic). Samples from the grave fill, the silhouette, and the natural soll outside and below the grave were analysed. Concentrations of 
phosphorus, manganese and iron (as oxides) were measured. A clear enhancement of phosphorus in the silhouette was iinked directly with corresponding manganese enhancement, with the iron oxide showing a random variation through the sample base. The comparative work was concluded by a lysimeter experiment in which phosphorus-enriched water was passed through a column of Sutton Hoo soll, and the amount of retained phosphorus measured. The conclusions of all this comparative study were that a body could almost completely decay under the prevalling conditions at Sutton Hoo, and that the IIkelihood of any traces of it being retained in the soll was small. Further similar analyses were conducted by Hughes (1980) on bone fragments and associated soil from the first 'sandmen' found on the site, in order to understand more about the differential preservation discernible in the 'sandmen'.

Mucking was used as the source for a fuller investigation of soll silhouettes, designed as part of a series to define the trace element content of body remains at different states of preservation (Keeley et. al., 1977). This was an expansion of an unpublished postgraduate study by Hudson (1974) which examined qualitatively the elemental make-up of material from one of the rucking body silhouettes, using atomic emission spectroscopy. Hudson identified a number of elements which were enhanced over the background levels in the body material, and she listed the elements likely to be involved in such a silhouette formation, 1.e. the so-called biophile elements, at the same time pointing out the likely importance of organic material (presumably body decay products) in the fixation of any elements at the site of burlal. From this information, the published paper concentrated on the behaviour of copper, manganese and phosphorus in the body silhouette. Conclusions were drawn about the origins of the detected enhancements of manganese and phosphorus in the silhouette, suggesting that the phosphorus was derived from the skeleton, and the manganese from the surrounding soil. This is a very important point, that residues of a body reduced to a 'shadow burial' will be products of material both from the decaying cadaver and the surrounding soll. This may appear obvious, but it is vital to grasp as a first step in understanding the mechanisms by which such residues are formed.

The example above was also notable for the employment of more systematic sampling than most of the preceding analyses. This is a very important part of any such analysis, which has all too often been forgotten in the past. Many of the 'shadow burial' investigations quoted have been very unscientific in the quantity of material examined, and have largely been carried out on samples not actually taken by the analyst. One recent (unpublished) burial investigation may be briefly looked at here, as an example of better practice. An apparently empty cist at Temple Wood, Argyllshire was sampled and analysed in 1979-1980 (Mate, personal communication). Although the analysis was simply a measurement of the total phosphorus content of the samples, what was important was the sampling array used, namely a $10 \mathrm{~cm}$ grid across the whole floor of the clst. This enabled the analyst to plot the result as a 'contour' map of the phosphorus variation across the grave. Assuming that the enhancements over background were the products of a decaying skeleton, the resulting peaks of phosphorus content visible on the 'map' could be equated with 
the parts of the higher density bones of the skeleton, and thus the likely position of the body deduced. The results of this are not totally convincing, but the careful construction of a sampling and analytical strategy are most noteworthy in the context of this discussion, and must be stated as prerequisites of any valid modern 'shadow burial' study.

This paper now turns to investigations carried out by the author on material from Sutton Hoo. This was undertaken as part of a wider project to investigate more fully the processes of decay undergone by buried organic matter. The study of material from the degraded burials was designed, amongst other things, to be able to answer the 'was there a body?' question for any future burial chambers investigated on the site. The following will not be an exhaustive description of the analysis, as this will be published elsewhere. The discussion will concentrate on the attempt to characterise chemically the visible body residues and use this information to locate the site of burial in an apparently empty burial chamber. This is intended to illustrate the potential of more exhaustive chemical studies of 'shadow burials'.

It was decided to subject material from one of the 'sandman' burials to a wider range of analysis, in order to establish a chemical 'signature' for the decay products of a body at an advanced stage of degradation. By this is meant the establishing of a pattern of chemical difference ( 1 .e. enhancement or diminution) between the body residues and the background pattern observed in the grave fill and surrounding soil. It was postulated that this 'signature' could then be extrapolated to a situation where no visible remains of a body could be found. Of course, the absolute levels of the various elements/compounds could be expected to be lower in the latter situation, but should follow the overall pattern established of the visible residues. Thus a number of analyses were instigated, to examine both the organic and inorganic contents of the 'shadow burial' residues. These included amino-acid analysis and tests for fatty acid presence, using thin-layer chromatography spectrometry (ICP). The approach was to use a wide range of techniques to define the material, and to find one or more which distinguished the body clearly fram the background.

Taking the organic analysis as a whole, the picture was rather diffuse. There was an enhancement of the concentrations of aminoacids in the body matrix, but unfortunately those amino-acids indicative of humans (particularly hydroxyproline) were not included in the standard array. There was some evidence that the residues recognised as human and wood could be distinguished by their aminoacid concentrations. Some evidence of fatty acid presence in the body samples was also found, (not present in the background), but this is vague. Work is currently continuing on the fractionation of the humic material in the samples, in order to understand more about the origins of the residues. The basic problem with these organic analyses is that the surviving fragments of broken down organic compounds in episodes of heavy decay tend to be very basic (i.e. simple) constituents of the original material. There is always a background of such organic matter derived from other sources, such as the soll 
biota, and so it is hard to extract evidence that can be specifically related to an interment. However, with the development of techniques such as GC/MS (gas chromatography/ mass spectrometry), NMR (nuclear magnetic resonance) and infra-red spectrometry, the analysis of the organic traces in shadow burials may become a more viable proposition. In contrast, the initial ICP analysis showed a clearer picture, with distinctions in elemental content discernible between bone, soil silhouette material and the grave fill. It was therefore decided to make ICP the basis of a larger-scale experiment.

ICP was used as a cheap, rapid analytical technique. It is an efficient method of analysing the concentrations of $25-30$ elements simultaneously. The basic experiment ran as folllows; an inhumation (without grave goods) at Sutton Hoo was systematically sampled from the top of the grave fill through to the natural soil below the burial silhouette. 131 fills and 28 body samples were submitted for ICP analysis, with the following array of elements analysed: $\mathrm{Al}, \mathrm{Fe}, \mathrm{Mg}$, $\mathrm{Ca}, \mathrm{Na}, \mathrm{K}, \mathrm{Ti}, \mathrm{P}, \mathrm{Mn}$, (as \% of oxides) and $\mathrm{Ba}, \mathrm{Ce}, \mathrm{Co}, \mathrm{Cr}, \mathrm{Cu}, \mathrm{La}, \mathrm{Li}$. $\mathrm{Mo}, \mathrm{NBb}, \mathrm{Ni}, \mathrm{Sc}, \mathrm{Sr}, \mathrm{V}, \mathrm{Y}, \mathrm{Zn}$ and $\mathrm{Zr}$ (as parts per million). Four colums of samples from outside the features were also analysed, in order to examine the vertical distribution of the various elements from the topsoil through to the subsoil, and check whether there were any large variations in the background.

It was established that clear enhancements were shown in the body silhouette over the background for $\mathrm{Al}, \mathrm{Ca}, \mathrm{P}, \mathrm{Ba}, \mathrm{Ce}, \mathrm{Co}, \mathrm{Cr}, \mathrm{La}, \mathrm{Mo}$, $S c$, and $Y$. Diminutions over background were noted for $\mathrm{Fe}, \mathrm{Na}, \mathrm{K}, \mathrm{Ti}$ and $\mathrm{Cu}$. Thus the repetition of this pattern, at least for those elements with stronger variations, should be an indication of the presence of a body. It cannot be stressed how much this is a simplification of the findings of this analysis - what is being done here is the application of the technique at its crudest level, and no attempt will be made to discuss the reasons why those particular elements are to be found in this specific array. It should also be noted that this chemical signature is of course highly site-specific. A fuller description of this portion of the experiment is forthcoming elsewhere (Bethell and Smith, 1989).

The second part of the experiment consisted of the analysis of a larger series of samples from a very heavily robbed burlal chamber located in Mound 2 at Sutton Hoo and excavated in 1987-1988. The floor of the chamber was sampled on a $10 \mathrm{~cm}$ grid, at a level just below the original interior floor, i.e. in undisturbed natural soil. 490 soll samples were analysed by ICP for the same set of elements. Initial mechanical plotting of the results for $\mathrm{Al}, \mathrm{P}, \mathrm{Fe}, \mathrm{La}, \mathrm{Ba}, \mathrm{Cu}$, and $\mathrm{Sr}$ indicates a clear area of enhancement of all those elements in the south-west corner of the burial chamber. It is postulated that this is indicative of the presence of a body in that area. Al, P, Ba and $\mathrm{La}$ are elements shown to be enhanced over background in the 'sandman' analysed above. Fe and $\mathrm{Cu}$ appeared to be present in smaller quantities in the 'sandman'. Their enhancement in the case of the burial chamber may possibly indicate the presence of iron and bronze 8rave goods with the body - there are also clear enhancements of these two elements over the eastern half of the chamber, where the bulk of grave goods would be expected to have been. 
It is to be regretted that the publication deadilne of this volume precludes the inclusion of the full analysis of these results. The apparent enhancements of those elements must be subjected to statistical checking, and the distribution of all the elements must be studied. However, the author is excited with the preliminary results, and is very hopeful that this particular method of multi-element analysis will be vindicated.

\section{Conclusion}

Regardless of the final outcome of this experiment, which takes its place here as a natural progression from the earlier analyses of shadow burials, I feel that the way forward with such analysis is through a multi-analytical approach, on a statistically viable number of carefully taken samples. A reliance on one or two elements, or just a few samples, is not enough. It is significant that in the above experiment at Sutton Hoo, phosphorus was the least enhanced of those elements in the burial chamber whose concentrations were plotted, (although what discernible enhancement there was, was concentrated in the south-west corner of the burial chamber). I hope this paper has illustrated something of the development of the analysis of 'shadow burlals'. I feel there is a lot of significant information to be gained from the pursuance of chemical study in archaeology as a whole, this being but one aspect of that wider picture. What is important is that the questions behind such studies are properly formulated; that adequate sampling is undertaken (including attention to post-excavation treatment of samples); and that the most useful analytical technique is employed for the job. As for the specific investigation of 'shadow burials', there is obviously potential for using information derived from degraded burials to locate invisible remains, as described above; and there may well be more information to be culled from in-depth study of the organic resides present in the body material, such as the separation of animal from human residues by amino-acid analysis. As chemical techniques advance, their value to archaeology will increase, and we may work towards the time when 'shadow burials' are no longer quite so shadowy.

\section{BIBLIOGRAPHY}

Arrhenius, 0., 1929 - "Die Phosphatmethode I \& II". Zeitschrift fur Pflanzenernährung. Düngung und Bodenkunde, Teil A 14, pp. 121-140, and pp. 185-194.

Barber, J.B., 1982 - "A short cist at Mordington Mains, Berwickshire, Borders Region". Broceedings of the Society of Antiquaries of Scotland, Vol. 112, pp. 536-541

Barker, H., 1950 - "Unusual phosphate material in the Sutton Hoo ship burial". Nature, Vol. 166, pp. 348.

Barker, H., Hughes, M. J., Oddy, W. A. and Werner, A. E., 1975 - "Report on phosphate analysis carried out in connection with the cenotaph problem" pp. 550-572 in R.L.S. Bruce-Mitford (Ed), The Sutton Hoo Shif Burial Vol I. British Museum, London. 
Bethel1, P.H. and Carver, M. O.H., 1987 - "Detection and enhancement of decayed inhumations at Sutton Hoo", pp. 10-21 in A. Boddington, A.M. Garland and R.C.Janaway (Eds), Death, decay and reconstruct1on. Approaches to archaeology and forensic science. Manchester University Press, Manchester.

Bethell, P.H. and Smith, J.U., 1989 - "Trace element analysis of an inhumation from Sutton Hoo, using inductively- coupled plasma emission spectrometry (ICP): an evaluation of the technique applied to analysis of organic residues". $J$. of Arch. Sc1, Vol. 16, pp. 47-56.

Bethell, P.H. and Máte, I., (in press) - "The use of soll phosphorus analysis in archaeology: a critique" in J. Henderson (Ed), Scientific analysis in archaeology and its interpretation. Oxford University Comittee for Archaeology, Monograph 19, Oxford.

Blek, L., 1957 - "The 'slihouette'" pp. 162-163 in P. Ashbee, The Great Barrow at Bishop's Waltham, Hampshire. Proceedings of the Prehistoric Society, Vol. 23, pp. 137-166

Biek, L., 1969 - "Soil Silhouettes", pp. 118-123 in D. Brothwell and E.S. Higgs (Eds), Sclence in Archaeology. 2nd Edition. Thames and Hudson, London.

Gay, F.W., 1964 - "Reports on phosphoric acid content of soil samples from Ballymacdermot court calrn", pp. 20-22 in A.E.P. Collins and B.C.S. Wilson, The excavation of a court cairn at Ballymacdermot, Co. Armagh. Ulster Journal of Archaeology, Vol. 27.

Hudson, G.E., 1974 - "The determination of trace elements in Saxon human remains". Unpublished dissertation, Post-Graduate Diploma in Analytical Chemistry, North-East London Polytechnic, London.

Hughes, M.J., 1980 - "Report on the scientific examination of bone and compacted sand from Mound 5", pp. 60-62 in I. Longworth and I. Kinnes (Eds), Sutton-Hoo Excavation 1966. 1968-1970. British Museum Occasional Paper 23.

Johnson, A.H., 1956 - "Examination of soil from Corrimony chambered calrn". Proceedings of the Society of Antiquaries of Scotland (19541956), Vol. 88, pp. $200-207$.

Keeley, H.C.M., Hudson, G.E. and Evans J., 1977 - "Trace element contents of human bones in various states of preservation 1: the soll sllhouette". I. of Arch. Sclence, Vol. 4., pp. $19-24$.

McCawley, J.C. and MacKerre11, H., 1972 - "Soll phosphorus levels at archaeological sites". Broceedings of the Soclety of Antiquaries of Scotland, Vol. 104, pp. 301-306.

MCGregor, A.J., 1950 - "A colorometric modification of Mclean's method for the determination of phosphorus in soils". Journal of the Science of Food and Agriculture. Vol.1, pp. 105-107. 
Murphy, J, and Riley, J.P., 1962 - "A modified single solution method for the determination of phosphate in natural waters". Analytica Chimica Acta, Vol, 27, pp. 31-36.

Solecki, R.S., 1951 - "Notes on soil analysis and archaeology". American Antiquity, Vol. 16, pp. 254-256. 
HUNAI BOIFE STROITIUI ANALYSIS III THE INVESTIGATION OF PALAEODIETS: A CASE STUDY FROY A BRITISH AMGLO-SAXOI SITE

\author{
Simon Mays \\ Ancient Monuments Laboratory \\ Fortress House \\ 23 Savile Row \\ London W1X $2 \mathrm{HE}$
}

Introduction

Since the pioneering work of Brown (1973) a large number of studies have attempted to use human bone trace element analysis in order to investigate diet in antiquity (reviews by Sillen and Kavanagh, 1982; Klepinger, 1984; Blakely, 1985; Price et. al., 1985a). Of a varlety of trace elements which have potential as palaeodietary indicators, strontium has probably received the most attention. Strontium undergoes fractionation in the food chain, so that meat contains generally lower levels than vegetable foods (Schroeder et, al., 1972). In man $99 \%$ of the body's strontium is located in the skeleton (Schroeder et, al., 1972), and studies (Comar et. al., 1957a, 1957b; Rheingold et. al., 1983) have shown a firm relationship between dietary intake and skeletal levels of strontium.

Although much strontium work on archaeological bone has been directed at analysis of relative meat:vegetable ratios in palaeodiets, the wide variety of foods characteristic of the human diet must be taken into account when interpreting bone strontium data. Due to the higher concentrations of strontium in sea water than in fresh water, levels of strontium in marine food webs are rather higher than those in terrestial ones. Thus, for example, marine fish contain rather higher levels of strontium than do freshwater species. In bony fish most strontium is sequestered in the skeleton; hence consumption of marine fish will result in elevated bone strontium levels in cases where significant portions of the skeleton are ingested (as, for example, in small fish eaten whole). In addition, both marine and freshwater shellfish are rich in many trace elements, including strontium (Schroeder et. al., 1972; Schoeninger and Peebles, 1981).

For a trace element to be useful in dietary studies using analyses of excavated bone, changes during interment must be sufficiently slight such that levels in excavated bone are an adequate measure of those obtaining in life. Techniques which have been used to assess postmortem change in trace element levels in excavated bone, include comparison of elemental levels in ancient and modern bones (Lambert et. al., 1979; Byrne and Parr1s, 1987), comparison of levels in different skeletal components (Lambert et. al., 1982), studies of the distribution of elements with respect to bone surface (Lambert et. al., 1983; Gilbert, 1975), comparison of levels of elements in bone with those in the surrounding soll (Lambert et. al., 1979, 1984), measures of the isotopic ratios of trace elements (Nelson et. al., 1986) and comparison of elemental levels in human bones with those in the bones of carnivores and herbivores recovered from the same site

(Sillen, 1981). The consensus from multi-element studies 1 s that 
strontium is among those least affected by post-depositional changes over a wide range of burial conditions.

Since its behaviour in the biosphere is particularly well documented, and $1 t$ has been shown to be relatively more resistant to post-depositional alteration than other bone trace elements, strontium was the element selected for study in the present work.

The aim of this study is to attempt to compare diets of individuals burled in different types of grave within a single cemetery using human bone strontium analysis; particular attention is paid to assessing the effects of postmortem change on the patterning in the results obtained.

\section{Materials and methods}

\section{(1) The site}

The material used in this study was excavated from the cemetery at Ulwell, Dorset, England. The site lies on steeply sloping ground about $55-61 \mathrm{~m}$ oD and about $1.5 \mathrm{~km}$ from the coast. The underlying geology is faulted Greensand, although the graves were malnly cut into colluvial deposits of Greensand and Chalk. Excavations in 1982 revealed 57 extended inhumations which represent but part of a larger cemetery. The burials were orientated roughly west-east and, apart from one individual buried with an iron knife, contained no grave goods. The majority of graves were simple earth pits, but some were stone-lined and some were limestone cists, with stone walls and, occasionally, surviving stone lids. Radiocarbon determinations suggest a 7 th century $A D$ date for the site (see Cox, forthcoming).

\section{(11) Choice of bone sample for analysis}

Using modern material, Sowden and Stitch (1957), Hodges et. al. (1950), Turekian and Kulp (1956) and Thurber et, al. (1958) found no significant variation in strontium levels in different parts of the human skeleton. However, Tanaka et. al. (1981) did find significant variation in strontium levels between different skeletal elements, and in different parts of the same bone, in autopsy specimens; they suggested that their findings were explicable in terms of differential bone turnover rates.

In addition to the possibility that differing elemental levels in different parts of the skeleton might arise from in-vivo factors, the possibility of differential susceptibility to postmortem change must be considered. Grupe (1988) studied levels of several trace elements in samples of compact and trabecular bone from a series of German Medieval skeletons. The total skeletal content of each element was also calculated. The results for strontium were that the mean levels for the compact and trabecular bone samples were significantly different; only the level in the former was a reliable measure of total skeletal content. These results were similar to those for the other trace elements studied. Although in-vivo differences in the elemental composition of different parts of the skeleton may exist, the results were interpreted as indicating that compact bone was less 
subject to post-depositional changes in elemental levels than trabecular bone (in agreement with Lambert et. al., 1982). Grupe (1988) recommended the use of compact bone from a standardised part of the skeleton in trace element studies of excavated bone.

In the present study all bone samples were taken from the mid shaft area of the humerus. This site was selected because it is mainly composed of compact rather than trabecular bone and because the humerus was the long bone present for the greatest number of Individuals from Ulwell. A sample (1-2g) of bone was removed in such a way as to leave the humeri intact for measurement.

\section{(1ii) Sample preparation and analytical techniques}

Bone samples were scraped clean with a glass slide and endosteal and periosteal surfaces were removed in order that any surface contaminants should not affect the results (cf. Pate and Brown, 1985; Grupe, 1988). Prior to use, all glassware was rinsed in concentrated nitric acid (diluted 1:1 with delonised water). The samples were ashed and dissolved in acid using the methods of Szpunar et. al. (1978). To the dissolved sample was added $5 \mathrm{ml}$ of an aqueous solution containing $10 \% \mathrm{La}$ and $0.5 \% \mathrm{~K}$ in $10 \%$ trichloroacetic acid and the solution made up to $10 \mathrm{ml}$ with delonised water. After filtration of the solution, strontium levels were determined using a Unicam SP9 atomic absorption spectrophotometer with the following settings:

$\begin{array}{ll}\text { Wavelength } & 460.7 \text { nanometers } \\ \text { Fuel } & \text { Acetylene at 9psi } \\ \text { Support } & \text { Air at } 30 \text { psi } \\ \text { Lamp current } & 10 \text { millivolts }\end{array}$

Most of the work on the passage of strontium through food chains has been done using strontium:calcium ratios (because in its passage through food chains strontium is discriminated against with respect to calcium), although in archaeological studies strontium levels in bone have been measured both in terms of strontium concentration per unit welght of ashed bone and as a strontium:calcium ratio. Strictly speaking, the strontium: calcium ratio is the more correct parameter to use in dietary studies; an assumption in using strontium alone is that the strontium concentration will be an adequate surrogate for the strontium:calcium ratio. Although it is well known that calcium levels in bone decrease slightly with age (e.g. Lambert et. al., 1979) physiological variations in calcium levels are trivial compared with those expected in strontium due to dietary factors. Hence this factor should not significantly affect the validity of using strontium level alone in this context; indeed archaeological studies which give both strontium and strontium:calcium figures (e.g. Sillen, 1981; Price, 1985; Runia, 1987a; Byrne and Parris, 1987) show similar patterning in the results from both measures, showing that the variation in the strontium:calcium ratio is essentially variation in strontium not calcium. In addition, studies (Lambert et, al., 1982, 1984, 1985a) have indicated that in some cases postmortem change in calcium levels In excavated bone may occur even when strontium levels are not significantly affected. This finding argues against the use of strontium:calcium ratios, and for the use of strontium values alone 
for dietary reconstruction using trace element analysis of excavated bone, "The pattern whereby strontium is stable in buried bone but calcium clearly leaches out into the soll over time confirms that the use of the strontium:calcium ratio in the analysis of buried bone is entirely inappropriate... this ratio is dependent on diagenesis and is not reliable for the archaeologist looking at ancient bone" (Lambert et. al., 1984, p.111). Pate and Brown (1985) and Beck (1985) have expressed similar views. Thus in the present work strontium values alone rather than strontium: calcium ratios were used.

\section{Study of post-depositional change}

Sources of postmortem change in levels of bone trace elements can be divided into three categories:

1. Chemical exchange of elements with the surrounding soil matrix. Variables affecting the extent and rate of chemical exchange include soil trace element levels, water content, redox potential and $\mathrm{pH}$ (discussion in Lambert et. al., 1985b; Sillen, 1981; Henderson et al., 1987; Nelson and Sauer, 1984; Nelson et. al., 1986).

2. Physical contamination of the bone. Kyle (1986) found that, because of its porosity, minute soil particles could penetrate buried bone and this contamination may not be completely removed by normal cleaning methods.

3. Chemical change initiated by soll-living microorganisms. Breakdown of the organic portion of bone (mainly collagen) by soll-living microorganisms creates acidic by-products. This acld milieu leads to dissolving and recrystallisation of the mineral portion of the bone (Hackett, 1981; Herrman and Newesley, 1982; Plepenbrink, 1986; Grupe and Piepenbrink, 1988). This process of solubilisation of bone mineral would facilitate exchange of bone trace elements with the surrounding matrix and hence is a potential source of post-depositional change in trace element levels (cf. Hanson and Buikstra, 1987; Grupe and Piepenbrink, 1988).

The trace element composition of an excavated bone will be the result of the action of a combination of these three types of postmortem change on the in-vivo trace element levels in the bone. Since bone excavated from archaeological sites has been in intimate contact with the soil matrix for many centuries it is, perhaps, unrealistic to expect that no postmortem changes in composition will have taken place. Hence the question to be answered in archaeological trace element studies seeking to investigate palaeodiets is not "has any postmortem change occurred in elemental levels in bone?" but rather, "are postmortem changes sufficiently slight such that the levels of the trace element(s) of interest are an adequate measure of those obtaining in life?". In the present work the aim is to investigate whether individuals in different grave types at UIwell had different dietary intakes of strontium - for this to be feasible, within-sample variation in bone strontium has to be a measure of 1 n $^{-}$ vivo rather than postmortem variation. In order to investigate directly whether this was so, patterns of variability found with 
respect to age and sex at UIwell were compared with those expected on physiological grounds.

\section{Variation with respect to sex}

Studies using laboratory animals have shown that pregnancy and lactation result in increased strontium levels in the maternal skeleton.

Kostial et. al. (1969) demonstrated an increased strontium: calcium ratio in the skeletons of lactating rats. The reasons for this difference were thought to be increased absorption of both strontium and calcium from the gut, together with maintenance of discrimination against strontium with respect to calcium at the level of the mammary gland (also discussed in Blanusa et al., 1970). Strontium stored in the bones before pregnancy is not mobilised in significant amounts during lactation (Kidman et, al., 1951).

Hartsook and Hershberger (1973) demonstrated that in pregnant rats there is discrimination against strontium with respect to calcium at the placenta and reported an increase in the strontium : calcium ratio of the maternal carcass during gestation. These results, together with the low strontium: calcium ratio found in foetal material are consistent with the evidence presented by Kidman et. al. (1951) that pregnancy does not lead to any dramatic mobilisation of strontium from the maternal skeleton.

As Sillen and Kavanagh (1982) have pointed out, extrapolation of these results to humans is complicated by the lower turnover rate for human bone. Modern studies generally report no significant difference in strontium levels between the sexes (e. 8 . Sowden and Stitch, 1957), although Schroeder et. al. (1972) did report significantly higher bone strontium levels in females from a U.S. population.

Against this, however, "studies of the strontium content of prehistoric skeletons have almost routinely reported relatively higher $\mathrm{Sr} / \mathrm{Ca}$ levels in the bones of adult females" (Sillen and Kavanagh, 1982:76), a point also noted by Blakely (1988). Sillen and Kavanagh (1982) link this with the probability that, in nonindustrialised populations, women are likely to be pregnant or lactating for a greater proportion of their adult lives than is the case in modern Western societies.

Archaeological studies by Brown (1973), Gilbert (1975), Mays (1987), Lambert et. al. (1979) and Blakely (1988) all report relatively higher strontium levels (whether measured as strontium concentration per unit weight of bone ash or as strontium: calcium ratio) in the bones of adult females. Price et. al. (1985a, 1985b) misquote the literature and hence are mistaken in believing higher strontium levels in males are usual in human populations.

In the Ulwell material, sex was determined in those individuals Judged to be adults (aged 17 years or over at death) using aspects of the morphology of the pelvis and skull (Workshop of European 
Anthropologists, 1980). The strontium results are summarised in Table 1.

Table 1: Sumary of bone strontium levels (parts per nillion - ppm in bone ash) from vlwell by age and sex.

$\begin{array}{lccr} & \text { N Mean str. concentration Standard } \\ \text { Males } & 14 & 105.5 & 19.6 \\ \text { Females } & 12 & 119.5 & 14.0 \\ \text { Unsexable } & & & \\ \text { Adults } & 4 & 124.5 & 9.7 \\ \text { Juveniles } & 9 & 140.1 & 34.0 \\ \text { TOTAL } & 39 & 119.7 & 25.4\end{array}$

A t-test (Blalock, 1972, p.223f) showed that the difference in bone strontium between the males and females was significant ( $t=1.98$, significant at the $5 \%$ level), the females having the higher value. There is no segregation between the sexes in terms of grave type or spatial distribution in the cemetery, hence there is no suggestion of the existence of any systematic difference in postmortem environment which might account for these results; it seems likely that the difference in bone strontium between the sexes is a reflection of invivo rather than postmortem factors.

It is also worth noting that the overall mean bone strontium level at Ulwell (119.7 ppm) is similar to that reported for modern populations (e.8. the modern British human bone samples studied by Sowden and Stitch, 1957, showed a mean strontium level of $95 \mathrm{ppm}$ ).

\section{Variation with respect to age}

As a result of a combination of the change from a milk to a solid diet on weaning and lower discrimination against strontium by the gastro-intestinal tracts of infants compared with those of older children and adults, the skeletal strontium levels of children are characterised by low levels in neonates followed by a rapid increase which peaks between the ages of 1 and 3 years, with a subsequent decline to adult levels (references in Sillen and Smith, 1984). This physiologically expected pattern has been found in a number of previous studies of archaeological bone (e.g. Sillen and Smith, 1984; Runia, 1987a). In contrast to this high degree of variability in children, studies on modern specimens show that levels of bone strontium in adults do not vary significantly with age (Turekian and Kulp, 1956; Thurber et. al., 1958; Comar et. al., 1957b; discussion in Sillen and Kavanagh, 1982).

In the Ulwell material age at death was determined for children and adolescents using dental development and epiphyseal fusion (Workshop of European Anthropologists, 1980). Recent work (e.8. Cox, this volume) suggests that some macroscopic age indicators are rather 
unreliable for determining age in adults. However, methods based on dental wear have been shown to be reliable for age determination in adults in a wide variety of populations of known age, both 11 ving (Kieser et. al., 1983; Tomenchuk and Mayhall, 1979; Richards and Brown, 1981, Molnar et.al., 1983) and dead (Johnson, 1976; Lovejoy et. al., 1985). It was thus thought appropriate to use dental attrition to determine adult age in the present case. Ideally age-attrition standards should be established for each group under study using immature individuals (cf. Miles, 1962), but the small number of Juveniles in the Ulwell sample prevents such a strategy. However, research by Brothwell suggests that the rate of attrition changes Iittle for British populations from Neolithic to Medieval times: the Ulwell adults were aged using his attrition standards (Brothwell, 1981: Figure 3.9).

The variation in bone strontium with respect to age at death is shown below:

Table 2: Bone strontium levels (ppm) in juveniles and adults

\section{Juveniles}

No. Mean ov

9
140.0
24.3

No.

Adults

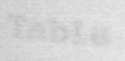

Table 3: Variation in bone strontium levels (ppm) with respect to age

Age

$0-2$

$5-13$

13-17

17-25

25-35

$35+$

\section{Unsexable}

No. mean sd

1210.6 -

$\begin{array}{lll}5 & 142.8 & 21.9\end{array}$

$\begin{array}{lll}3 & 112.0 & 14.7\end{array}$

\section{Hales}

No. mean sd No.mean sd

The figures in Table 3 are presented graphically in Figure 1. The difference between the mean strontium levels in adults and juveniles is statistically significant $(t=2.98$, significant at the $5 \%$ level). The pattern shown in Figure 1 is of a high level of strontium in Juveniles, declining with age to the lower, adult level. In contrast to the situation with the juveniles there is less varlability in bone strontium in the adults. Table 2 and inspection of Figure 1 reveals no suggestion of a consistent trend in bone strontium concentration with respect to adult age. There is no suggestion of any difference in postmortem environment which may account for these results; it seems probable that they are a reflection of the expected physiological pattern. 


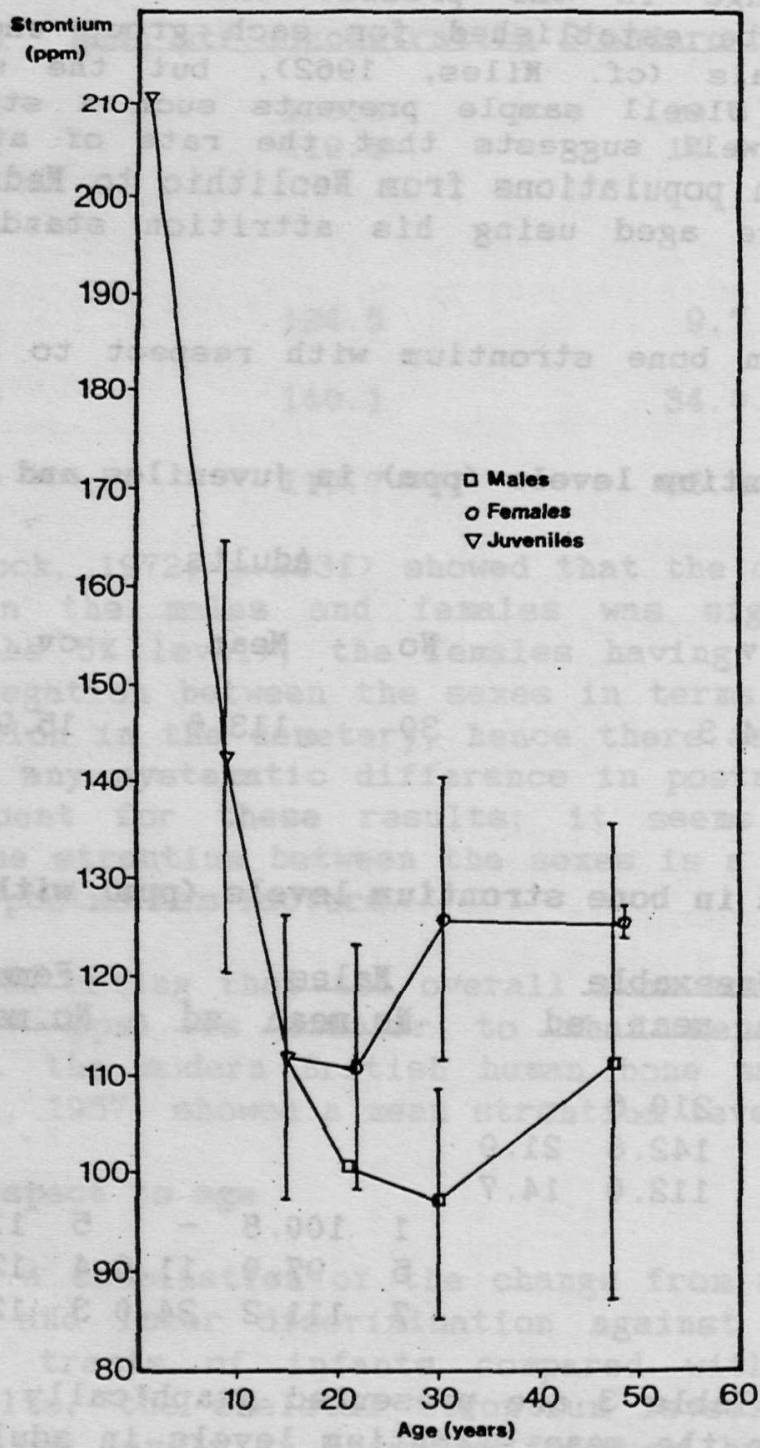

Fig. 1: Mean strontium concentration grouped with respect to age and sex. 
Analysis of diet

\section{(i) Bone strontium}

The presence of statistically significant differences in bone strontium levels between subgroups of the Ulwell population has been demonstrated. Comparison with modern populations has shown that the patterning observed in the Ulwell results is explicable in terms of in-vivo rather than postmortem factors. This suggests that the data are sultable for studying dietary differences between groups of individuals burled in the cemetery. This inference is also supported to some extent by the fact that bone strontium levels at Ulwell are similar to those from modern samples.

For the analysis of diet Sillen and Kavanagh (1982) recommend the exclusion of juvenile individuals on account of the great variability in bone strontium values in these individuals due to physiological factors, a strategy followed by many writers (e.g. Schoeninger, 1979; Sillen, 1981; Blakely and Beck, 1981; Price, 1985). Hence, juveniles were excluded in the study of diet at Ulwell.

The summary statistics for the strontium analyses from adult individuals buried in the three different grave types at Ulwell are shown in Table 4.

Table 4: Variation in bone strontiun level (ppm) in adults with respect to grave type

Grave type

Type I: simple pit

Type II: stone-lined pit

Type III: stone cist

$\begin{array}{rll}1 & \text { Lean } & \text { s.d. } \\ 14(6 \mathrm{M}, 5 \mathrm{~F}, 3 U) & 120.7 & 17.0 \\ 9(4 \mathrm{M}, 4 \mathrm{~F}, 1 \mathrm{U}) & 101.9 & 14.5 \\ 7(4 \mathrm{M}, 3 \mathrm{~F}) & 114.5 & 16.9\end{array}$

Table 4 shows that the mean strontium level in adults from grave type II is rather lower than for those buried in the other graves. A $t$-test shows this difference to be statistically significant ( $t=2.46$, significant at the $2.5 \%$ level). It thus seems that individuals buried in grave type II had a lower dietary intake of strontium than those in other graves.

Although much human bone strontium work has been directed at the investigation of relative meat : vegetable ratios in palaeodiets, the great variety of foods which make up human diets means that differences in bone strontium values do not necessarily reflect differences in meat : vegetable ratios. It was thus thought necessary to use a second variable to aid interpretation of the strontium results. To this end a study of dental caries was undertaken.

\section{(ii) Dental caries}

Dental caries is a condition characterised by progressive destruction of the tooth structure by organic acids produced as byproducts of the metabolising of carbohydrate residues by plaque-living bacteria. 
Carbohydrate residues are necessary for the inftiation of carious lesions. Although modern refined sugars are highly cariogenic (Newbrunn, 1982), starchy foods, too, can be important causes of dental caries. Although they are not directly metabolisable by microorganisms, starchy residues in the mouth are broken down to low molecular weight sugars by salivary amylase; these sugars can then be fermented by the plaque-living bacteria (Mormann and Muhlemann, 1981; discussion in Moore and Corbett, 1971, 1973).

By contrast fats, oils and meat are non-cariogenic (Shaw, 1954) and Dreizen and Spies (1948) have shown that bacterial breakdown of proteins may inhibit the growth of the aciduric and acidogenic microorganisms responstble for dental carles. In this way the presence of meat residues in the mouth could help inhibit the formation of carious lesions on the teeth.

Ethnographic evidence links levels of carbohydrate consumption to dental caries rates in non-industrialised populations. Caries levels in pre-contact Greenland Eskimos are negligible, but when these peoples adopt carbohydrate foods dental caries is frequent (Pedersen, 1947). Schwartz (1946) assoclated the low rate of dental caries he observed in the Masal of Kenya with the diet of mainly milk, blood and meat and very little carbohydrate consumed by these pastoralist people. In a comparison between the Masai and their agricultural neighbours, the Kikuyu, Orr and Gilks (1931) found that the caries rate in a sample of children from the latter was approximately 13 times that in the former. From a review of the literature Turner (1979) found that hunter-gatherers showed $1.72 \%$ of the total teeth to be carious. In groups with mixed hunter-gatherer and agricultural economies the figure was $4.37 \%$, and for agriculturalists the figure was $8.56 \%$. This pattern was thought to reflect differential carbohydrate consumption under these three subsistence strategies.

Thus, although dental caries must be thought of as a multifactorial disease (White, 1975), the strong correlation between caries and carbohydrate consumption has resulted in the use of caries prevalences to investigate the relative proportion of carbohydrate in palaeodiets (e.8. Larsen, 1983; Turner, 1979; Walker and Erlandson, 1986; papers in Cohen and Armelagos, 1984). It was thus thought that if the difference in bone strontium levels between individuals in grave type II and those in the other grave types reflected a difference in the meat : vegetable ratio of the diet a difference in dental caries rate might also be expected.

Dental caries was scored on a presence / absence basis in each tooth and as present or absent in individuals with one or more teeth avallable for study. The results are shown in Table 5 .

Table 5: Prevalence of dental caries at 0lwell (adults only)

Grave type Prevalence (indivs) Prevalence (teeth)

Mean age

$\begin{array}{llll}\text { II } & 3 / 9 & 3 / 174 & 34.6 \\ I+I I I & 7 / 22 & 8 / 378 & 34.4\end{array}$


The mean age at death is recorded for the two samples because caries prevalence varies with age; a greater prevalence of caries is often found in older populations since older individuals have been longer exposed to the agents of decay (Brabant, 1967). The two groups at Ulwell have similar mean ages and hence are comparable in this respect.

Statistical analyses are only valid for prevalences recorded with respect to individuals rather than total teeth since teeth in a particular mouth do not constitute independent observations. The prevalences with respect to individuals are similar and Fisher's exact test (Blalock, 1972 pp.287-291) shows that the difference between the two groups in terms of caries prevalence is nowhere near significant $(\mathrm{p}=0.70)$. The prevalences with respect to total teeth are also similar. Hence there is no suggestion from the dental caries data of any difference in the meat : vegetable ratio of the diets of those interred in grave types II and those interred in the other graves.

As stated in the introduction, marine food webs contain greater amounts of strontium than terrestrial ones, hence the differential dietary intake, Inferred for the individuals buried in the different grave types at Ulwell, could be related to differential consumption of marine resources; this is particularly relevant in view of the site's proximity to the coast. An additional possibility is that the different groups were consuming vegetable foods with differing strontium contents (cf. Runia, 1987b).

\section{Discussion and conclusions}

The aim of the present study was to compare diets of individuals interred in different grave types within the cemetery at Ulwell using an analysis of variation in bone strontium. In order for this to be a valid procedure it was necessary to demonstrate that within-sample variability was indeed indicative of in-vivo variation rather than postmortem factors. In an attempt to do this, patterns of variation in bone strontium levels in the Ulwell individuals were compared with those expected on physiological grounds. This is akin to the established technique of comparing levels of strontium in archaeological human bone with those in carnivore and herbivore bones excavated from the same site, in that in both cases we are investigating whether the patterning in the results from the archaeological material conforms to that expected $1 n-v i v o$ (in the cases af the animal bone comparison it is assumed that the strontium level of the human bones should be somewhere between that of the herbivores and the carnivores, reflecting the omnivorous nature of human diet).

Comparisons between strontium levels in excavated human bone with those in the bones of carnivorous and herbivorous animals in order to assess post-depositional change are compllcated by the great diversity of human diet (cf. Runia, 1987b). In addition, in cases such as the present work, analysis of intra-sample variation in human bone strontium is a more direct test of the hypothesis underlying the dietary investigation: that the variation in human bone strontium between individuals within the cemetery reflects in-vivo rather than 
postmortem effects. It may thus be that when the aim is to compare the diets of groups of individuals within a cemetery, comparisons of within sample variation with those expected on physiological grounds may be preferable to comparison of the human bones with excavated animal bone to investigate post-depositional change in bone strontium levels.

In the present work interpretation of the strontium results was facilitated by using an analysis of a dental pathology. It is recommended that trace element studies be integrated with palaeopathological techniques rather than used in isolation.

\section{Acknowledgements}

Thanks are due to the Trust For Vessex Archaeology and particularly to Peter Cox, for allowing me access to the skeletal material and to unpublished data concerning the site. The strontium analysis was carried out in the Departments of Archaeology and Oceanography at the University of Southampton. Acknowledgements are due to the staff in these departments, particularly Sue and Stephen Shennan, Professor Ucko and Professor Lockwood.

\section{BIBLIOGRAPHY}

Beck, L.A., 1985 - "Bivariate analysis of trace elements in bone". I. Human Evolution, Vol, 14, pp. 493-502.

Blakely, R. L., 1985 - "Stress, palaeonutrition and trace elements", pp. 339-358, in R.I. Gilbert and J.M. Mielke (Eds). The analysis of prehistoric diets. Academic Press, London.

Blakely, R.L., 1988 - "Bone strontium content in pregnant and lactating females from archaeological samples", p. 10 in Papers presented at the 15th Annual Meeting of the Palaeopathology Association (Abstracts). Missouri, Kansas City.

Blakely, R.L. and Beck, L.A., 1981 - "Trace elements, nutritional status and social stratification at Etowah, Georgia", pp. 417-431 in A.E. Cantwell, J.B. Griffin and N.A. Rothschild (Eds), The research potential of anthropological museum collections. Annals of the New York Academy of Sciences, Vol. 376.

Blalock, H. M., 1972 - "Social statistics". 2nd edition. McGraw-Hill, New York.

Blanuša, M., Harmut, K. and Kostial, K., 1970 - "Comparative strontium and calcium metabolism in lactation". Achiv. za Higijenu Badai Ioksikologiju, Vol. 21, pp. 125-127.

Brabant, H., 1967 - "Palaeostomatology", pp. 538-550, in D.R. Brothwell and A.T. Sandison (Eds), Diseases in antlquity. Charles Thomas, Springfield, Illinois. 
Brothwel1. D. R., 1981 - "Digging up bones. The excavation. treatment and study of human skeletal remains". 3rd edition. Oxford University Press, Oxford and British Museum (Natural History), Oxford.

Brown, A. B., 1973 - "Bone strontium content as a dietary indicator in human skeletal populations". Unpublished PhD Dissertation, University of Michigan.

Byrne, B. B. and Parris, D.C., 1987 - "Reconstruction of the diet of the Middle Woodland Amerindian population at Abbott Farm by bone trace-element analysis". Amer. J. Phys. Anthrop., Vol. 74, pp. 373384.

Cohen, M. N. and Armelagos, G.J. (Eds), 1984 - "Palaeopathology at the origins of agriculture". Academic Press, London.

Comar, C.L., Russell, R.S. and Wasserman, R.H., 1957a - "Strontium calcium movement from soll to man". Science, Vol. 126, pp. 485-492.

Comar, C.L., Wasserman, R.H., Ullberg, S. and Andrews, G. A., 1957b -

"Strontium metabolism and strontium - calcium discrimination in man". Proceedings of the Society for Experimental Blology and Medicine, Vol. 95, pp. 386-391.

Cox, P. (forthcoming), - "An inhumation cemetery at Shepherd's Farm, Ulwell, Near Swanage, Dorset (SZ02268092)". Broceedings of the Dorset Natural History and Archaeology Society.

Dreizen, S. and Spies, T.D., 1948 - "Further studies on the association between the products of protein putrefaction and dental caries activity". L. Dental Research, Vol. 27, pp. 305-315.

Gilbert, R., 1975 - "Irace element analyses of three skeletal Amerindian populations at Dickson Younds". Unpublished PhD Dissertation, University of Massachusetts.

Grupe, G., 1988 - "Impact of cholce of bone samples on trace element data in excavated human skeletons". J. Arch. Sc1., Vol. 15, pp. 123129.

Grupe, G. and Piepenbrink, H., 1988 - "Trace element contaminations in excavated human bone by micro-organisms", pp. 103-112 in G. Grupe and B. Herrman (Eds), Irace elements in environmental history. Springer, Berlin.

Hackett, C.J., 1981 - "Microscopical focal destruction (tunnels) in exhumed human bones". Medicine, Science and the Law, Vol. 21, pp. 243265.

Hanson, D.B. and Buikstra, J.E., 1987 - "Histomorphological alteration in buried human bone from the Lower Illinols Valley: implications for palaeodietary research". J. Arch. Sc1., Vol. 14, pp. 549-563. 
Hartsook, E. W. and Hershberger. T.V., 1973 - "Strontium - calcium discrimination during placental transfer and foetal uptake in rats". Proceedings of the Society for Experimental Biology and Hedicine, Vol. 143, pp. 343-349.

Henderson, P., Pickford, M. and Williams, C. T., 1987 - "A geochemical study of rocks and spring waters at Kanam and Kanjera, Kenya and the implications concerning element mobility and uptake". I. African Earth Sciences, Vol. 6 , pp. 221-227.

Herrman, B. and Newesley, H., 1982 - "Dekompositionsvorgange des Knochens unter langer Liegezeit. 1. Die mineralische Phase". Anthropologische Anzeiger, Vol. 40, pp. 19-31.

Hodges, R. M. , Macdonald, N.S., Nusbaum, R. , Stearns, R., Ezmirlian, F., Spain, P. and MacArthur, C., 1950 - "The strontium content of human bones". J. Biological Chemistry, Vol. 185, pp. 519-524.

Johnson, J.S., 1976 - "A comparison of age estimation using discriminant function analysis with some other age estimations of unknown skul1s". I. of Anatomy, Vol. 121, pp. 475-484.

Kelser, J.A., Preston, C.B. and Evans, V.G., 1983 - "Skeletal age at death: an evaluation of the Miles Method of ageing". L. Arch. Sc1." Vol. 10, pp. 9-12.

Kidman, B., Tutt, M.L. and Vaughan, J.M., 1951 - "Retention of radioactive strontium and Yttrium ( $\mathrm{Sr}, \mathrm{Sr}$ and $\mathrm{Y}$ ) in pregnant and lactating rabbits and their offspring". I. Pathology and Bacteriology, Vol. 63, pp. 253-268.

Klepinger, L.L., 1984 - "Nutritional assessment from bone". Annual Review of Anthropology, Vol. 13, pp. 75-96.

Kostial, K., Grunden, N. and Durakovic, A., 1969 - "Intestinal absorption of calcium-47 and strontium-85 in lactating rats". Calcified Iissue Research, Vol. 4, pp. 13-19.

Kyle, J.H., 1986 - "Effects of post burial contamination on the concentrations of major and minor trace elements in human bones and teeth - the implications for palaeodietary research". J. Arch. Sc1., Vol. 13, pp. 403-416.

Lambert, J.B., Szpunar, C.B, and Bulkstra, J.E., 1979 - "Chemical analysis of excavated human bone from Middle and late Woodland sites". Archaeometry, Vol. 21, pp. 115-129.

Lambert, J.B., Vlasak, S.M., Thometz, A.C. and Buikstra, J.E., 1982 "A comparative study of the chemical analysis of ribs and femurs in Woodland populations". Amer. J. Phys, Anthrop., Vol. 59, pp. 289-294.

Lambert, J.B., Simpson, S.V., Buikstra, J.E. and Hanson, D. B. , 1983"Electron microprobe analysis of elemental distribution in excavated human femurs". Amer. J. Phys. Anthrop., Vol. 62, pp. 409-423. 
Lambert, J.B., Simpson, S.V., Buikstra, J.E. and Charles, D.K., 1984 - "Analysis of soil associated with Voodland burials", pp. 97-113 in J.B. Lambert (Ed), Archaeological chemistry III. Advances in Chemistry Series No. 205. American Chemical Society, Washington D.C.

Lambert, J.B., Simpson, C.B. and Buikstra, J.E., 1985a - "Bone diagenesis and dietary analysis". J. Human Evolution, Vol. 14, pp. $477-482$.

Lambert, J.B., Simpson, S.V., Weiner, S.G. and Buikstra, J.E. . 1985b - "Induced metal Ion exchange in excavated human bone". I. Arch. Sci., Vol. 12 , pp. 85-92.

Larsen, C.S., 1983 - "Behavioural 1mplications of temporal change in carlogenesis". I, Arch. Sc1., Vol. 10, pp. 1-8.

Lovejoy, C.O., Meindl, R.S., Mensforth, R.P. and Barton, T.J., 1985 "Multifactorial determination of skeletal age at death: a method and blind tests of its accuracy". Amer. J. Phys. Anthrop. . Vol. 68, pp. 114.

Mays, S.A., 1987 - "Social organtsation and social change in the Early and Middle Bronze Age of Lower Austria: A study using human skeletal remains". Unpublished PhD Thesis, Department of Archaeology, University of Southampton.

Miles, A.E.W., 1962 "The dentition in the assessment of individual age in skeletal material", pp. 191-209 in D.R. Brothwell (Ed), Dental Anthropology. Pergamon, London.

Molnar, S., McKee, J.K. and Molnar, I., 1983 - "Measurement of tooth wear among Australian aborigines: I Serial loss of enamel crown". Amer. J. Phys. Anthrop., Vol, 61, pp. 51-65.

Moore, W.J. and Corbett, M.E., 1971 - "The distribution of dental carles in ancient British populations I. Anglo-Saxon Period". Caries Research. Vol.5, pp. 151-168.

Moore, W.J. and Corbett, M.E., 1973 - "The distribution of dental carles in ancient British populations II. Iron Age, Romano-British and Mediaeval periods". Carles Research, Vol.7, pp. 139-153.

Mormann, S.E. and Muhlemann, H.R., 1981 - "Oral starch degradation and its influence on acid production in human dental plaque". Caries Research, Vol. 15, pp. 166-175.

Nelson, D.A. and Sauer, N.J., 1984 - "An evaluation of post depositional changes in the trace element content of human bone". American Antiquity, Vol. 49, pp. 141-147.

Nelson, B.K. , DeNiro, M.J., Schoeninger, M. J. and DePaolo. D.J., 1986 - "Effects of diagenesis on strontium. carbon, nitrogen and oxygen concentration and isotopic composition of bone". Geochimica et Cosmochimica Acta, Vol. 50. pp. 1941-1959. 
Newbrunn, E., 1982 - "Sugar and dental carles: A review of human studies". Science, Vol. 217, pp. 418-423

Orr, J.B. and Gilks, J.L., 1931 - "Studies of nutrition. The physique and health of two African tribes". Medical Research Council Special Report Series, No. 155. London.

Pate, D. and Brown, K.A., 1985 - "Stability of bone strontium in the geochemical environment". I. Human Evolution, Vol. 14, pp. 483-491.

Pedersen, P.O., 1947 - "Dental Investigations of Greenland Eskimos". Broc. of the Royal Society of Medicine, Vol. 40, pp. 726-732.

Plepenbrink, H., 1986 - "Two examples of blogenous dead bone decomposition and their consequences for taphonomic interpretation". J. Arch. Sc1., Vol. 13, pp. 417-430.

Price, T.D., 1985 - "Late archaic subsistence in the Midwestern United States". I. Human Evolution, Vol. 14, pp. 449-459.

Price, T.D., Schoeninger, M.J. and Armelagos, G.J., 1985a - "Bone chemistry and past behaviour: an overview". J. Human Evolution, Vol. 14, pp. 419-447.

Price, T.D., Connor, M. and Parsen, J.D., 1985b - "Bone chemistry and the reconstruction of diet: strontium discrimination in white-tailed deer". I. Arch. Sci., Vol. 12, pp. 419-442.

Rheingold, A.L., Hues, S. and Cohen, M. N., 1983 - "Strontium and zinc content in bones as an indication of diet". L. Chemical Education, Vol. 60 , pp. 233-234.

Richards, L.C. and Brown, T., 1981 - "Dental attrition and age relationships in Australian aborigines". Archaeology and Physical Anthropology in Dceania, Vol. 16, pp. 94-98.

Runia, L., 1987 a - "The chemical analysis of prehistoric bones". British Archaeological Reports. International Series, Vol. 363, Oxford.

Runia, L., 1987b - "Strontium and calcium distribution in plants: effect on palaeodietary studies". J. Arch, Sc1., Vol. 14, pp. 599-608.

Schoeninger, M.J., 1979 - "Diet and status at Chalcatzingo. Some empirical and technical aspects of strontium analysis". Amer. J. Phys. Anthrop., Vol. 51, pp. 295-310.

Schoeninger, M. J, and Peebles, C.S., 1981 - "Effect of mollusc eating on human bone strontium levels". J, Arch, Sc1., Vol. 8, pp, 391-397.

Schroeder, H.A., Tipton, I.H. and Nason, A.P., 1972 - "Trace metals in man: strontium and barium". L of Chronic Diseases, Vol. 25, pp. 491-517. 
Schwartz, J., 1946 - "The teeth of the Masai". I, Dental Research. Vol. 25, pp. 17-20.

Shaw, J.H., 1954 - "The effect of carbohydrate-free and carbohydratelow diets on the incidence of dental caries in white rats". J. of Nutrition. Vol. 53, pp. 151-162.

Sillen, A., 1981 - "Strontium and diet at Hayonim Cave". Amer. J. Phys. Anthrop., Vol. 56, pp. 131-137.

Sillen, A. and Kavanagh, M., 1982 - "Strontium and palaeodietary research: a review". Yearbook of Physical Anthropology, Vol. 25, pp. $67-90$.

Sillen, A. and Smith, P., 1984 - "Weaning patterns are reflected in strontium: calcium ratios of Juvenile skeletons". J. Arch. Sc1., Vol. 11. pp. 237-245.

Sowden, E.M. and Stitch, S.R., 1957 - "Trace elements in human tissue". Blochemical J., Vol. 67, pp. 104-109.

Szpunar, C.B., Lambert, J.B. and Bulkstra, J.E., 1978 - "Analysis of excavated bone by atomic absorption". Amer. J. Phys. Anthrop., Vol. 48, pp. 199-202.

Tanaka, G., Kawamura, H. and Nomura, E., 1981 - "Distribution of strontium in the skeleton and in the mass of mineralised bone". Health Bhysics, Vol. 40, pp. 601-614.

Thurber, D.L., Kulp, J.L., Hodeges, E., Gast, P.W. and Wampler, J.M., 1958 - "Common strontium content of the human skeleton". Science. Vol. 128, pp. 256-257.

Tomenchuk, J, and Mayhall, J.T., 1979 - "A correlation of tooth wear and age among modern Igloolik eskimos". Amer. J. Phys. Anthrop. , Vol. 51, pp. $67-78$.

Turektan, K.K. and Kulp, L., 1956 - "Strontium content of human bọnes". Sclence, Vol. 124, pp. 405-407.

Turner, C.G., 1979 - "Dental anthropological indicators of agriculture among the Jomon people of Central Japan". Amer. J. Phys, Anthrop., Vol. 51, Pp. 619-636.

Walker, P.L. and Erlandson, J.M., 1986 - "Dental evidence for prehistoric dietary change in the Northern Channel Islands, California". American Antiquity, Vol. 51, pp. 375-383.

White, G.E., 1975 - "Dental caries, a multifactorial disease". Charles Thomas, Springfield, Illinois.

Workshop of European Anthropologists 1980 - "Recommendations for age and sex diagnoses of skeletons". L. Human Evolution. Vol. 9, pp. 517549. 
Appendix: Catalogue of burials used in the present work

Burial Grave type Strontium (ppm) Sex Age Dental caries Ne.

\begin{tabular}{|c|c|c|c|c|c|}
\hline 2 & 1 & 125.6 & F & $35-45$ & $0 / 10$ \\
\hline 4 & 3 & 100.0 & - & $13-17$ & $0 / 30$ \\
\hline 5 & 1 & 124.5 & & $25-35$ & $0 / 21$ \\
\hline 0 & 1 & 210.5 & - & $0-2$ & $0 / 1$ \\
\hline 8 & 3 & - & F & $25-35$ & $0 / 21$ \\
\hline & 2 & 134.8 & - & $5-9$ & $0 / 27$ \\
\hline 0 & 3 & 159.2 & - & $5-9$ & $0 / 26$ \\
\hline 11 & 1 & 135.0 & F & $25-35$ & $1 / 30$ \\
\hline 12 & 1 & 122.1 & M & $45+$ & $0 / 21$ \\
\hline 15 & 2 & 120.4 & $\mathrm{~F}$ & $17-25$ & $0 / 27$ \\
\hline 17 & 2 & 113.8 & F & $17-25$ & $\quad 0 / 25$ \\
\hline 18 & 1 & 100.8 & M & $17-25$ & $0 / 29$ \\
\hline 19 & 1 & 119.7 & - & $5-9$ & $0 / 22$ \\
\hline 20 & 2 & 86.9 & F & $17-25$ & $0 / 31$ \\
\hline 21 & 3 & 114.8 & M & $25-35$ & $2 / 17$ \\
\hline 22 & 2 & 90.0 & M & $35-45$ & $0 / 11$ \\
\hline 23 & 1 & 123.5 & - & $9-13$ & $0 / 24$ \\
\hline 26 & tenges & 145.3 & M & $35-45$ & $0 / 5$ \\
\hline 27 & 2 & 132.6 & - & $13-17$ & $0 / 23$ \\
\hline 28 & 1 & 141.7 & F & $25-35$ & $0 / 22$ \\
\hline 29 & 1 & 139.2 & $\mathrm{U}$ & adult & $\operatorname{man} x-1$ \\
\hline 30 & 3 & 123.6 & $\mathrm{~F}$ & $45+$ & $1 / 13$ \\
\hline 31 & 1 & 122.6 & F & $17-25$ & 99.08 \\
\hline 32 & 2 & 109.6 & $\mathrm{~F}$ & $17-25$ & $0 / 8$ \\
\hline 33 & 2 & 177.0 & - & $9-13$ & $0 / 23$ \\
\hline 35 & $3-x=10$ & 103.3 & - & $13-17$ & $0 / 30$ \\
\hline 36 & 3 & 126.8 & $\mathrm{~F}$ & $35-45$ & $0 / 22$ \\
\hline 37 & 1 & 117.2 & U & $25-35$ & $1 / 19$ \\
\hline 39 & Foratesta & 102.9 & F & $25-35$ & $1 / 30$ \\
\hline 40 & 1 & 92.5 & M & $25-35$ & $0 / 13$ \\
\hline 41 & 2 & 103.2 & M & $45+$ & $1 / 14$ \\
\hline 42 & 1 & 105.9 & M & $45+$ & $0 / 9$ \\
\hline 43 & 2 & 105.4 & M & $25-35$ & $1 / 32$ \\
\hline 44 & 3 & 138.8 & M & $45+$ & $\operatorname{cov} 1200-$ \\
\hline 46 & 2 & 73.3 & M & $45+$ & $0 / 23$ \\
\hline 47 & 1 & 89.9 & M & $25-35$ & $1 / 15$ \\
\hline 48 & 2 & 114.3 & U & adult & 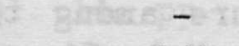 \\
\hline 49 & 1 & 127.1 & U & adult & $0 / 1$ \\
\hline 51 & 1 & - & F & $17-25$ & $1 / 16$ \\
\hline 52 & 1 & $-2+y=1$ & F & $35-45$ & $0 / 2$ \\
\hline 53 & 2 & - & M & $45+$ & $1 / 3$ \\
\hline 54 & . $258-218$ & 82.4 & M & $25-35$ & $0 / 30$ \\
\hline 55 & 3 & 112.5 & M & $30-55$ & $0 / 4$ \\
\hline
\end{tabular}


N.B. Burial 51 consieted of the comingled remaine of a minimum of three individuals; data here are for the skull only.

KEY: Grave type $I=$ earth pit

$I I=$ stone lined pit

III = stone cist

Sex

$$
\begin{aligned}
& \mathbf{Y}=\text { male } \\
& \mathbf{F}=\text { female } \\
& \mathrm{U}=\text { unsexable adult } \\
& -=\text { juvenile }
\end{aligned}
$$

Dental carles is expressed as number of teeth showing caries/total number of teeth present for observation to be made. 
ह

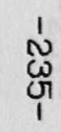

0
$H$
0
0
0
0
0 


\title{
SPOHG HILL ANGLO-SAXOI CEIETERY
}

\author{
Catherine Hills \\ Department of Archaeology \\ University of Cambridge \\ Cambridge
}

Spong Hill is on the southern edge of the parish of North Elmham in Norfolk. Between 1972 and 1981 (after a trial season in 1968) an Anglo-Saxon cemetery there was excavated in its entirety, in advance of destruction by ploughing, together with part of a contemporary settlement site (investigated further in 1984 by A. Rogerson) and prehistoric and Roman features. The project was funded by the D.O.E., later the H.B.M.C.E., and the excavation was directed by R. Carr, P. Wade-Martins and J. Gassowski, then since 1975 by the author. So far three-quarters of the cemetery has been published in catalogue form (Hills, 1977; Hills and Penn 1981; Hills, Penn and Rickett, 1984, 1987) and there is also a report on the pre-Roman phases of occupation (Healy, 1988).

More than 2300 cremations and fifty-seven inhumations were excavated, and the limits of the cemetery were established in all directions. Therefore, although some burials have been lost by erosion and sporadic earlier digging, the cemetery is essentially complete. It is also the largest cremation cemetery of its period to have been excavated so far in England. It therefore offers the potential to test various assumptions about Anglo-Saxon cemeteries, and cremations, which have derived in the past from incomplete and often quite small samples of burials. It is especially important that we have both the human remains and the artefacts, and that these have both been properly examined and described. Despite the fragmentary nature of the bones a great deal of information has been recovered from them by Jacqueline McKinley, outlined in the next section.

The inhumations included very little preserved bone, and as a group they are not so unusual in an Anglo-Saxon context, so concentration will be directed to the cremations. These were mostly contained in handmade, decorated pots; a number were recorded as unurned but most of these were probably disturbed and redeposited heaps of bone. A few may have been buried either directly in a pit or in an organic container such as a bag or wooden box which did not survive. Some burials consisted of pits with a bone deposit under or beside a pot, which also contained bones. In most of these cases all the bones seem to have belonged to the same burial, either all parts of the same individual or human bones within the pot accompanied by an accessory animal cremation in the pit.

In addition to the bones, there were grave goods, usually burnt and/or fragmentary. Some of these were parts of the clothing or equipment laid out with the corpse on the pyre, but others, such as sets of miniature toilet implements, may have been put into the pot as part of the funeral ritual. Although fragmentary, most objects could be identified; even very small fragments of glass or bronze, for example, could be recognised as parts of specific types of 8 lass or bronze vessels. Older cemetery reports which ignore all but 
substantially complete artefacts missed much useful evidence. Also, as Mckinley shows, very careful examination of the bones is necessary to ensure recovery of all artefacts, especially those made of bone or antler which can easily be confused with cremated bone.

Nearly all the bones were excavated from the pots on site. This was done for several reasons. Firstly, experience from 1968 had shown that, if left to dry out, the bone and sand contents of the pots formed a hard concrete which was very difficult to extract. Also, it was originally intended that much of the post-excavation work should be carried out in Poland. Transport of complete unemptied pots, except in a few cases, did not seem very practical. Apart from anything else, it would have been difficult to satisfy Customs' requirements as to the precise nature of all the material if we had not known what was in the pots. Lists of what went out would not have tallied with what came back. Also, many of the cremations were crushed and fragmentary and could not have been lifted intact for subsequent dissection. Another problem was that the project was funded for excavation and not at that stage for post-excavation, so if the pots had not been emptied at once it might have been a very long time before any funds could have been forthcoming to do the work; meanwhile, nothing could have been done towards restoring, drawing and cataloguing the pottery and grave goods. As it was, it was possible to produce catalogues relatively quickly, which showed that it was worth continuing to fund the project.

A more fundamental problem was that of finding a specialist willing and competent to take on the analysis of 2300 cremations. Such people are very rare, and after the initial Polish collaboration had ended the next person to take on the work could not complete $1 t$, and it was not until long after the excavation had ended that we were fortunate enough to find Jacqueline McKinley. Ideally there is no doubt that such cremations should be emptied under the supervision of, if not actually by, a bone specialist. If nothing else, that would have avolded the tedious relisting of grave goods which is necessary now that so many extra small fragments have been found, despite the fact that all the bones had been sleved at least twice before. It would also provide information as to the arrangement of bones within the pot which have probably been lost, even though many of them were excavated in centimetre layers. It is to be hoped that in future, enough people can be persuaded to specialise, at least part-time, in this field, so that any archaeologist faced with the prospect of excavating a cremation cemetery would be able to find a bone specialist to work on site.

Up unt1l now it has been difficult to conduct any proper analysis of the material because there has not been a complete, definitive catalogue. This is now nearly complete, including the bone report. So far, only provisional suggestions can be made about spatial patterning and associations. Distributions of some types of artefact, notably brooches and bone combs, appear to be complementary to the distribution of some types of pottery decoration (Hills, 1980: Figures $9.1,9.2)$. So far it looks as if this can be interpreted as a chronological pattern, with earlier burials occupying the central part of the site, and later ones distributed around the periphery. 
Distribution patterns of most other artefact types or pottery attributes do not show such clear patterns, but these were complled before the extra grave goods had been recovered, and must now be reinterpreted. Now that the bone data exists, it will be very interesting to see whether there are consistent relationships between types of pottery and grave goods, and the age or sex of the person buried with them. At present it appears that the stereotyped equation between Anglo-Saxon women and jewellery, and men and weapons, is not always apparent at Spong Hill. Inconsistencies have been discovered even amongst inhumation burials, with physical anthropology pointing one way and artefacts the other (see Henderson, this volume). Cremations have always shown a relative lack of "male" grave goods, and a different range of material, so that it should be expected that they conform to patterns derived from inhumations. Preliminary consideration of this problem (Brush, 1988) is perhaps not conclusive in showing no clear relationship between sex and grave goods but there are certainly no obvious clear cut patterns. A similar conclusion has been reached from the analysis of the contemporary continental cremation cemetery of Suderbrarup in Schleswig-Holstein, one of the few published examples of a cremation cemetery where a large number of the cremated bones have been properly examined (Bantelmann, 1988; Wahl, 1988). This raises all sorts of questions about the difference between cremation and inhumation in the Anglo-Saxon period, and the relationship between the sexes, whether alive or dead.

We are still at the beginning of work of this kind, but now at last there is both a catalogue of the artefacts and the bone report from a very large number of cremation burials. This is a proper basis from which to begin an investigation of the kinds of information which can be recovered from a cemetery of this kind, and its limitations. This is important not just for Anglo-Saxon studies, and for the information about Anglo-Saxon society and history which it might yield, but also methodologically. There is a crisis in the interpretation of cemeteries at present, where a traditional culture-historical, chronological, approach, based largely on typology, has been assailed by transatlantic anthropological archaologists and statisticians, while both approaches have been undermined from varlous critical philosophical standpoints. It is now very difficult to decide how best to proceed, especially since it seems clear that no one school of thought has the monopoly of wisdom. It is probably necessary to try out various different kinds of analysis on cemeteries of adequate size, like Spong Hill, to find out what does, and what does not, really provide useful information.

At the moment, one of the more hopeful lines of enquiry, which seems to offer some way into the quagmire of conflicting theories, is physical anthropology. Reconstruction of society, if possible at all, must surely start from some idea of the age, sex and pathology of the individuals concerned. The quantity of the material from Spong Hill should compensate to some extent for what, to a physical anthropologist, must look like its very bad quality. The size of the sample should allow some patterns to become clear, or to be shown as 11 lusory, in a way which they cannot when only dozens of graves are concerned. In the next section Jacqueline McKinley discusses the kinds 
of information which have been recovered from the Spong Hill bones so far.

\section{BIBL IOGRAPHY}

Bantelmann, N., 1988 - "Süderbrarup. Ein Gräberfeld der römischen Kaiserzeit und Völkerwanderungszeit in Angeln. I. Archäeologische Untersuchungen". Offa-Bücher. Band 63 .

Brush, K., 1988 - "Gender and mortuary analysis in pagan Anglo-Saxon archaeology". Archaeological Review from Cambridge, Val.7 (1) (Spring 1988), pp. 76-89.

Healey, F., 1988 - "Spong Hill Part VI: 7th to 2nd millennia B. C". East Anglian Archaeology Report, Vol. 39.

Hills, C.M., 1977 - "The Anglo-Saxon cemetery at Spong Hill, North Elmham, Norfolk I". East Anglian Archaeology, Vol.6.

Hills, C.M., 1980 - "Anglo-Saxon cremation cemeteries with particular reference to Spong Hill, Norfolk, pp. 197-208 in P. Rahtz, $T$. Dickinson and L. Watts (Eds), Anglo-Saxon Cemeteries 1979. British Archaeological Reports, British Series, Vol.82, Oxford.

Hills, C.M., and Penn, K.J., 1981 - "The Anglo-Saxon cemetery at Spong Hill, North Elmham, Norfolk, II". East Anglian Archaeology, Vol. 11.

Hills, C.M., Penn, K.J. and Rickett, R.J., 1984 - "The Anglo-Saxon cemetery at Spong Hill, North Elmham, Norfolk III". East Anglian Archaeology, Vol. 21.

Hills, C.M., Penn, K.J. and Rickett, R.J., 1987 - "The Anglo-Saxon cemetery at Spong Hill, North Elmham, Norfolk IV". East Anglian Archaeology, Vol.34.

Wahl. J., 1988 - "Süderbrarup. II Anthropologische Untersuchungen". Offa-Bücher, Band, 64 . 


\section{SPOEG HILI, ANGLO-SAXOI CREHATIOI CEIFTERY,}

Jacqueline McKinley

Norfolk Archaeological Unit

Union House

Gressenhall

Dereham

Norfolk

NR20 $4 \mathrm{DR}$

\section{Introduction}

The data presented in this paper should be treated as preliminary. Though the examination of all the collections recovered from the cemetery is complete, analysis of the data is as yet in the early stages and changes may be needed following the receipt of information on the animal bone.

Cremated bone is not subject to the same destruction from acid attack in the soil as is inhumed bone due to reduction of the organic component during the cremation process (see Mckinley, this volume), hence at Spong Hill, although the bone from the 57 inhumations was largely destroyed, most of the cremations survived.

2262 individuals were identified, an estimated $86 \%$ of the original cremation cemetery population. This percentage was derived from recorded numbers of urns removed in the $18 \mathrm{th}$ and $19 \mathrm{th}$ centuries and from estimates of minimum numbers of urns by weight of pot fragments from the disturbed areas of the site (R. Rickett pers. comm). It will be noted that there is some discrepancy between the number of individuals and the number of cremations excavated (Hills, this volume). As will be discussed below, there were a number of multiple collections and conversely, some of the individuals were distributed between two urns. About $3 \%$ of the collections excavated have subsequently gone missing and some of the "urns" did not actually contain any bone. Some collections were found to be part of other cremations. Taken together the above points account for the difference between cremations excavated and individuals identified.

\section{Demography}

It was possible to age, within limits, $91.1 \%$ of the individuals identified, with most of the others falling into the subadult/adult category.

\section{Table 1: Age categories used.}

Infant

Juvenile

Subadult

Young adult

Mature adult

Older adult

$$
\begin{array}{r}
0-4 \text { years } \\
5-12 \text { years } \\
13-18 \text { years } \\
18-25 \text { years } \\
26-40 \text { years } \\
40 \text { years }+
\end{array}
$$


The infant category (see Table 1 and Figure 1 on page 248) included a number of very young infants under 6 months and a minimum of 2 neonates, which from a collection the size of Spong Hill is a very small number. The overall percentage of infant deaths was rather low, a number about three times that identified would have been at a more expected level working on Brothwell's hypothesis (Brothwell, 1971) that the normal ratio of infants of less than one year to those individuals between $1-20$ years, should be between $4: 3$ and $4: 1$, which is far from being the case at spong Hill.

Cremation of young infants in a modern crematorium, produces as with adults, a total skeleton - such as it is in a young infant where much that will be bone is still in the unossified, cartilaginous stage but the remains are obviously very small and fragile. In archaeological cremations, such young individuals are often represented by very little other than unerupted tooth crowns and the petrous temporals, which are the densest areas of bone in a young infant skeleton. Collection of such fragile remains from a pyre must have been difficult (in modern crematoria, a special metal tray carries the coffin so that none of the remains are lost), and much must have been lost at this stage, especially if the infant was cremated together with the adult. Once in the ground, infant remains would be subject to the usual biases of preferential destruction due to the extreme fragility of the bone.

It would be fair to say therefore, that a large number of young infants have probably been 'lost' from the 'population' at Spong Hill and this will be a point to bear in mind when attempting any demographic analysis.

The average life expectancy, on a very crude level, appears to have been between 30 - 40 years. The subadult years were apparently fairly 'safe' (a generally noted trait in demographic analysis), with infancy being rather more traumatic. Over $6 \%$ of the adults survived over 40 years, the number will probably be in excess of this as some of the 'mature' individuals in this category (see Table 1) are in fact in the maturel older category, but the groups have been slightly simplified for the present discussion.

Vith very few exceptions, only the adult individuals were sexed. $54.5 \%$ of the adults identified had sufficient evidence to enable gender to be suggested, of those $41.3 \%$ were male and $58.7 \%$ female, though it should be noted that only $11.5 \%$ of the total were unquestionably so (see McKinley, this volume).

Whether the greater number of females is a true reflection of the general 'population' of the cemetery or not is difficult say. There did appear to be a slight trend towards more gracile morphological features even amongst the males identified. However, the trend did occasionally work the other way, especially with respect to size, with some very large females being present. A further point would be that $45.5 \%$ of adults were not sexed and there may have been a slight bias towards the sexing of females. Some morphological traits used to indicate sex of individuals were found to be unreliable with respect to the Spong Hill collection, and for this reason assessment of sex on 
a single trait was felt to be unacceptable. Correlation of age and sex has not yet been analysed.

Any overall demographic comment at this stage must be tentative. The crude annual death rate was assessed by correlation to known annual death rates (Ubelaker, 1974), as $22 / 1000$ (allowances having been made for the 'missing' infants - see above). The cremation cemetery at Spong Hill appears to have been in use for between 150 - 200 years (Catherine Hills, pers.comm). On this basis the 'population' being served by the cemetery may be calculated as being about 550 - 850 individuals at any one time, i.e. $70-100$ family units. By way of comparison, the Domesday records for the parish of North Elmham records the presence of 41 villeins, 63 smallholders, 24 freemen and 6 slaves, which including their families, would give an estimated number of 646 individuals.

Use of the cemetery would doubtless not have been on a continuous level, but may well have peaked in the middle and talled off towards the end. Further analysis following fuller phasing of the site together with demographic studies may illustrate changes in useage of the cemetery over time similar to those found by $\mathrm{Wahl}$ (Wahl, 1988) in his examination of the cremation cemetery at Suderbrarup, where the later phases of the cemetery showed a preponderance of older adults.

Certain 'ritualistic' traits became evident during the basic identification work on the Spong Hill cremations which the writer hopes to expand on in future analysis; the basic premisses are outlined below.

Glass and bronze were amongst the common grave good categories at Spong Hill, these two substances were frequently melted in the heat of the pyre and would adhere to adjacent bones. Plotting which grave goods were attached to which bones offers a number of insights. Glass and bronze were most frequently recovered adhering to skull (especially the temporal region), arms, hands, and less frequently the ribs. As these goods generally represent necklaces and brooches the positioning is not surprising. As well as illustrating the laying out of the body, these grave goods also show something of the pyre temperature in different places and 'pyre technology'. The grave goods, by being attached to the bones one would expect, illustrate little movement of the body on the pyre, probably because it was positioned low down in the pyre and minimal tending took place (see McKinley, this volume).

At Spong Hill, all ivory and most glass and bronze were burnt or melted. Iron goods were difficult to assess. In the case of worked antler/bone (most of the combs etc. were of antler, - Julie Bond pers. comm., from an $8 \%$ sample examined, $81.6 \%$ were burnt and all the unburnt fragments were of comb (in one case, half the comb was burnt/scorched and the other half was not). Were the remaining $17.5 \%$ unburnt due to accident or design? It is possible that some of the combs may have been placed in such a position as to escape burning. If for instance, a decorated comb was used as a hair ornament, the hair would rapidly burn and the comb fall out of position and possibly out of the pyre. Further analysis on the degree of burning of 
different grave-goods, and where poselble their position in the urn, may give interesting indications on cremation ritual. Ivory bag rings, presumably attached to the waist and probably containing any spindlewhorls, playing pieces etc. would be unlikely to escape the pyre and are, in fact, always burnt.

$67 \%$ of the cremations contained grave goods. Although each collection was checked at least twice for grave goods during postexcavation work, many were missed, particularly fragments of worked antler and bone which were difficult to spot amongst the mass of cremated bone. The author was able to recover 201 new grave goods, at least half from collections where no grave goods had previously been recorded. 329 fragments in addition to already existing grave goods were also recovered, often in fairly large quantities. The lesson here is that without analysis of the bone by a specialist much information with regard to grave goods may be missed, as well as information about the individuals (and the human element is, after all, why the cemeteries exist!).

$48 \%$ of the collections from Spong Hill contained burnt animal bone. The animal bone, which is being examined by Julie Bond (Department of Archaeological Sciences, University of Bradford), has not yet been fully assessed and the results presented here are from a sample of 100 cremations.

The species being recovered and their relative frequencies are fairly similar to other Anglo-Saxon cremation cemeteries (Richards, 1987): $56 \%$ sheep, $30 \%$ cattle, $13 \%$ horse (generally recovered from the same contexts as cattle) and $5.6 \%$ pig. Smaller quantities of bird, dog, bear and fish bone have also been recovered. The bone elements being recovered are not those generally considered to be 'meat' joints; these particular elements are usually removed and discarded in any butchery of large animals. Virtually none of the bones show butchery marks though they are not totally unrecorded (Julie Bond, pers. comm.). What we may be seeing is part of the funerary ritual involving a feast. Animals would be slaughtered and butchered, the meat removed for cooking and the remnants - head, feet, tail and possibly hide - placed on the pyre. There are frequent references to deposits of these elements of animal skeletons, particularly from horses, from Germanic sites of both Iron Age and Migration periods, as well as entire horse burials (Todd 1975, 1980; Wahl, 1982). It is likely that what we are seeing at spong Hill is part of this continental pattern.

There were several unusual elements amongst the animal bone worthy of note; the entire skeleton of a piglet; two bear claws, possibly from a fur, which could again be paralleled with similar occurrences in Germany (Wahl, 1982) and an almost entire dog skeleton, presumably a pet. The presence of dogs in Anglo-Saxon burials, though not exactly common, has been recorded from several sites, for example in the Loveden Hill inhumations, where an elderly man was buried with a child and a dog (Wilkinson, 1980).

One interesting feature emerging from the Spong Hill collections is the occurrence of 'animal accessories'. This is where there are 
adjacent, contemporary vessels, one containing mostly human bones with a little animal, the other mostly animal bone with a small human element. In both vessels the human and animal elements represent the same individuals.

Only two have so far been looked at in detail. The author had thought that Urns 2667 and 2668 were a pair with the subadult individual in both vessels apparently matching. Julie Bond independently, decided that the dog bones in the two urns were from the same animal. Another pair of urns provided even further confirmation when several fragments of different grave goods recovered from both urns were found to match; the human and animal bone had already been seen to match.

Further investigation of other pairs of urns awaits the animal bone report, but it would appear that roughly $5 \%$ of the collections are likely to be paired. Once the animal bone report is finished it will also be possible to ascertain any correlation of animal type with age and sex.

$4.5 \%$ of the collections contained the remains of two individuals, though there may have been more multiples of adult females with very young infants which were undetectable. About three-quarters of the multiples were adults with immature individuals, usually female adults where sexable, although some were male. Some collections contained two adults together, generally female with male, although there were some instances of the same sex occurring together. Two immature individuals together were very rare but not unrecorded.

Contamination occurred in some adjacent urns which had been smashed and disturbed resulting in some mixing of both bone and pot sherds. This caused some interpretative problems, but by working with the site records it was generally possible to ascertain where this had occurred.

The occurrence of neonates and young infants, though few in the archaeological record (see above), would suggest that even the youngest members of society were afforded the same treatment as everyone else. This would be in contrast to some past societies. For example, the Romans did not consider an infant of less than one year as an 'individual' and they were therefore disposed of outside the cemetery.

The organisation of the cemetery appears likely to have been on a 'family' basis with no deliberate zoning with regard to age or sex. Mixed groups of different ages and sexes, quite often respecting surrounding urns, suggest contemporary deposition and or the presence of grave markers. An impression of family groups is given. For example, a group of sixteen urns in one pit comprised 10 adults covering all the age ranges, with a minimum of 2 females and 2 males 3 infants, 3 juveniles, 2 multiples (adults with immature individuals) and 2 'animal accessories'.

As yet there has been ilttle examination of the data collected with reference to the 'technology' employed. It would appear, however, that 
care to ensure complete combustion was not always taken (see above in grave good section). Much of the spongy bane tends to survive, bones of the feet and lower leg are often poorly burnt, as are the small bones of the hands. It was occasionally noted that one side of the skeleton was considerably less well cremated than the other.

Fractionation of the bone was not great, most of each collection falling into the $10 \mathrm{~mm}$ sieve range and occasionally appearing no more broken up than a modern cremation prior to it being fragmented in the 'cremulator' (see McKinley, this volume).

Taken together, the two points above indicate a lack of tending of the pyre. The lack of spinal combustion and fusion of grave goods to the bones that one would expect, suggests the bodies were placed low in the pyre or on the ground (Wells, 1960) and that little subsequent movement took place. This may explain the state of low fragmentation. Robinson (Hiatt, 1969) in the 19th century, recorded that the Aborigines in Australia lit their cremation pyres and left them to burn out; this may well have been the case at Spong Hill.

Though in many cases a large proportion of the remains appears to have been collected (in one case for instance, all cervical and lumbar and eleven of the thoracic vertebrae were present), total recovery does not appear to have occurred. Most collections represent less than $50 \%$ of the expected quantity of bone (see KcKinley, this volume) and the maximum was c. $70 \%$. It is also likely all the grave goods were not recovered.

Collections generally consisted of bone and grave goods only, though a few cremations did contain several grams of charcoal - usually a single large fragment, - burnt flint and fuel ash slag and, of course, the inevitable pea-grit (small grade gravel) which had worked its way into the assemblage.

The inclusion of fuel ash slag and burnt flint, both products of the pyre, was doubtless accidental. The inclusion of these products would depend on soil type. The cemetery at Spong Hill was situated on sandy gravel with bands of largish flints, i.e. sand for fuel ash slag production and flints to be burnt!

The inclusion of these pyre products with the deliberately cleanedup bones led the writer to question individual bone recovery as the mode of collection. If just bone and grave goods were wanted then why pick up flint and fuel ash slag? This 'en masse' collection, using winnowing or water separation, would not distinguish between the heavier elements so accidental inclusion may be explained (experimental work to test these hypotheses is hoped for in the future)..

$31.2 \%$ of the individuals at Spong Hill presented some form of pathological change or morphological variation. The various forms of arthritic related lesions were most common. Dental lesions, usually the most common type recorded, were limited mostly to those affecting the supporting structures as a result of loss of the tooth crowns in the cremation process. Other lesions occurred with the same relative 
frequencies as on most other sites, but diagnosis was aften limited due to the incomplete nature of the remains.

Two points the writer feels may be worthy of note, however, were the presence in three cremations (all older adults) of small, calcined 'stones', possibly calcified lymph nodes or kidney stones (at present being examined by Neil Garland of the Pathology Department, University of Manchester). A third centre of ossification was noted at the distal end of the 1st metacarpal and metatarsal in $70 \%$ of the 1 mmature individuals where the relevant bones were recovered, (though generally fused by $c .5$ years, the epiphyseal line is still evident). This morphological variation has apparently gone largely unrecorded in past literature (Warwick 1986), though its occurrence is by no means rare ( Rogers and Waldron 1986), a 70 - $80 \%$ incidence apparently being the norm. In two other cases, a third, distal centre of ossification was also noted in the finger phalanges of immature individuals. The occurrence of these variations and others like them, particularly relating to teeth, may be of use in a large cemetery study as an indication of genetic links. It is unfortunate that the erratic collection of cremated bones makes it unlikely that the relevant ones are always present, thereby limiting the application of data relating to morphological variations.

Future analysis of the Spong Hill cremation data hopes to expand on the points outlined in this paper and broaden our understanding of both Anglo-Saxon and cremation ritual.

\section{Acknowledgements}

Thanks to Robert Rickett and Catherine Hills for their assistance with writing this paper.

\section{BIBLIOGRAPHY}

Brothwell, D.R., 1971 - "Palaeodemography", pp. 111-129 in W. Bass (Ed.), Biological aspects of demography. Taylor and Francis, London.

Hiatt, B., 1969 - "Cremation in Aboriginal Australia". Hankind, Vọl.7(2), pp. 104-115.

Richards, J.D., 1987 - "The significance of form and decoration of Anglo-Saxon cremation urns". British Archaeological Reports. British Series, Vol. 166, Oxford.

Rogers, J. and Waldron T., 1986 - "Letters - Anne Mowbray". London Archaeologist, Vol. $5(9)$, p. 232 .

Todd, M. , 1975 - "The Northern Barbarians.". Hutchinson, London.

Todd, M., 1980 - "The Barbarians". Batsford, London.

Ubelaker D.H., 1974 - "Reconstruction of demographic profiles from ossuary skeletal samples. (Case study from Tideswater Potomac)". Smithsonian Contributions to Anthropology, Vol. 18, pp. 59-70. 
Wabl, J., 1982 - "Leichenbranduntersuchungen. Ein Uberblick uber die Bearbeitungs und Aussage-Moglichkeiten von Brandgraben". Praehistorische Zeitschrift, Vol. 57 (1), pp. 1-125.

Wahl J., 1988 - "Suderbrarup". Karl Vachholtz Verlag, Neumunster.

Varwick R., 1986 - "Anne Mowbray: skeletal remains of a medieval child". London Archaeologist, Vol. 5(7), pp. 176-179.

Vells C., 1960 - "A study of cremation". Ant1quity, Vol. 34, pp. 2937.

Vilkinson L., 1980 - "Problems of analysis and interpretation of skeletal remains", pp. 221-231 in P. Rahtz, S. Dickinson and L. Vatts (Eds), Anglo Saxon Cemeteries 1979. British Archaeological Reports. British Series, Vol. 82, Oxford.

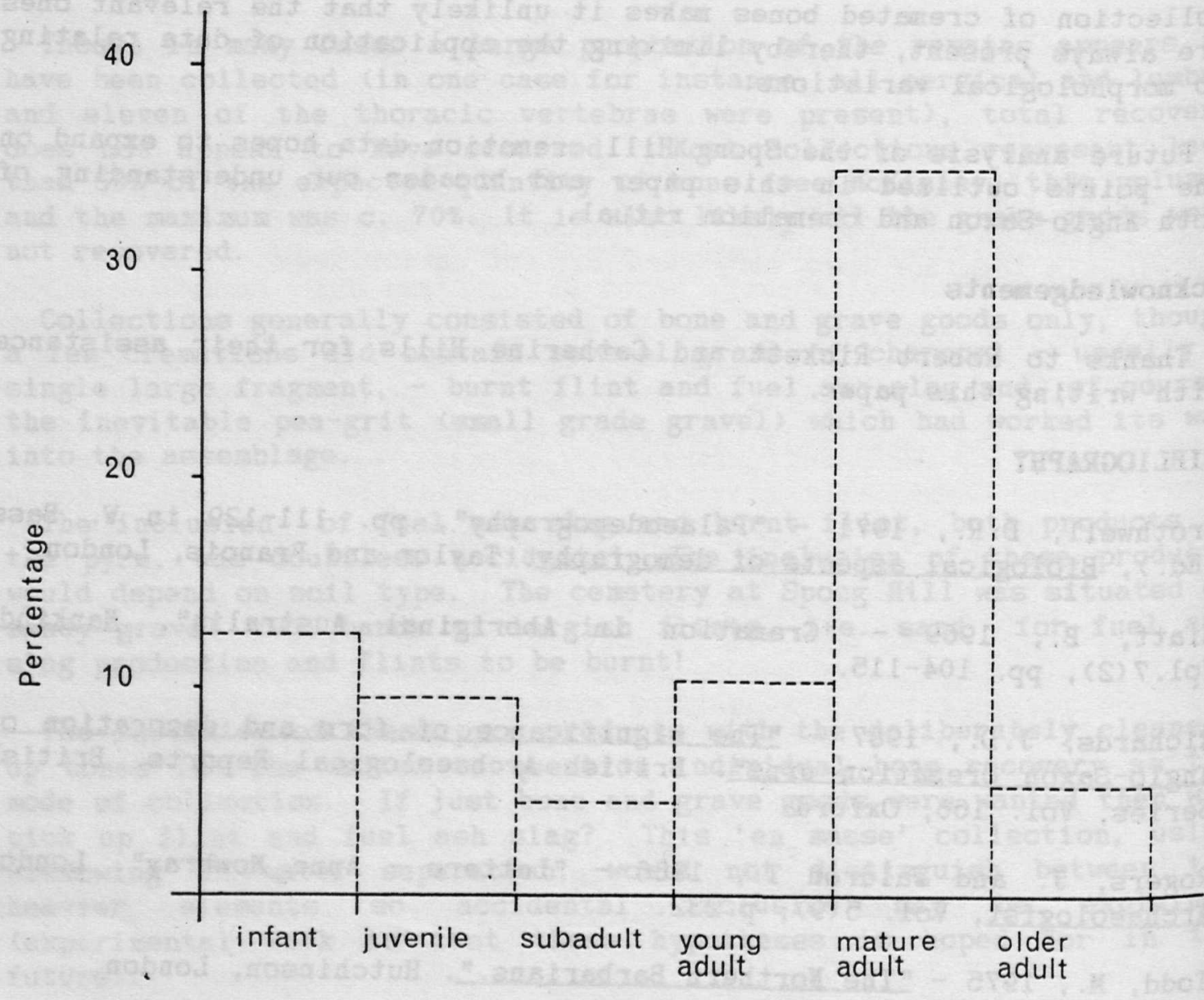

$A G E$

Figure 1 
THE LEPER HOSPITAL OF ST JAYES AID ST MARY KAGDALEIE, CHICHIESTER.

\author{
John Magilton, \\ Chichester District Archaeological Unit, \\ East Pallant House, \\ Chichester P019 1TY. \\ Frances Lee, \\ Calvin Wells Laboratory \\ Department of Archaeological Sciences \\ University of Bradford \\ Bradford BD7 1DP
}

\title{
Background
}

Medieval Chichester, enclosed within and spreading beyond the Roman walls of Noviomagus Reginorum (RIvet and Smith, 1979,p. 427) was of regional importance as both a market centre and a port. An early stimulus to growth was provided by the translation of the see from Selsey, a coastal village, to Chichester in c. 1075; between 1066 and 1086 the value of the city increased from 215 to 225 , and in fact 235 was returned in 1086 (Page, 1905, p.382; Salzman, 1935, p. 84). Although without direct access to the sea, Chlchester had a harbour at Dell Quay two miles to the south-west and numerous others under 1 ts jurisdiction. Exports to Flanders are first recorded in a licence of 1226, and by 1341 the port of Chichester ranked as seventh in the k1ngdom (Salzman, 1935, p. 101).

\section{Medieval Hospitals}

Chichester had five Medieval hospitals (F1gure 1). St Mary's, the only one within the walls, was founded by 1172 (Knowles and Hadcock, 1953, p.264), moved to 1ts present site at some time between 1269 and 1290 (Page, 1907, p.101) and is still functioning. It catered for the poor and pilgrims. The rest were all originally leper hospitals. One was at Stockbridge south of the city, where the Medieval (and perhaps Roman) road to Sidlesham crossed a small stream, and is recorded only In an early 13th century deed (Page, 1907, p.103). The others lay east or north-east of the clty, on or close to Stane Street, the Roman road and princlpal Kedieval route to London, perhaps with a view to the alms-gathering potential of the sites. Just outside the walls lay the hospital of Newykestrete, in Rumboldswyke parish on the south side of the street now known as The Hornet. This is first recorded in the same early 13th century deed as the Stockbridge hospital, and was still functioning in 1374 (Page, 1907, p. 103; Knowles and Hadcock, 1953, p.264). Half a mile beyond the walls, on the north side of Stane Street (F1gure 2), was the hospltal of St James and St Mary Magdalene, probably founded before 1118 and originally for lepers (Knowles and Hadcock, 1953, p. 263), which later became an almshouse (Page, pp. 1907, 99-100). Further st1ll, at Vesthampnett two miles north-east of the clty, where the road to Arundel diverged from Stane Street, was another hospital of St Mary Magdalene, also known as Loddesdown, whlch had become an almshouse by 1404 (Page, 1907, 103). Of these hospitals, St. James' outside the walls and St Mary's within both survived the Reformation as they were administered by the Dean 


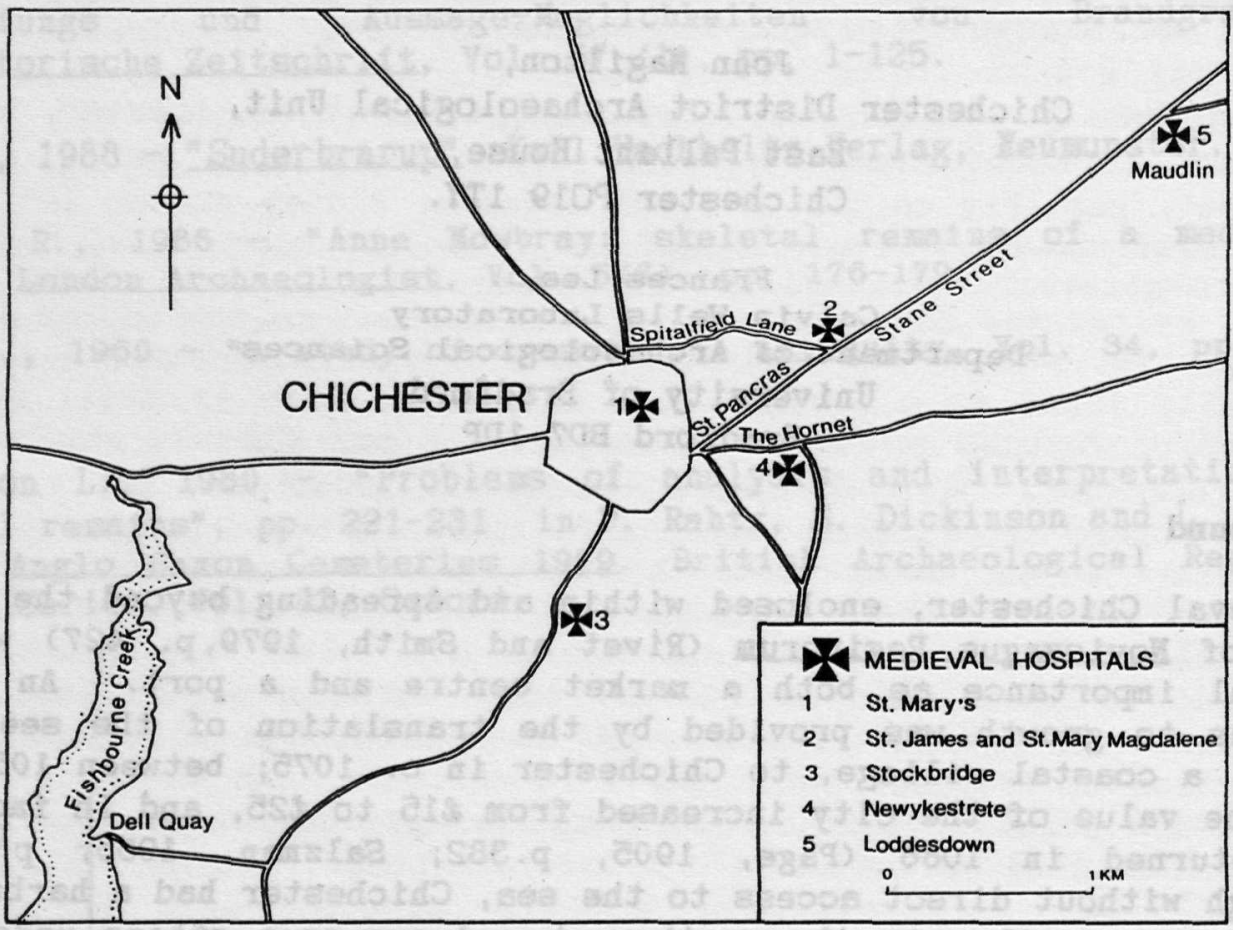

Figure 1. The Medieval hospitals of Chichester.

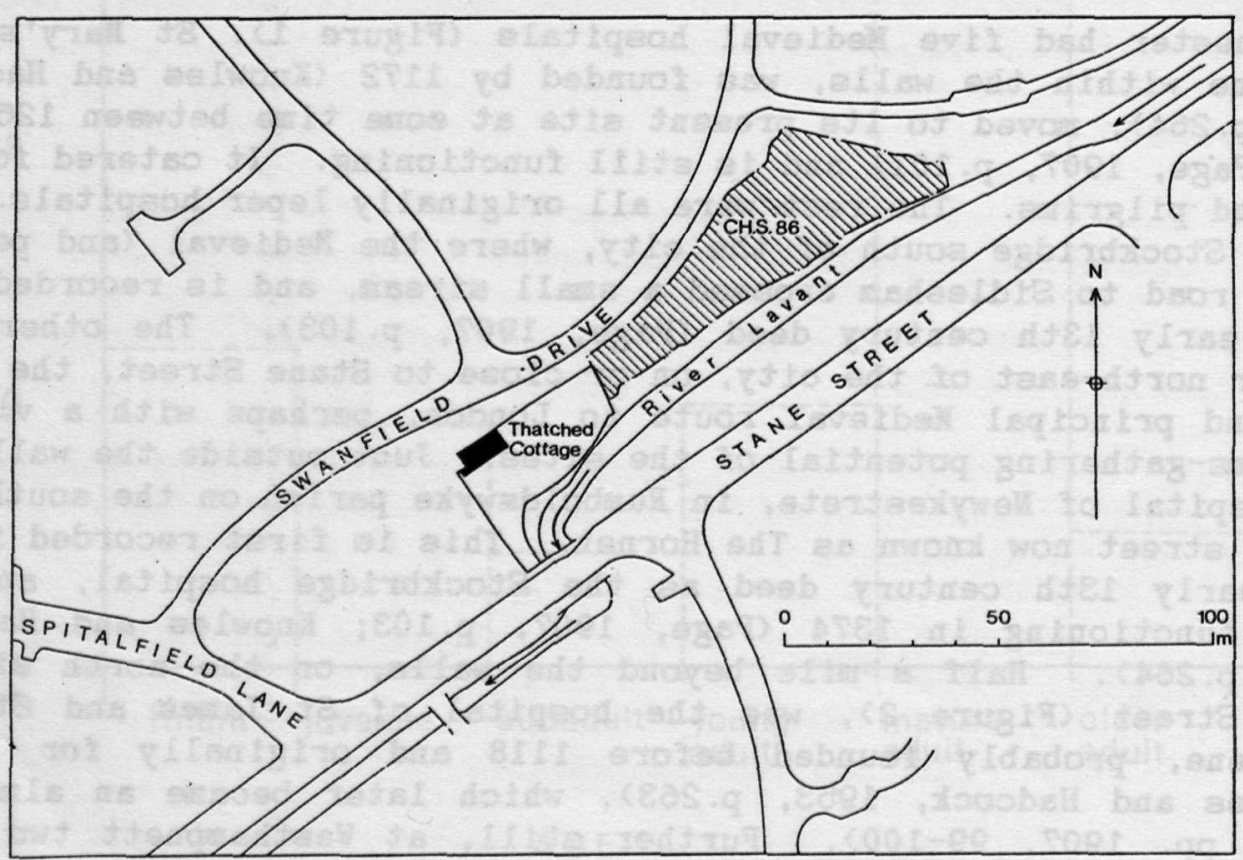

Figure 2. The site of the medieval cemetery associated with the hospital of St James and St Mary Magdalene, Chichester. 
and Chapter. The other three may have gone out of use before the end of the Middle Ages.

\section{The Hospital of St James and St Mary lagdalene}

The administrative records of the hospital do not survive, and the earliest known documentary record is a confirmation charter of 1187 , which 1 mplies that its foundation occurred before 1118 and that there were eight leper inmates (Page, 1907, pp.99-100). Later documents indicate that it was run by a chaplain or master, assisted by a 'prior', the senior inmate, and that candidates were admitted by consent of the chaplain and a majority of the brethren, who could also fine or expel inmates. The last reference to the inmates as lepers is In a will of 1418. By 1442 six of elght inmates were married, including the prior, and spent most nights at home with their wives. All had secured admission by payments. In 1478 a prior and five inmates are l1sted (McCann, 1987, p.253).

The constitution of the hospital was amended in 1540 to admit sisters as well as brethren, and the master was a layman. Thls was a perhaps a belated recognition that the hospital was no longer needed for its original function, and it may well have been an almshouse in all but name for much of the previous century. The will of the tallor. John Redfern, who in 1589 was 'of the poorhouse or Hospital of St James near Chichester ' raises doubts about the qualifications for admission, since he was a married man with a house in St Pancras, the Chichester suburb nearest the hospital, and he had two servants. A list of inmates in 1594, however, recording eleven inhabitants in addition to the proctor and his wife, makes it clear that most were crippled, although two are described as '1diots'. Amongst the crippled were 'Agnes Patchinge a mald without legs, 30, Agnes Barnes a mald without legs' (Page, 1907, p.99). Vith the exception of the proctor and his wife, all were aged 40 or younger, and four were teenagers (see Appendix 1).

During the $17 \mathrm{th}$ century the hospital declined. In 1618 the number of inmates was restricted to 1 ts original number of elght, and although bequests to the hospital continued, they dwindled in the latter part of the century. In c. 1685-9 the Master reported 'there is one inmate on'ly, but she is a miserable 1dlot' - possibly one Ann Dested, whose burlal is recorded in the St Pancras parish register of 7 th February 1705 (McCann, 1987, p.253). In effect, the last master of the hospital was Peter Edge, who died in 1702. During the 18th and first half of the 19th century the post of master became a prerequisite of members of the cathedral establishment, Income being derived from tithes and property rents. Ultimately, the income was given to the Royal Vest Sussex Hospital (Salzman, 1935, p. 167).

Nothing survives of the hospital buildings apart from a late 18th century thatched cottage (F1gure 2) 1ncorporating some Hedieval architectural fragments in 1ts north wall, including part of a spiral staircase, which indlcates that one of the buildings was of two storeys. A report in 1705 records that the domest1c accommodation was ruinous, as was 'an anclent plece of building called the Chapel ... for many years past used as a barn'. Repairs were ordered, but it is 
not known if they were carried out (McCann, 1987, p. 254). According to the memoirs of James Spershott, a local antiquary, in 1721 ( and st1ll some years after) 'the walls of St James's Chapel were standing showing the form of 1 ts windows and door, but are since demolished' (Steer, 1962, p.16). In 1755 St James' seems to have been used as a convalescent home for smallpox sufferers (Anon, 1938, p.14) and Yeakell and Gardner's map of 1769 shows a structure on or near the site of the present thatched cottage with foundations to the northeast.

According to Spershott, the 'large old Spittle House belonging to St James' Chapel burnt down on December 13th 1781 (Steer, 1962, p. 23) and the present cottage is sald to have been bullt from its ruins (Salzman, 1935, p. 82).

\section{THE HOSPITAL CEIETERY}

\section{Documentary sources}

If It is assuned that the hospital occupied the same site fron its foundation to 1ts denise, and that the custom of burial within its cemetery dates from the establishment of the hospltal, interments must date from the early 12 th century until about the mid 17 th century, with the possibility of a few later burials. Up to perhaps the 15th century these will have comprised the leper brethren, the master and occastonal benefactors who asked to be burled there (one 1s recorded in the chartulary of Chichester cathedral (Peckham, 1943)) and therefore these burials were predominantly male.

There should be a discernible change in c.1540, when female inmates were formally admitted. From this time onwards, infants and young children may also be expected. In practice, women are likely to have been interred before this date. There may already have been some women admitted to the almshouse before the rules were altered to regularise $1 t$; other women, as wives of inmates, benefactors or servants, may have sought burial at the hospital from the time of its establishment.

The only documentary clue to the inflictions suffered by the inhabitants of the almshouse is given by the 1594 list, which describes the results of deformities and disease on Elizabethan inmates. It should be noted that the two '1diots' listed will not necessarily have had any physical condition which would have affected the skeleton. The nature of medical treatment, if any, supplied by the almshouse is nowhere specified, and it could be surmised that the role of the institution was primarily to provide care and sheltered accommodation.

The slender data avallable do not permit any estimate of the total cemetery population. It is not known how long inmates survived on average after admission, how many inmates the hospital usually held, whether inmates were invariably burled at the hospital, or how many people in some way associated with the institution sought burial there. The restriction imposed on the number of inmates in 1618 suggests that they exceeded the hospital's resources by this date, and 
had perhaps done so for some time before, so statistical guesees based on the hospital's theoretical complement of elght inhabitants plus master would not be valid. Conversely, in 1478, a prior and only five Inmates are 11sted (McCann, 1987), indicating that, at t1mes, fewer than the maximum were housed there.

\section{Excavation}

The only documented disturbance to the hospital cemetery before systematic excavations in 1986-7 took place in 1947 when 'a tangled mass of human remains' was found during the construction of a new housing estate at Swanfield Drive (Sussex County Magazine Vol. 21 1947, p. 173).

According to the former City Engineer, the burlals lay at a depth of 18 inches beneath the new road north of the thatched cottage incorporating remains of the hospital, and were lald out in ranks. The finger-tips of skeletons were examined for leprosy, but no trace of the disease was found (R.A.J. Cork, pers. comm.). The renalns were reinterred in The Litten cemetery, St Pancras. Further burlals are sald to have been disturbed during later building works when police houses were constructed near the Junction of Swanfield Drive and Spitalfield Lane, but the reports may not be reliable. The houses are distant from the known area of the cemetery.

Systematic excavations were carried out between July 1986 and February 1987 of part of the cemetery south of Swanfield Drive and east of the thatched cottage (Figure 2) in advance of the construction of bungalows for the elderly by Chichester District Council, who funded the work. Subsequent exanination of the skeletons has shown that remains of a minimum of 351 individuals were recovered, not all of them from defined grave pits. A full report of the excavations will be published in the Chichester Excavations series. Detalled analysis of the archaeology of the site has yet to be undertaken, and the osteoarchaeological analysis still has to be completed and the results are only preliminary findings.

Excavation revealed the south-eastern portion of the cemetery. The canalised River Lavant now marks the southern boundary (F1gure 2), and the eastern boundary was defined by ditches. Observations in 1947 and again in 1987 during the digging of a service trench beneath the pavement on the south side of Swanfield Drive have shown that the cemetery extends at least as far west as the thatched cottage as well as beneath and perhaps north of the road. The orfinal boundary ditch on the east side of the cemetery had been superseded by another $5 \mathbf{n}$ further east, but no burials lay beyond the later ditch.

The relative chronology of the graves is to some extent speculative. However the cemetery organisation, the general alignment of the graves, the structure of the population (age and sex), and the types of pathological lesions present make it possible to divide the site Into three discrete areas (F1gure 3). Area 1, the westernmost part of the cenetery, is considered to be the earliest part (Figure 4). Planning is apparent with groups of graves sharing a common northsouth line, although there are many intersections between graves, as 


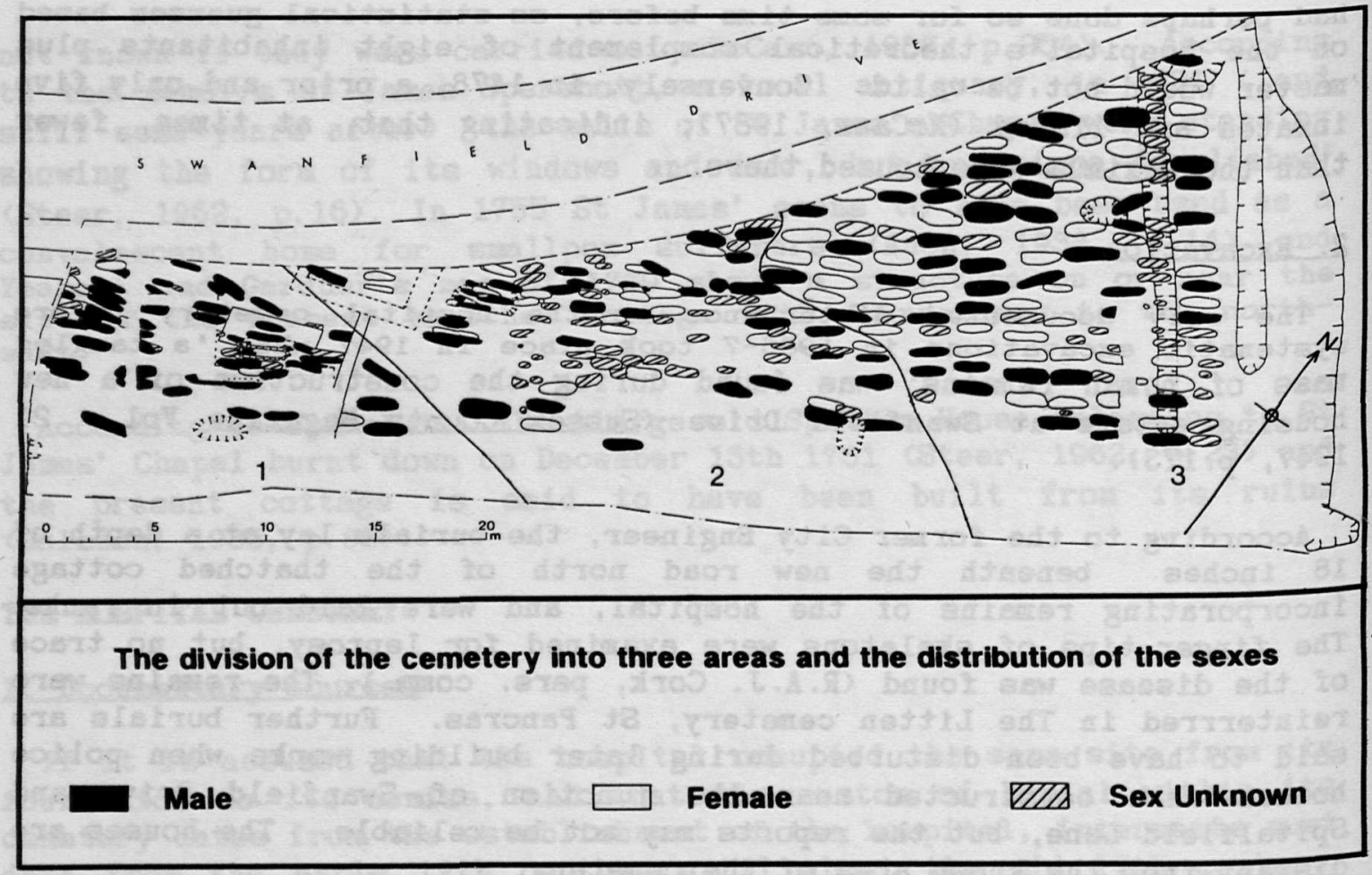

Figure 3.

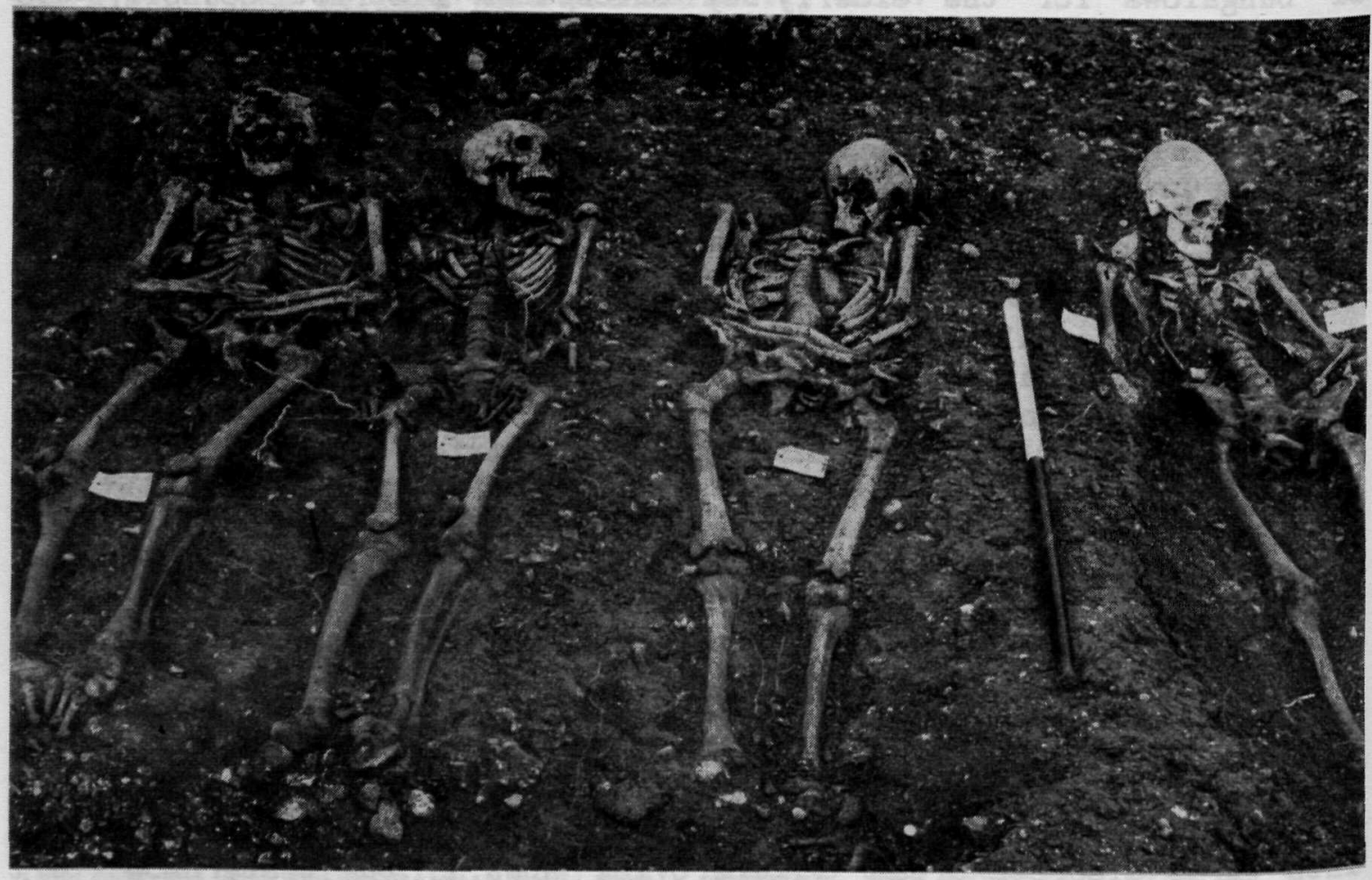

Figure 4. Burlals from the early or western end of the cemetery. The skeleton, third from the left, is a leper. 
if there had been a relatively restricted area for burlals. Most of the burials are male, with a few exceptions, and it is also the area with the greatest concentration of skeletons exhibiting bone change compatible with a diagnosis of leprosy (Figure $4 \& 5$ ). In Area 2 the graves were much more disorganised with graves intersecting one another and with no obvious plan to their placement. Both sexes were present with a localised area of immature individuals. The final area, area 3 , is in the easternmost part of the cemetery and 1s thought to represent the alms house phase of the cemetery. The graves were aligned east - west and placed in rows, both women and children were admitted, and moreover there was a wider range of pathological conditions present, including not only leprosy, but also tuberculosis, osteoarthrosis and traumatic lesions.

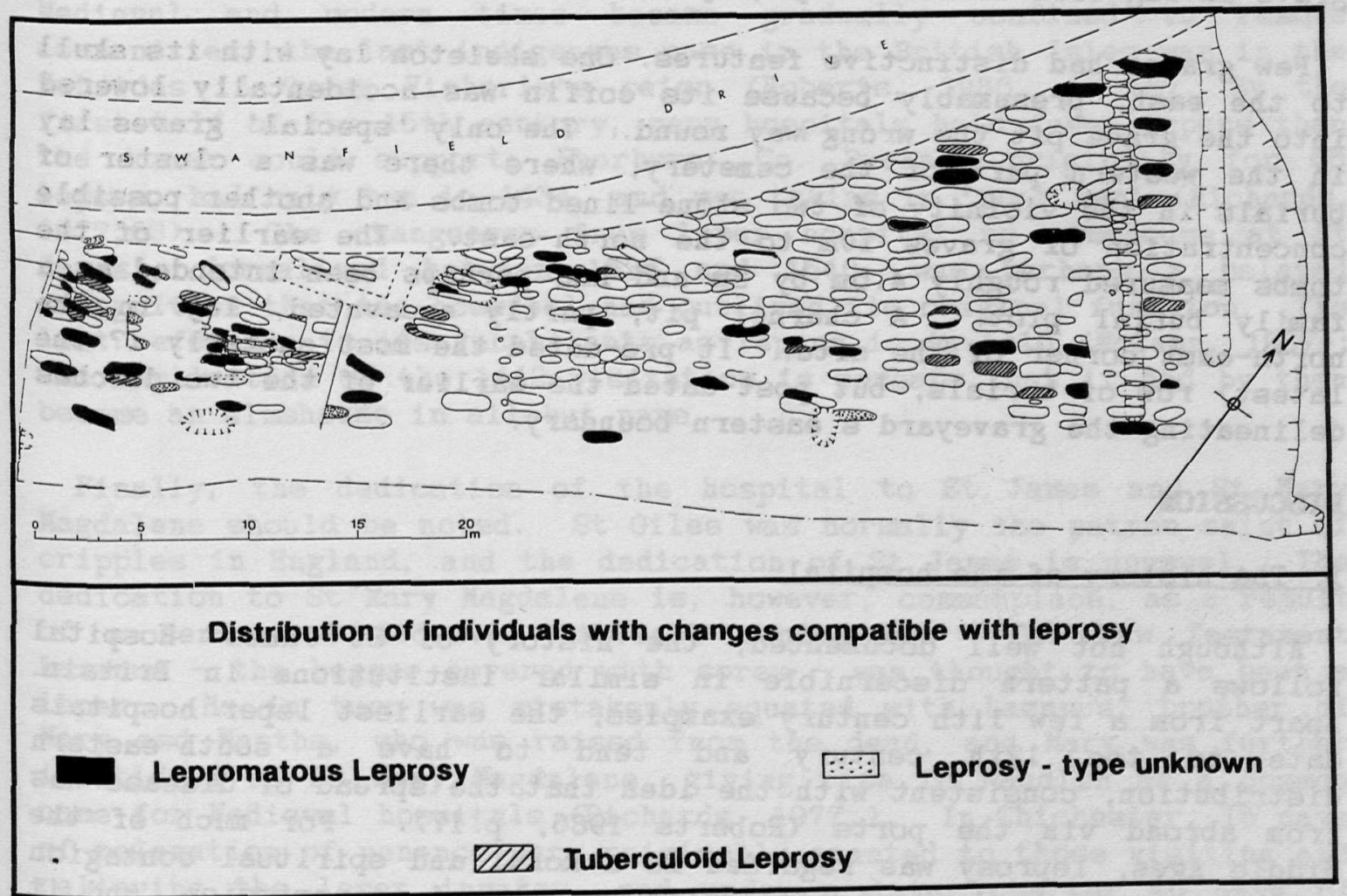

Figure 5.

Organisation seemed to have come about gradually rather than having been imposed at a specific point in time, and there was no indication that the cemetery had not been in constant use.

A surprising feature of the cemetery was the relative absence of graves close to the present course of the River Lavant to the south. The river 1tself cannot have formed the boundary of the cenetery, since unt1l 1768 it flowed on the south side of the road (Steer, 1962, p.21). The differences in alignment of graves at the western end of the cemetery could be explained by burlals having been aligned parallel to the hospital buildings. The only bullding encountered within the excavated area, which post-dated all the burials in its 


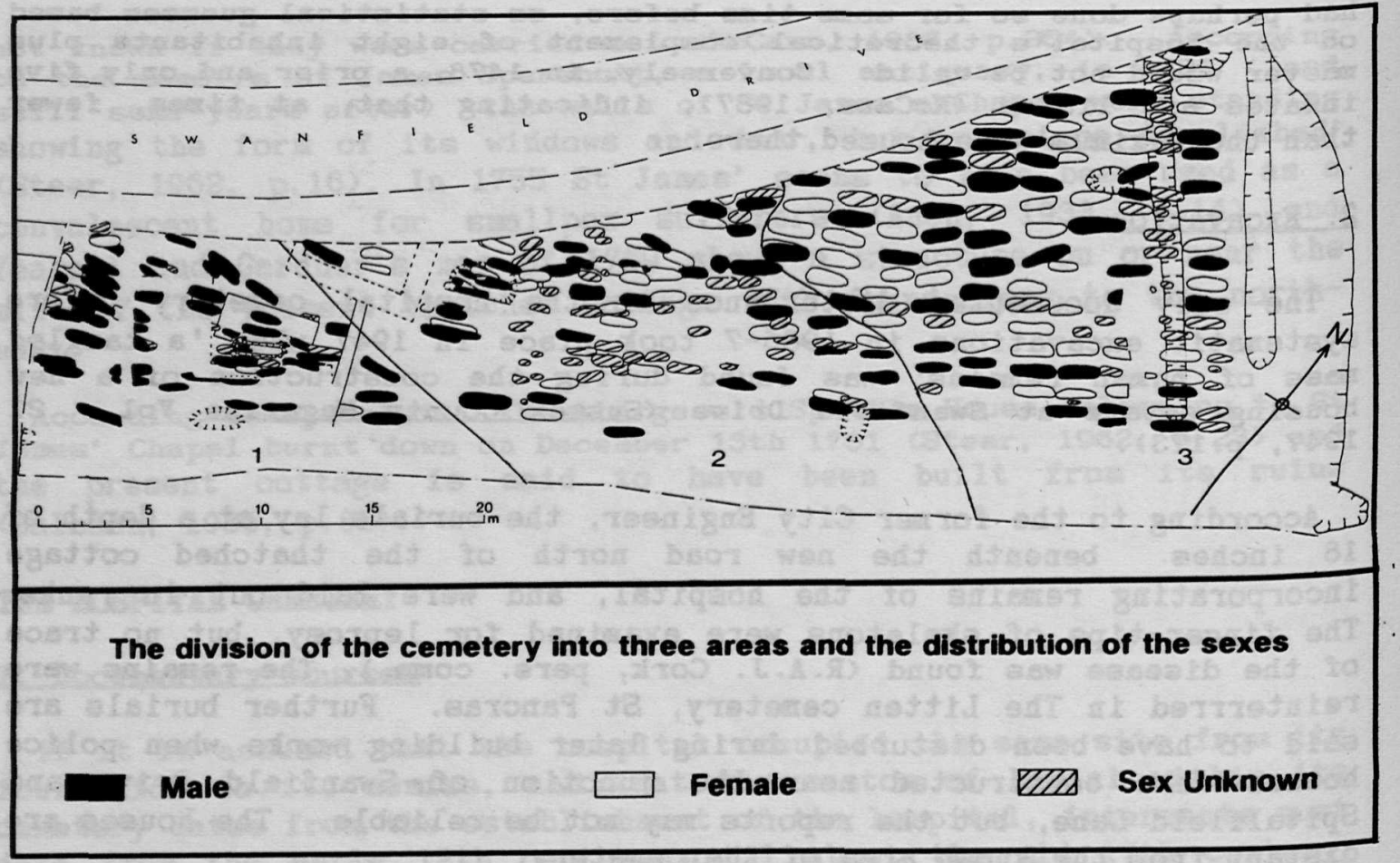

Figure 3.

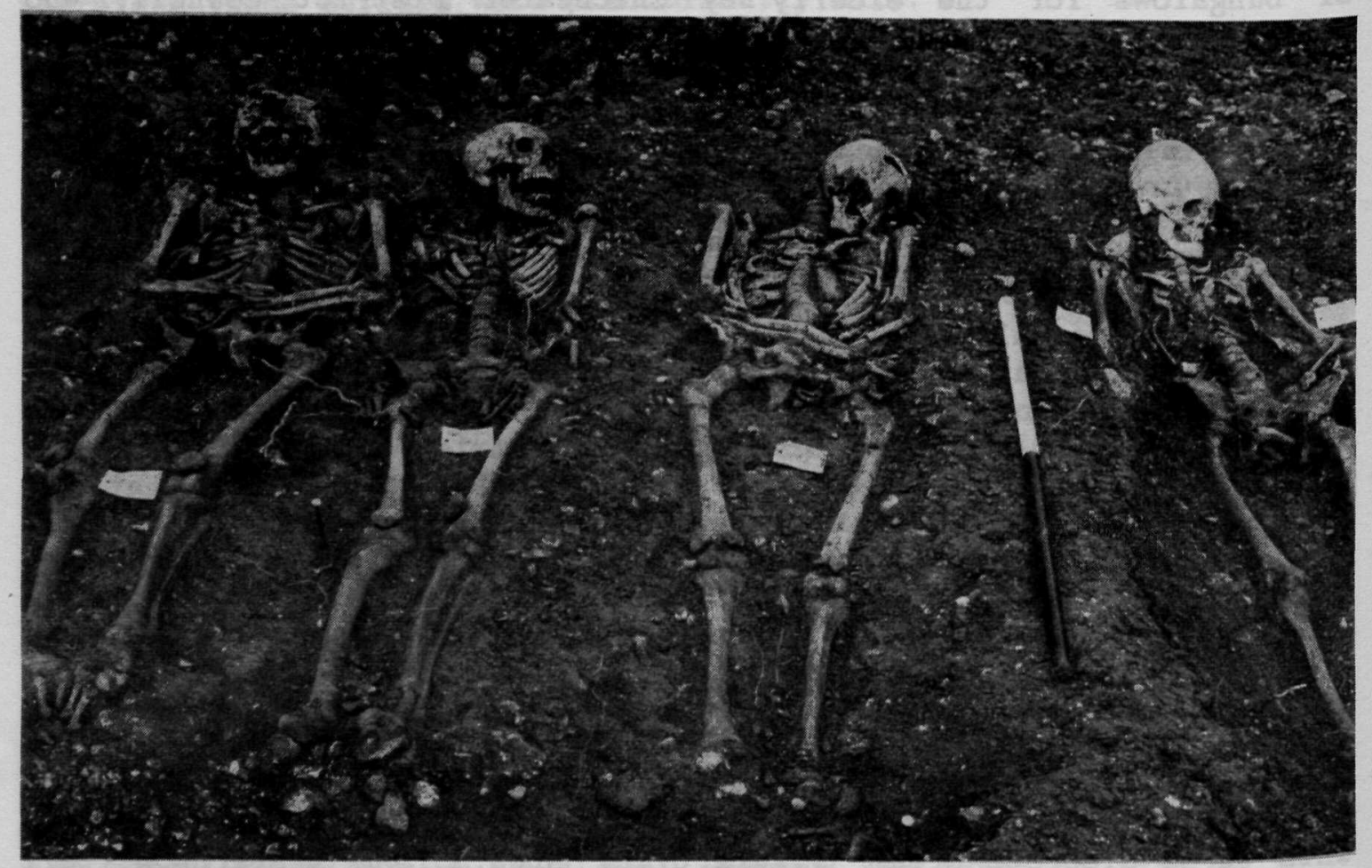

Figure 4. Burials from the early or western end of the cemetery. The skeleton, third from the left, is a leper. 
if there had been a relatively restricted area for burlals. Most of the burials are male, with a few exceptions, and it is also the area with the greatest concentration of skeletons exhibiting bone change compatible with a diagnosis of leprosy (Figure 4 \&). In Area 2 the graves were much more disorganised with graves intersecting one another and with no obvious plan to their placement. Both sexes were present with a localised area of immature individuals. The final area, area 3, is in the easternmost part of the cemetery and is thought to represent the alms house phase of the cemetery. The graves were aligned east - west and placed in rows, both women and children were admitted, and moreover there was a wider range of pathological conditions present, including not only leprosy, but also tuberculosis, osteoarthrosis and traumatic lesions.

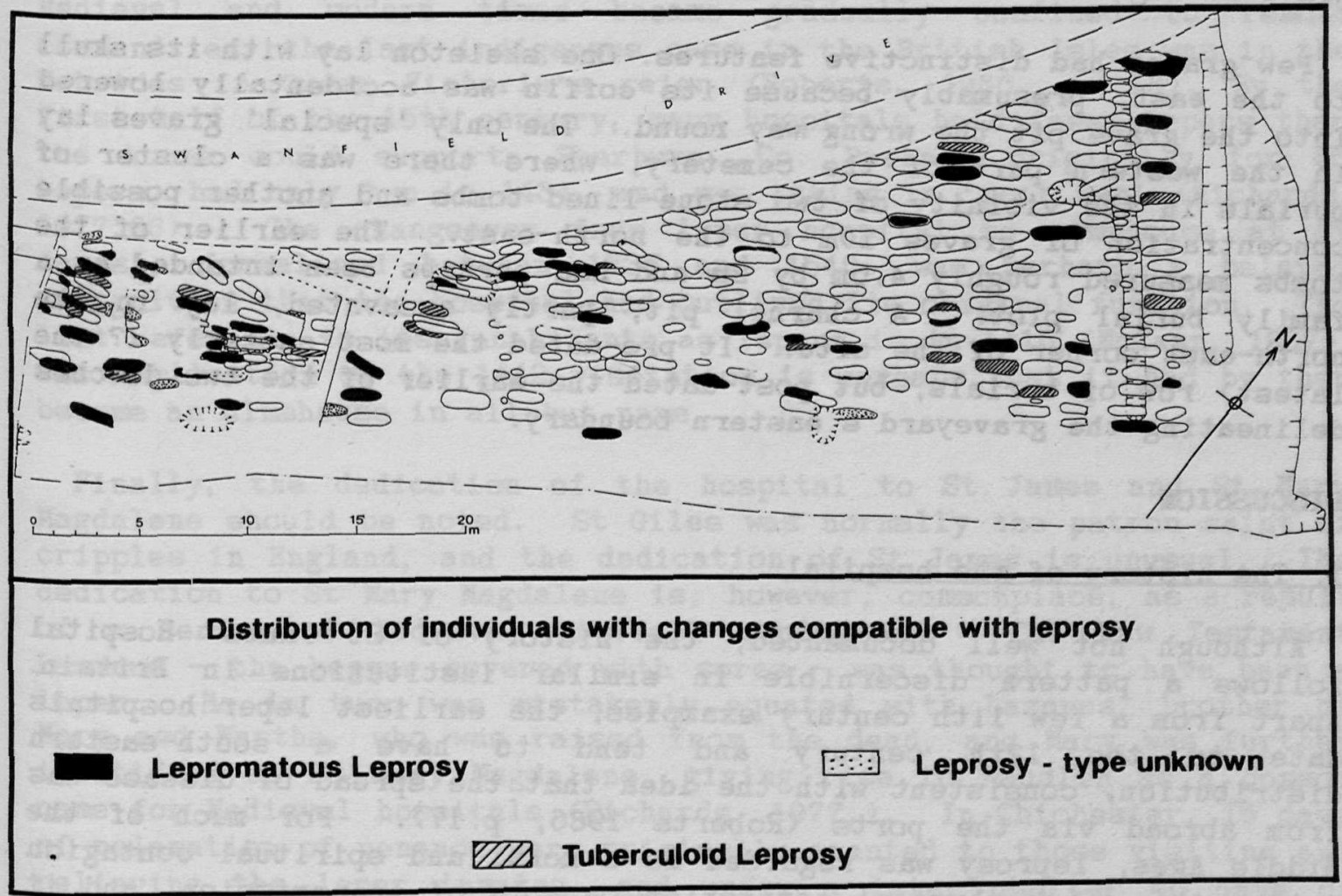

\section{Figure 5.}

Organisation seemed to have come about gradually rather than having been 1 mposed at a specific point in time, and there was no indication that the cemetery had not been in constant use.

A surprising feature of the cemetery was the relative absence of graves close to the present course of the River Lavant to the south. The river 1tself cannot have formed the boundary of the cemetery, since unt1l 1768 it flowed on the south side of the road (Steer, 1962, p.21). The differences in alignment of graves at the western end of the cemetery could be explained by burlals having been aligned parallel to the hospital buildings. The only bullding encountered within the excavated area, which post-dated all the burials in its 
vicinity, shared the same alignment. The relative density of burlals at the western end of the site could be a result of inmates seeking burlal close to the hospital chapel, which was perhaps just beyond the excavated area.

Individual graves had mostly been in coffins, of which the nails survived. In the eastern part of the graveyard stones had sometimes been put in coffins on both sides of the skull to hold it in position or to act as a kind of pillow. One, a chalk block, bore an incised cross. There was no trace of grave markers. The laying out of the body within the coffin showed some variation. Many bodies appeared to have been interred with their arms folded. Displacement may sometimes have occurred during burial, and other variants will have resulted from pathological conditions suffered by the deceased. There was at least one example of a grave having been dug for two burlals and of a grave having been deliberately reopened to take a second body.

Few graves had distinctive features. One skeleton lay with its skull to the east, presumably because 1 ts coffin was accidentally lowered into the grave pit the wrong way round. The only 'special' graves lay in the western part of the cemetery, where there was a cluster of burials in the vicinity of two stone-lined tombs and another possible concentration of graves $10 \mathrm{~m}$ to the north-east. The earlier of the tombs measured roughly $4.5 \mathrm{~m}$ by $2 \mathrm{n}$ and had perhaps been intended as a family burial plot. A charnel pit, partly excavated, lay in the north-east corner of the site. It pre-dated the most easterly (? the latest) row of burials, but post-dated the earlier of the two ditches delineating the graveyard's eastern boundary.

\section{DIscussiou}

\section{The history of the hospital}

Although not well documented, the history of St James' Hospital follows a pattern discernible in similar institutions in Britain. Apart from a few 11 th century examples, the earliest leper hospitals date to the 12th century and tend to have a south-eastern distribution, consistent with the 1 dea that the spread of disease was from abroad via the ports (Roberts 1986, p.17). For much of the Middle Ages, leprosy was regarded as a moral and spiritual contagion rather than as a physical affliction capable of transmission, and $1 t$ is plain that the first purpose of a leper hospital was not to stem the disease through isolating the inmates from society but to offer up prayers for its founder and benefactors (RIchards, 1977, p.11). That this was so at St James', traditionally a royal foundation, as elsewhere, is plain from the rule of the house, confirmed in 1408 , which states that the sacrist had to rise an hour after midnight to summon all to pray for the $\mathrm{king}$, the realm and all benefactors, and to recite the Creed, a hundred Lord's Prayers and Salutations (Page, 1907, p. 99).

Although leper hospitals tended to be sited outside towns, to fulfil the Levitical precept that lepers should dwell 'without the camp' (and perhaps also because land was cheaper), the siting of St James' and other Chichester hospitals on or close to the main London road makes 
It clear that alms gathering was an important source of income, and contact with the public was thus unavoidable. From the 1408 customs of St James', it is also clear that inmates could be expelled for transgressing the rules of the house, again emphasising that the containment of disease through ' isolation hospitals' was not one of the primary functions of a leper house. From a 1442 visitation of $5 t$ James' (Page, 1907, p.99), it seems that it had not been the custom to galn admission by payment, but elsewhere this had been normal, with some fit but wealthy people admitted to what was, in effect, sheltered housing, because they provided sizeable donations (Richards, 1977, p.33). Again, fear of catching the disease seems not to have been an important consideration, at least in the earlier Middle Ages.

The rise and fall of leprosy in Medleval Europe is not fully understood, but whatever the precise reason, European leprosy in late Medieval and modern times became gradually confined to remote communities; the last indigenous case in the British Isles was in the Hebrides in Queen Victoria's relgn (Roberts, 1986, p. 18). By the first half of the $15 \mathrm{th}$ century, many hospitals held fewer lepers than the house could support; Sherburn, Co. Durham, originally for 65 lepers, had only two in 1434, and was taking in 'poor men' (Richards, 1977, 83). The changeover from leper hospltal to almshouse at St James', formalised between 1535 and 1540 , was perhaps a belated recognition that the hospital had outlived its original function. The last reference to 1 ts inhabitants as lepers is in 1418 (McCann, 1987); the implication of the 1442 visitation is perhaps that it had by then become an almshouse in all but name.

Finally, the dedication of the hospital to St James and St hary Magdalene should be noted. St Giles was normally the patron saint of cripples in England, and the dedication of St James is unusual. The dedication to St Mary Magdalene 1s, however, commonplace, as a result of a series of Medieval Biblical confusions. The New Testament Lazarus - the beggar covered with sores - was thought to have been a leper. He in turn was mistakenly equated with Lazarus, brother of Mary and Martha, who was ralsed from the dead, and Mary was further Identifled as St Mary Magdalene, giving rise to Maudlin as a common name for Medieval hospitals (Richards, 1977,). In Chichester, 15 days of relaxation of penance were originally granted to those visiting and relleving the leper inmates, and under a later charter 40 days of indulgence were granted to persons visiting the house on the feast days of St Mary Magdalene or St James (Page, 1907, p. 99). The other hospital in Chichester dedicated to St Mary Magdalene, at Westhampnett (where Maudlin still survives as a mlnor place-name), was contemporary with St James'; the latter may have recelved 1 ts additional dedication to St James in order to distinguish between them. Its chapel was dedicated to St Mary Magdalene, not to St James.

\section{The skeletal evidence}

The skeletal material has presented a unique opportunity to look at leprosy within its historic context since the burial ground encompasses the period when the disease was at 1 ts peak and continues well into the later Medieval period when the disease is documented to be on the decline (Manchester, 1986). Over 83 of the skeletons 
excavated exhlbited some form of change resulting from leprous infection, representing $24 \%$ of the total burial sample.

Leprosy

Leprosy is a chronic infective disease caused by the Mycobacterium leprae, and is transmitted mainly through droplet infection. The bacteria primarily affect the peripheral nervous system and secondarily the skin and other tissues causing pigmentation change and bacilli containing nodule development. Infection to the peripheral nerves near the skin surface results in paralysis and anaesthesia.

The wide variety of lesions and the way in which leprosy develops is never random but is directly dependent upon the immune status of the individual. The most mutilating and infectious type of the disease is lepromatous leprosy (LL). At the other end of the spectrum is tuberculoid leprosy (TL), which may simply present as skin changes with no involvement of the bone. The individual may not remain stable within this system of gradation. Poor nutrition, 111 health or pregnancy may all have a worsening effect due to cell mediated immunity, with the individual passing through the borderline form of the disease to lepromatous leprosy. Through careful study of the skeletal material at Chichester it may prove possible to determine the position of each individual (in broad terms) within the immune spectrum, and by comparing these individuals within the three main areas of the site (Figure 3) it may indeed prove possible to show any change in the disease through time, thereby contributing to our understanding of the palaeoepidemiology of leprosy.

The bone changes of leprosy occur to the face, hands, feet and lower legs, (Koller-Christensen, 1961 and 1978, Jopling, 1978) and are the result of bone infection and erosion. The specific changes are to the facial region and are known as the rhinomaxillary features; these are consistent with lepromatous or near lepromatous disease. They result from oro-nasal soft tissue infection, which includes resorption of the alveolar bone surrounding the inclsor teeth of the upper jaw. This is progressive until all the bone is resorbed and the teeth lost or retained simply in the gums. Another clinical feature is the collapse of the nose seen osteoarchaeologically as resorption of the anterior nasal spine (Figure 6) and rounding or smoothing of the margins of the nasal orifice. Inflammatory change to both the nasal and oral aspects of the maxilla is associated in life with a foul smelling purulent discharge.

Approximately 36 individuals from the cemetery at Chichester exhibited definite rhinomaxillary change with a further 10 individuals exhibiting possible rhinomaxillary change (insufficient for a firm diagnosis) giving a total of 46 individuals who may have had the low resistance form of the disease. (Figure 5). The indirect changes are not due specifically to the leprosy bacillus but to the indirect effect of sensory nerve loss caused by Mycobacterfum leprae, resulting in anaesthesia. Superficlal trauma then occurs and leads to ulceration with secondary pyogenic bacteria entering through open cuts and wounds, giving rise to osteomyelitis and septic arthritis. These changes are accentuated by inadequate blood supply. 


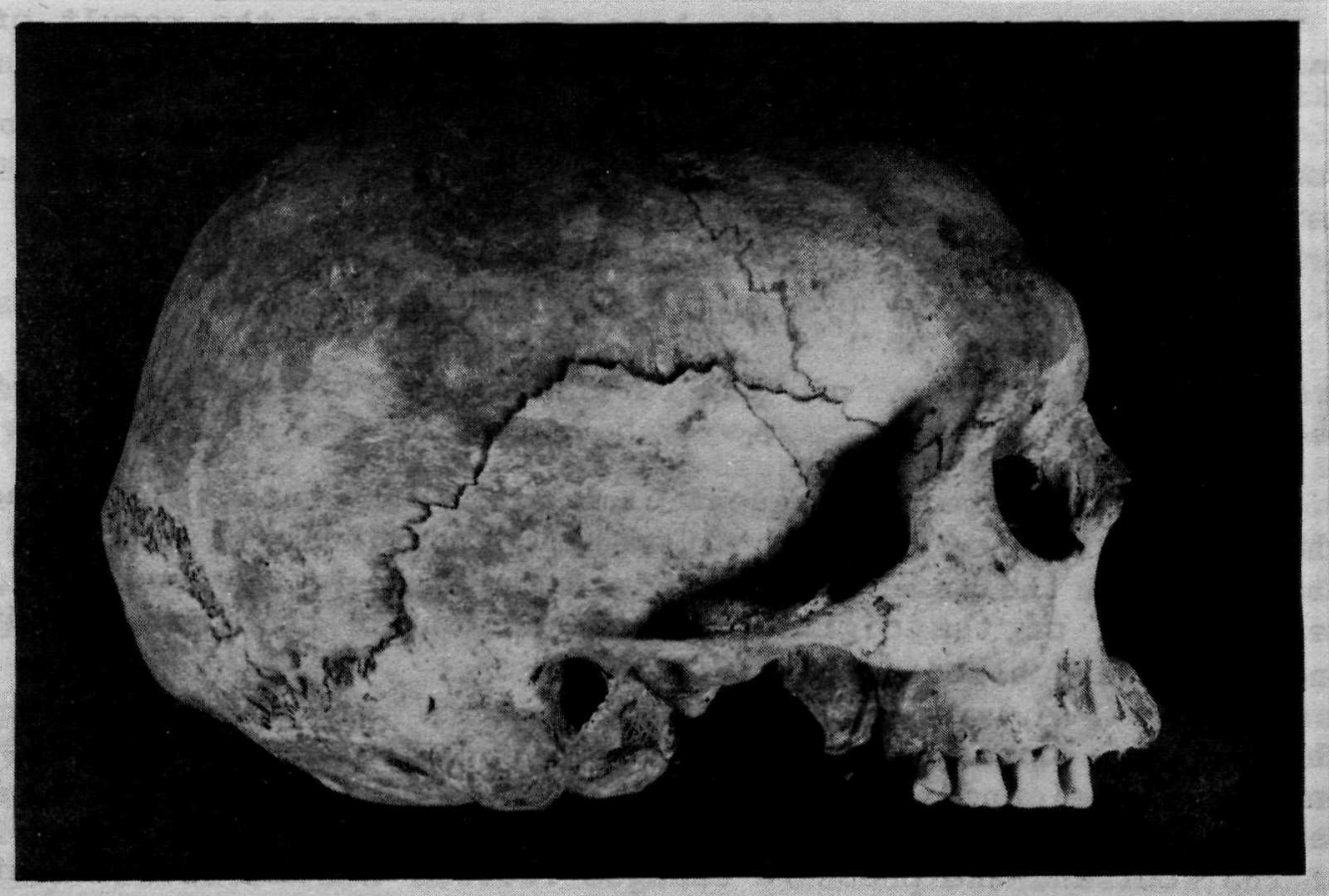

Figure 6. Skull of a male leper showing loss of the anterior nasal spine at the base of the nose.

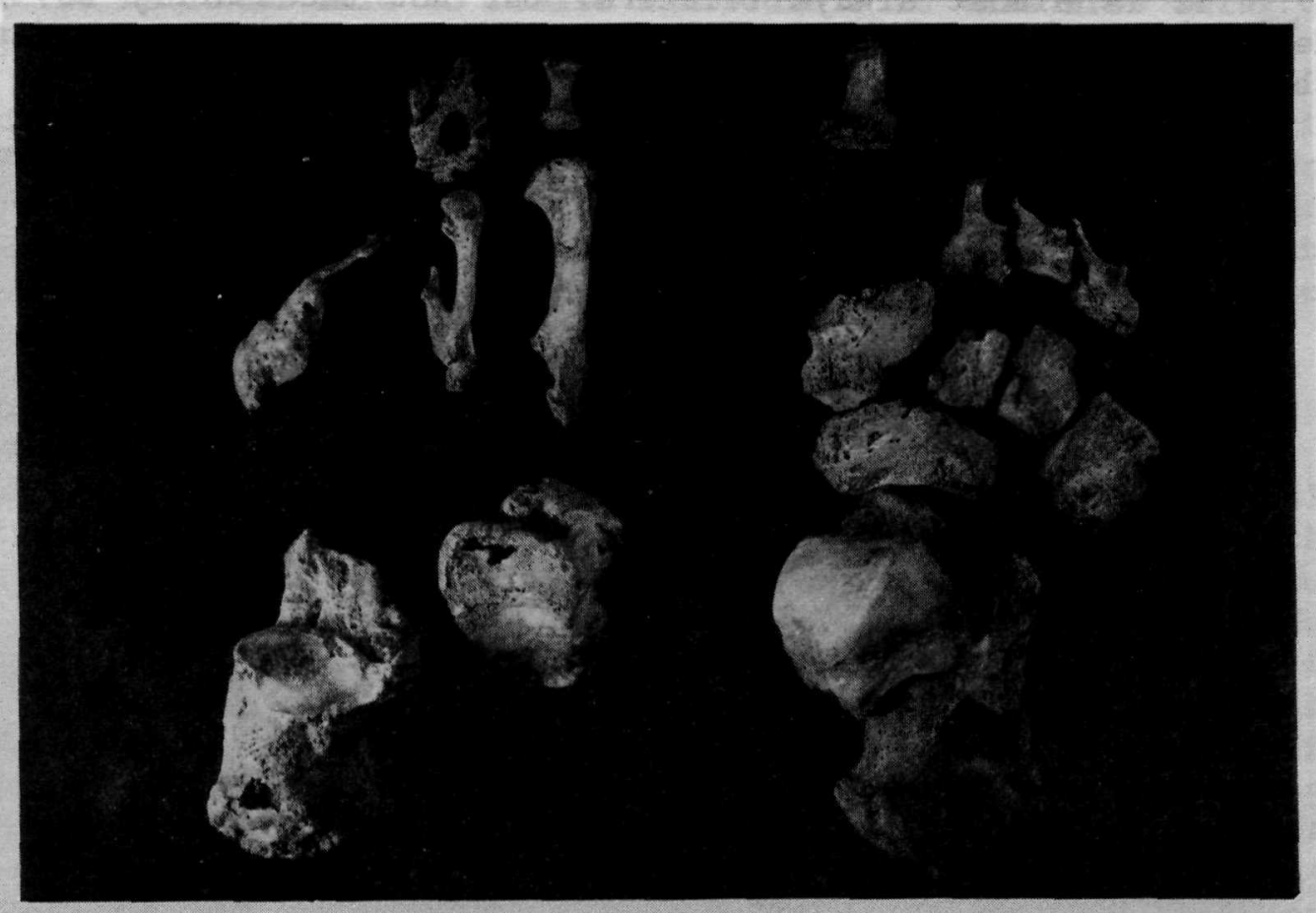

Figure 7. Secondary changes to the feet as the result of leprous infection. The left foot exhibits destruction of the midfoot, while the right shows ulceration and infection to the metatarso-phalangeal joint the point of maximum pressure. 
The indirect changes to the bone are therefore the result of three main processes:

1. The loss of peripheral bone substance through diffuse absorption, concentric diaphyseal remodelling to the shafts of the metacarpals and metatarsals, and terminal bone absorption.

\section{Sepsis or secondary pyogenic infection,}

3. The modification of the architecture of the bones through mechanical adaptation

In the feet there is frequent ulceration with infection spreading to the bone. Absence of pain allows the individual to continue to use the foot and the infection spreads, resulting in the eventual loss or reabsorption of the digits and destruction of the foot by infection and inadequate blood supply (Figure 7 ).

These ulcers occur predominantly at the pressure points of the feet, under the heel and to the base of the 1 st and 5 th toe. Later through paralysis there may be loss of the transverse and longitudinal arches of the foot and the pressure changes include the midfoot ulceration.

Changes also occur to the lower leg, clinically seen as swelling of the $11 \mathrm{mb}$ and thickening of the skin. Osteoarchaeologically, gross inflammatory change with a chronic indolent appearance is seen (Plate 8). It is almost always bilateral but not necessarily to the same degree in each leg. The cause is unknown but toxins ascending from the infected feet have been suggested.

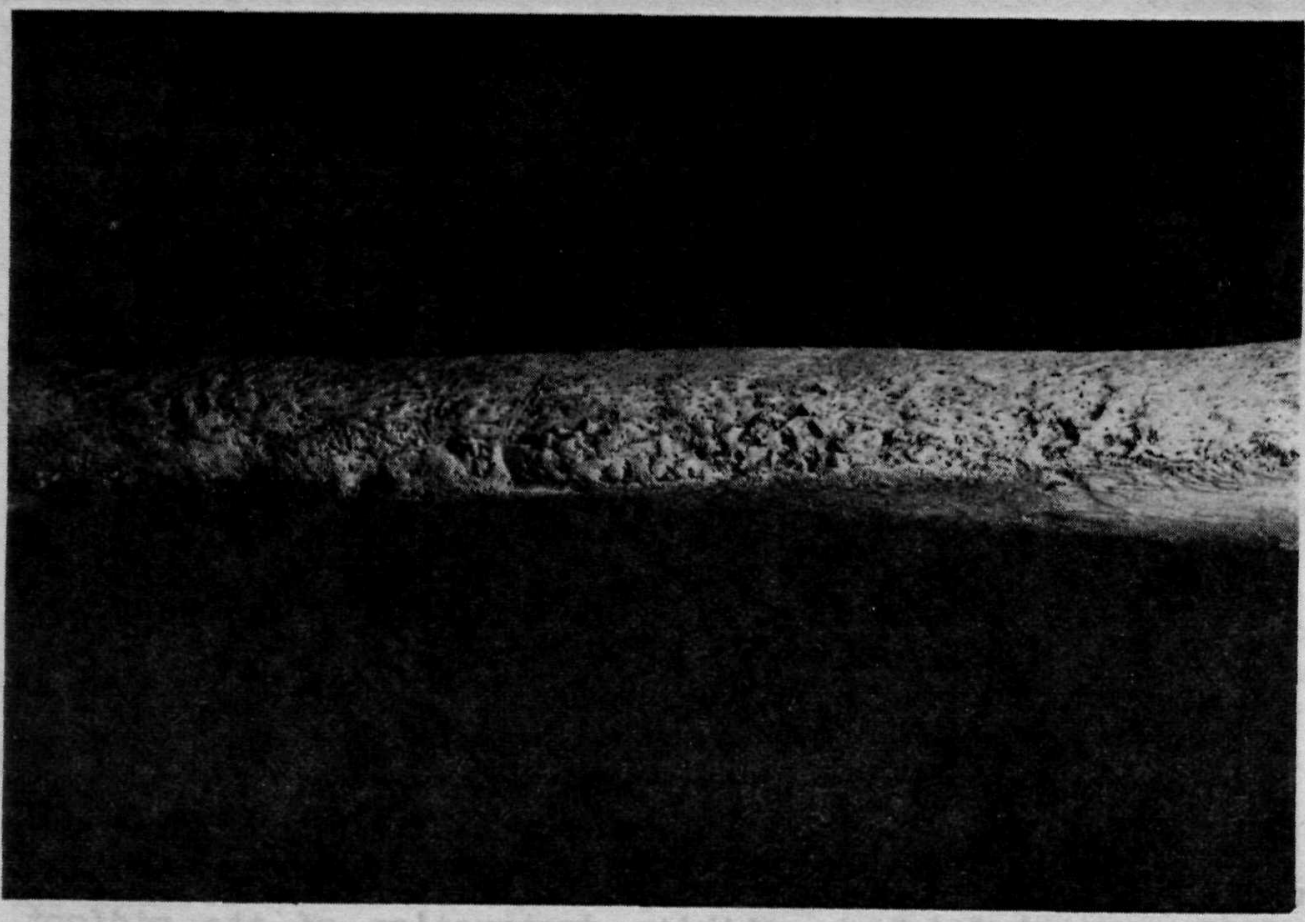

Figure 8. Changes to the tibia the result of gross inflammatory change to the lower leg and assoclated with leprosy. 
In the hands, trauma occurs initially to the ends of the fingers and palms. Later, motor nerve damage results in the involvement of the backs of the hands as the fingers become clawed; this effectively prevents further damage to the palm. Chronic spasticity of the hand, or the claw hand appearance, may result in pressure atrophy of the the palmar aspect of the phalanges, the so - called volar grooves (Andersen and Manchester, 1987).

Anaesthesia and nerve damage occur early in tuberculoid leprosy and one may expect to see bllateral damage to the hands and feet with little change to the nasal area in the highest resistance form of the disease. 49 individuals exhibited changes to the hands, feet and lower legs of which only 20 could be positively ascribed to the tuberculold leprosy category, having no change to the facial region (Figure 5).

The preliminary results from the hospltal cemetery of St James and St Mary Magdalene show that approximately three quarters of the leprous individuals were male, only 13\% were female while $15 \%$ proved impossible to sex. The predominance of male lepers 15 explained in area 1 by the fact that in the earliest perlod of the cemetery only elght leper brethren were admitted at any one time. From 1540 onwards sisters were also admitted although the number of female lepers in areas 2 and 3 is still well below the expected rate, with Just over a quarter of the total number of lepers being female despite the ratio of male to female individuals in this area being in the region of $5: 4$.

The disease is known to have a long incubation period and this is reflected in the low number of immature individuals with evidence for the disease. Moreover the high number of individuals exhibiting bone change resulting from leprosy to some extent supports the suggestions by Manchester and Roberts (1986) that individuals were not admitted until physical mutilation, particularly facial, had developed.

\section{The decline in leprosy}

The decline in leprosy towards the later Medieval period is well demonstrated in the hospital cemetery. The earliest period of the cemetery, area 1, has a significant clustering of leprous individuals, with $54 \%$ of the burials exhibiting some form of leprous change, compared to $17 \%$ in area 2 and $16 \%$ in area 3 . Not only is there a decline in the number of individuals suffering from the disease, but there also would appear to be a significant change in the type of leprosy. $45 \%$ of skeletons with rhinomaxillary change occur in area 1, although significant numbers of these individuals were also to be found in areas 2 and $3,22 \%$ and $32 \%$ respectively, indicating that the most mutilating form of leprosy was still present but in decreasing numbers until the cemetery went out of use in the 17th century. However, by the time that area 3 came into use, the hospital of St James and St Mary Magdalene may have been the only leper hospital still functioning in Chlchester. If this was indeed the case then it could be argued that a figure of $32 \%$ for the lepromatous individuals gives a false impression of the prevalence of the disease in the later period. 
The distribution of individuals with changes attributed to tuberculoid leprosy show a significant increase in incidence in area 3. In area 1, once the incomplete skeletons have been discounted, only $16 \%$ of the leprous individuals had pathological changes to the hands and feet consistent with a diagnosis of tuberculoid leprosy, whereas $21 \%$ occur in area 2 and $35 \%$ in area 3 . When these figures are looked at as a ratio of lepromatous to tuberculoid leprosy there appears to be a consistant rise in the number of TL sufferers: Area 1 has a ratio of 4 (LL) : 1 (TL) whilst area 2 has $3: 1$ and area 3 , a ratio of $2: 1$.

The reasons for the decline in the disease are not fully understood. Segregation is unlikely to have halted the transmission of the disease. In the early stages of lepromatous leprosy there would be little nerve involvement and skin lesions are rarely noticed. Clinically the disease would present itself as nasal congestion and oedema, or swelling to the lower legs (Jopling 1978). Consequently, these highly infectious individuals would have avoided discovery until the progression of the disease led to their eventual detection. Anaesthesia and nerve damage, on the other hand, occur early on in tuberculoid leprosy. Detection through pigmentation change to the skin and lack of sensation to the extremities may have led to an early diagnosis. The rate and spread of the disease without treatment would therefore have been difficult to control as the most highly infectious individuals may have remained undetected in the community for some time during a very infectious stage of the disease.

The osteoarchaeological analysis from Chichester does little to further our understanding of the method and effectiveness of segregation. The palaeopathological observations are made on the manifestations of the disease on the skeleton at the time of death. Many individuals may have entered the hospital in the high resistant form of the disease (TL), and later have downgraded through 111 health into the low resistant (LL) and more mutilating stage of the disease. However if, as has been suggested, there is a significant increase in the relative proportion of individuals with tuberculaid leprosy compared to epromatous leprosy, then the transmission of the disease within the community would have been seriously affected. Tuberculaid leprosy is the less infectious form of the disease and the increase in proportion may have significantly contributed to the decline in the disease.

The second possiblity is that the increase in tuberculasis in the later Middle Ages afforded some degree of cross-immunity to the individual, induced by the two closely related bacteria (Manchester, 1983). Tuberulosis has a long history, but there is a well documented rise amongst urban populations in the later Middle Ages continuing well into the 20th century, until its eradication with the introduction of antibiotics. At Chichester, 10 individuals have lesions which are attributed to tuberculous destruction of the bone with a further 2 possible cases. Lesions to the visceral aspect of the ribs, considered to result from an infection of the pleura (the membrane surrounding the lungs), occur in a further 9 individuals. The most common causes of pleurisy are pneumonia, bronchiectasis and tuberculosis. The distribution of the tuberculous and possible 
tuberculous lesions along with the rtb lesions can be seen in Figure 9. Moreover the actual number of individuals suffering from tuberculosis at Chichester would almost certainly have been greater as only between $3-5 \%$ of tuberculous patients will exhibit skeletal lesions, the rest escaping palaeopathological diagnosis. Consequently the possible number of tuberculosis sufferers may have been anything up to 200 individuals with the majority occurring in areas 2 and 3 , where the discussion has already shown there to be a concurrent decline in lepers.

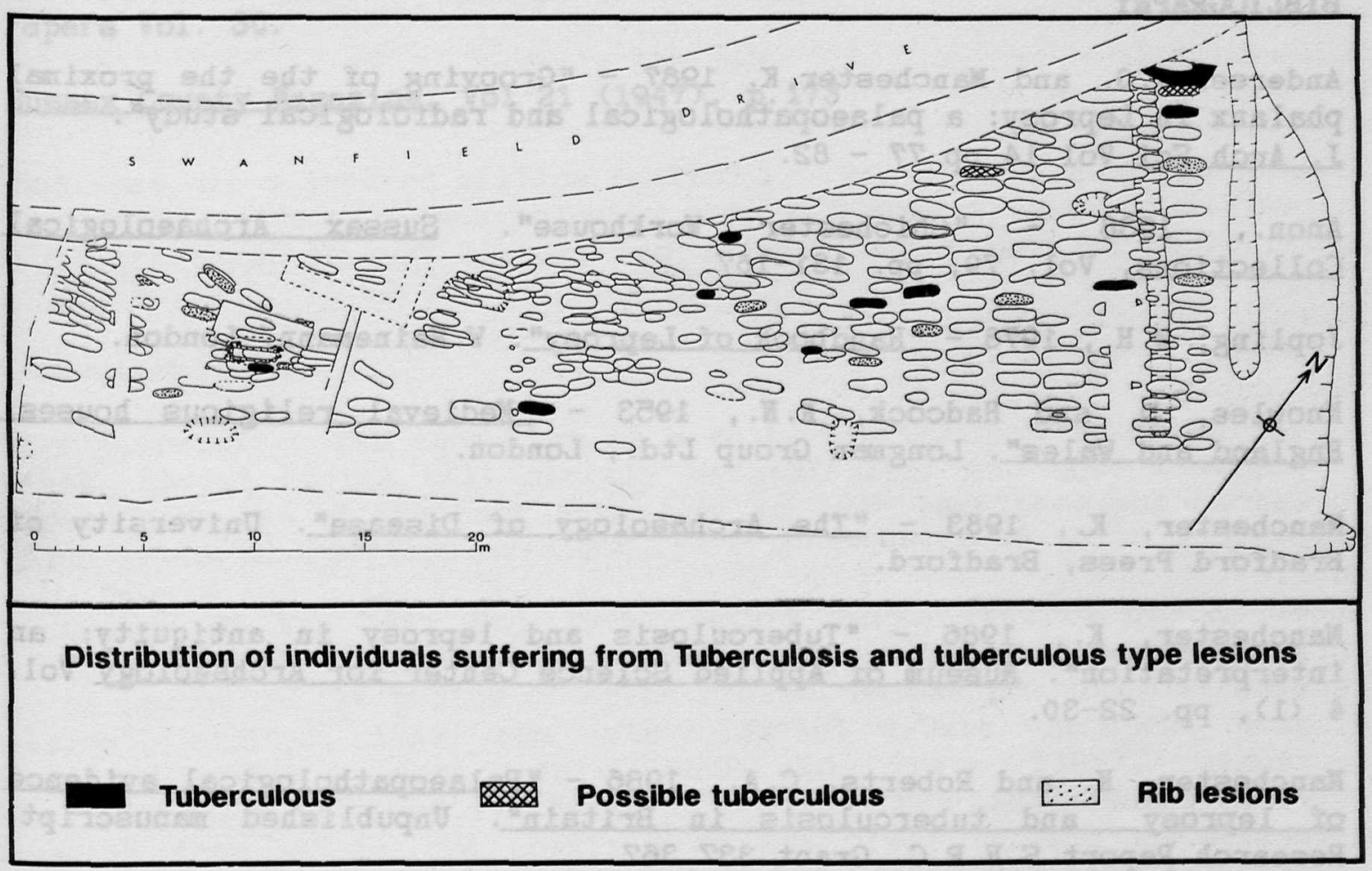

\section{Figure 9}

In summary, the palaeopathological study of the leprous individuals from the cemetery has shown the potential to differentiate between the highly infectious and less infectlous form of the disease. Moreover through studying the changing patterns of these within the three areas of the site, it may be possible to see a change in the disease over time and therefore prove to be a valuable contribution to our understanding of the disease and the reasons for its decline in the later Medleval period. 


\section{APPEWDIX 1}

16 th century list of alms house residents

" Villiam Egle, now proctor, and Dorothy his wife, both about 50 , Hugh Young impotent, age 33, Richard Iottle cripple, 35, Richard Parshaw cripple, 16, Thomas Kawrynge cripple,18, John Pellard a diseased 1diot,30, Agnes Patchinge a maid without legs, 30, Agnes Barnes a maid without legs, Jargaret Crowcher a maid about 40 , a cripple, Elizabeth Vody an idiot, 17, Allce Taylor a cripple, 30, and Constance Cutt an impotent cripple in her loins, 15. All of honest conversation". (Page, 1907).

\section{BIBLIOGRAPHY}

Andersen, J.G. and Manchester,K. 1987 - "Grooving of the the proximal phalanx in Leprosy: a palaeopathological and radiological study".

L. Arch SC1 Vol 14 pp $77-82$.

Anon., 1938 - "Chichester Workhouse". Sussex Archaeological Collections, Vol. 79, pp. 131-167.

Jopling, W. H., 1978 - "Handbook of Leprosy". W. Heinemann, London.

Knowles, D. and Hadcock, R. N., 1953 - "Kedieval religious houses. England and Wales". Longman Group Ltd., London.

Manchester, K., 1983 - "The Archaeology of D1sease". Un1versity of Bradford Press, Bradford.

Manchester, K., 1986 - "Tuberculosis and leprosy in antiquity: an interpretation". Kuseum of Applied Sclence Center for Archaeology Vol. 4 (1), pp. $22-30$.

Manchester, K. and Roberts, C.A., 1986 - "Palaeopathological evidence of leprosy and tuberculosis in Britain". Unpublished manuscript. Research Report S.E.R.C. Grant 337.367.

McCann, A., 1987 - "Further Notes on St James' Hospital, Chichester". Sussex Archaeological Collections Vol. 125, pp. 252-254.

Moller-Christensen, V. 1961 - "Bone change in Leprosy". Munksgaard, Copenhagen, Denmark.

Moller-Christensen, V. 1978 - "Leprosy changes of the skuII" Odense University Press.

Page, V., 1905 - "V1ctoria County History Sussex". Vol. 1.

Page, V., 1907 - "Victoria County History Sussex". Vol. 2.

Peckham, W.D., 1943 - "The Chartulary of the High Church of Chichester". Sussex Record Soctety for 1942 and 1943. 
Richards, P. . 1977 - "The Medieval Leper and His Northern Heirs", D, S Brewer/Rowman and Littlefield, London.

Rivet, A.L.F, and Smith, C., 1979 - "The Place Names of Roman Britain". Batsford, London.

Roberts, C.A., 1986 - "Leprosy and Leprosarla in Medieval Britain", Wuseum of Applied Science Center for Archaeology. Vol.4 (1), pp. 1521.

Salzman, L.F., 1935 - "Victoria County History Sussex". Vol. 3.

Steer, F.W., 1962 - "The memolrs of James Spershott". Chichester Papers Vol. 30.

Sussex County Nagazine, Vol 21 (1947), p. 173 
IT'S A DIRTY JOB, BUT SOIEBODY'S GOT TO DO IT.

\author{
Max Adams \\ 1 The Nook \\ Hoylands Swain \\ Sheffield \\ S30 6JW \\ and \\ Jez Reeve \\ Norfolk Archaeological Unit \\ 17 George Street \\ Norwich \\ Norfolk NR3 $1 \mathrm{AB}$
}

\begin{abstract}
"But what are a hundred million deaths? ... And since a dead man has no substance unless one has actually seen him dead a hundred million corpses broadcast through history are no more than a puff of smoke in the imagination". (Albert Camus, The Plague).
\end{abstract}

\title{
Introduction
}

Five years after its inception as a multi-disciplinary human burial project, Christ Church will shortly be published: the most detailed and extensive set of mortuary data ever to have been produced in the British Isles, and perhaps anywhere.

Clearance of the $18 \mathrm{th}$ and $19 \mathrm{th}$ century burial vaults at Christ Church, Hawksmoor's baroque masterpiece lying just to the east of the City of London in the parish of Spitalfields, became the focus of much technical, ethical, legal and methodological debate which has been treated elsewhere in some detail (Adams and Reeve, 1987). Almost 1000 individuals interred in the crypt between 1729 and 1859 had to be excavated from within the confines of the crypt beneath an active place of worship and opposite the bustling Spitalfields fruit and vegetable market. It was essential that excavation and recording should provide a tightly controlled context within which assessment of the human remains could be carried out by anthropologists from the British Kuseum (Hatural History).

Such a project had never been contemplated before, and it was clear from an early stage that specialists and technicians from a wide range of disciplines would have to be involved so that a unique archaeological and anthropological resource should not be squandered in an ill-prepared salvage operation. Accordingly links were established between archaeological technicians and anthropologists so that the former could adapt to the requirements of the latter. At a later stage other specialists were called in to deal with the vast quantitiy of textiles preserved with bodies, the historical background, and the technology of the material culture. 


\section{Archaediogy and anthropology: an uneagy truce}

Yuch has been written about the relationship forged between two disciplines whose apparently diverse interests cloak a common cause: to understand life through death. It is axiomatic that both the archaealogical burial and the skeletal elements represent the sum, a single sum of the formation processes, both cultural and non-cultural, which have acted upon past peoples.

Many writers from both disciplines have been highly critical of the ways in which this relationship has developed, failing to adapt to the voracious demands of new trends in technology, technique and theory. Roberts (1986) has claimed that if palaeopathology is a 'cottage industry' which fails to produce the goods that archaeologists require in their excavation reports, then, equally, archaeologists fall to recognise the potential which pathology offers in reconstructing people's lives.

At Christ Church the relationship between the two 'halves' of the project was difficult because of different priorities. For example, health and safety restrictions meant that soft tissue could not be removed from the church crypt and therefore analysis of histalogy was impossible.

Examples from Christ Church 1llustrate some of the problems experienced by excavators and laboratory technicians. In coffins which have remained sealed within lead caskets for a hundred and fifty years there is a reasonable expectation that at the very least an almost total bone assemblage might be retrieved. Burial archaeologists are acutely aware that their techniques are scrutinised and criticised because of certain under-representation of specific skeletal elements from burials, notably patellae and hand and foot phalanges. It was entirely possible that, given conditions under which excavators had to work, the occasional bone would be discarded amongst the tons of building rubble, lead, corrasion products, soft tissue, coffin liquor and decayed wood which characterised the depasits.

Vithin the context of recent work (especially Boddington et. al., 1987) which has attempted to create a strategy for understanding all aspects of the differential retrieval of human remains, the excavators can state in retrospect that problems of retrieval at Christ Church were not sufficlently considered at the time.

Ve would now like to put the common experience of petty practical disputes into a theoretical framework within which we might jointly resolve some problems and derive mutual benefit.

\section{A theoretical framework}

If the bone and the burial represent the sum of processes past and present, then it seems logical to apply a sort of accountancy to the subject. In short, we should try to balance the books. The credit side of the page must provide an analogy for the resources contained in the burial environment. On the debit side are the processes, or 
bills paid, as it were, which impact upon these resources. In order at the end of the day to achieve balanced books, we must apply methodological solutions. The difference between resources and impacts is a figure which represents net information gain, or possibly loss, in which the unit of currency is information, or the trait. Sadly, archaeologists frequently forget that we should always be trying to profit from the past, in one way or another.

Here, then, we attempt to create a practical framework of ideas based on this analogy: we shall look at resources, impacts and solutions using the example of Christ Church as an illustration where appropriate. We offer the framework as a strategy for assessing the future relationship between archaeologists and anthropologists.

\section{Resources: the human burial environment.}

\section{Archaeological}

An archaeological resource is one which contains potentially retrievable information about the past. These resources can be thought of in terms of the quality of inferences that may be drawn from them (IQ). A resource has a high IQ when the traits it possesses are diagnostic of a particular process or series of processes. A resource has a low IQ when its traits, because they are too subtle, too destructive or too equivocal, are not diagnostic. Christ Church was widely recognised as a site with enormous inference potential: 1000 individuals from a highly documented period of history, of which an eventual 400 or so were identified by means of biographical information inscribed on coffin plates. $40 \%$ of archaeological contexts were thus dateable to within a few days of their first introduction into the crypt, and the majority of the rest closely dated within the relative chronology established for the vaults.

Individual cultural and non-cultural events which occurred during the use of the crypt could be identified with a high degree of confidence because traces of activity were created and cleared in predictable ways. Such was the excavators' confidence that we belleve we can identify the change of tenure between one sexton and another from their different behavioural patterns.

Goldstein (1981, 59) and others have identified the principal resources, especially spatial, which the modern archaeologist must be expected to exploit, fust as more than a hundred years ago Vorsane (1859) identified the nature of artefactual resources from graves. Christ Church possessed an additional resource rare in burial contexts outside bogs. Not only did environmental conditions favour the preservation of human soft and skeletal tissue, but the crypt itself could be viewed as a laboratory in which assumptions about the formation processes which act upon human remains could be tested and archaeological techniques enhanced. The sum of these resources is the archaeological context. It is not simply the duty of the archaeologist to provide that context; it is also the duty of the human biologist to exploit that context fully, and with all its nuances. 


\section{Anthropological}

The study of human remains, largely through metrical and nonmetrical observations of the skeleton, has a potential for reconstructing aspects of past lives which grows greater as techniques are devised and corroborated by experiment. The burial environment at Christ Church favoured the preservation of soft tissue, but also contained a great many micro-environments in which combinations of factors produced widely differing types of decay and preservation. As Garland (1988) has pointed out, this type of resource can be exploited using basic histological techniques which could enhance data derived simply from gross skeletal observations.

The remains at Christ Church were of particular importance to palaeopathologists and anthropologists, not merely because of the quality of the archaeological context. The positive identification of 387 individuals, many of them related famllially, and the vast wealth of social and economic data available to place those individuals within their society, were all virtually unique features. This population could vastly enhance our understanding of environmental and hereditary factors influencing our own society, through the identification of work-related stress, dietary factors and genetic trends. Crucially, the size of the sample would enable ageing and sexing techniques to be tested and evaluated, and new techniques to be generated.

A combination of the archaeological and anthropological resources contained within the burial vaults at Christ Church should enable the generation of the most complete socio-historic framework ever attempted for a burial population in this country. In more general terms, the project has broken new methodological ground and should continue to challenge the ways in which burial studies are used.

\section{Impacts}

The study of impacts has been used, especially in American archaeology, to predict the destruction of the archaeological resources by modern human behaviour, and especially the industrial and agricultural behaviour (Schiffer 1987: 132). The most 1mportant attribute of impacts is that they tend to be both predictable and regular in their effects. It is possible to apply impact theory to understanding the ways in which all archaeological and related resources are transformed or destroyed. As we suggested above, impacts acting on resources create traits which can sometimes enhance inference quality (a sort of claim against tax), but more frequently reduce it.

Ve have stressed that the archaeologist and anthropologist must regard the transition from life through death to deposition and decay as a single continuum in which a variety of processes act and may continue to act in consort with each other, with an end product which may only very subtly (Sutton Hoo shadow burials being a fine example) reflect the reality of a living person. As Camus wrote (see above), a hundred million deaths are no more than a puff of smoke in the imagination, and sometimes in reality too. But as Boddington et. al. 
(1987, preface) encouragingly point out "Despair is ... unwarranted... the analysis of the decay process itself can be harnessed for the purposes of reconstruction".

The human body undergoes its first impacts prior to death, as anthropological studies have amply shown over the years. These factors have been termed intrinsic (Henderson, 1987:44). They include the effects of degeneration with age, size, and diseases. They influence the relative survival of bone, and the speed at which processes may operate upon it. These processes begin prior to death and continue after it has occurred.

Extrinsic factors ( 1 bid, $p, 45$ ) are those which operate in the environment in which the body is located after death. These are influenced by the postmortem interval between death and burial (which was known in the cases of many individuals at (hrist (hurch), by environmental condition, and by cultural treatment of the individual. After deposition impacts may be cultural (e.g. disturbance by grave cutting) and must certainly also be non-cultural. The latter are increasingly understood and have been covered by two recent papers (Henderson, op. cit.; Mant, 1987).

Far too little attention has been pald to impacts which occur when archaeologists 'rescue' burial sites from the impacts of developers and farmers' ploughs. Firstly, excavators may inadvertently cause primary impacts on burials by accidentally destroying them. Secondly, archaeological examination is certain to destabilise the environment containing human remains to a greater or lesser extent depending on the fragility of that environment. Excavators at Christ Church are unlikely to forget the experience of opening a lead coffin before lunch and returning to find that scores of fly larvae had hatched within it during the interval to swarm around the crypt. The crypt environment had remained stable since its closure in 1867: temperature, soil moisture and humidity levels are unlikely to have altered substantially prior to the re-opening of the sealed vaults.

Thirdly, impacts which occur during recording and retrieval which have been covered extensively in archaeological literature over the years (e.g. Brothwel1, 1981), cannot be underestimated. At Christ Church the 'floor' surface upon which excavators moved and worked was for the most part made up of coffins in various states of decay; the obligatory use of heavy overalls and steel-toed rubber boots was hardly likely to minimise the impact of the excavation process. The site methodology, strictly laid down at Christ Church by the government's Health and Safety Executive, involved the separation of head and body for removal in a box and a bag. Needless to say, a less tightly controlled operation than was in existence at Christ Church (and, of course, most other burial sites) would have led to a potentially disastrous 1mpact: giving a wrong number to an individual would create an entirely false context. Nevertheless, perhaps the greatest destruction of resources took place at this stage of the operation. The anthropological team were only able to deal with clean, dry bones in a good state of preservation. Garland ( 1988) has demonstrated that such a simplistic attitude towards bone condition, and the corollary that it discards at this stage most if not all of 
the soft tissue on a body, is nothing less than a gross waste of resources. However, the anthropological investigation for the individuals at Christ Church did not include the provision for histological study at that level. In such a case it appears that lack of co-ordinated specialist advice is in itself a most devastating impact on the burial resource.

The entire post-archaeological phase of human burial studies is again fraught with impacts which have received too little attention. cleaning bones, like cleaning pottery, may satisfy museum aesthetics, but it impacts upon the material which it is duty bound to study and curate. The very processes of examination, storage and curation are under-rated as sources of transformation of traits.

\section{Solutions}

We destroy data. We impact upon precious resources so as to decrease the inference potential contained in the archaeological context, and, perhaps worse, we fail to recognise potential resources and consequently fail to exploit them.

Any set of solutions to current problems will lie in a stategy which reduces impacts caused by ourselves, and increases the recognition and consequent exploitation of resources. The following are intended as practical means of reaching those ends.

\section{Inference quality}

It is entirely appropriate that scientists apportion their own resources to where the greatest profit lies. The identity of areas of greatest profit can be determined by the inference potential of an arcaheological resource: the higher its IQ the greater the chance we have of making sound, confident inferences about the past. IQ can be measured by assessing the diagnostic characteristics possessed by artefacts and ecofacts. The fact that we have traditionally practised this sort of assessment intuitively, and often with regard to strong aesthetic considerations, should now provide us with the incentive to create a rigorous strategy on, to extend an earlier analogy, a costbenefit basis.

\section{Impacts}

Archaeology and anthropology must integrate their views of 1 mpacts. They must ensure that regular, predictable impacts are anticipated, and retain control over those impacts. Using an accounting strategy like that outlined above, areas of. greatest information loss can be highlighted and strategies within research designs generated to limit such impacts. Such strategies must inevitably involve improvements in training, techniques and recognition of processes. Demands that one discipline may have on the other have to be more explicit; they also have to be justified. 


\section{Context}

The context which links archaeology with anthropology and beyond, to anthropology and history, is the formal evidence of traits left as characteristic attributes on artefacts and ecofacts by physical processes. It may be possible in the future to replicate and therefore reconstruct some, perhaps many, of these processes. That is the easy part: we can go out into the field and watch pyres and rotting carcasses until eventually we can diagnose. The hard part, of course, is to infer behaviour of past peoples from those processes. Nevertheless, if we can get the first part right, novelists and filmmakers will probably be able to deal with the rest.

\section{BIBLIOGRAPHY}

Adams, M. and Reeve, J., 1987 - "Excavations at Christ Church, Spitalfields 1984-6". Antiquity, Vol. 61, pp. 247 - 255.

Boddington, A., Garland, A.R. and Janaway, R.C., (Eds) 1987 "Death. decay and reconstruction. Approaches to archaeology and forensic science". Manchester University Press, Manchester.

Brothwe11, D., 1981 - "Digging up bones. The excavation, treatment and study of human skeletal remains". Oxford University Press, Oxford and British Museum (Natural History), London.

Camus A., 1947 - "The Plague". Gallinard.

Garland, A.N., 1988 - "Histology, taphonomy and human skeletal remains". Arch - Form, Vol. 2, pp.12-16.

Goldstein, L., 1981 - "One dimensional archaeology and mult1dimensional people: spatial organisation and mortuary analysis", pp. 53-69 in R. Chapman, I. Kinnes and K. Randsborg (Eds), The Archaeology of death. Cambridge University Press, Cambridge.

Henderson, J., 1987 - "Factors determining the state of preservation of human remains", pp. 43-54 in A. Boddington, A.I. Garland and R.C. Janaway (Eds), Death, decay and reconstruction, Approaches to archaeology and forensic science. Manchester University Press, Nanchester.

Mant, K., 1987 - "Knowledge acquired from post war exhumations", pp. 65-78 in A. Boddington, A.I. Garland and R.C. Janaway (Eds), Death. decay and reconstruction. Approaches to archaeology and forensic science, Manchester University Press, Manchester.

Roberts, C.A., 1986 - "Palaeopathology: cottage Industry or interacting discipline? ", pp. 110-128 in J. Bintliff and C. Gaffney (Eds), Archaeology at the interface: studies in archaeology's relationships with history, geography, biology and physical science. British Archaeological Reports. International Series, Vol. 300. Oxford. 
Schiffer, M.B., 1987 - "Formation processes of the archaeological record". Ist edition. University of New Mexico Press.

Worsaae, J.J.A., 1859 - "The Primeval Antiquities of Denmark". 


\title{
THE GASE FOR CRYPT EXCAVATIOT HOT CRYPT CLEARATCE
}

\author{
Nargaret Cox \\ Department of Human Environment \\ Institute of Archaeology \\ 31-34 Gordon Square \\ London WC1H OPY
}

Following the excavation of the crypts beneath Christ Church, Spitalfields, directed by Jez Reeve between 1984 and 1986, and the subsequent post-excavation analysis, it seems an expedient moment in time at which to discuss the merits of the archaeological recovery of crypt populations.

The human skeletal biologist confronted with a skeletal sample derived from an archaeological context is faced with the awesome task of producing a report which justifies the cost entailed. Why an awesome task? The reality of the situation is that much of the methodology which is expected to be applied produces results which lack real credibility.

The underlying reason for this situation is that several of the analytical techniques currently in use were developed on archaeological samples for which there were no independent corroborating data. For example, methods for estimating whether or not women have borne children as put forward by Houghton (1974) and Ullrich (1975) have been established on archaeological series of unknown parity status. The ageing methodology based on dental attrition advocated in Brothwell (1981, p.72) was developed on skeletal samples of unknown age. The reason for this situation is that skeletal collections with known demographic and other life history data are extremely rare. Those ageing techniques developed on autopsy material of known age are considered useful as they can provide an age range. However, that range can, and often does, span a perlod of several decades. A predicted age ranging from twenty-six to seventy, with a mean of 38.2 years (Suchey and Brooks, 1988) is of little value when one seeks to establish demographic profiles or to understand the reproductive capability of an individual. Similarly, assumptions about non-metric traits which may be genetic, but are possibly subject to an unknown degree of environmental modification, are dogged by the fact that in archaeological series relationships are never independently known. Furthermore, there is a strong possibility that in periods of restricted geographical mobility the majority of individuals may have shared a similar environment.

The reality of human bone reporting today is that skeletal biologists collect large amounts of descriptive data, the significance of which are rarely understood. Indeed, a great deal of time is spent collecting data in the anticipation that future research will facilitate meaningful interpretation.

The excavation at Christ Church was undertaken to provide skeletal biologists with an archaeological sample, a percentage of which would have biographical data. It was known that the crypts were in use for interments from 1729 to 1859. At the outset 1 t was not known how many 
of the estimated 1,000 inhumations would be retrieved with securely associated and legible coffin plates. These were known to state name, and consequently sex, and the age of the individual at death. A tantalising potential bonus was that it might prove possible to retrieve other types of biographical data from the abundance of documentation relating to individuals which both church and state were beginning to demand in the eighteenth century.

In fact, the one year's historical research into the life histories and life styles of the 387 individuals with coffin plates proved nore successful than had been anticipated. The types of information retrieved were diverse and provide the opportunity to both test and possibly establish numerous techniques of use to skeletal biologists. These may consequently improve our understanding of past lives and early environments.

The historical anthropologist confronted with this research had a list of names and dates of death. From this data base other information was gleaned piece by piece. The whole process was one of enquiry, collation, rejection and compilation, ultimately establishing ife histories of varying degrees of completeness. Use was made of such primary source material as parochial registers, trade directories and vestry minute books. The International Genealogical Index (Guildhall, London) was an invaluable ald as were family letters and recipe books kindly donated by interested parties whose ancestors lived in the Spitalfields area in the eighteenth and early nineteenth centuries.

One year later three "CARDBOX" files had been established for each individual. The baptism file contained such information as date of birth, date and place of baptism, parents' names, father's occupation, address at birth, number of siblings and godparents' names. The marriage file listed such information as date and place of marriage, spouse's name and address, the age of both parties, number of marriages, literacy (not functional), number of children, birth spacing and age at first and last births. The largest file was the burial file as it covered those aspects of life occurring between marriage and death. Listed was such data as date of death and burial, the interval between the two, "abode at death", other addresses, occupation, status, rateable value of property, cause of death (for those dying after the beginning of civil registration in 1837), relationship with other members of the sample and "notes", which listed information as diverse as " Lord Nayor of London 1747 " or " fined by the manorial courts for blocking Elder street with his brewers drays".

Consequently, the opportunity exlsted to examine the reliability of such methodology as ageing and sexing techniques, the significance of "scars of parturition" and the question of occupationally related disease.

An unexpected but very welcome bonus was that among the named sample of 387 individuals, there are at least 250 related pairs; these are derived from approximately 35 lineages and range from a twin to great great grandparents and children. The opportunity now exists to examine 
the question of genetic markers and of the issue of skeletal pathologies and familial trends.

An issue which arouses considerable interest is whether or not the cause of death of an individual can be deduced from skeletal remains. The death certificates exist for 26 individuals and state the cause of death; that of another individual is stated in a letter. In many cases there are problems in deducing actual cause of death from nineteenth century diagnoses. For example, "decay of nature" and "general decay" have little value in this area of inquiry. However, in five individuals, it was considered that there should be skeletal pathologies reflecting the conditions mentioned. In no instance was this the case. An indication of the "state of the art" in this respect can be gleaned from the case of one particular individual. The cranium of a mature adult male had been examined by five experienced individuals and an experienced radiographer. The interest in this case was generated by a superb partial denture. It had been observed but not considered unusual, that there was "postmortem" damage to the sirull. The later revelation as noted on his death certificate left six red faces; under cause of death is stated, "Shooting himself in the head...!". It would seem that skeletal biologists should take a greater interest in forensic science.

Possibly the most amusing "occupationally related disease" revealed by the death certificates were the three cases of "dropsy" or oedema. This is a symptom which can reflect several conditions. The occupations of those concerned lead to the conclusion that their dropsy was caused by cirrhosis of the liver. Two of the individuals were the landlord of a public house and his wife; the third was a retired mariner!

There can be no doubt that the skeletal sample excavated from the crypts at Christ Church has provided what is potentially the most important collection ever recovered in Great Britain. Why are further crypt samples considered necessary? The reality is that when one breaks down a sample of 387 into subgroups for specific purposes, the numbers are often too small to provide anything other than an indication of specific factors. For example, silk weaving was the dominant occupation among the named sample from Christ Church, yet less than twenty adult male skeletons which survive in good condition are known to have been silk weavers. In order to develop fully the potential so evident in the Christ Church material more of the skeletal material being "cleared" from many church crypts, not only in London but in other cities, is desperately needed. For this we are dependent on the church authorities and grant giving bodies but also on the skills and methods developed by the archaeologists at Christ Church.

The human bone report on the remains from Christ Church, Spitalfields (Theya Molleson, Margaret Cox, Tony Waldron and David Whittaker) is being published by the C.B.A. 


\section{BIBLIOGRAPHY}

Brothwel1, D.R., 1981 - "Digging up bones". Oxford University Press, Oxford and British Nuseum (Natural History), London.

Houghton, P., 1974 - "The relationship of the pre-auricular groove of the ilium to pregnancy". Amer. J. Phys. Anthrop., Vol. 41, pp. 381390.

Ullrich, H., 1975 - "Estimation of fertility by means of pregnancy and childbirth alterations at the pubis, the ilium and the sacrum". Ussa, Vol. 2, pp. 23-39.

Suchey, J.M. and Brooks, S.T., 1988 (in press) - "Skeletal age determination based on the male os pubis". Paper given at the 12 th International Congress of Anthropological and Ethnological Sciences. Zagreb, Yugoslavia, July 24th-31st 1988. 
ABSTRACTS OF PAPERS AND

POSTERS PRESENTED AT THE

CONFERENCE BUT NOT PUBIISHED

IN THIS VOLUME 


\section{HAKIMG BOHES COUET: A CASE STUDY OF AIGLO-SATON EIGLATD}

A. Boddington, Academic Computing Centre, The Open University, Milton Keynes, MKT 6AA

One of the richest resources for the study of Anglo-Saxon England is the osteological data from its pagan and Christian cemeteries. Around 20,000 burials are known from the period, though rather less have been subject to useful osteological analysis. Given this resource is it possible to make useful statements about the demography of the period? Anglo-Saxon England in the 6 th century was largely a landscape of dispersed farmsteads without towns. In contrast 10th century England had both urban centres and nucleated villages. It would be simple if there were no demographic developments accompanying this change. This paper considers the data available, the limitations of osteodemographic analysis and suggests a framework for the future study of Anglo-Saxon demography.

\section{BRICKS OR BOIFS}

W. Bouts, Hinthamerstrat 153, 5211 MK's Hertogenbosch, The Netherlands.

In the summer of 1984 part of the area to the north of St John's Cathedral at $s^{\prime}$-Hertogenbosch (the Hetherlands) was excavated by the Municipal Archaeological Service. The reason for this excavation was the planned construction of a large bullding with deep cellars, which would cause the loss of all archaeological data.

The object of the archaeological investigation was twofold:

1) According to historical and topographical evidence part of the locality had been built on in Medieval times. Kaps from later periods however show an empty area. By excavating, an attempt was made to elucidate the relationship between this phenomenon and the use of this area as a cemetery (see under 2 ).

2) Until the beginning of the 19th century the area had been used as a cemetery. The date of the earliest burial was unknown. The human skeletal material was expected to fill a gap in the extensive series of Dutch skeletal assemblages.

Because there was insufficient time to excavate the whole area in detail, two trenches were laid out at an angle of $90^{\circ}$ exposing two sides of the threatened terrain. The results of this first investigation determined the strategy to be followed later. Excavation in this manner allowed rapid removal of skeletons and ensured construction work was not impeded. Due to pressure of time and the lack of skilled excavators a simple method of recording the skeletal material was used.

In this way sufficient time was available to investigate the history of the cemetery's use in the earlier period. A direct relationship between the termination of building activities and the later use as a burial ground could not be established. The cemetery had been in use 
between c. 1700 and $c$. 1845 . The $c 400$ individuals which have been population buried at the building site.

Preliminary (odontological) research on the skeletal remains has already shown that, despite the necessarily crude method of excavation, the preservation of the skeletal material is sufficient to produce both qualitative and quantitative information on demography and the health status of the population in question.

\section{STUDIES OI ARCHAFOLOGICAL DFITAL CALCULUS}

K. M. Dobney, The Old Customs House, Hoy, Orkney Islands

Dental calculus, although found commonly on archaeological teeth, has hitherto been largely ignored as a potential source of information. This study presents the general findings of a three year research project, the main aim of which was to assess the relevance of dental calculus to ancient diet.

The diversity of information collected is widespread and by employing a variety of techniques, several new and potentially exciting avenues of research were realised and explored.

\section{GEOPHYSICAL PROSPECTIOI AID BURIAL ARCHAEOLOGY.}

C. Gaffney, Department of Archaeological Sciences, University of Bradford.

Inhumation areas are not at first sight an easy prospection target for the archaeophysicist. The area that individual graves cover is relatively small compared with geophysical sample intervals and a lack of contrast between the fill of the graves and surrounding medium means that identification of an individual burial is problematic. However, significant boundary areas may be discerned, such as churchyard walls, buried barrow mounds and areas of "disturbance". When metallic objects are located within graves a secondary signal may be measured. Recent surveys on both archaeological and experimental burials will be used to illustrate the points outlined above.

PUBIC STIPHYSEAL AGEIIG: A COIPARISOI OF TECHITUES

R. Gillett, Department of Anthropology, Rawles Hall 108, Indiana University, Bloomington, Indiana 47405, U.S.A.

The Todd (1920, 1921) and Suchey-Brooks (Katz and Suchey, 1986) methods for determining age at death in human skeletal remains are applied to a sample of 450 skeletons from central California, U.S.A. The purpose was to compare these two ageing methods and their effect on the population distributions.

Two distinct data sets are derived. Data set 1 (DS1) and data set 2 (DS2) contain the same sex designations for each individual and the same age determinations for sub-adults through the age of 15 years. 
The databases are different only in their age designations of the adult skeletons.

Notwithstanding the possibility of interobserver error, this is due to the different ageing methods used whllst examining the gross morphological changes that occur at the pubic symphyeal face. In DS1 the symphyseal face was examined using a combined Todd and HcKernStewart eleven-phase system as described by J.L. Angel, while in DS2 the symphyseal face was examined using the Suchey-Brooks six-phase system as described by Katz and Suchey (1986). Based upon these data sets, two sets of life tables were constructed.

When comparing DS1 to DS2, it is apparent that there is a basic difference in the age distributions between the two samples as pertains to the upper decades. Although a statistical difference cannot be demonstrated between the two population distributions, there does however appear to be a biologically meaningful difference. DS2 appears to be more likely as a normal distribution of a population in comparison to DS1 where it would appear that the entire population suddenly expires when it reaches 50 years of age.

Due to the possibility of distortion of the data from using a male standard in making the phase designations for the females in both data sets, it would prove more reliable to compare only the male results. Differences between the male portions of the sample appear to be the result of the difference in the phase age limits between the two methods. To compare the data then will require a conversion of Todd phase designations to their Suchey-Brooks equivalents. Life tables are computed for this new data set-data set 3 (DS3).

DS3 appears to have a more realistic population distribution. When compared to the original DS1, the effect of the conversion is an averaging of the upper decades (fourth decade and up) due to the age distribution within the phases being stretched.

It is demonstrated that the resulting population distributions based upon the Todd and Suchey-Brooks techniques are sufficiently different, particularly in the upper decades, to warrant a conversion of some type. The conversion provided can be used only in a limited way. Caution should be used when comparing populations whose ages are determined by potentlally very different techniques.

\section{Bibliography}

Katz, D. and Suchey, J.M., 1986 - Age determination of the male os pubis. Amer. J. Phys. Anthrop., Vol. 69, pp. 427-435

Todd, T.W., 1920 - Age changes in the pubic bone. I The male white pubis. Amer. J. Phys. Anthrop., Vol. 3, pp. 285-334

Todd, I.W., 1921 - Age changes in the pubic bone. II, III, IV. Amer. J. Phys. Anthrop., Vol. $4(1)$, pp. 1-70. 
Todd, T.W. 1921 - Age changes in the pubic bone. VI Interpretation of variations in the symphyseal area. Amer. J. Phys. Anthrop., Vol. 4, pp. 407-424.

\section{METHODOLOGICAL ISSUES II DETERIIIIIG THE IIDIVIDUAL'S AGE-AT-STRESS FROI EHAIEL HYPOPLASIA DEFECTS}

D.C. Hodges and R.G. Wilkinson, Office of the State Archaeologist, Eastlawn Bullding, University of Iowa, Iowa City, IA 52242, U.S.A.

Enamel hypoplasia is a developmental defect in which the formation of enamel is disrupted. The defect has been associated with a variety of different diseases and with malnutrition. As a result of its multiple potential etiologies, hypoplasia defects have been interpreted by skeletal biologists as a non-specific indicator of an early childhood stress episode. The frequency of enamel hypoplasia is often reported for archaeological samples and has been used in comparing the relative health status of different samples.

Not only has the frequency of the defect been investigated but the timing of the stress episode that produced the defect has also been investigated. The age-at-stress of an individual has been determined using the location of the defect on the crown and standard rates of tooth formation. The assumptions underlying this method of ageing hypoplasia defects have not, however, been fully examined. This presentation focuses on one assumption, that inter-population variation in tooth size will not substantially influence age estimates. The results of a study examining the effect of tooth size variation on chronological distributions using modern and archaeological tooth specimens are discussed.

\section{EVIDEICE OF IITESTIIAL PARASITES ASSOCIATED UITH HUIAT REILIIS}

A.K.G. Jones, Environmental Archaeology Unit, Walled Garden, University of York, Heslington, York, YO1 5DD.

Intestinal parasites rarely leave obvious traces on human skeletal materials yet under exceptional circumstances cysts and eggs of helminth parasites survive associated with human remains. Examples of burials where evidence of parasitism has been found and the variable conditions of eggs and cysts will be described. In addition, the methods currently used to sample burials and to examine samples in the laboratory will be discussed. Practical, Inexpensive and simple procedures for establishing the presence of parasite ova and cysts will be suggested.

\section{CULTURAL ASPECTS OF BURIAL ARCHAEOLOGY}

R. Jones, Department of Archaeological Sciences, University of Bradford.

This paper concerns the funerary sample and the legitimacy of generalising from it to the whole buried population and thence to living populations. The examination of cemeteries with abundant grave goods demonstrates that careful processes of selection have governed 
what the archaealogist finds there. Such patterns allow varying soctal inferences to be drawn about the living populatians with the result that burial archaeology has become a prime source of evidence for the archaealogy of society. Some of these approaches may be mare securely used than others, but the variety observed within such burial traditions means that it should not be accepted that populations with a tradition of unaccompanied inhumations always left homogeneous cemeteries with no pattern of selection. Therefore it is necessary to represent a valid sample of the total burled population of the particular community. At least simple demographic tests need to be used to determine the nature of the sample recovered.

\section{IIHUIATIOI IIISECTS: MYTHS AID MAGGOTS}

H. Kenward, Environmental Archaeology Unit, Valled Garden, University of York, Heslington, York, Y01 5DD.

Insect remains have been recorded from a number of internments in 'anaerobic' deposits, and from sealed coffins, both burled and in crypts. Dehydrated bodies offer another potential source. Wany more insects would be recorded from the soil around skeletons were the appropriate samples collected.

The insects recorded in association with burials fall into three categories:

1. Those which entered with or on the corpse

2. Those dumped in with the backfill soil

3. Those attracted to the corpse after burial

There may also be insects which entered purely accidentally (or incidentally) long after burial, as in any archaeological deposit.

Insects buried with the corpse are likely to give interesting information. There may be parasites such as flies, lice (and their eggs, nits), and (not insects but best considered with them) ticks. Other insects may have been attracted to the corpse prior to burfal. The range increases with length of exposure. The species include flies and carrion beetles, and following established forensic techniques it is possible to determine with moderate reliability for how long the corpse was exposed. Clearly both these groups of insects deserve attention.

Insect remains which entered with backfills may have almost any origin and may well pre-date the corpse considerably. They may incidentally give information about the origin of backfills, but are generally unlikely to be of any value.

The insects attracted to buried corpses include a distinctive suite of species. They do not have much interpretative value, although they are of some biological interest so that some sampling is worthwhile. Insects which invade dehydrated human corpses are Itkely to include a range of species adapted to dry organic matter, and again will probably be primarily of interest as curiosities. It is possible to 
imagine unueual cases where these insects would be archaeologically informative.

The implications of these observations for sampling and research strategies are clear. In general, 'waterlogged' preservation, in soil or a sealed coffin, or dehydration (in mummies or sand burials) is a prerequisite to study. There is a need to examine large volumes of soil with good preservation if parasites are to be recovered from burials, though direct examination of mummies or bog bodies for insects of all origins may be more productive. To recover invaders of exposed corpses it may again be necessary to examine all the soil from around a skeleton, since the remains may be few. Routine 5-10 kg 'general biological analysis' samples will suffice for the examination of post-burial invaders.

PALAEOPATHOLOGY: EXPECTATIOIS, NFTHODOLOGIES AID REALITIES.

D.J. Ortner, Dept of Anthropology, Smithsonian Institution, Washington D.C.

\section{Introduction}

Palaeopathology now incorporates within its purview a diverse subject matter that includes research on: (1) mummies, (2) skeletons, (3) various forms of art and (4) ancient text materials. The following comments are limited to a review of some aspects of skeletal palaeopathology.

The initial stage of a biological science is usually characterized by a research emphasis on description and classification; palaeopathology is still largely at that stage of development. Indeed, many problems in description and classification remin to be resolved. Nevertheless, we now know a great deal about the presence of many diseases in ancient human societies. However, we have only begun to understand the role disease has played in human evolutionary processes. As we develop a greater research emphasis on hypothesis testing and theory development in palaeopathology, we must deal more effectively with the broad theoretical significance of our research.

\section{Expectations}

Palaeopathology has at least the potential to contribute to our understanding of several important processes including: (1) a greater understanding of the biological and evolutionary role of disease in human societies particularly as data on palaeoepidemiology accumulate, (2) the complex relationships between disease and the epochal social changes that took place in human history such as sedentism and urbanism, and an improved biomedical understandng of the skeletal response to disease.

\section{Methodologies}

One of the most critical requirements of skeletal palaeopathology is the need to intergrate data and observations from multiple research sources. It is likely that there will always be problems in doing 
this but the development and widespread use of a rigorous descriptive methodology with a precise terminology for skeletal lesions and their location in the skeleton would bring this goal much closer to reality. Computer aided design software offers an important research tool in recording distribution patterns of skeletal disease.

Bone is a tissue as well as an organ and responds to a variety of systemic conditions at the microscopic as well as at the gross level of biological organization. Palaeopathology has made minimal effort to use microscopic data in archaeological specimens. Part of the problem is that the biological significance of many microscopic features apparent in bone is poorly understood. Use of this potential source of data will require basic research on the biological significance of these features.

Antibodies can now be detected at the parts per billion level. If antibodies, or other proteins linked to the disease response in the body, survive in archaeological skeletal tissue they can now almost certainly be detected. Preliminary research is promising and suggests that such research will open up a new and important source of data in palaeopathology.

\section{Realities}

There are practical limits on what we can say about major processes, including disease, that affect human populations. Almost certainly there are new diseases today that were not present in antiquity and vice versa. It is also likely that the skeletal response in some disease processes has changed. Chronic diseases are the ones that are most likely to affect the skeleton. This means that many skeletal disease processes will have minimal impact on overall biological function or longevity.

I remain concerned about some of the easy assumptions that are made in skeletal palaeopathology. While enlightened speculation may be helpful, it is very easy to career down scientifically blind alleys because of ignorance or because we have overextended our data. We must avoid this.

\section{THE EXPERIMEITAL IIVESTIGATIOI OF THE POTEITIAL OF CREMTED BOIE AS AI IIDICATOR OF PAST CREWATIOI PRACTICES AID TBCHIIQUES}

S.J. Parker, Department of Archaeology and Prehistory, University of Sheffield, S10 2TH.

When faced with the cremated remains of prehistoric man there are two lines of enquiry which must be followed:

1) to discover a demographic profile of the remains by establishing their age at death, sex and patterns of disease.

2) to find out what processes have produced the remains and therefore give some insight into past cremation practices and techniques. 
The latter line of enquiry is the one with which this research is concerned. Some research has already been carried out but has been somewhat 1 imited by concentrating on one aspect of cremation. For example, the state or position of the cadaver at the time of burning, or the temperature of the fire.

This research programme takes as its brief the hypothesis that the physical characteristics of cremated bone have been determined by their cremation environment and that because of this they can be used to identify those conditions. In order to test this hypothesis it was necessary to conduct a number of experimental cremations in a contralled environment. The problem here is how to control the environment. Wany of the factors involved in cremation are extremely erratic and do not, therefore lend themselves to control. For instance, the unique nature of the cadaver or the variability of the weather. For the purposes of this research three variables were used; the state of the cadaver at the $t$ ime of burning, the temperature of the fire and its duration.

For the experiments samples of fleshed, defleshed and partially fleshed bone* were subjected to burning at different temperatures, $(500,600,700,800$ and $800 * *$ degrees $C)$, and for varying lengths of time, ( 1 hour, 2 hours, 3 hours). The experiments provided a collection of burnt bone whose cremation environment is known. It is hoped that it will be possible to detect variations in the size, weight, colour, patterns of cracking and fracturing, degrees of distortion and the chemical and histological changes undergone by the bone and that these variations can be related to one of the test environments.

* The samples used in the experimentation were the trotters from immature pigs.

* The adaptations to the furnace used in the experiments prevented it attaining its maximum temperature of $1000 \mathrm{C}$.

\section{THE HUIAT REIAIIS FROY BECKFORD}

C. Roberts, Calvin Vells Laboratory, Department of Archaeological Sciences, University of Bradford

There has, in the past, been much criticism levelled at the noncommunicative and non-collaborative nature of the archaeologist and human bone specialist when concerned with cemetery studies. In addition, limited finance has prevented, in the majority of cases, involvement of the human bone specialist from the earliest stage of the work.

This case study presents an outline of the analysis of the human remains from Beckford, Hereford and Worcester, an Iron Age / early Roman site. This cemetery is an important site, certainly in terms of the Iron Age burials recovered; few skeletons of this date have been excavated in Britain. The site also presented material remains of such a varied nature that attempts at integrating different sets of data into one interpretation was potentially possible. In terms of 
arohaeglagical relevanoe this was desmed important. The aim was to provide reliable information about the sample population represented and their interaction with the environment.

The merits and pitfalls of the way in which this analysis was performed are discussed with recommendations for future work in burlal archaeology.

\section{EXAYIIATIOI OF SKELETAL REMUIIS FROY THE LOIG BARROI AT HAZLETOI}

J. Rogers Department of Rheumatology, Bristol Royal Infimary, Bristol, BS2 8HW.

The excavation of the long barrow yielded well over 9000 separate human bones and fragments of bone representing a minimum number of 41 individuals.

The methods of examination are described together with the difficulties associated with the analysis of a disarticulated assemblage of bone representing small number of individuals deposited over a long period of time.

\section{PALARORHEUIATOLOGY}

J. Rogers, Department of Rheumatology, Bristol Royal Infirmary, Bristol, BS2 8HW.

Joint changes are the commonest lesions seen in skeletal collections but there are over 250 rheumalogical diseases currently defined. The method of approach to the analysis and classification of a few of these diseases in skeletal material will be demonstrated.

\section{HAZLETOII. GLOUCESTERSHIRE}

A. Saville, Leckhampton, Chel tenham.

Between 1979 and 1982 the neolithic Cotswold-Severn tomb at Hazleton was totally excavated as a rescue project funded by the D.O.E. and organized through C.R.A.A.G.S./W.A.Y. and Cheltenham Art Gallery and Museum. The case study will briefly describe the site and its excavation, the burial evidence, the methods of recovery and the postexcavation procedures, before considering the interpretation of the evidence.

The tomb was a laterally-chambered type, with two separate chambered areas of similar groundplan located some $25 \mathrm{~m}$ back from the broader end of the enclosing long cairn. Virtually all the human bones found during the excavation came from two chambered areas. In the south chambered area the burial deposits comprised a continuous spread of disarticulated remains over a distance of nearly $6 \mathrm{~m}$, with the only major disturbance occurring just inside the outer entrance. On the north side, collapsing stonework early in the life of the monument had sealed the north chamber, so that the burial deposits in the north chamber were totally separate from the burials in the north entrance. 
The north chamber deposits, comprising only disarticulated bones, had been disturbed from above at an unknown date; those in the north entrance, comprising both articulated and disarticulated remains, survived intact and undisturbed.

The procedure during excavation was progressively to uncover the burial deposits, allowing each bone to be drawn and photographed in situ. Whilst each substantial bone was separately recorded, this was not feasible for every small scrap or for all isolated small bones such as loose teeth. In the attempt to achieve total bone recovery, however, all the residues of deposits remaining in each of the chambered zones were sieved on site through a inch mesh sieve. All bones caught in the sieve were recorded on site, whilst the sieved residues were bagged and taken of $f$ site for more detailed scrutiny to remove all further bone fragments. Bone retention therefore went beyond the practical ability of specialist analysis at present, the material being stored for potential use.

Individual numbers were allocated to each distinct bone within the chamber deposits, so that the numbers could be recorded on overlays to each bone plot. During post-excavation, catalogues were compiled for the bones from each of the two chambered areas, using field identifications where available, and rationalized bone plots were drawn up. These were passed with the bones to the speciallst, who produced detailed identifications. Subsequently, catalogues of the different skeletal parts were compiled, together with lists of bones which paired or articulated with others. Much time was spent on rejoining and attempting to rejoin fragmentary longbones, though other fragmentary skeletal parts, such as ribs, were ignored after basic identification.

It has been concluded that the normal burial rite at Hazleton was one of direct inhumation within chambered areas of the tomb. This rite was accorded to both sexes and all age groups, and the $40 t$ individuals represented are seen as probably the deceased of a single local farming group. Burial took place progressively, with subsequent burials necessitating the disturbance of all previous burials, leading to the disarticulated state of most of the bones. Some fragments of cremated bone were present, mainly confined to the north entrance. Radiocarbon dates suggest that the period of burial activity may have been less than 300 years in total, from about 3,800 to 3,500 calendar years BC.

\section{SOYE EPIDEIIIOLOGICAL PROBLEIIS II PALAEOPATHOLOGY}

T. Waldron, 31 Maidstone Road, London, N11 2TR.

One of the important aspects of palaeopathology is to determine the frequency of different diseases in the past and to relate any changes which may be evident to enviromental, social, occupational or other factors. 'In order to do this, some measures of disease frequency must be used. The measures most commonly used in modern epidemiological studies are incidence and prevalence. The incidence of a disease is defined as the number of new cases which arise in unit time in the population at risk; prevalence is the total number of cases in unit 
time in the total population. Incidence can only be determined in a prospective study whereas prevalence can be measured using a crosssectional design.

It is clear that the incidence of a disease cannot be determined in palaeopathological studies since new cases cannot be ascertained nor is the population at risk known. Prevalence can be determined but the result cannot be generalised because there is no contral over the selection of population because of 1 ts non-random nature.

Both incidence and prevalence rates are said to be denominator dependent and it is preferable, in palaeopathological work to use rates which are not so dependent. An example, which will be discussed in more detall, is the proportional morbidity ratio which defines the frequency of one or more diseases as a proportion of all disease in the population under examination. Proportional morbidity ratios in different populations may be compared formally in order to detect any significant differences.

As an alternative, some form of standardisation can be used, either direct or indirect. These methods take account of the different age and sex structures of populations which are being compared. These methods will be described in more detail and examples of their use will be given.

\section{MICROSCOPICAL FEATURES OF BLADE-IIJURIBS TO BOIE SURFACES II SII AIGLO-SATOI SKELETOHS FROY ECCLES, KEIT.}

S.J. Wenham and J. Wakely, Department of Anatomy, University of Leicester, University Road, Leicester, LE1 7RH.

All the skeletons showed one or more unhealed cranial injuries and two had additional postcranial infuries. Criteria were used based on visual and low magnification light microscopical (up to $x$ 50) examination to distinguish true edged-weapon injuries from "pseudopathology". These were: Iinearity, a well defined edge to the cut, a flat smooth polished cut surface and usually, unless removed by erosion, fine parallel scratch marks on the cut surfaces of compact cortical bone.

- Because of the possibility that these were caused by irregularities in the weapon blade as it passed through the living bane, these scratches were subjected to further examination using the threedimensional presentation and high resolution of surface detail obtainable by scanning electron microscopy (S.E.M.).

Experimental cutting of modern bone samples by replica weapons produced scratch patterns aligned with the passage of the blade through the bone. This finding supports the view that the scratches on the Eccles bones are indeed, microscopical evidence of the action of the weapon and confirms the value of S.E.M. as a technique for examining injured bone surfaces in specimens obtained from burial sites. 
DEXTAL CARIES PATTER II THE PRITARY DEITITION AIOUG EIGLISH CHILDREI LIVIIG BETVEFI THE PRE-ROIAT ATD LATE HEDIEVAI PERIODS.

Williams, S.A., O'Sullivan, E. and Curzon, K.E.J., Department of Child Dental Health, University of Leeds, LS2 9LU.

A number of studies have reported caries experience since pre-Roman times in the permanent dentition. Moore and Corbett (Broc. Sympos, on Diet. Nutrition and Dental Caries, published by the University of Michigan in 1978, pp. 3-19) noted a fluctuating pattern, with an increase between the Iron Age and Roman periods, a decrease in Saxon times, and later a return to values similar to the Roman Period in Medieval times. Subsequently, the greatest increase in caries was observed between the $17 t h$ - 19th centuries.

Far less information is available concerning the primary dentition. Brabant (Int. Rech. Sc. Stomat, Vo1. 8, p. 235, 1965) suggested that a trend towards the ultimate involvement of the primary teeth occured only after carious attack of the permanent dentition had increased considerably in terms of the number of people and teeth per person affected, and lowering of the age of onset.

In this study caries patterns in the primary dentition during different archaeological periods were examined. The percentage of each tooth-type affected and site of initiation of carious attack were recorded. The skeletal remains of 221 English children dating from Pre-Roman to Late Medieval times were examined.

It was found that molars were the most frequently attacked teeth in all periods. Varying trends were observed; primary molars affected were:
5\% Pre-Roman
$16 \%$ Romano-British
8\% Anglo-Saxon
23\% 13th-15th Century.

Attrition remained similar throughout these periods. No consistent change was noted in the site of interproximal attack, it being more frequent at the cemento-enamel junction than at the contact points. Caries patterns in the primary teeth generally followed that recorded for the permanent dentition. However, the increase in primary molar carles seen in the $13 \mathrm{th}$ - 15th century, while simflar in value to the percentage affected as recorded by James and Miller (Brit. Dent. J., Vol. 128, p. 391, 1970) and Lunt (Brit. Dent. J., Vol. 132, p. 443, 1972) for the same period, is not easily explicable in dietary terms. Historically, this time does not coincide with reports of increasing sugar importation, but rather with a period of civil unrest, plague and pestilence. Since dental carles is multifactorial, the possibility of the influence of nutritional stress factors at this time may be important.

It is interesting to note that caries, experience is now declining in England, and the proportion of affected molars in 5 year olds is similar again to the 13 th - 15th century. 
DEATH AWD DISEASE II THE BYZATTIIT NOIASTERIES OF THE JUDEAT DESERT

J. Zias, Department of Antiquities, Rockefeller Huseum, Jerusalem

The skeletal material represented here is a representative sample drawn from $5 t h$ - 7 th century Judean Desert monasteries. A high degree of pathology was noted in these collections whlch suggests that these early monasteries administered to the needs of the sick from various countries surrounding the Hediterranean. The presence of Hansen's disease (leprosy) in several of the monasteries provides archaeological evidence as to when the disease was first established in the Eastern Kediterranean, as well as shedding light on one of the functions of these isolated desert monasteries. 